\author{
CENTRO UNIVERSITÁRIO FEI \\ MARIANA TORTELLA MERLI FIORANTE
}

MODELAMENTO COMPUTACIONAL DAS TRANSFORMAÇÕES DE FASE DURANTE OS CICLOS TÉRMICOS DE PROCESSAMENTO DE UM AÇO INOXIDÁVEL SUPERDÚPLEX

São Bernardo do Campo 


\title{
MODELAMENTO COMPUTACIONAL DAS TRANSFORMAÇÕES DE FASE DURANTE OS CICLOS TÉRMICOS DE PROCESSAMENTO DE UM AÇO INOXIDÁVEL SUPERDÚPLEX
}

\begin{abstract}
Dissertação de mestrado apresentada ao Centro Universitário FEI como parte dos requisitos necessários para obtenção do título de Mestre em Engenharia Mecânica, orientado pelo Prof. Dr. Rodrigo Magnabosco.
\end{abstract}

São Bernardo do Campo 
O presente trabalho foi realizado com o apoio da Coordenação de Aperfeiçoamento de Pessoal de Nível Superior - Brasil (CAPES) - Código de Financiamento 001. 
Tortella Merli Fiorante, Mariana .

Modelamento computacional das transformações de fase durante os ciclos térmicos de processamento de um aço inoxidável superdúplex. / Mariana Tortella Merli Fiorante. São Bernardo do Campo, 2021.

123 p. : il.

Dissertação - Centro Universitário FEI.

Orientador: Prof. Dr. Rodrigo Magnabosco.

1. Aço Inoxidável Superdúplex. 2. Conformação Plástica. 3.

Transformação de Fases. 4. Modelamento Computacional. 5. DICTRA®.

I. Magnabosco, Rodrigo, orient. II. Título.

Elaborada pelo sistema de geração automática de ficha catalográfica da FEI com os dados fornecidos pelo(a) autor(a). 
Título do Trabalho: Modelamento computacional das transformações de fase durante os ciclos térmicos de processamento de um aço inoxidável superdúplex.

Área de Concentração: Materiais e Processos

Orientador: Prof. Dr. Rodrigo Magnabosco

Data da realização da defesa: 19/02/2021

\section{ORIGINAL ASSINADA}

\section{Avaliação da Banca Examinadora:}

A candidata demonstrou segurança na apresentação, e conhecimento técnico do tema da dissertação, que tem grande aplicabilidade nos tratamentos termomecânicos de aços inoxidáveis dúplex, implementando metodologias de simulação de transformação de fases para a otimização dos ciclos térmicos. O trabalho foi aprovado por unanimidade pela banca.

São Bernardo do Campo, 19 / 02 / 2021.

\section{MEMBROS DA BANCA EXAMINADORA}

Prof. Dr. Rodrigo Magnabosco

Ass.:

Profa Dra Daniella Caluscio dos Santos

Ass. :

Prof. Dr. José Wilmar Calderon Hernandez

Ass. :

A Banca Julgadora acima-assinada atribuiu ao aluno o seguinte resultado:

APROVADO $\bigotimes \quad$ REPROVADO

\section{VERSÃO FINAL DA DISSERTAČ̃̃O}

APROVO A VERSÃO FINAL DA DISSERTAÇÃO EM QUE FORAM INCLUÍDAS AS RECOMENDAÇÕES DA BANCA EXAMINADORA
Aprovação do Coordenador do Programa de Pós-graduação 
Aos meus pais, com amor. 


\section{AGRADECIMENTOS}

Agradeço ao Todo, pela oportunidade de vida e evolução. Agradeço aos meus pais e irmão, pelo amor incondicional. Agradeço ao Gabriel, pela parceria e paciência. Agradeço ao professor Rodrigo, pela orientação e confiança em mim depositada. Agradeço à FEI, por me proporcionar crescimento e conhecimento. Agradeço à CAPES, pela bolsa de estudos a mim concedida. 


\section{RESUMO}

O presente projeto tem por objetivo realizar a simulação computacional da cinética de transformação e evolução das fases durante os ciclos térmicos de processamento de um aço inoxidável superdúplex, considerando as etapas de aquecimento, conformação plástica e resfriamento, com uso do software DICTRA ${ }^{\circledR}$. Os dados de entrada para as simulações foram composição química e tamanho das fases, temperatura pretendida de simulação, e taxas de aquecimento e resfriamento quando necessárias a descrição do ciclo térmico. Foram utilizadas as bases de dados termodinâmica TCFE9 e de mobilidade atômica MOBFE4, com intuito de se obter resultados para diferentes modelos, possibilitando encontrar o que melhor descreve a cinética de transformação das fases. Foram simuladas diferentes taxas durante o aquecimento do material a partir de $950{ }^{\circ} \mathrm{C}$, considerando condição microestrutural inicial de $50 \%$ de ferrita $(\alpha)$ e $50 \%$ austenita $(\gamma)$, até $1250{ }^{\circ} \mathrm{C}$, temperatura típica de conformação. No aquecimento, obteve-se fração máxima de $66,6 \% \alpha$ à taxa de $0,30{ }^{\circ} \mathrm{C} / \mathrm{s}$, valor próximo aos $70 \%$ esperados pela simulação de equilíbrio em Thermo-Calc ${ }^{\circledR}$. Após $1000 \mathrm{~s}$ de patamar a $1250{ }^{\circ} \mathrm{C}$ e resfriamento até a temperatura de solubilização, $1090{ }^{\circ} \mathrm{C}$, à taxa de $0,30{ }^{\circ} \mathrm{C} / \mathrm{s}$, a fração de $\alpha$ reduziu para valores de $58,7 \%$. Na sequência, também simulou-se diferentes taxas de resfriamento com ou sem a presença de patamar de solubilização. Considerando-se $3600 \mathrm{~s}$ de patamar a $1090{ }^{\circ} \mathrm{C}$, foi possível recuperar a condição dúplex desejada, atingindo-se $55,5 \% \alpha$, mas não atingindo os $50 \%$ esperados pelo equilíbrio, visto que ainda há gradiente de composição em $\alpha$ e $\gamma$ nas simulações em DICTRA ${ }^{\circledR}$. A fim de se manter a microestrutura dúplex anterior, realizou-se resfriamentos até $790{ }^{\circ} \mathrm{C}$ à taxa crítica de $3,0{ }^{\circ} \mathrm{C} / \mathrm{s}$, obtendo-se frações volumétrica de $56 \% \alpha, 43 \%$ y e frações de sigma $(\sigma)$ iguais ou inferiores a $1 \%$. Por outro lado, ao não se considerar o patamar à $1090^{\circ} \mathrm{C}$, isto é, promovendo o resfriamento até $790{ }^{\circ} \mathrm{C}$ à taxa de $3,0{ }^{\circ} \mathrm{C} / \mathrm{s}$ a partir da condição de $58,7 \% \alpha$, obteve-se frações volumétricas de $59,6 \% \alpha$,

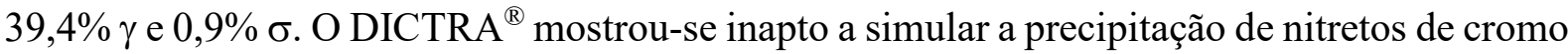
$\left(\mathrm{Cr}_{2} \mathrm{~N}\right)$ no resfriamento, ou por não haver supersaturação de nitrogênio $(\mathrm{N})$ em $\alpha$ ou por ser incapaz de prever esta supersaturação. A partir dos resultados de cinética e evolução da fração volumétrica das fases no ciclo térmico de processamento do aço UNS S32750, foi possível obter o modelo computacional que melhor descreve o comportamento real do aço estudado.

Palavras-chave: Aço Inoxidável Superdúplex, Conformação Plástica, Transformação de Fases, Modelamento Computacional, DICTRA ${ }^{\circledR}$. 


\begin{abstract}
This project aims to perform the computer simulation of the transformation's kinetics and phase evolution during the thermal processing cycles of a superduplex stainless steel, considering the stages of heating, hot working and cooling, using DICTRA ${ }^{\circledR}$ software. The input data for the simulations were chemical composition and phase size, desired simulation temperature, and heating and cooling rates when necessary to describe the thermal cycle. TCFE9 thermodynamic database and MOBFE4 atomic mobility database were used in order to obtain results for different models, determining the one that best describes the phase transformation kinetics. Different rates were simulated during the heating of the material from $950^{\circ} \mathrm{C}$, considering the initial microstructural condition of $50 \%$ of ferrite $(\alpha)$ and $50 \%$ austenite $(\gamma)$, up to $1250^{\circ} \mathrm{C}$, typical forming temperature. In heating, a maximum fraction of $66.6 \% \alpha$ was obtained at a rate of $0.30{ }^{\circ} \mathrm{C} / \mathrm{s}$, a value close to the $70 \%$ expected by the equilibrium simulation in Thermocalc ${ }^{\circledR}$. After $1000 \mathrm{~s}$ of plateau at $1250^{\circ} \mathrm{C}$ and cooling to the solubilization temperature, $1090^{\circ} \mathrm{C}$, at the rate of $0.30^{\circ} \mathrm{C} / \mathrm{s}$, the fraction of $\alpha$ reduced to values of $58.7 \%$. In the sequence, different cooling rates were also simulated with or without the presence of solubilizations plateau. Considering $3600 \mathrm{~s}$ of plateau at $1090^{\circ} \mathrm{C}$, it was possible to recover the desired duplex condition, reaching $55.5 \% \alpha$, but not reaching the $50 \%$ expected by the equilibrium balance, since there is still a composition gradient in $\alpha$ and $\gamma$ by DICTRA ${ }^{\circledR}$ simulations. Seeking the maintenance of the duplex microstructure, a cooling was performed from $1090{ }^{\circ} \mathrm{C}$ to $790^{\circ} \mathrm{C}$ at a critical rate of $3.0^{\circ} \mathrm{C} / \mathrm{s}$, obtaining volumetric fractions of $56 \% \alpha$, $43 \% \gamma$ and sigma fractions $(\sigma)$ equal to or less than $1 \%$. If the plateau at $1090^{\circ} \mathrm{C}$ was not considered, that is, promoting cooling from $1250{ }^{\circ} \mathrm{C}$, where the condition of $58.7 \% \alpha$ was reached, to $790^{\circ} \mathrm{C}$ at the rate of $3.0^{\circ} \mathrm{C} / \mathrm{s}$ volumetric fractions of $59.6 \% \alpha, 39.4 \% \gamma$ and $0.9 \%$ $\sigma$ were obtained. DICTRA ${ }^{\circledR}$ was unable to simulate the precipitation of chromium nitrides $\left(\mathrm{Cr}_{2} \mathrm{~N}\right)$ during cooling, either because there was no nitrogen supersaturation $(\mathrm{N})$ in $\gamma$ or because it was unable to predict this supersaturation. From the results of kinetics and evolution of the phases' volumetric fraction obtained in the thermal cycle of steel processing UNS S32750, it was possible to obtain the computational model that best describes the real behavior of the studied steel.
\end{abstract}

Keywords: Superduplex Stainless Steel, Plastic Forming, Phase Transformation, Computational Modeling, DICTRA ${ }^{\circledR}$. 


\section{LISTA DE FIGURAS}

Figura 1 - Seção isotérmica do sistema ternário Fe-Cr-Si a $1000^{\circ} \mathrm{C}$....................................... 19

Figura 2 - Seção isotérmica do sistema ternário Fe-Cr-Ni a $1100^{\circ} \mathrm{C}$.................................... 19

Figura 3 - Seção isotérmica do sistema ternário Fe-Cr-Ni a $1200^{\circ} \mathrm{C}$.....................................20

Figura 4 - Seção isotérmica do sistema ternário Fe-Cr-Ni a $1300^{\circ} \mathrm{C}$................................... 20

Figura 5 - Diagrama de fases do aço superdúplex UNS S32750 com base de dados TCFE8, considerando composição química $\mathrm{Fe}-25,17 \% \mathrm{Cr}-6,88 \% \mathrm{Ni}-3,61 \% \mathrm{Mo}-0,27 \% \mathrm{Ni}$

Figura 6 - Diagrama de fases do aço inoxidável dúplex UNS S31803 com base de dados TCFE8 considerando composição química Fe-22,48\%Cr-5,74\%Ni-3,2\%Mo-0,16\%N ...... 23

Figura 7 - Seção isotérmica do sistema ternário Fe-Cr-Ni a $800{ }^{\circ} \mathrm{C}$....................................... 25

Figura 8 - Seção isotérmica do sistema ternário Fe-Cr-Ni a $900{ }^{\circ} \mathrm{C}$...................................... 25

Figura 9 - Precipitação de sigma entre ferrita/ferrita e ferrita/austenita no aço superdúplex UNS S32750

Figura 10 - Precipitação de nitretos de cromo e austenita secundária na interface ferrita/ austenita no aço superdúplex UNS S32750

Figura 11 - Seções isotérmicas do sistema Fe-Cr-Ni-Mo-N a $900^{\circ} \mathrm{C}$ (a) e $800^{\circ} \mathrm{C}$ (b)

Figura 12 - Diagrama TTP de formação de sigma no aço UNS S31803, solubilizado a $1065^{\circ} \mathrm{C}$

Figura 13 - Diagrama TTP de formação de sigma no aço UNS S31803, solubilizado a $1120^{\circ} \mathrm{C}$

Figura 14 - Fração volumétrica de sigma em função do tempo de envelhecimento a $850^{\circ} \mathrm{C} .36$

Figura 15 - Fração volumétrica de ferrita em função do tempo de envelhecimento a $850^{\circ} \mathrm{C} .36$

Figura 16 - Diagrama de precipitação isotérmica de fase sigma no aço UNS S31803

Figura 17 - Diagrama de precipitação isotérmica do aço UNS S32750, solubilizado a $1060^{\circ} \mathrm{C}$

Figura 18 - Precipitação de fases secundárias no aço superdúplex UNS S32750 a $950^{\circ} \mathrm{C}$ por 300 s (a) e 2400 s (b)

Figura 19 - Diagrama TRC do aço UNS S32750

Figura 20 - Taxas de resfriamento do aço superdúplex UNS S32750 a partir da temperatura de solubilização de $1100^{\circ} \mathrm{C}$

Figura 21 - Micrografias da amostra do aço superdúplex UNS S32750 resfriado a três diferentes taxas de resfriamento: a) rápida; b) moderada; c) lenta 
Figura 22 - Fração volumétrica das fases em função da temperatura de solubilização para diferentes taxas de resfriamento

Figura 23 - Fração das fases em função da temperatura para o aço UNS S31803 48

Figura 24 - Comparação entre a temperatura de solubilização para o aço UNS 31803 de composição química completa em a) e composição química reduzida em b)

Figura 25 - Diagrama de fases do aço inoxidável superdúplex UNS S32750 com base de dados TCFE8 e composição química completa .50

Figura 26 - Modelo geométrico utilizado na simulação computacional. 51

Figura 27 - Perfil de Cr na interface ferrita/austenita do aço UNS S31803 a diferentes temperaturas

Figura 28 - Perfil de Cr em função do tempo a $950^{\circ} \mathrm{C}$ do aço UNS S32750. 54

Figura 29 - Fração volumétrica de sigma em função do tempo a $950^{\circ} \mathrm{C}$ do aço UNS S31803

Figura 30 - Perfil de Mo em função do tempo a $940^{\circ} \mathrm{C}$ para o modelo 1 do aço UNS S31803

Figura 31 - Perfil de Mo em função do tempo a $940^{\circ} \mathrm{C}$ para o modelo 2 do aço UNS S31803

Figura 32 - Fração volumétrica de sigma em função do tempo a $940^{\circ} \mathrm{C}$ do aço UNS S31803

Figura 33 - Perfil de Mo em função do tempo a $800^{\circ} \mathrm{C}$ .58

Figura 34 - Fração volumétrica de sigma em função do tempo a $800^{\circ} \mathrm{C}$ .59

Figura 35 - Fração volumétrica de ferrita a $1250^{\circ} \mathrm{C}$ com base de dados TCFE8 e MOBFE3.60 Figura 36 - Fração volumétrica de austenita a $1088^{\circ} \mathrm{C}$. 61

Figura 37 - Modelo esquemático das transformações de fases que serão simuladas.. 63

Figura 38 - Diagrama de equilíbrio do aço UNS S32750 com base de dados TCFE9 68

Figura 39 - Fração de ferrita no aquecimento de $950^{\circ} \mathrm{C}$ até $1250^{\circ} \mathrm{C}$ (trecho 1 ) à taxa de $2^{\circ} \mathrm{C} / \mathrm{s}$

Figura 40 - Fração de ferrita no aquecimento de $950^{\circ} \mathrm{C}$ até $1250^{\circ} \mathrm{C}$ (trecho 1 ) à taxa de $1,2^{\circ} \mathrm{C} / \mathrm{s}$ 70

Figura 41 - Fração de ferrita no aquecimento de $950^{\circ} \mathrm{C}$ até $1250^{\circ} \mathrm{C}$ (trecho 1 ) à taxa de $1,0^{\circ} \mathrm{C} / \mathrm{s}$ 70

Figura 42 - Fração de ferrita no aquecimento de $950^{\circ} \mathrm{C}$ até $1250^{\circ} \mathrm{C}$ (trecho 1 ) à taxa de $0,86^{\circ} \mathrm{C} / \mathrm{s}$ 
Figura 43 - Fração de ferrita no aquecimento de $950^{\circ} \mathrm{C}$ até $1250^{\circ} \mathrm{C}$ (trecho 1 ) à taxa de $0,75^{\circ} \mathrm{C} / \mathrm{s}$

Figura 44 - Fração de ferrita no aquecimento de $950^{\circ} \mathrm{C}$ até $1250^{\circ} \mathrm{C}$ (trecho 1 ) à taxa de $0,50^{\circ} \mathrm{C} / \mathrm{s}$

Figura 45 - Fração de ferrita no aquecimento de $950^{\circ} \mathrm{C}$ até $1250^{\circ} \mathrm{C}$ (trecho 1 ) à taxa de $0,40^{\circ} \mathrm{C} / \mathrm{s}$

Figura 46 - Fração de ferrita no aquecimento de $950^{\circ} \mathrm{C}$ até $1250^{\circ} \mathrm{C}$ (trecho 1 ) à taxa de $0,30^{\circ} \mathrm{C} / \mathrm{s}$

Figura 47 - Frações de ferrita em função da taxa de aquecimento no trecho 1 74

Figura 48 - Perfil de composição de $\mathrm{Cr}$ no aquecimento de $950^{\circ} \mathrm{C}$ a $1250^{\circ} \mathrm{C}$ (trecho 1 ) em função da distância à taxa de $0,30^{\circ} \mathrm{C} / \mathrm{s}$ 75

Figura 49 - Perfil de composição de Mo no aquecimento de $950^{\circ} \mathrm{C}$ a $1250^{\circ} \mathrm{C}$ (trecho 1) em função da distância à taxa de $0,30^{\circ} \mathrm{C} / \mathrm{s}$. .76

Figura 50 - Perfil de composição de Ni no aquecimento de $950^{\circ} \mathrm{C}$ a $1250^{\circ} \mathrm{C}$ (trecho 1 ) em função da distância à taxa de $0,30^{\circ} \mathrm{C} / \mathrm{s}$

Figura 51 - Perfil de composição de $\mathrm{N}$ no aquecimento de $950^{\circ} \mathrm{C}$ a $1250^{\circ} \mathrm{C}$ (trecho 1) em função da distância à taxa de $0,30^{\circ} \mathrm{C} / \mathrm{s}$

Figura 52 - Perfil de composição de $\mathrm{Cr}$ no aquecimento de $950^{\circ} \mathrm{C}$ a $1250^{\circ} \mathrm{C}$ (trecho 1 ) em função da distância à taxa de $0,30^{\circ} \mathrm{C} / \mathrm{s}$ em 1000 s................................................ 78

Figura 53 - Fração de ferrita em função do tempo no patamar a $1250^{\circ} \mathrm{C}$ (trecho 2) ............... 79

Figura 54 - Fração de austenita em função do tempo no patamar a $1250^{\circ} \mathrm{C}$ (trecho 2 )........... 79

Figura 55 - Perfil de composição de Cr no patamar à $1250^{\circ} \mathrm{C}$ (trecho 2) em função da distância 80

Figura 56 - Perfil de composição de Mo no patamar à $1250^{\circ} \mathrm{C}$ (trecho 2) em função da distância

Figura 57 - Perfil de composição de Ni no patamar à $1250^{\circ} \mathrm{C}$ (trecho 2) em função da distância

Figura 58 - Perfil de composição de $\mathrm{N}$ no patamar à $1250^{\circ} \mathrm{C}$ (trecho 2) em função da distância

Figura 59 - Fração de ferrita no resfriamento do aço de $1250^{\circ} \mathrm{C}$ até $1090^{\circ} \mathrm{C}$ (trecho 3 ) à taxa de $0,30^{\circ} \mathrm{C} / \mathrm{s}$

Figura 60 - Fração de austenita no resfriamento do aço de $1250^{\circ} \mathrm{C}$ até $1090^{\circ} \mathrm{C}$ (trecho 3) à taxa de $0,30^{\circ} \mathrm{C} / \mathrm{s}$. 
Figura 61 - Perfil de composição de $\mathrm{Cr}$ no resfriamento de $1250^{\circ} \mathrm{C}$ a $1090^{\circ} \mathrm{C}$ (trecho 3) em função da distância à taxa de $0,30^{\circ} \mathrm{C} / \mathrm{s}$

Figura 62 - Perfil de composição de Mo no resfriamento de $1250^{\circ} \mathrm{C}$ a $1090^{\circ} \mathrm{C}$ (trecho 3) em função da distância à taxa de $0,30^{\circ} \mathrm{C} / \mathrm{s}$

Figura 63 - Perfil de composição de Ni no resfriamento de $1250^{\circ} \mathrm{C}$ a $1090^{\circ} \mathrm{C}$ (trecho 3) em função da distância à taxa de $0,30^{\circ} \mathrm{C} / \mathrm{s}$

Figura 64 - Perfil de composição de $\mathrm{N}$ no resfriamento de $1250^{\circ} \mathrm{C}$ a $1090^{\circ} \mathrm{C}$ (trecho 3) em função da distância à taxa de $0,30^{\circ} \mathrm{C} / \mathrm{s}$ 86

Figura 65 - Fração de ferrita no resfriamento do aço de $1250^{\circ} \mathrm{C}$ até $1090^{\circ} \mathrm{C}$ (trecho 3) à taxa de $0,10^{\circ} \mathrm{C} / \mathrm{s}$

Figura 66 - Fração de ferrita no resfriamento do aço de $1250^{\circ} \mathrm{C}$ até $1090^{\circ} \mathrm{C}$ (trecho 3) à taxa de $0,10^{\circ} \mathrm{C} / \mathrm{s}$ 87

Figura 67 - Fração de ferrita em função do tempo no patamar a $1090^{\circ} \mathrm{C}$ (trecho 4) 89

Figura 68 - Fração de austenita em função do tempo no patamar a $1090^{\circ} \mathrm{C}$ (trecho 4). 89

Figura 69 - Perfil de composição de Cr no patamar a $1090^{\circ} \mathrm{C}$ (trecho 4) em função da distância 90

Figura 70 - Perfil de composição de Mo no patamar a $1090^{\circ} \mathrm{C}$ (trecho 4) em função da distância 91

Figura 71 - Perfil de composição de Ni no patamar a $1090^{\circ} \mathrm{C}$ (trecho 4) em função da distância 91

Figura 72 - Perfil de composição de N no patamar a $1090^{\circ} \mathrm{C}$ (trecho 4) em função da distância 92

Figura 73 - Fração de ferrita no resfriamento do aço de $1090^{\circ} \mathrm{C}$ até $790^{\circ} \mathrm{C}$ (trecho 5) à taxa de $0,30^{\circ} \mathrm{C} / \mathrm{s}$

Figura 74 - Fração de austenita no resfriamento do aço de $1090^{\circ} \mathrm{C}$ até $790^{\circ} \mathrm{C}$ (trecho 5) à taxa de $0,30^{\circ} \mathrm{C} / \mathrm{s}$........ 93

Figura 75 - Fração de sigma no resfriamento do aço de $1090^{\circ} \mathrm{C}$ até $790^{\circ} \mathrm{C}$ (trecho 5) à taxa de $0,30^{\circ} \mathrm{C} / \mathrm{s}$

Figura 76 - Perfil de composição de $\mathrm{Cr}$ no resfriamento de $1090^{\circ} \mathrm{C}$ a $790^{\circ} \mathrm{C}$ (trecho 5) em função da distância à taxa de $0,30^{\circ} \mathrm{C} / \mathrm{s}$.

Figura 77 - Perfil de composição de Mo no resfriamento de $1090^{\circ} \mathrm{C}$ a $790^{\circ} \mathrm{C}$ (trecho 5) em função da distância à taxa de $0,30^{\circ} \mathrm{C} / \mathrm{s}$ 95

Figura 78 - Perfil de composição de Ni no resfriamento de $1090^{\circ} \mathrm{C}$ a $790^{\circ} \mathrm{C}$ (trecho 5) em função da distância à taxa de $0,30^{\circ} \mathrm{C} / \mathrm{s}$ 
Figura 79 - Fração de ferrita no resfriamento do aço de $1090^{\circ} \mathrm{C}$ até $790^{\circ} \mathrm{C}$ (trecho 5) à taxa de $0,60^{\circ} \mathrm{C} / \mathrm{s}$

Figura 80 - Fração de austenita no resfriamento do aço de $1090^{\circ} \mathrm{C}$ até $790^{\circ} \mathrm{C}$ (trecho 5) à taxa de $0,60^{\circ} \mathrm{C} / \mathrm{s}$

Figura 81 - Fração de sigma no resfriamento do aço de $1090^{\circ} \mathrm{C}$ até $790^{\circ} \mathrm{C}$ (trecho 5) à taxa de $0,60^{\circ} \mathrm{C} / \mathrm{s}$ 98

Figura 82 - Fração de sigma formada ao longo do tempo em função da taxa de resfriamento no trecho 5

Figura 83 - Fração de ferrita no resfriamento do aço de $1090^{\circ} \mathrm{C}$ até $790^{\circ} \mathrm{C}$ (trecho 5) à taxa de $3,0^{\circ} \mathrm{C} / \mathrm{s}$ 100

Figura 84 - Fração de austenita no resfriamento do aço de $1090^{\circ} \mathrm{C}$ até $790^{\circ} \mathrm{C}$ (trecho 5) à taxa de $3,0^{\circ} \mathrm{C} / \mathrm{s}$. 100

Figura 85 - Fração de sigma no resfriamento do aço de $1090^{\circ} \mathrm{C}$ até $790^{\circ} \mathrm{C}$ (trecho 5) à taxa de $3,0^{\circ} \mathrm{C} / \mathrm{s}$ 101

Figura 86 - Perfil de composição de $\mathrm{Cr}$ no resfriamento de $1090^{\circ} \mathrm{C}$ a $790^{\circ} \mathrm{C}$ (trecho 5) em função da distância à taxa de $3,0^{\circ} \mathrm{C} / \mathrm{s}$

Figura 87 - Perfil de composição de Mo no resfriamento de $1090^{\circ} \mathrm{C}$ a $790^{\circ} \mathrm{C}$ (trecho 5) em função da distância à taxa de $3,0^{\circ} \mathrm{C} / \mathrm{s}$

Figura 88 - Perfil de composição de Mo no resfriamento de $1090^{\circ} \mathrm{C}$ a $790^{\circ} \mathrm{C}$ (trecho 5) em função da distância à taxa de $3,0^{\circ} \mathrm{C} / \mathrm{s}$ 103

Figura 89 - Fração de ferrita no resfriamento do aço de $1090^{\circ} \mathrm{C}$ até $790^{\circ} \mathrm{C}$ (trecho 6) à taxa de $0,30^{\circ} \mathrm{C} / \mathrm{s}$

Figura 90 - Fração de austenita no resfriamento do aço de $1090^{\circ} \mathrm{C}$ até $790^{\circ} \mathrm{C}$ (trecho 6) à taxa de $0,30^{\circ} \mathrm{C} / \mathrm{s}$. 104

Figura 91 - Fração de sigma no resfriamento do aço de $1090^{\circ} \mathrm{C}$ até $790^{\circ} \mathrm{C}$ (trecho 6) à taxa de $0,30^{\circ} \mathrm{C} / \mathrm{s}$ 105

Figura 92 - Fração de ferrita no resfriamento do aço de $1090^{\circ} \mathrm{C}$ até $790^{\circ} \mathrm{C}$ (trecho 6) à taxa de $3,0^{\circ} \mathrm{C} / \mathrm{s}$ 105

Figura 93 - Fração de austenita no resfriamento do aço de $1090^{\circ} \mathrm{C}$ até $790^{\circ} \mathrm{C}$ (trecho 6) à taxa de $3,0^{\circ} \mathrm{C} / \mathrm{s}$ 106

Figura 94 - Fração de sigma no resfriamento do aço de $1090^{\circ} \mathrm{C}$ até $790^{\circ} \mathrm{C}$ (trecho 6) à taxa de $3,0^{\circ} \mathrm{C} / \mathrm{s}$ 106

Figura 95 - Perfil de composição de $\mathrm{Cr}$ no resfriamento de $1090^{\circ} \mathrm{C}$ a $790^{\circ} \mathrm{C}$ (trecho 6) em função da distância à taxa de $3,0^{\circ} \mathrm{C} / \mathrm{s}$ 
Figura 96 - Perfil de composição de Mo no resfriamento de $1090^{\circ} \mathrm{C}$ a $790^{\circ} \mathrm{C}$ (trecho 6) em função da distância à taxa de $3,0^{\circ} \mathrm{C} / \mathrm{s}$ 108

Figura 97 - Perfil de composição de Ni no resfriamento de $1090^{\circ} \mathrm{C}$ a $790^{\circ} \mathrm{C}$ (trecho 6) em função da distância à taxa de $3,0^{\circ} \mathrm{C} / \mathrm{s}$.......................................................... 108

Figura 98 - Modelo esquemático final das transformações de fases simuladas para o aço UNS S32750 110

Figura 99 - Perfil de composição de Cr no resfriamento de $1250^{\circ} \mathrm{C}$ a $1090^{\circ} \mathrm{C}$ em função da distância à taxa de $0,10^{\circ} \mathrm{C} / \mathrm{s}$ 120

Figura 100 - Perfil de composição de Mo no resfriamento de $1250^{\circ} \mathrm{C}$ a $1090^{\circ} \mathrm{C}$ em função da distância à taxa de $0,10^{\circ} \mathrm{C} / \mathrm{s}$.

Figura 101 - Perfil de composição de Ni no resfriamento de $1250^{\circ} \mathrm{C}$ a $1090^{\circ} \mathrm{C}$ em função da distância à taxa de $0,10^{\circ} \mathrm{C} / \mathrm{s}$. 121

Figura 102 - Perfil de composição de $\mathrm{N}$ no resfriamento de $1250^{\circ} \mathrm{C}$ a $1090^{\circ} \mathrm{C}$ em função da distância à taxa de $0,10^{\circ} \mathrm{C} / \mathrm{s}$ 


\section{LISTA DE TABELAS}

Tabela 1 - Composição química típica do aço superdúplex UNS S32750 obtida dos principais fabricantes.

Tabela 2 - Composição química das fases do aço superdúplex UNS S32750.

Tabela 3 - Comparativo entre os tempos e temperaturas de formação de fase chi entre os aços dúplex e superdúplex

Tabela 4 - Expoente ' $n$ ' de K-J-M-A

Tabela 5 - Comparativo entre a temperatura de cinética máxima de formação de fase sigma entre os aços dúplex e superdúplex

Tabela 6 - Composição química dos niretos de cromo a diferentes taxas de resfriamento ..... 45

Tabela 7 - Taxas de resfriamento contínuo críticas para evitar a formação de fases deletérias no aço UNS S32750......

Tabela 8 - Composição química do aço superdúplex UNS S32750 de análise química realizada pela Villares Metals....

Tabela 9 - Parâmetros utilizados para simulação do trecho 1

Tabela 10 - Parâmetros utilizados para simulação do trecho 2 ............................................... 65

Tabela 11 - Parâmetros utilizados para simulação do trecho 3 ...............................................65

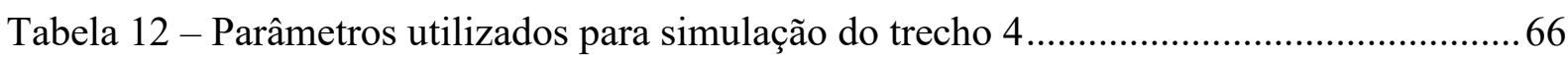

Tabela 13 - Parâmetros utilizados para simulação do trecho 5 ................................................67

Tabela 14 - Parâmetros utilizados para simulação do trecho 6 ................................................. 67

Tabela 15 - Fração máxima de ferrita formada em função da taxa de aquecimento no trecho 1

Tabela 16 - Fração máxima de sigma formada em função da taxa de resfriamento no trecho 5

Tabela 17 - Fração volumétrica das fases obtidas no resfriamento dos trechos 5 e 6 à taxa de resfriamento de $3,0{ }^{\circ} \mathrm{C} / \mathrm{s}$

Tabela 18 - Condição ideal de processamento do aço superdúplex UNS S32750

Tabela 19 - Perfis de composição química do trecho 1 para simular o trecho 2

Tabela 20 - Perfis de composição química do trecho 2 para simular o trecho 3

Tabela 21 - Perfis de composição química do trecho 3 para simular o trecho 4 a $0,3^{\circ} \mathrm{C} / \mathrm{s}$ e para simular o trecho 6

Tabela 22 - Perfis de composição química do trecho 4 para simular o trecho 5 118

Tabela 23 - Perfis de composição química do trecho 3 para simular o trecho 4 a $0,1^{\circ} \mathrm{C} / \mathrm{s} \ldots .122$ 


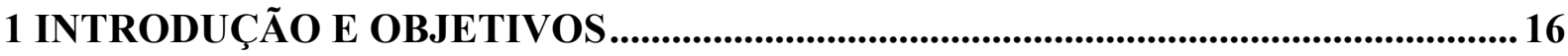

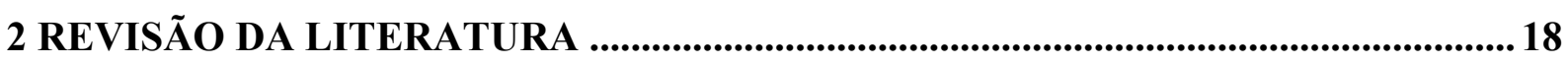

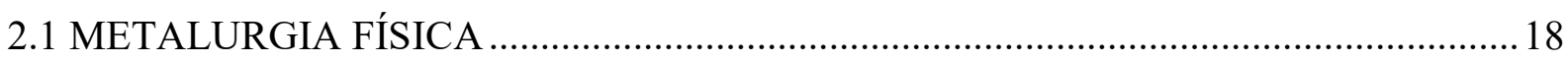

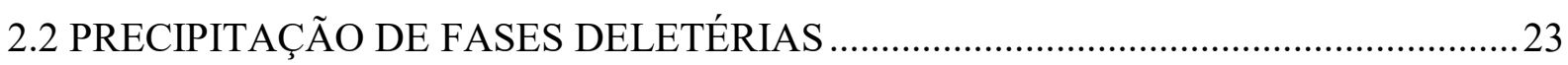

2.2.1 Sigma

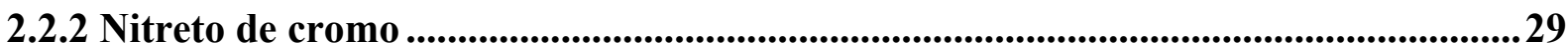

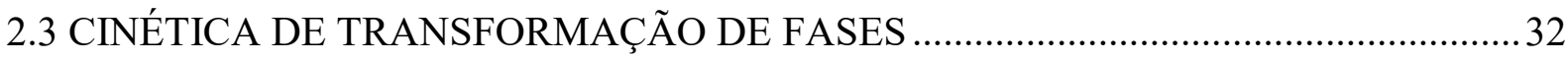

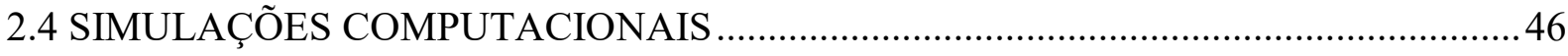

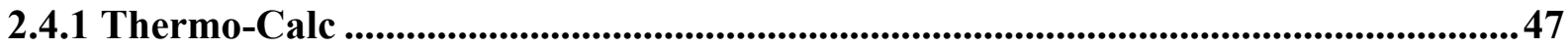

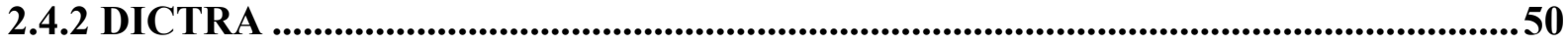

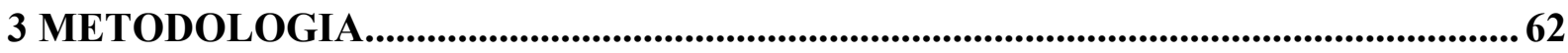

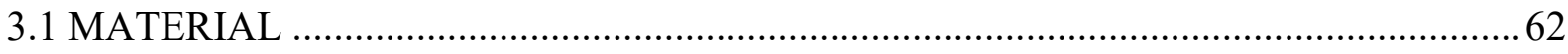

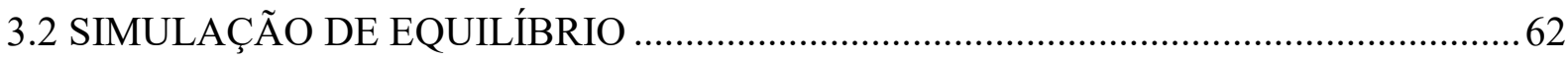

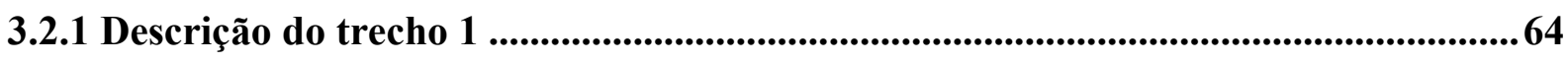

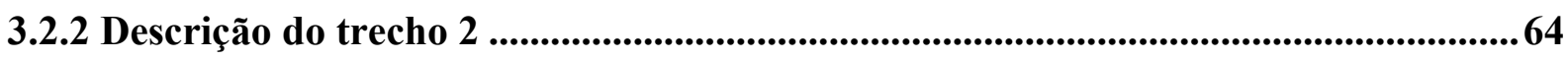

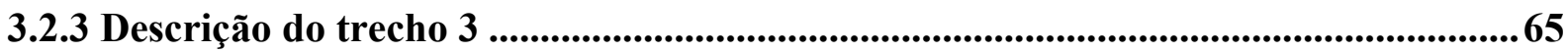

3.2.4 Descrição do trecho 4 .......................................................................................................66

3.2.5 Descrição do trecho 5 ...........................................................................................................66

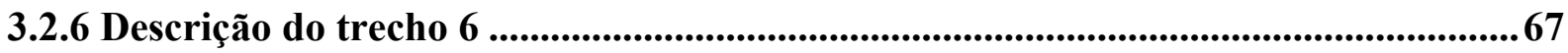

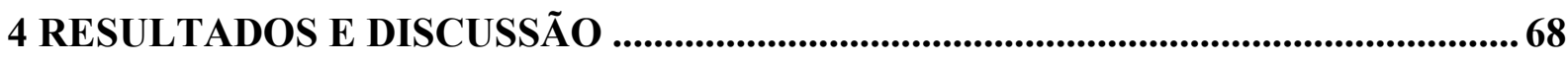

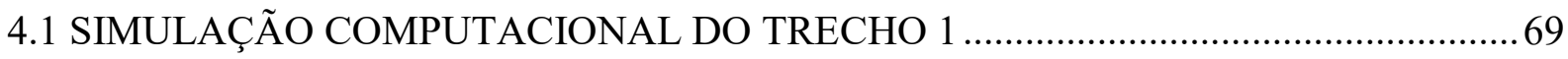

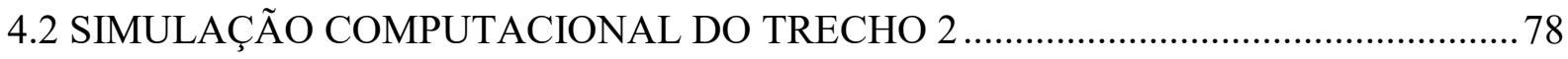

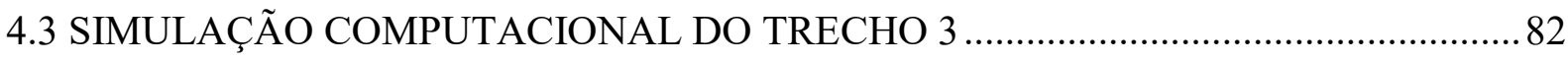

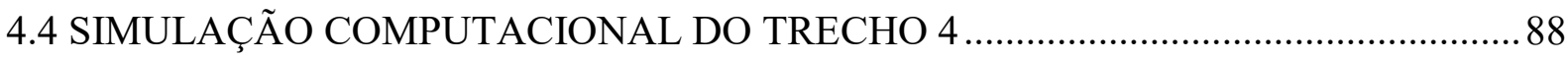

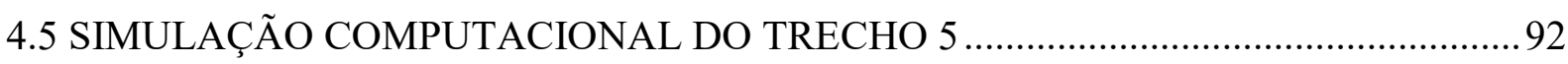

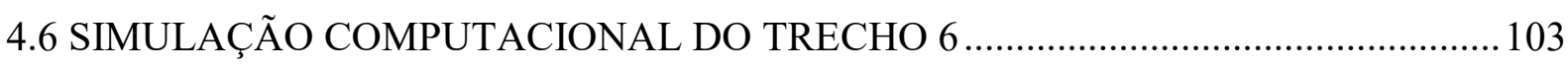

4.7 USO DOS RESULTADOS NA DETERMINAÇÃO DE CICLO TÉRMICO DE

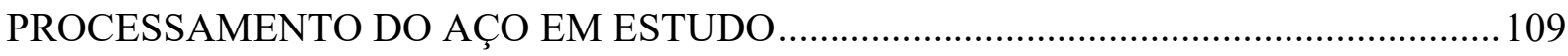

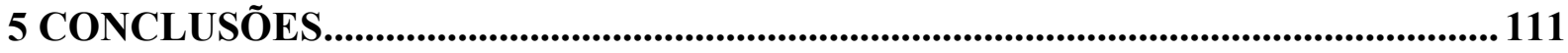


APÊNDICE I - FUNÇÕES MATEMÁTICAS DOS PERFIS DE COMPOSIÇÃO..119 APÊNDICE II - PERFIS DE COMPOSIÇÃO DO TRECHO 3 À TAXA DE 0,1 ${ }^{\circ} \mathrm{C} / \mathrm{s.} .116$ 


\section{INTRODUÇÃO E OBJETIVOS}

Aços inoxidáveis são ligas ternárias do sistema ferro-cromo-níquel que são produzidas para nobres aplicações, incluindo setores petroquímico, aeronáutico, nuclear e de óleo e gás, por apresentarem excelentes resistências mecânica e à corrosão. Pertencentes à família dos aços inoxidáveis, os dúplex possuem microestrutura típica de ferrita e austenita, com frações de ferrita variando entre 40 e $60 \%$ em volume, e os superdúplex, que além da coexistência das fases do dúplex com fração de ferrita variando entre 35 e 55\%, possuem resistência equivalente a pite (PREN) superior a 40, calculada como PREN $=\% \mathrm{Cr}+3,3 \% \mathrm{Mo}+1,6 \% \mathrm{~N}(\mathrm{SOLOMON}$; DEVINE, 1982; BAIN; GRIFFITHS, 1997; RAYNOR; RIVLIN, 1988; FRAZÃO, 2018).

O papel do cromo está na formação de uma película passiva e auto-regenerativa, que atua como uma barreira física entre o material e o meio corrosivo, o que torna o aço inoxidável, se houver ao menos $12 \%$ de cromo em solução sólida. Ambas as fases do dúplex são inoxidáveis (SEDRIKS, 1996; SOLOMON; DEVINE, 1982; POTGIETER e CORTIE, 1991). O molibdênio, cujo teor varia entre 1 e $4 \%$, auxilia na redução da tendência de quebra desta película e, em sinergia com o nitrogênio, presente em frações inferiores a $0,4 \%$, colabora na repassivação da mesma, no caso de dano (ALVAREZ-ARMAS, 2008; POTGIETER e CORTIE, 1991; NOBLE, 1993; FRAZÃO, 2018). Apesar de não serem considerados no PREN, microestrutura e condições superficiais do aço também influenciam na resistência à corrosão por pite (NILSSON, 1992; NOBLE, 1993).

Os aços inoxidáveis dúplex, por conterem frações volumétricas equivalentes de ferrita e austenita, favorecem a combinação de propriedades mecânicas individuais de cada fase, as quais não são atingidas pelos aços convencionais. Segundo Solomon e Devine (1982) e Potgieter e Cortie (1991) o teor de ferrita minimiza a ocorrência de trincas a quente e tem influência benéfica na sensitização e na resistência à corrosão, enquanto que a presença de austenita aumenta a ductilidade e tenacidade do material (SOLOMON; DEVINE, 1982; ECKENROD; PINNOW, 1984; NILSSON, 1992; POTGIETER; CORTIE, 1991).

A obtenção destes aços se dá pela conformação a quente, geralmente entre $1000{ }^{\circ} \mathrm{C}$ e $1300{ }^{\circ} \mathrm{C}$, e tratamento térmico de solubilização entre $1050{ }^{\circ} \mathrm{C}$ e $1125{ }^{\circ} \mathrm{C}$, com intuito de recuperar a estrutura bifásica característica destes materiais, permanecendo em equilíbrio metaestável (NILSSON, 1992; BAIN; GRIFFITHS, 1927; RAYNOR; RIVLIN, 1988; SANDVIK, 2019). 
Dentre os aços inoxidáveis, o superdúplex UNS S32750 ou SAF 2507, objeto de estudo desta dissertação, apresenta composição química típica $\mathrm{Fe}-25 \% \mathrm{Cr}-7 \% \mathrm{Ni}-4 \% \mathrm{Mo}-0,28 \% \mathrm{~N}$ - $1,20 \% \mathrm{Mn}-0,4 \% \mathrm{Si}$ e é produzido através de sistema AOD (descarburação por sopro de oxigênio e argônio), e por isso apresenta baixo teor de carbono, $0,01 \% \mathrm{C}$. Após a solubilização, este aço apresenta frações volumétricas aproximadamente iguais de ferrita e austenita e atinge valores de propriedades mecânicas mínimos como limite de escoamento de $530 \mathrm{MPa}$, limite de resistência de $730 \mathrm{MPa}$, alongamento de $20 \%$ e dureza máxima de $32 \mathrm{HRC}$, devido ao diminuto tamanho de grão após processamento (GIRALDO, 2001; SEDRIKS; 1996).

No entanto, durante os diversos ciclos térmicos que o material sofre na fabricação do produto final, principalmente entre $600{ }^{\circ} \mathrm{C}$ e $1000{ }^{\circ} \mathrm{C}$, pode ocorrer a precipitação de outras fases como sigma e nitretos de cromo, que são deletérias às propriedades do aço, principalmente à tenacidade e à corrosão (SOLOMON; DEVINE, 1982; NILSSON, 1992; MAGNABOSCO, 2015). Portanto, é de suma importância que se investigue o comportamento dos aços inoxidáveis superdúplex durante o processo de fabricação do produto, no que diz respeito às transformações das fases que ocorrem, objetivando a estrutura dúplex.

Em face do exposto, o objetivo da presente dissertação é avaliar a cinética de transformação de fases e evolução da ferrita, austenita, nitretos de cromo e sigma durante os ciclos térmicos de processamento do aço inoxidável superdúplex UNS S32750. Utilizando-se o software DICTRA ${ }^{\circledR}$, simulou-se diferentes taxas de aquecimento a partir da temperatura ambiente, isto é, a partir da condição microestrutural inicial de 50\% de ferrita e 50\% de austenita até $1250{ }^{\circ} \mathrm{C}$, temperatura típica de conformação plástica, e em diferentes tempos de patamar nesta temperatura, bem como no resfriamento subsequente até a temperatura de solubilização, a fim de recuperar a condição dúplex. Em seguida, também simulou-se o resfriamento até $790^{\circ} \mathrm{C}$ a diferentes taxas com a presença ou não de patamar de solubilização, sendo possível selecionar-se o ciclo térmico que melhor otimiza o processo de processamento. 


\section{REVISÃO DA LITERATURA}

Com o intuito de obter um aço inoxidável superdúplex com propriedades mecânicas e resistência à corrosão otimizadas, é necessário conhecer com detalhes a ocorrência de fases secundárias, a cinética de transformação de fases e o efeito dos elementos de liga nas propriedades. Os conceitos que envolvem o estudo termodinâmico e cinético que o aço inoxidável superdúplex UNS S32750 sofre durante os ciclos térmicos de trabalho a quente, a diferentes taxas de aquecimento e resfriamento, serão apresentados a seguir, desde a metalurgia física até a metodologia de modelagem computacional em DICTRA ${ }^{\circledR}$.

\subsection{METALURGIA FÍSICA}

Campos de coexistência de ferrita e austenita em sistemas ternários Fe-Cr-Ni foram descobertos em 1927 por Bain e Griffiths (1927), observados nas seções isotérmicas a $1000{ }^{\circ} \mathrm{C}$, $1100{ }^{\circ} \mathrm{C}, 1200{ }^{\circ} \mathrm{C}$ e $1300{ }^{\circ} \mathrm{C}$ deste sistema ternário, que mais tarde teve os diagramas ternários

publicados por Raynor e Rivlin (1998), os quais podem ser vistos das Figura 1 a 4 . Visto que a ferrita e austenita são termodinamicamente estáveis e coexistem dentro da faixa de $1000{ }^{\circ} \mathrm{C} \mathrm{a}$ $1300{ }^{\circ} \mathrm{C}$, temperaturas representativas do trabalho a quente e solubilização, tem-se então as condições sob as quais a estrutura dúplex é possível. Portanto, abaixo desta faixa, a estrutura dúplex não existe mais em condições de equilíbrio estável e sua obtenção se dá por meio de equilíbrio metaestável (NILSSON, 1992), que será discutido no item 2.3.

Analisando-se os ternários das Figuras 1 a 4, nota-se que com o aumento da temperatura, o campo de coexistência da austenita e da ferrita diminui, uma vez que a solubilidade dos elementos aumenta em cada fase separadamente (BAIN; GRIFFITHS, 1927; SOLOMON; DEVINE; 1982). 
Figura 1 - Seção isotérmica do sistema ternário $\mathrm{Fe}-\mathrm{Cr}-\mathrm{Si}$ a $1000^{\circ} \mathrm{C}$

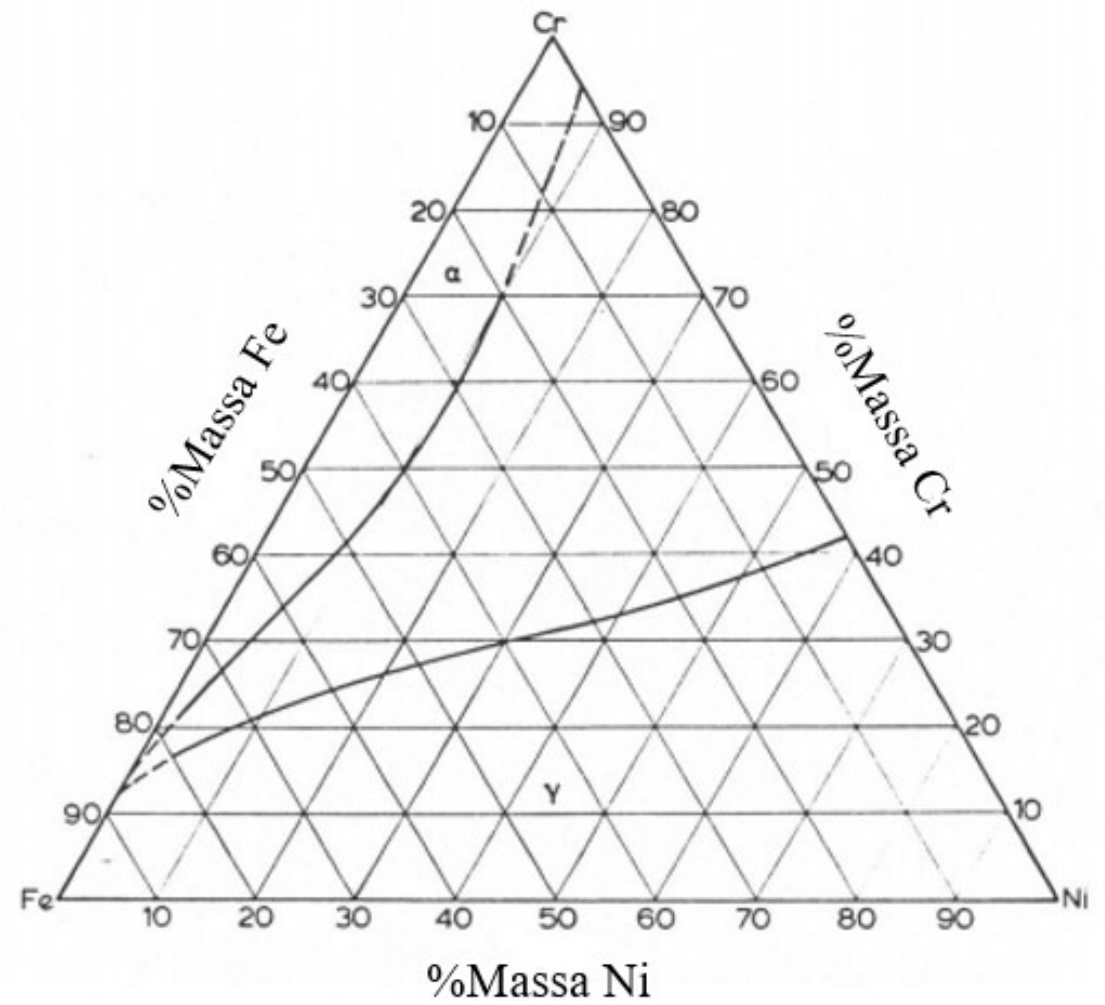

Fonte: Autora "adaptado de" Raynor e Rivlin, 1998, p. 323

Figura 2 - Seção isotérmica do sistema ternário $\mathrm{Fe}-\mathrm{Cr}-\mathrm{Ni}$ a $1100^{\circ} \mathrm{C}$

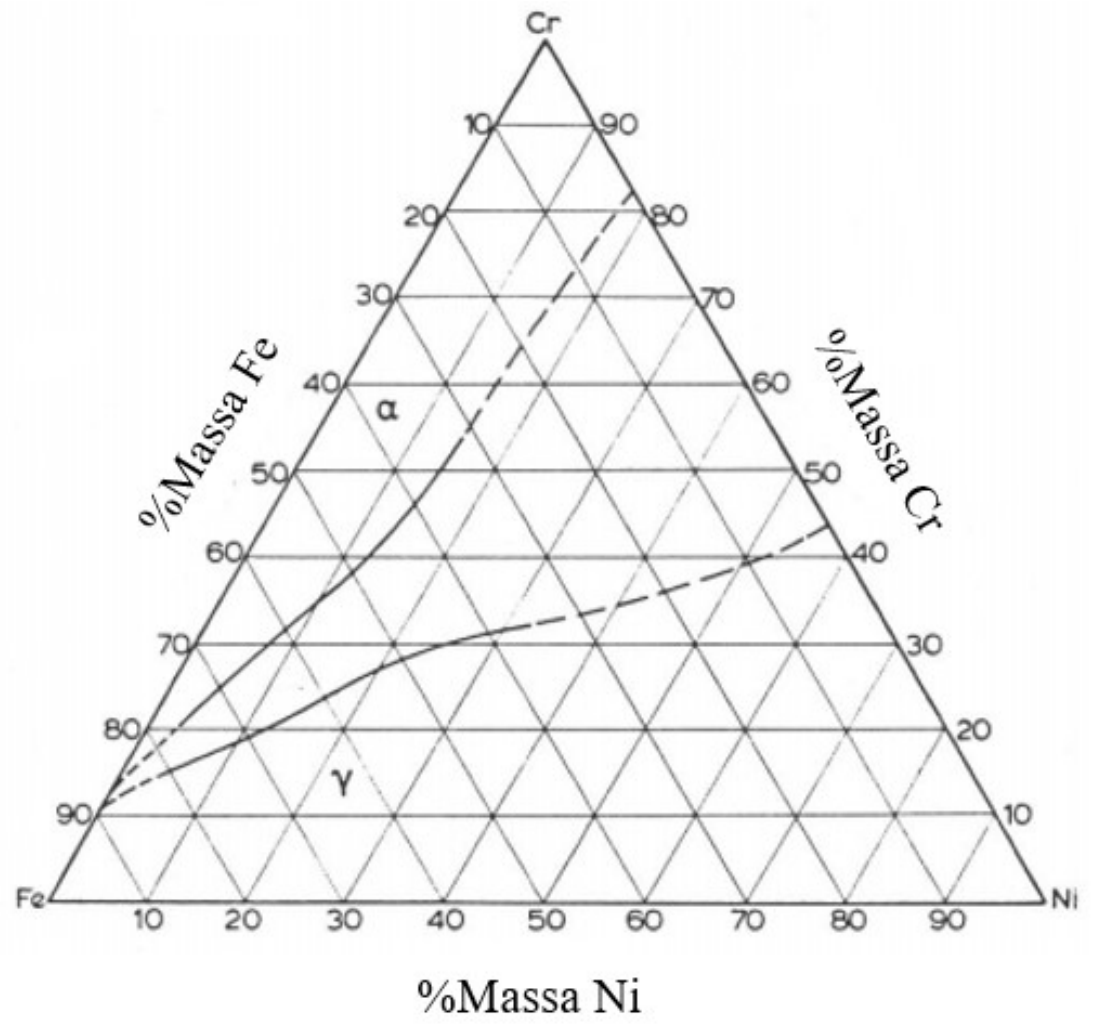

Fonte: Autora "adaptado de" Raynor e Rivlin, 1998, p. 323 
Figura 3 - Seção isotérmica do sistema ternário Fe-Cr-Ni a $1200^{\circ} \mathrm{C}$

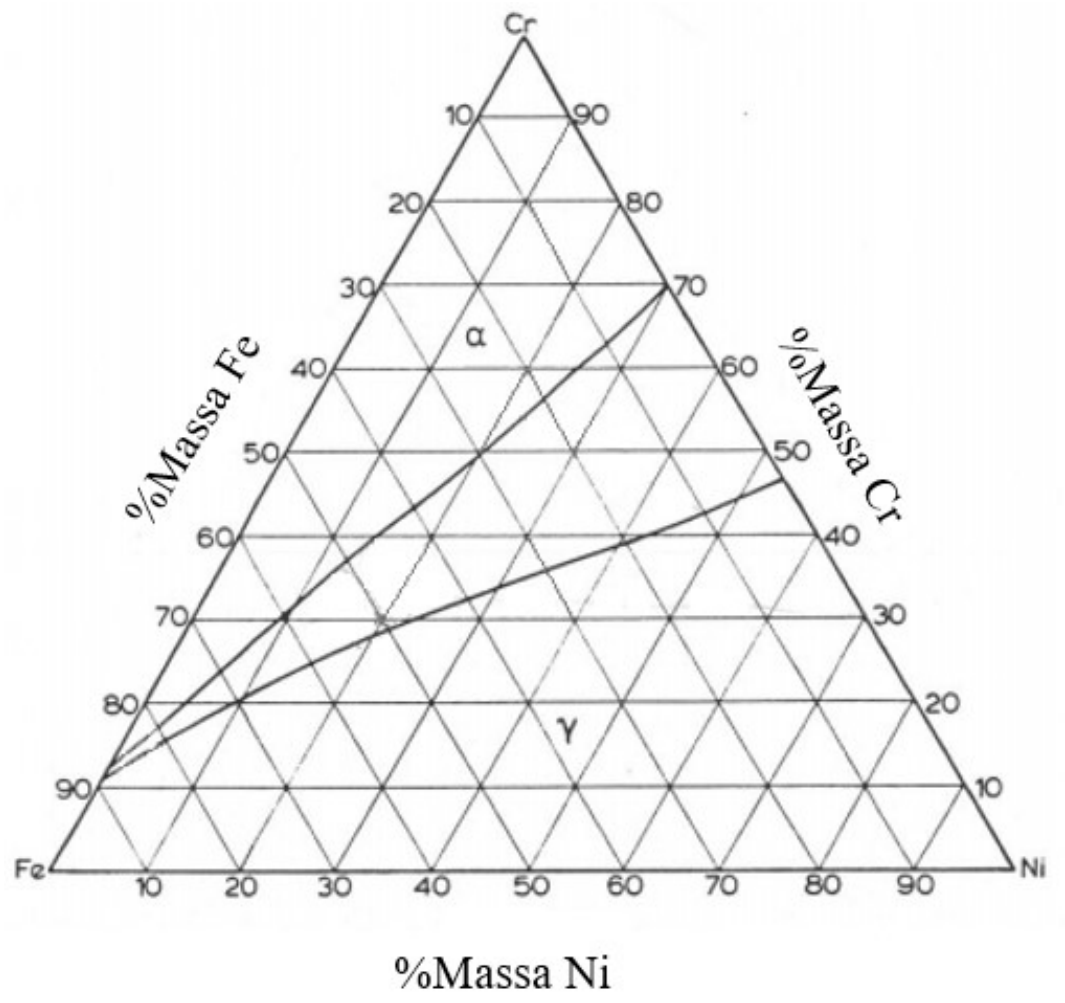

Fonte: Autora "adaptado de" Raynor e Rivlin, 1988, p. 322

Figura 4 - Seção isotérmica do sistema ternário Fe-Cr-Ni a $1300^{\circ} \mathrm{C}$

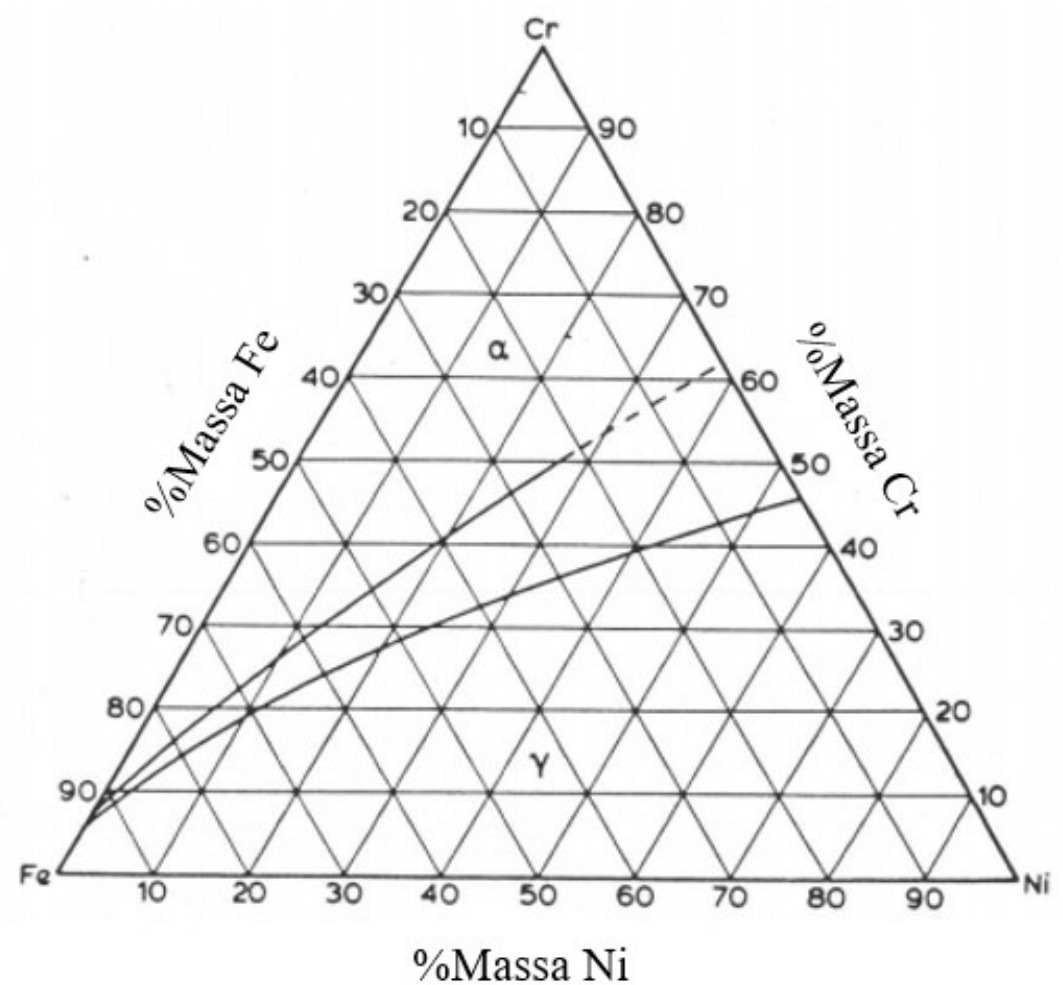

Fonte: Autora "adaptado de” Raynor e Rivlin, 1988, p. 321 
Elementos químicos presentes no aço também podem atuar como estabilizadores da fase ferrítica ou austenítica, visto que a partição ocorre em função da atividade termodinâmica de cada elemento nas fases existentes para cada temperatura, visando sempre a redução da energia livre do sistema (POTGIETER; CORTIE, 1991; PORTER; EASTERLING, 2004). Portanto, a introdução destes elementos no aço, por estabilizarem preferencialmente uma ou outra fase, resulta em diferentes propriedades mecânicas, e principalmente de resistência à corrosão (POTGIETER; CORTIE, 1991; SOLOMON; DEVINE, 1982).

Alguns elementos como cromo, molibdênio, silício e nióbio, atuam como estabilizadores da ferrita, $\alpha$, (estrutura cúbica de corpo centrado) e, portanto, são chamados de ferritizantes ou alfagênicos. Já outros elementos como níquel, manganês e nitrogênio são estabilizadores da austenita, $\gamma$, (estrutura cúbica de face centrada), sendo chamados de austenitizantes ou gamagênicos (SOLOMON; DEVINE, 1982). Portanto, o correto balanço entre tais elementos e a temperatura permite que o aço dúplex seja constituído por frações volumétricas aproximadamente iguais de ferrita e austenita (POTGIETER; CORTIE, 1991).

Dentre eles, o molibdênio, de característica ferritizante, e o nitrogênio, de característica austenitizante, são tão relevantes aos aços inoxidáveis superdúplex quanto os elementos-base $\mathrm{Fe}-\mathrm{Cr}-\mathrm{Ni}$, visto que além de auxiliarem na resistência à corrosão por pite, como visto no cálculo do PREN, também são os principais responsáveis pela formação de fases deletérias (SOLOMON; DEVINE, 1982; NILSSON, 1992), que serão abordadas no próximo item. Logo, pode-se afirmar que os aços inoxidáveis superdúplex constituem um sistema complexo Fe-CrNi-Mo-N. Os principais elementos que constituem o aço superdúplex UNS S32750 podem ser vistos na Tabela 1.

Tabela 1 - Composição química típica do aço superdúplex UNS S32750 obtida dos principais fabricantes

\begin{tabular}{|c|c|c|c|c|c|c|c|}
\hline \multicolumn{6}{|c|}{ Composição química } & \multirow{2}{*}{ Fabricante } & \multirow{2}{*}{ Referência } \\
\hline$\% \mathrm{Fe}$ & $\% \mathrm{Cr}$ & $\% \mathrm{Ni}$ & $\% \mathrm{Mo}$ & $\% \mathrm{~N}$ & $\% \mathrm{C}$ & & \\
\hline \multirow{4}{*}{ Bal. } & 24,75 & 6,70 & 4,00 & 0,28 & 0,03 máx. & $\begin{array}{l}\text { Villares } \\
\text { Metals }\end{array}$ & $\begin{array}{l}\text { Villares Metals, } \\
2019\end{array}$ \\
\hline & 25,10 & 6,90 & 4,00 & 0,27 & 0,03 máx. & Sandvik & Sandvik, 2019 \\
\hline & 25,80 & 7,00 & 3,80 & 0,30 & 0,02 máx. & Aperam & Aperam, 2019 \\
\hline & 24,84 & 6,90 & 3,80 & 0,28 & 0,015 máx. & Outokumpu & Outokumpu, 2020 \\
\hline
\end{tabular}


Diagramas de equilíbrio de fases como o da Figura 5, que Magnabosco e Fiorante (2019) simularam para o aço UNS S32750, também mostram como evoluem as fases em função da temperatura para determinada composição química do aço. É possível observar que dentro da faixa de temperatura utilizada para conformação plástica de $1000{ }^{\circ} \mathrm{C}$ a $1300{ }^{\circ} \mathrm{C}$, quanto maior a temperatura for, tanto maior será a fração de ferrita formada, atingindo-se $70 \%$ de ferrita (BCC_A2) e $30 \%$ de austenita (FCC_A1) em $1250{ }^{\circ} \mathrm{C}$, por exemplo. Apesar de o material manter-se na condição dúplex, isto é, sem que haja qualquer outra fase secundária precipitada, torna-se necessário recuperar o balanço de $50 \%$ em volume de cada fase com tratamento térmico de solubilização, geralmente entre $1050{ }^{\circ} \mathrm{C}$ e $1125^{\circ} \mathrm{C}$. Para a composição química simulada $(\mathrm{Fe}-25,17 \% \mathrm{Cr}-6,88 \% \mathrm{Ni}-3,61 \% \mathrm{Mo}-0,27 \% \mathrm{Ni})$ e base de dados termodinâmica TCFE8, os autores encontraram a temperatura de solubilização de $1088^{\circ} \mathrm{C}$.

Figura 5 - Diagrama de fases do aço superdúplex UNS S32750 com base de dados TCFE8, considerando composição química $\mathrm{Fe}-25,17 \% \mathrm{Cr}-6,88 \% \mathrm{Ni}-3,61 \% \mathrm{Mo}-0,27 \% \mathrm{Ni}$

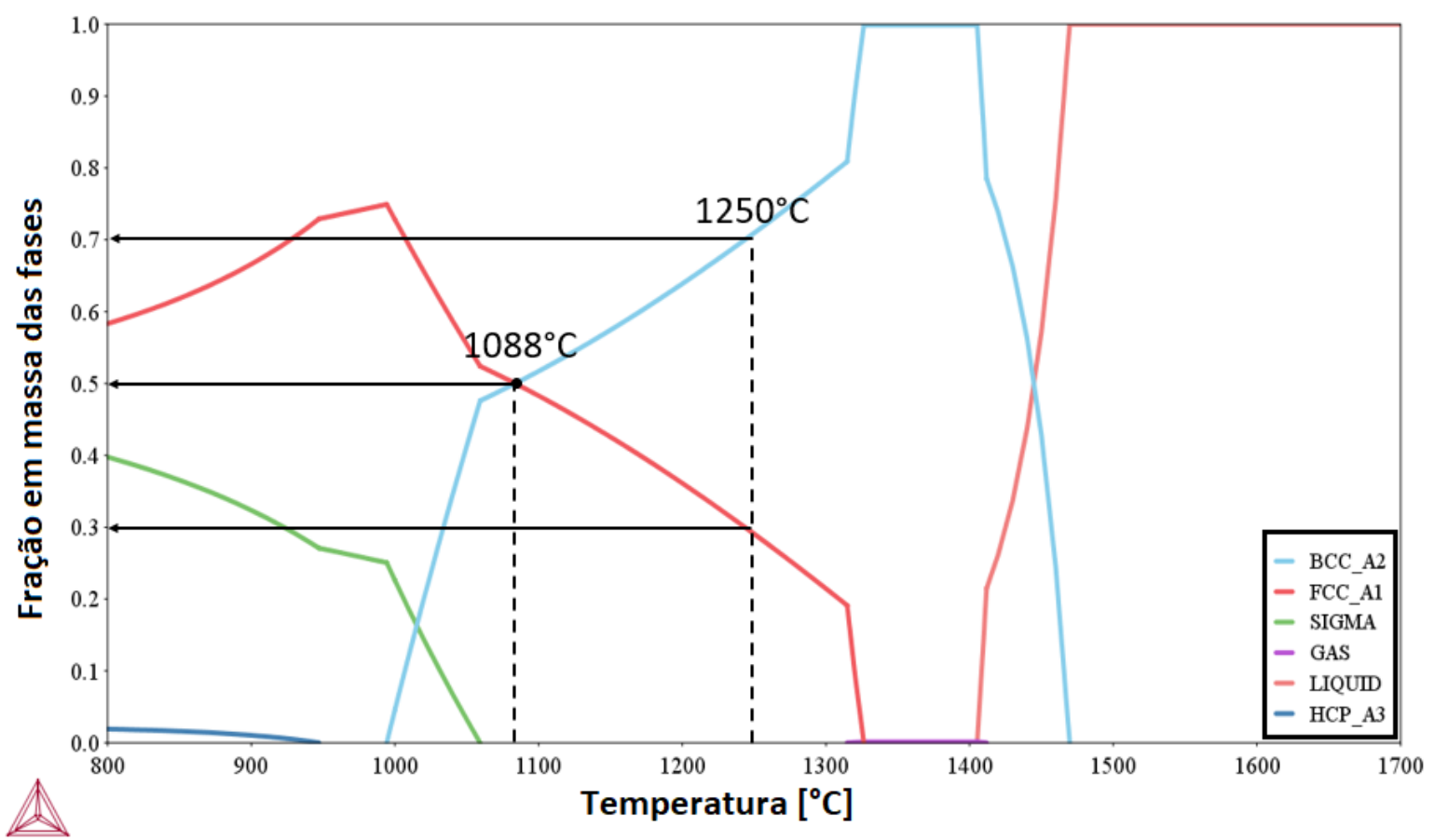

Fonte: Magnabosco e Fiorante, 2019

Os aços inoxidáveis dúplex apresentam o mesmo comportamento termodinâmico, como mostra o diagrama de fases do aço dúplex UNS S31803 da Figura 6 simulado com o ThermoCalc $^{\circledR}$ e base de dados TCFE8, indicando o aumento do teor de ferrita com o aquecimento, atingindo-se os mesmos $70 \%$ de ferrita do exemplo acima, com aproximadamente $1200{ }^{\circ} \mathrm{C}$ e recuperando o balanço de $50 \%$ de cada fase com temperatura de solubilização de $1115^{\circ} \mathrm{C}$. 
Figura 6 - Diagrama de fases do aço dúplex UNS S31803 com base de dados TCFE8 considerando composição química Fe-22,48\%Cr-5,74\%Ni-3,2\%Mo-0,16\%N

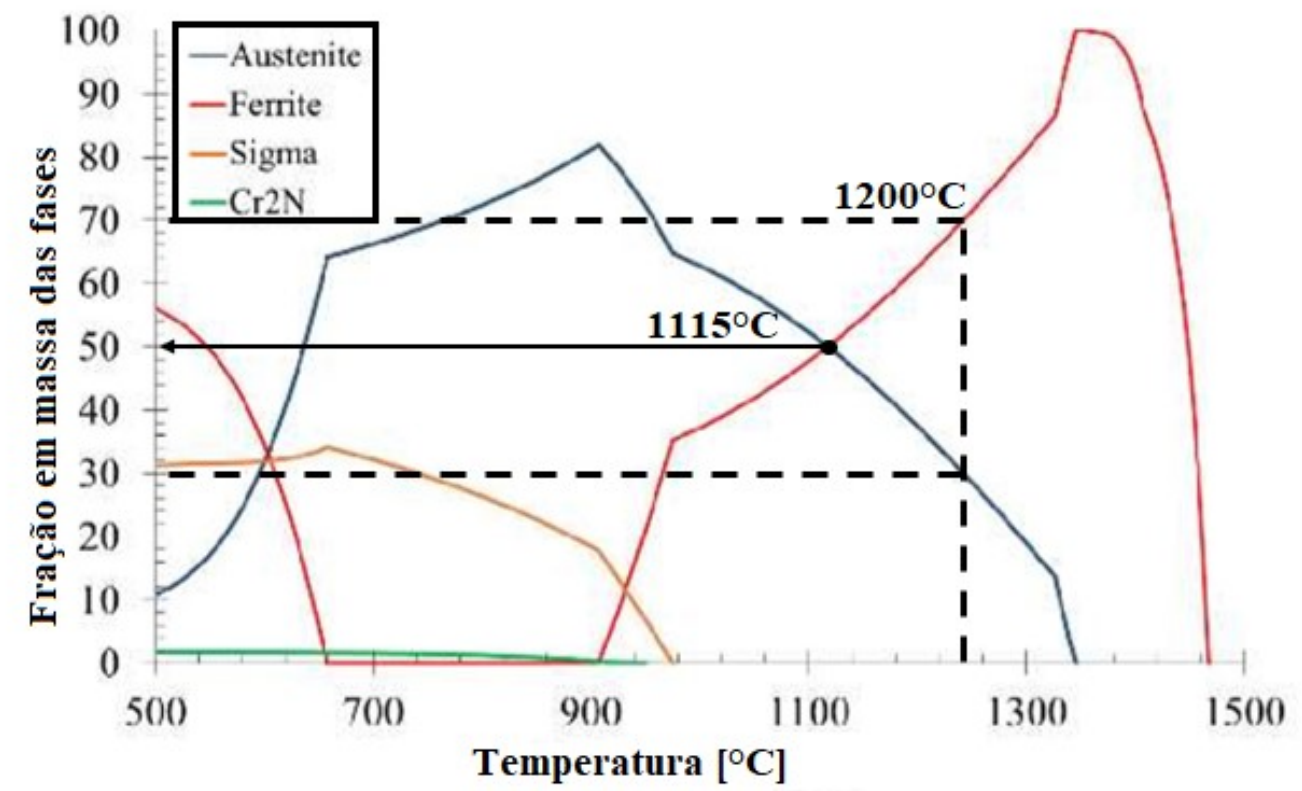

Fonte: Autora “adaptado de” Santos; Macarrão; Magnabosco, 2019, p. 82

Sendo assim, tanto a simulação computacional quanto a consulta à literatura, em conjunto, permitem que sejam feitas previsões das transformações de fases que podem ocorrer durante o processo produtivo do aço, evidenciando que a obtenção de um aço inoxidável dúplex e superdúplex se dá pela correta escolha de composição química e temperatura de tratamento térmico de solubilização, permitindo que se alcance a fração volumétrica desejada de cada fase e propriedades correspondentes (BAIN; GRIFFITHS, 1927; PORTER; EASTERLING, 1992).

\subsection{PRECIPITAÇÃO DE FASES DELETÉRIAS}

Há uma grande variedade de fases secundárias indesejadas que podem precipitar entre $300{ }^{\circ} \mathrm{C}$ e $1000{ }^{\circ} \mathrm{C}$ nos aços dúplex e superdúplex durante tratamentos isotérmicos e ciclos térmicos de processamento, anulando a condição de equilíbrio desejada entre ferrita e austenita. Dentre as fases secundárias encontram-se a sigma $(\sigma)$, nitretos de cromo (particularmente $\mathrm{Cr}_{2} \mathrm{~N}$ ), chi $(\chi)$, alfa linha $\left(\alpha^{\prime}\right)$, austenita secundária $\left(\gamma_{2}\right)$, entre outras (NILSSON, 1992; SOLOMON; DEVINE, 1982; BRANDI; PADILHA, 1990).

A Tabela 2 apresenta a composição química das fases sigma, nitreto de cromo e chi que o aço superdúplex UNS S32750 forma segundo Nilsson e Wilson (1993), quando envelhecido 
a $850{ }^{\circ} \mathrm{C}$ durante 10 minutos; e de alfa linha num aço dúplex envelhecido entre $450{ }^{\circ} \mathrm{C}$ e $525{ }^{\circ} \mathrm{C}$ segundo Gunn (2003). Nota-se que sigma, nitreto de cromo e alfa linha são ricas em cromo, elemento de maior fração volumétrica nos aços dúplex e superdúplex, enquanto a fase chi é composta de frações aproximadamente iguais de cromo e molibdênio; além disso, o fato dos aços superdúplex serem constituídos de quase $0,3 \%$ de nitrogênio colabora para que nitretos precipitem. Também é possível notar que Nilsson e Wilson (1993) encontraram Mo e Ni na composição química do nitreto de cromo via análise de EDS, que apesar de surpreendente, não é justificado pelos autores no artigo. Provavelmente, o Ni resulta da análise semi-quantitativa de EDS no MEV, que acaba por analisar também a redondeza de fases diminutas, como normalmente são os nitretos. Mo, por sua vez, é um elemento que pode estar dissolvido na estrutura do nitreto, assim como outros elementos formadores de carbonetos, que também tem afinidade pelo $\mathrm{N}$.

Tabela 2 - Composição química das fases do aço superdúplex UNS S32750

\begin{tabular}{cccc}
\hline \multirow{2}{*}{ Fase } & \multicolumn{3}{c}{ Composição química } \\
\cline { 2 - 4 } & $\mathrm{Cr}$ & $\mathrm{Ni}$ & $\mathrm{Mo}$ \\
\hline$\sigma$ & $31,0 \%$ & $3,8 \%$ & $9,7 \%$ \\
\hline $\mathrm{Cr}_{2} \mathrm{~N}$ & $71,5 \%$ & $1,1 \%$ & $6,0 \%$ \\
\hline$\chi$ & $26,2 \%$ & $2,9 \%$ & $23,1 \%$ \\
\hline$\alpha^{\prime}$ & $65,0 \%$ & $2,5 \%$ & $13,0 \%$ \\
\hline
\end{tabular}

Fonte: Nilsson; Wilson, 1993; Gunn, 2003

As fases sigma e alfa linha (rica em cromo), podem ser vistas nas seções isotérmicas do diagrama ternário Fe-Cr-Ni obtidas por Raynor e Rivlin (1988) para temperaturas abaixo da solubilização, como a $800{ }^{\circ} \mathrm{C}$ e $900{ }^{\circ} \mathrm{C}$, Figura 7 e Figura 8, respectivamente. Entretanto, chi e nitreto de cromo não podem ser observadas nas seções expostas, pois seus constituintes não aparecem no ternário Fe-Cr-Ni, uma vez que chi também é rica em molibdênio e nitreto de cromo é formada por nitrogênio, além do cromo (NILSSON; WILSON, 1993). 
Figura 7 - Seção isotérmica do sistema ternário Fe-Cr-Ni a $800{ }^{\circ} \mathrm{C}$

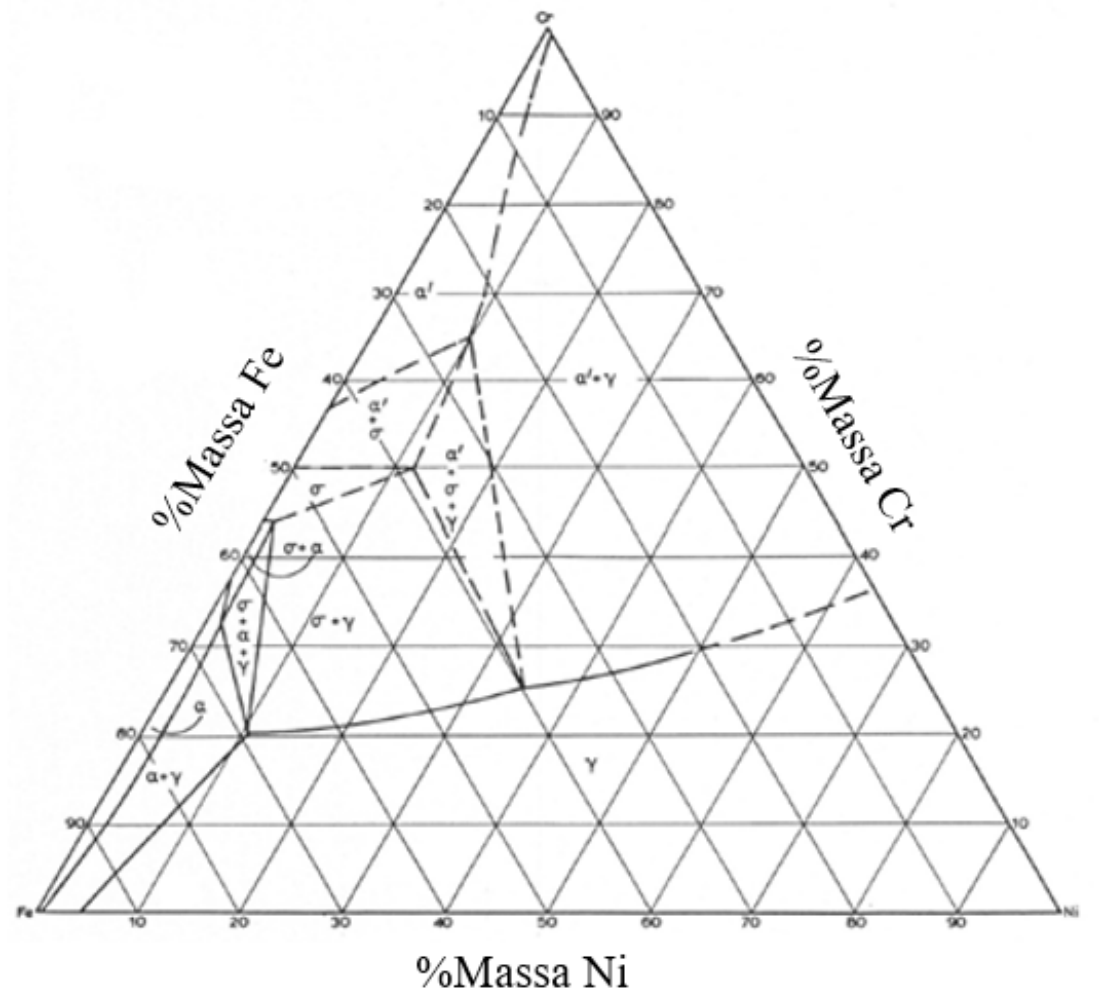

Fonte: Autora "adaptado de" Raynor e Rivlin, 1988

Figura 8 - Seção isotérmica do sistema ternário Fe-Cr-Ni a $900{ }^{\circ} \mathrm{C}$

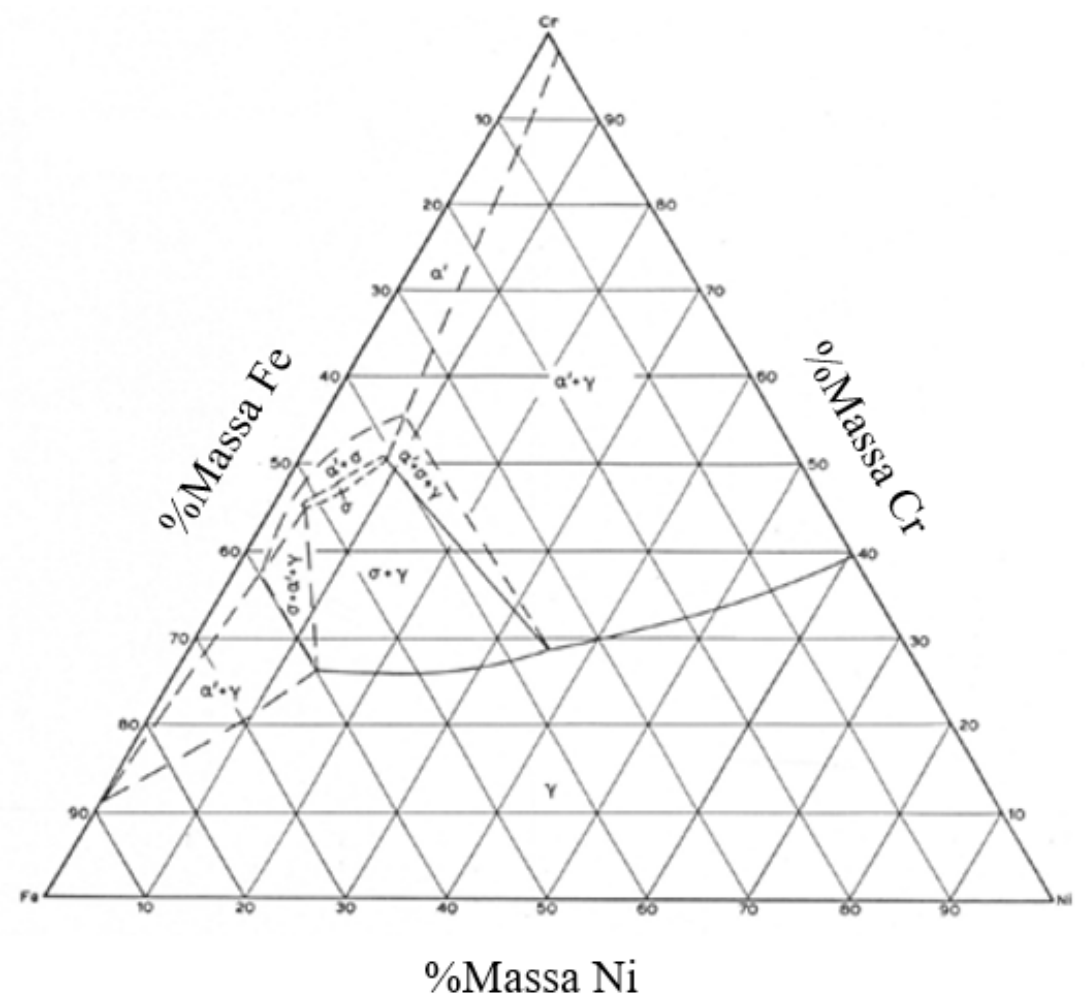

Fonte: Autora “adaptado de" Raynor e Rivlin, 1988 
Embora as fases citadas possam se formar, os ciclos térmicos de processamento impossibilitam que alfa linha e chi ocorram, uma vez que o surgimento nos aços dúplex está relacionado ao tempo e temperaturas de solubilização e envelhecimento. O surgimento de chi, por exemplo, pode levar de 6 a 10 horas quando envelhecido entre $600{ }^{\circ} \mathrm{C}$ e $700{ }^{\circ} \mathrm{C}$ no aço superdúplex UNS S32750, conforme mostra Thorvaldsson et al. (1984) e pode levar 5h quando envelhecimento a $750{ }^{\circ} \mathrm{C}$ do aço dúplex UNS S31803, como mostra Michalska e Sozanska (2006). Segundo Nilsson (1993), chi pode formar mais facilmente quando o aço superdúplex UNS S32750 é envelhecido a temperaturas entre $800{ }^{\circ} \mathrm{C}$ e $900{ }^{\circ} \mathrm{C}$, uma vez que notou o aparecimento da fase nos contornos ferrita/ferrita após 1 min a $850{ }^{\circ} \mathrm{C}, 3 \mathrm{~min}$ a $900{ }^{\circ} \mathrm{C}$ e $10 \mathrm{~min}$ a $800{ }^{\circ} \mathrm{C}$. $\mathrm{O}$ autor também observou que apesar da rápida formação de chi, principalmente em $850{ }^{\circ} \mathrm{C}$, a fase transforma-se em sigma após $72 \mathrm{~h}$ de envelhecimento nesta temperatura. Ainda, após $950{ }^{\circ} \mathrm{C}$, não observou-se mais precipitação de chi.

Contudo, a cinética de formação das fases que cada autor encontrou experimentalmente é influenciada pela temperatura de solubilização prévia ao envelhecimento, visto que a utilização de diferentes temperaturas de solubilização com o uso da mesma temperatura de envelhecimento, geram frações de fases distintas. Enquanto Thorvaldsson et al. (1985) encontraram chi após $5 \mathrm{~h}$ de envelhecimento a $750{ }^{\circ} \mathrm{C}$ no aço dúplex UNS S31803, Santos (2017) evidencia a formação da fase em apenas $40 \mathrm{~min}$ na mesma temperatura de envelhecimento para o mesmo aço, no entanto Thorvaldsson et al. (1985) solubilizaram o aço à $1050{ }^{\circ} \mathrm{C}$ e Santos $(2017)$ à $1175^{\circ} \mathrm{C}$. Os valores de tempo e temperatura de formação de fase chi citados podem ser vistos na comparação da Tabela 3.

Assim como a fase chi, o surgimento de alfa linha também necessita de tempos e temperaturas que são incompatíveis com a conformação plástica e solubilização do aço superdúplex, uma vez que esta se forma entre $450{ }^{\circ} \mathrm{C}$ e $525^{\circ} \mathrm{C}$ (BRANDI; PADILHA, 1990; GUNN, 2003). Em contrapartida, como sigma e nitretos de cromo têm maior probabilidade de ocorrer nos ciclos térmicos usuais de processamento, serão consideradas nos modelos de simulação e explanadas a seguir. 
Tabela 3 - Comparativo entre os tempos e temperaturas de formação de fase chi entre os aços dúplex e superdúplex

\begin{tabular}{|c|c|c|c|}
\hline Aço & $\begin{array}{c}\text { Temperatura de } \\
\text { solubilização }\end{array}$ & $\begin{array}{c}\text { Tempo e } \\
\text { temperatura de } \\
\text { envelhecimento }\end{array}$ & Referência \\
\hline $\begin{array}{c}\text { UNS S32750 } \\
\mathrm{Fe}-22,8 \% \mathrm{Cr}-7 \% \mathrm{Ni}- \\
3,6 \% \mathrm{Mo}\end{array}$ & $1050^{\circ} \mathrm{C}$ & $\begin{array}{c}6-10 \mathrm{~h} \\
600-700{ }^{\circ} \mathrm{C}\end{array}$ & $\begin{array}{l}\text { Thorvaldsson et al. } \\
\text { (1984) }\end{array}$ \\
\hline $\begin{array}{c}\text { UNS S31803 } \\
\text { Fe- } 22 \% \mathrm{Cr}-4,5 \% \mathrm{Ni}- \\
3 \% \mathrm{Mo}\end{array}$ & $1050^{\circ} \mathrm{C}$ & $5 \mathrm{~h} \mathrm{a} 720^{\circ} \mathrm{C}$ & $\begin{array}{c}\text { Michalska e } \\
\text { Sozanska (2006) }\end{array}$ \\
\hline $\begin{array}{c}\text { UNS S32750 } \\
\mathrm{Fe}-22,9 \% \mathrm{Cr}-6,9 \% \mathrm{Ni}- \\
3,8 \% \mathrm{Mo}\end{array}$ & $1060^{\circ} \mathrm{C}$ & $\begin{array}{l}1 \min \text { a } 850{ }^{\circ} \mathrm{C} \\
3 \min \text { a } 900{ }^{\circ} \mathrm{C} \\
10 \min \text { a } 800{ }^{\circ} \mathrm{C}\end{array}$ & Nilsson (1993) \\
\hline
\end{tabular}

Fonte: Thorvaldsson et al., 1985 ; Michalska e Sozanska, 2006; Nilsson, 1993

\subsubsection{Sigma}

De todas as fases mencionadas, a sigma é a de maior influência nas propriedades mecânicas e de resistência a corrosão dos aços inoxidáveis dúplex e superdúplex, pois apresenta considerável volume em relação as demais. Por tratar-se de um composto intermetálico rico em cromo e molibdênio, sua formação leva ao empobrecimento destes elementos nas redondezas, o que compromete a resistência à corrosão, especialmente a localizada, e reduz a tenacidade, por possuir comportamento frágil, além de elevada dureza, de até 68 HRC (MAGNABOSCO, 2015; NILSSON, 1992). A formação de sigma se dá entre $600{ }^{\circ} \mathrm{C}$ e $1000{ }^{\circ} \mathrm{C}$ nos aços inoxidáveis dúplex, dependendo da composição química (SOLOMON; DEVINE, 1982; BRANDI; PADILHA, 1990; NILSSON, 1992).

Encontra-se amplamente descrito na literatura que a formação de sigma ocorre preferencialmente por nucleação heterogênea, nos contornos ferrita/ferrita e nas interfaces ferrita/austenita, como mostra a Figura 9, e nos pontos triplos, já que estas são regiões de alta energia livre, cuja precipitação de sigma preferencial nestes locais tem o intuito de minimizála e atingir o equilíbrio (SOLOMON; DEVINE, 1982; NILSSON; WILSON, 1993; SEDRIKS, 1996 PORTER; EASTERLING, 1992). Melo e Magnabosco (2017), autores do grupo de 
pesquisa em que esta dissertação se insere, realizaram diversos tratamentos térmicos a fim de validar esta preferência de formação heterogênea para o aço dúplex UNS S31803. Os tratamentos térmicos foram realizados com temperatura de solubilização de $1100{ }^{\circ} \mathrm{C}$ por 1,24 , 96 e $192 \mathrm{~h}$, seguido de resfriamento em água e envelhecimento a $850^{\circ} \mathrm{C}$ por $5,8,10,20,30$ e 60 minutos. Desta forma, puderam constatar por imagens de elétrons retroespalhados que a fase sigma se forma, em todos os casos, nos contornos entre ferrita/ferrita e em maior quantidade nas interfaces entre ferrita/austenita, seguido de crescimento da fase sigma por difusão, a medida em que se aumenta o tempo de exposição à temperatura.

Figura 9 - Precipitação de sigma entre ferrita/ferrita e ferrita/austenita no aço superdúplex UNS S32750

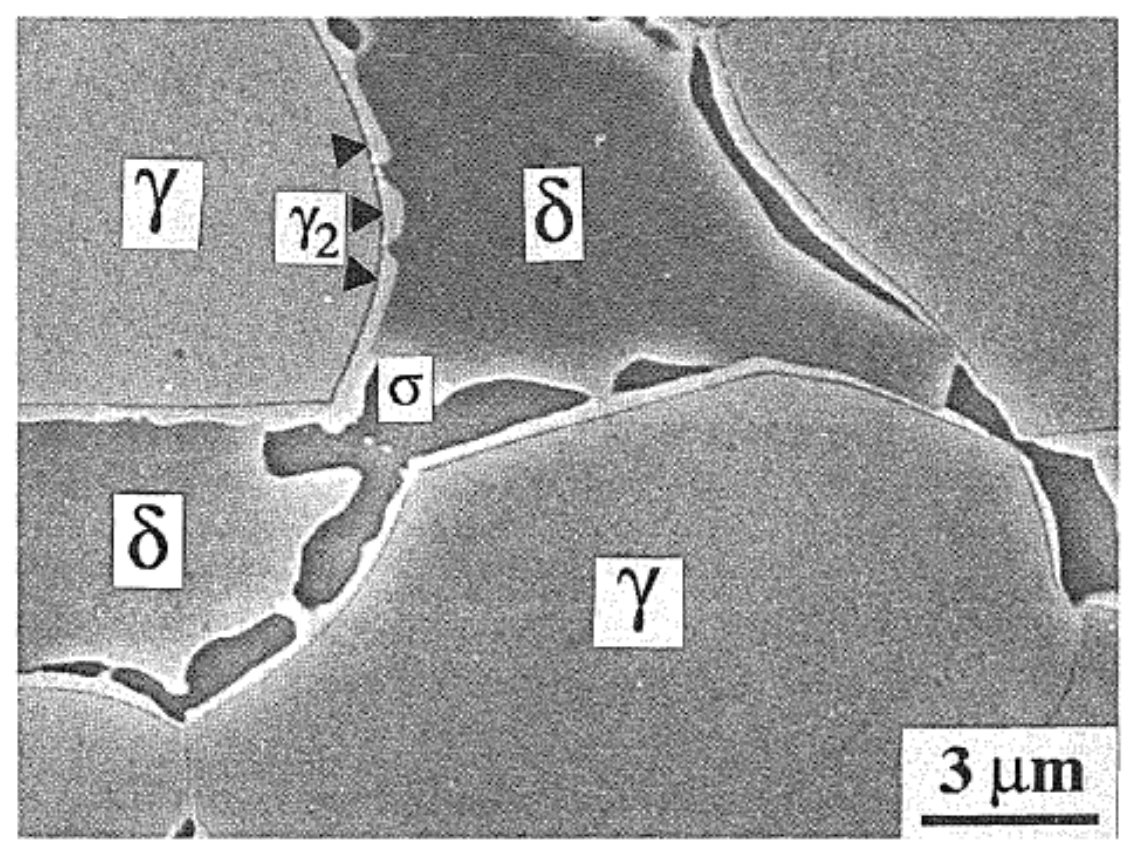

Fonte: Nilsson e Wilson, 1993

Visto que sigma é rica em cromo e molibdênio, elementos alfagênicos, o crescimento desta fase se dá preferencialmente na ferrita (SOLOMON; DEVINE, 1982; NILSSON, 1992; BRANDI; PADILHA, 1990). Além disso, tais elementos de liga apresentam maior taxa de difusão na ferrita que na austenita (WANG, 2003; CHEN; YANG, 2001). Quando os sítios heterogêneos se saturam, a fase sigma pode nuclear homogeneamente no interior dos grãos austeníticos, formando austenita secundária pobre em cromo e molibdênio, geralmente em tempos mais longos de envelhecimento (NILSSON, 1992; MAGNABOSCO, 2009). 
Por conta do alto teor de cromo e molibdênio nos aços superdúplex em relação aos dúplex, a formação de fase sigma é acentuada, pois a curva TTP (Tempo-TemperaturaPrecipitação) da fase sigma é deslocada para tempos mais curtos, como será visto no item 2.3 (Cinética de Transformação de Fases). Pela mesma razão, sigma pode precipitar a temperaturas superiores à máxima esperada pela literatura, de $1000^{\circ} \mathrm{C}$, como mostra o diagrama de fases do aço inoxidável superdúplex UNS S32750 da Figura 5 obtido por Magnabosco e Fiorante (2019) com a base de dados termodinâmica TCFE8, uma vez que a fase aparece abaixo de $1050{ }^{\circ} \mathrm{C}$.

\subsubsection{Nitreto de cromo}

As classes de aços dúplex e superdúplex, que têm elevados níveis de nitrogênio e cromo em relação aos aços inoxidáveis comuns, são suscetíveis à precipitação de nitretos de cromo. Segundo Thorvaldsson et al. (1985) e Petterson, N., Petterson, R. e Wessman (2015) devido a solubilidade restrita de nitrogênio nos aços inoxidáveis, nitretos de cromo $\left(\mathrm{Cr}_{2} \mathrm{~N}\right)$ podem precipitar quando os aços ao $\mathrm{N}$ são envelhecidos isotermicamente, principalmente entre $700{ }^{\circ} \mathrm{C}$ e $900{ }^{\circ} \mathrm{C}$ (mesmo intervalo de temperaturas da formação de fase sigma) ou durante o resfriamento a partir da temperatura de solubilização em regiões onde há supersaturação de nitrogênio na ferrita.

Apesar do nitrogênio ser particionado principalmente na fase austenítica, para temperaturas de solubilização acima de $1200{ }^{\circ} \mathrm{C}$ a concentração de nitrogênio na ferrita é suficientemente alta a ponto de ser difícil mantê-lo em solução sólida, aumentando-se a probabilidade de precipitação da fase quando do resfriamento de ferrita nestas condições de supersaturação (KNYAZEVA; POHL, 2013; PETTERSON, N.; PETTERSON, R.; WESSMAN, 2015).

Segundo Nilsson (1992) e Ramirez, Lippold e Brandi (2003) nitretos de cromo são preferencialmente formados nos contornos ferrita/ferrita e/ou interfaces ferrita/austenita e até mesmo nas interfaces austenita/sigma, fatos também confirmados experimentalmente por Melo e Magnabosco (2017) para o aço dúplex UNS S31803, através de tratamentos térmicos de solubilização de $1100{ }^{\circ} \mathrm{C}$ por 1, 24, 96 e 192 horas, seguido de resfriamento em água e envelhecimento a $850^{\circ} \mathrm{C}$ por $5,8,10,20,30$ e 60 minutos. Os autores verificaram preferência de formação inicial nas interfaces ferrita/austenita, as quais possuem maior quantidade da nitretos precipitados. Micrografias obtidas por Ramirez, Lippold e Brandi (2003) mostram a precipitação de nitretos de cromo no aço inoxidável superdúplex UNS S32750, envelhecido a 
$850{ }^{\circ} \mathrm{C}$ em apenas 10 minutos, nas interfaces ferrita/austenita, simultaneamente à precipitação de austenita secundária $\left(\gamma_{2}\right)$, Figura 10.

Figura 10 - Precipitação de nitretos de cromo e austenita secundária na interface ferrita/ austenita no aço superdúplex UNS S32750

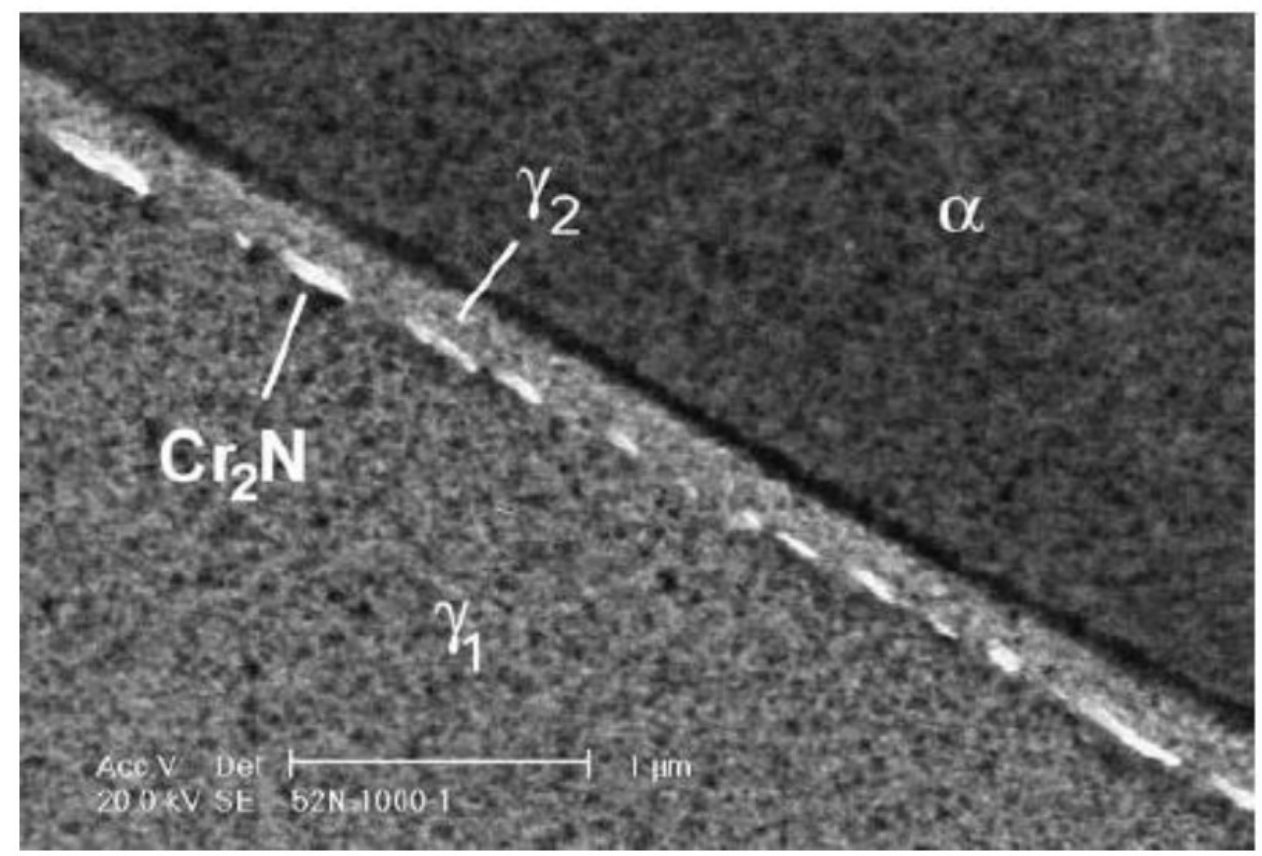

Fonte: Ramirez, Lippold e Brandi, 2003

Assim como a sigma, a formação de nitretos de cromo também é prejudicial ao aço, pois o nitrogênio e o cromo deixam de estar em solução sólida, reduzindo tanto a resistência mecânica quanto à corrosão, principalmente por pite. Além disso, o nitrogênio que é consumido deixa de estabilizar a fase austenítica (NILSSON, 1992; SANTOS, 2013).

Também semelhante a sigma, o diagrama de equilíbrio obtido por Magnabosco e Fiorante (2019) na Figura 5, mostra que os nitretos de cromo do tipo $\mathrm{Cr}_{2} \mathrm{~N}$ (de estrutura hexagonal compacta $\mathrm{HCP} \_\mathrm{A} 3$ ) também podem precipitar a temperaturas superiores à máxima esperada pela literatura, de $900^{\circ} \mathrm{C}$, uma vez que aparecem logo abaixo de $950{ }^{\circ} \mathrm{C}$.

Nilsson (1992) obteve as seções isotérmicas do sistema Fe-Cr-Ni-Mo-N entre $800{ }^{\circ} \mathrm{C} \mathrm{e}$ $1200{ }^{\circ} \mathrm{C}$ via simulação computacional com Thermo-Calc ${ }^{\circledR}$, com composição química fixa em $4 \%$ Mo e $0,3 \%$ N. Considerando que o aço inoxidável superdúplex em estudo UNS S32750 possui $25 \% \mathrm{Cr}$ e $7 \% \mathrm{Ni}$, vale mostrar que para a temperatura de $900{ }^{\circ} \mathrm{C}$, Figura 11 (a) não se observa a presença de nitretos de cromo $(\varepsilon)$, apenas sigma e austenita, enquanto que para a temperatura de $800{ }^{\circ} \mathrm{C}$ há nitretos de cromo coexistindo com sigma e austenita, Figura 11 (b), 
o que mostra que nitretos de cromo somente apareceriam para eventuais temperaturas mais baixas durante os ciclos térmicos de processamento.

Figura 11 - Seções isotérmicas do sistema Fe-Cr-Ni-Mo-N a $900^{\circ} \mathrm{C}$ (a) e $800^{\circ} \mathrm{C}$ (b)
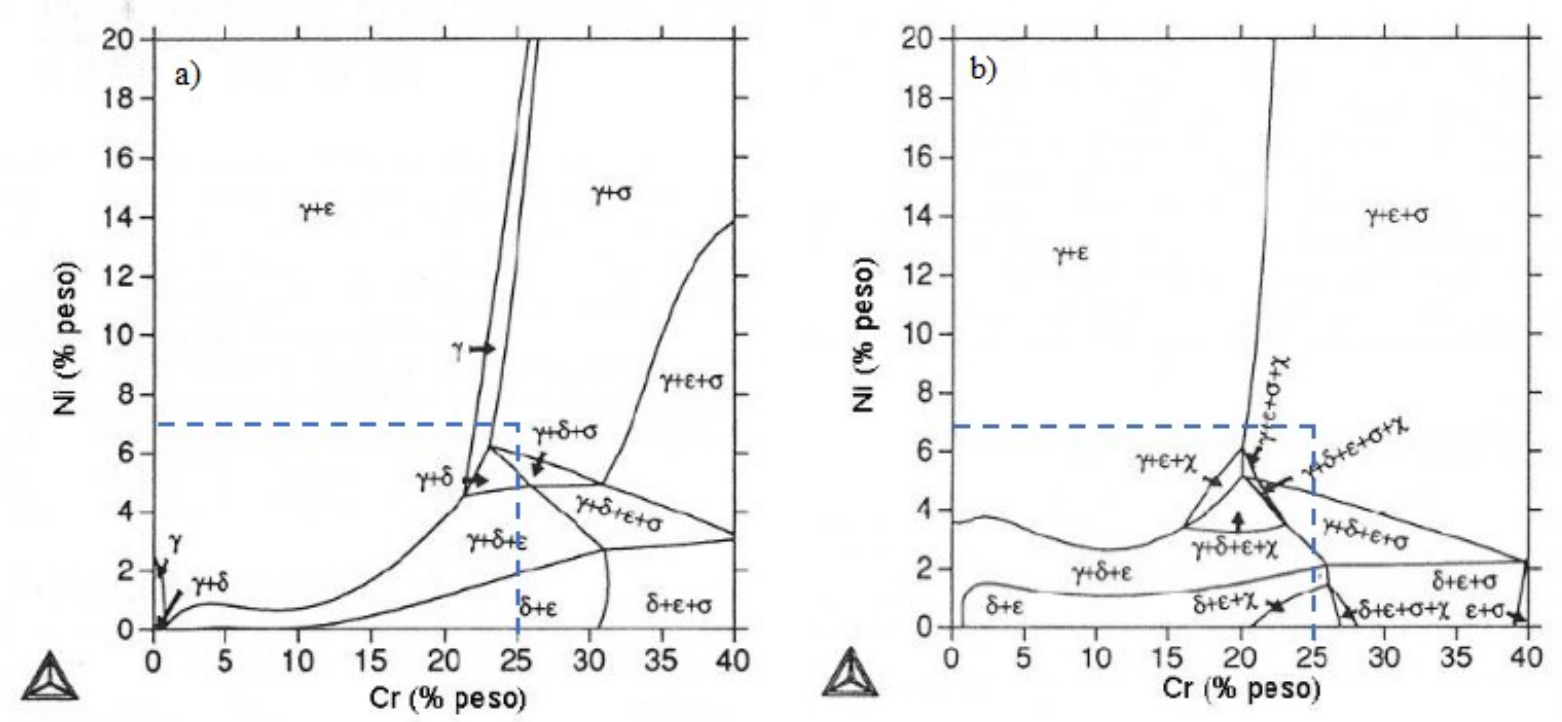

Fonte: Autora “adaptado de" Nilsson, 1992, p. 687

Segundo autores como Thorvaldsson et al. (1985) e Magnabosco e Alonso-Falleiros (2003) a formação de nitretos de cromo pode ser retardada por conta da baixa difusividade do cromo e da alta solubilidade do nitrogênio na fase austenítica. Ao efetuarem o envelhecimento isotérmico a $850{ }^{\circ} \mathrm{C}$ do aço dúplex UNS S31803 de composição química $\mathrm{Fe}-22 \% \mathrm{Cr}-6 \% \mathrm{Ni}$ $-3 \% \mathrm{Mo}-0,14 \% \mathrm{~N}$, Thorvaldsson et al. (1985) registraram a precipitação de nitretos de cromo em tempos superiores a 300h e Magnabosco e Alonso-Falleiros (2003) em tempos superiores $1000 \mathrm{~h}$, mostrando a necessidade de tempos longos para que a precipitação ocorra neste aço, isto é, a necessidade de taxas de resfriamento muito baixas para a formação de nitretos a partir de condição onde o nitrogênio está em solução sólida na austenita.

Já Strafellini et al. (2009), investigando a formação de nitretos de cromo em aços lean dúplex, de menor teor de níquel e molibdênio em relação aos dúplex, reportaram que para o aço UNS S32101 de composição Fe - 22,6 \%Cr - 1,1\%Ni - 0,07\% Mo - 0,12\%N- 0,69\% $\mathrm{Si}-$ $3,95 \% \mathrm{Mn}$ a formação de nitretos de cromo se dá após $20 \mathrm{~min}$ de envelhecimento a $850^{\circ} \mathrm{C}$, enquanto que o aço UNS S32304 de composição $23,17 \% \mathrm{Cr}-4,29 \% \mathrm{Ni}-1,43 \% \mathrm{Mo}-0,12 \% \mathrm{~N}$ - 0,56\% $\mathrm{Si}-1,43 \% \mathrm{Mn}$, tem formação de nitretos a partir de $45 \mathrm{~min}$ de envelhecimento na mesma temperatura, provavelmente devido ao maior teor de molibdênio em solução sólida. 
Nota-se, portanto, que a composição química de diferentes aços afeta as temperaturas e tempos de formação de nitretos de cromo.

\subsection{CINÉTICA DE TRANSFORMAÇÃO DE FASES}

Enquanto a termodinâmica justifica a força motriz de uma transformação de fase, a taxa na qual a transformação ocorre pertence à ciência da cinética. Segundo Porter e Easterling (1992) a cinética de formação de fases em estado sólido é função de diversos fatores como tempo, temperatura, taxa de nucleação, taxa de crescimento e número de sítios de nucleação. Em geral, dependendo das suposições feitas em relação à cinética de nucleação e crescimento das fases, uma variedade de equações similares pode ser obtida, todas baseadas na equação de Kolmogorov-Johnson-Mehl-Avrami (KJMA), publicada em sua forma original e genérica em 1939, Equação 1 (AVRAMI, 1939; PORTER; EASTERLING, 1992; CHRISTIAN, 2002).

Elmer, Palmer e Specht (2007), Badji et al. (2008) e Magnabosco (2009) mostram em seus estudos que a cinética de formação de fases em aços inoxidáveis dúplex é descrita pela Equação KJMA, seja para evolução de ferrita, austenita, sigma e/ou nitretos de cromo. Sendo assim, segundo a Equação 1, a evolução das fases em função do tempo descreve um comportamento sigmoidal.

$$
f=1-e\left(-K \cdot t^{n}\right)
$$

Segundo a Equação 1, 'f' é a fração transformada que varia de 0 a 1, 't' é o tempo, ' $k$ ' é uma constante dependente da energia de ativação para formação de fase e ' $n$ ' é o expoente de KJMA, o qual varia inicialmente de $2 / 3$ a 4 ou valores maiores, vide Tabela 4 . O valor do expoente ' $n$ ' não depende da temperatura e se relaciona com o mecanismo de nucleação e crescimento da fase, variando em relação à mudança na forma dos núcleos formados, que segundo Avrami (1940), seria dado por: núcleo bidirecional $(n=3)$, unidirecional $(n=2)$ e independente da forma das partículas ( $\mathrm{n}=1)$ (CHRISTIAN, 2002). A variável ' $\mathrm{k}$ ', depende das taxas de nucleação e crescimento de um sistema e é calculada em função da energia de ativação para formação de fase ' $Q$ ' e da constante universal dos gases ' $R$ ' (8,31 J/mol.K) apresentada na Equação 2, sendo 'T' a temperatura absoluta e k0 uma constante pré-exponencial (AVRAMI, 1939; PORTER; EASTERLING, 1992; MAGNABOSCO, 2009).

$$
k=k_{0} \cdot e^{\frac{Q}{R \cdot T}}
$$


Tabela 4 - Expoente 'n' de K-J-M-A

\begin{tabular}{|c|c|c|}
\hline \multirow{7}{*}{$\begin{array}{c}\text { Precipitação } \\
\text { descontínua, reações } \\
\text { eutetóides, crescimento } \\
\text { controlado por interface }\end{array}$} & Condições & $\mathbf{n}$ \\
\hline & Taxa de nucleação crescente & $>4$ \\
\hline & Taxa de nucleação constante & 4 \\
\hline & Taxa de nucleação decrescente & $3-4$ \\
\hline & $\begin{array}{c}\text { Taxa de nucleação nula (saturação dos sítios de } \\
\text { nucleação) }\end{array}$ & 3 \\
\hline & Nucleação após a saturação no ponto triplo & 2 \\
\hline & Nucleação em contorno de grão após saturação & 1 \\
\hline \multirow{7}{*}{$\begin{array}{c}\text { Crescimento controlado } \\
\text { por difusão }\end{array}$} & $\begin{array}{l}\text { Todas as formas crescendo a partir de pequenas } \\
\text { dimensões, com taxa de nucleação crescente }\end{array}$ & $>21 / 2$ \\
\hline & $\begin{array}{l}\text { Todas as formas crescendo a partir de pequenas } \\
\text { dimensões, taxa de nucleação constante }\end{array}$ & $2 \frac{1}{2}$ \\
\hline & $\begin{array}{l}\text { Todas as formas crescendo a partir de pequenas } \\
\text { dimensões, com diminuição na taxa de nucleação }\end{array}$ & $1 \frac{1}{2}-2 \frac{1}{2}$ \\
\hline & $\begin{array}{c}\text { Todas as formas crescendo a partir de pequenas } \\
\text { dimensões, taxa de nucleação nula }\end{array}$ & $1 \frac{1}{2}$ \\
\hline & $\begin{array}{c}\text { Crescimento de partículas com volume inicial } \\
\text { apreciável }\end{array}$ & $1-1 \frac{1}{2}$ \\
\hline & Espessamento de placas grandes & $1 / 2$ \\
\hline & Precipitação em discordâncias & $\sim 2 / 3$ \\
\hline
\end{tabular}

Fonte: Santos, 2010

Elmer, Palmer e Specht (2007) estudaram a cinética de formação de fase sigma do aço dúplex UNS S31803 de composição química $\mathrm{Fe}-22,4 \% \mathrm{Cr}$ - 4,88\%Ni - 3\%Mo envelhecido entre 700 e $850{ }^{\circ} \mathrm{C}$, após solubilização a $1065^{\circ} \mathrm{C}$, relacionando frações de sigma de 1 a $99 \%$ com tempo e temperatura, obtendo a máxima cinética em $800^{\circ} \mathrm{C}$, vide diagrama TTP (Tempo - Temperatura - Precipitação) da Figura 12, o qual também demonstra a necessidade de taxas de resfriamentos, a partir da temperatura de solubilização, que não cruzem com a linha de $1 \%$ de sigma em diante, mantendo-se o aço na condição dúplex metaestável. Os autores levantaram o expoente 'n' a partir da linearização da equação de KJMA, obtendo-se o valor 7 no início da transformação, que significa que a formação de sigma é controlada inicialmente por nucleação heterogênea e 0,75 em tempos mais longos, indicando crescimento de sigma controlado pela difusão das espécies que a formam. 
Figura 12 - Diagrama TTP de formação de sigma no aço UNS S31803, solubilizado a $1065^{\circ} \mathrm{C}$

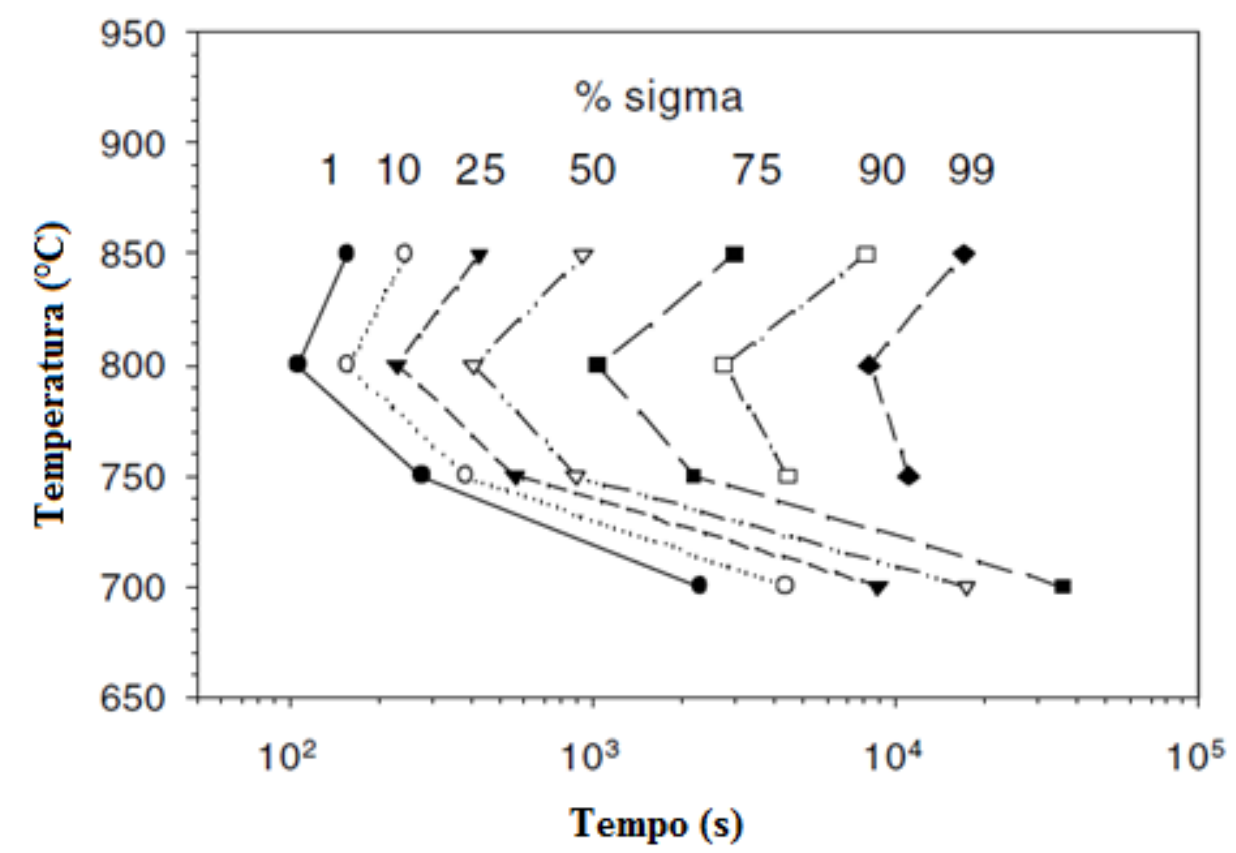

Fonte: Autora “adaptado de” Elmer, Palmer e Specht, 2007, p. 470

Magnabosco (2009), também investigando a cinética de formação de fase sigma no aço dúplex UNS S31803 de composição química $\mathrm{Fe}-22 \% \mathrm{Cr}-5,7 \% \mathrm{Ni}-3 \% \mathrm{Mo}$ entre $700{ }^{\circ} \mathrm{C}$ e $900{ }^{\circ} \mathrm{C}$, após solubilização a $1120^{\circ} \mathrm{C}$, mostra que a máxima cinética de formação de fase sigma se dá em $850{ }^{\circ} \mathrm{C}$, como mostra o diagrama TTP da Figura 13, para frações de sigma de 0,1 a $50 \%$, necessitando de resfriamento rápido o suficiente para manter a estrutura dúplex, a partir da temperatura de solubilização. Também afirma que a energia de ativação para precipitação de fase sigma entre $700{ }^{\circ} \mathrm{C}$ e $900{ }^{\circ} \mathrm{C}$ do aço UNS S31803 é próxima à energia de ativação para difusão do cromo na ferrita, e é menor do que a energia para difusão do cromo na austenita. Com isso, comprova-se que o mecanismo de nucleação e crescimento de sigma depende, principalmente, da difusão de cromo na ferrita, mostrando-se ainda que a formação preferencial desta fase ocorre, inicialmente, nos contornos de grão ferrita/ferrita ou interfaces ferrita/austenita. O autor obteve como valor do expoente 'n' 0,915 para temperaturas entre $700^{\circ} \mathrm{C}$ e $850^{\circ} \mathrm{C}$, relacionado à nucleação em contorno de grão após a saturação ou controle por difusão. 
Figura 13 - Diagrama TTP de formação de sigma no aço UNS S31803, solubilizado a

$1120^{\circ} \mathrm{C}$

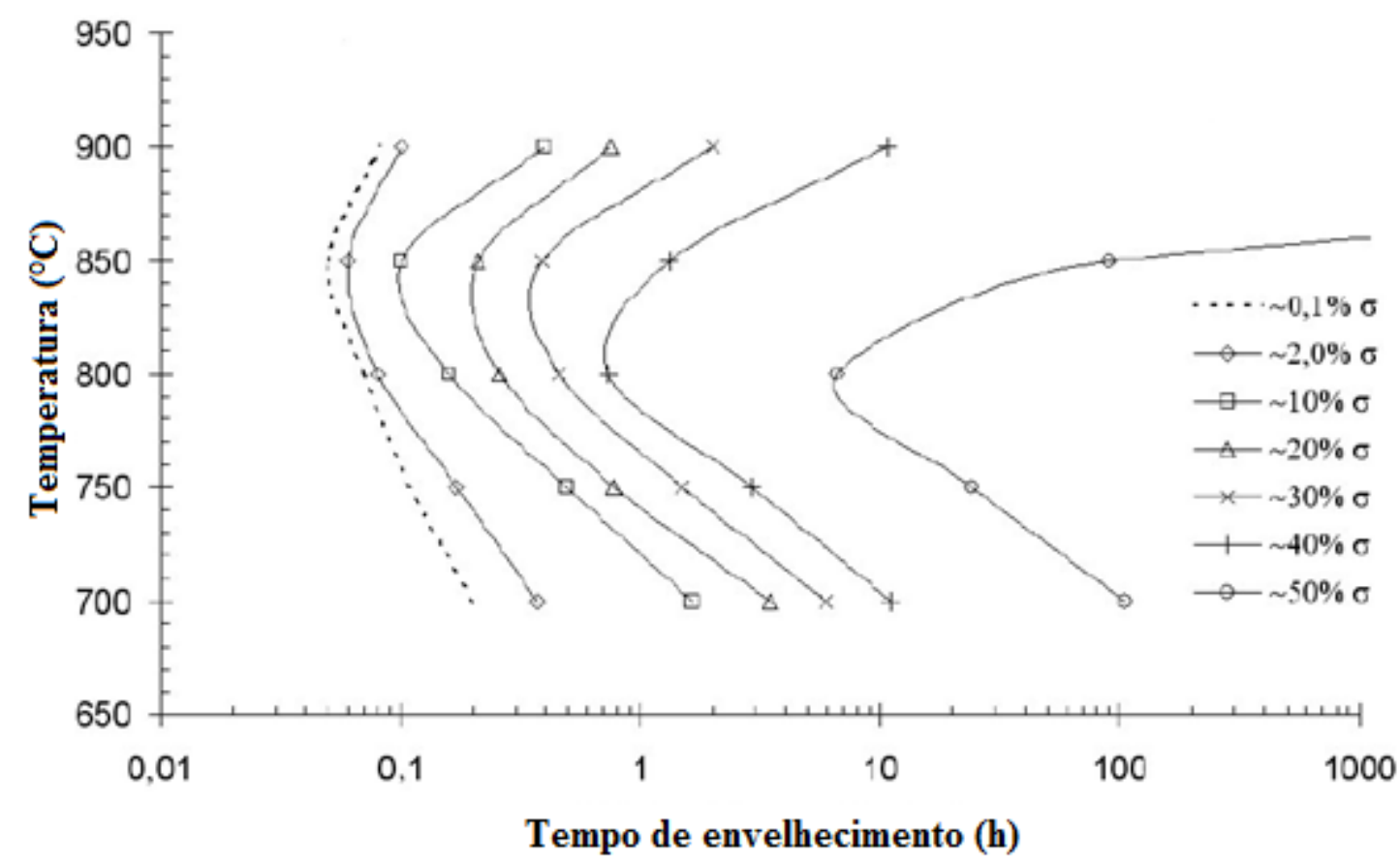

Fonte: Autora "adaptado de" Magnabosco, 2009, p. 324

Santos (2013) também investigou a formação de fase sigma no aço UNS S31803 de composição química $\mathrm{Fe}-22,07 \% \mathrm{Cr}-5,68 \% \mathrm{Ni}-3,2 \% \mathrm{Mo}$, entre $700{ }^{\circ} \mathrm{C}$ e $950{ }^{\circ} \mathrm{C}$, por até 360 h de envelhecimento, após solubilização a $117{ }^{\circ} \mathrm{C}$. A fração volumétrica das fases foi obtida por estereologia quantitativa em cada condição de tratamento térmico. A autora também confirmou que a amostra envelhecida a $850^{\circ} \mathrm{C}$ apresenta maior cinética de formação de fase sigma. Nas Figura 14 e 15, respectivamente, nota-se o aumento na fração volumétrica de sigma e a diminuição na fração volumétrica de ferrita conforme aumenta-se o tempo de envelhecimento, para a temperatura da máxima cinética obtida. Posteriormente, Santos e Magnabosco (2016) levantam valores do expoente ' $n$ ' para o mesmo aço e faixa de envelhecimento. No início da transformação de sigma obtiveram de 2 a 4, o que indica que a transformação é heterogênea controlada por nucleação nas interfaces, enquanto que para tempos mais longos, obtiveram 'n' de 0,3 a 0,5 , que indica crescimento controlado por difusão. 
Figura 14 - Fração volumétrica de sigma em função do tempo de envelhecimento a $850^{\circ} \mathrm{C}$

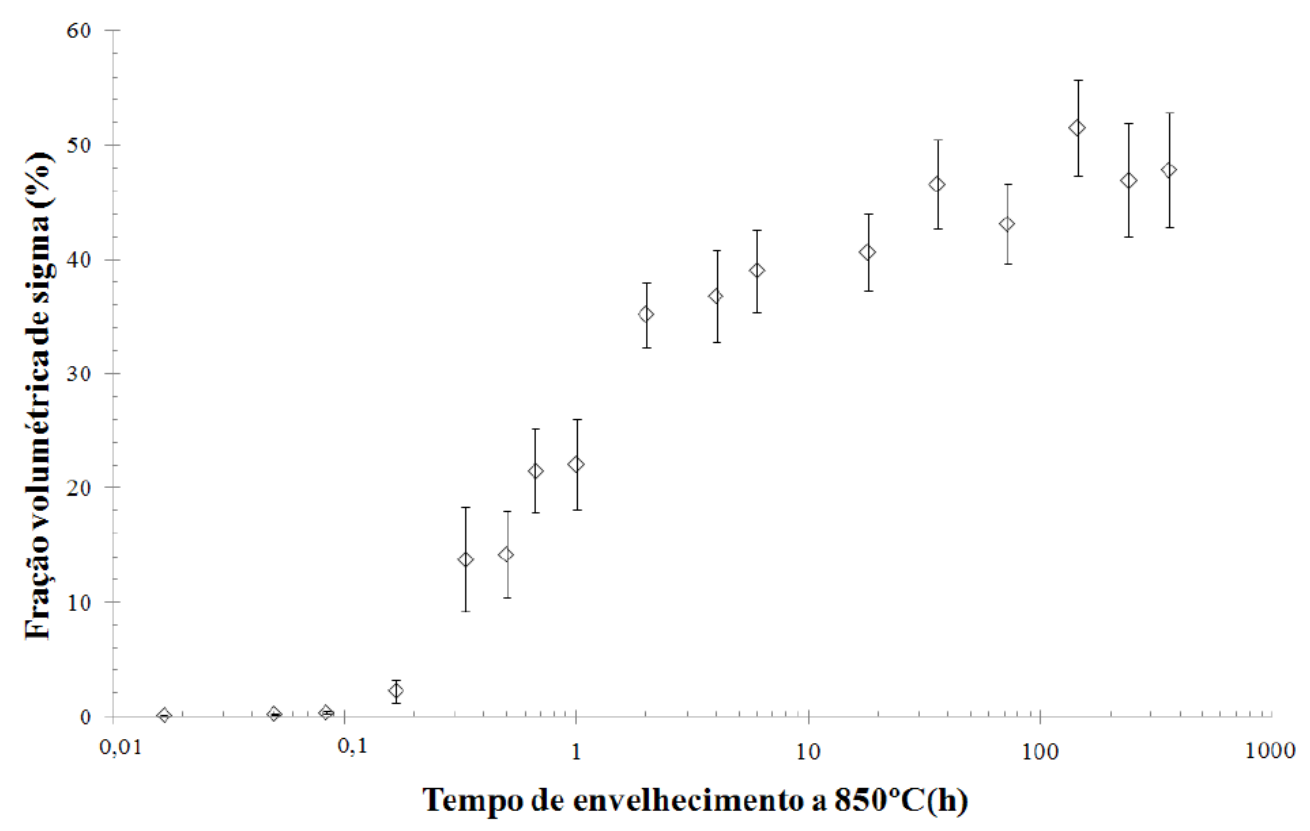

Fonte: Santos, 2013

Figura 15 - Fração volumétrica de ferrita em função do tempo de envelhecimento a $850^{\circ} \mathrm{C}$

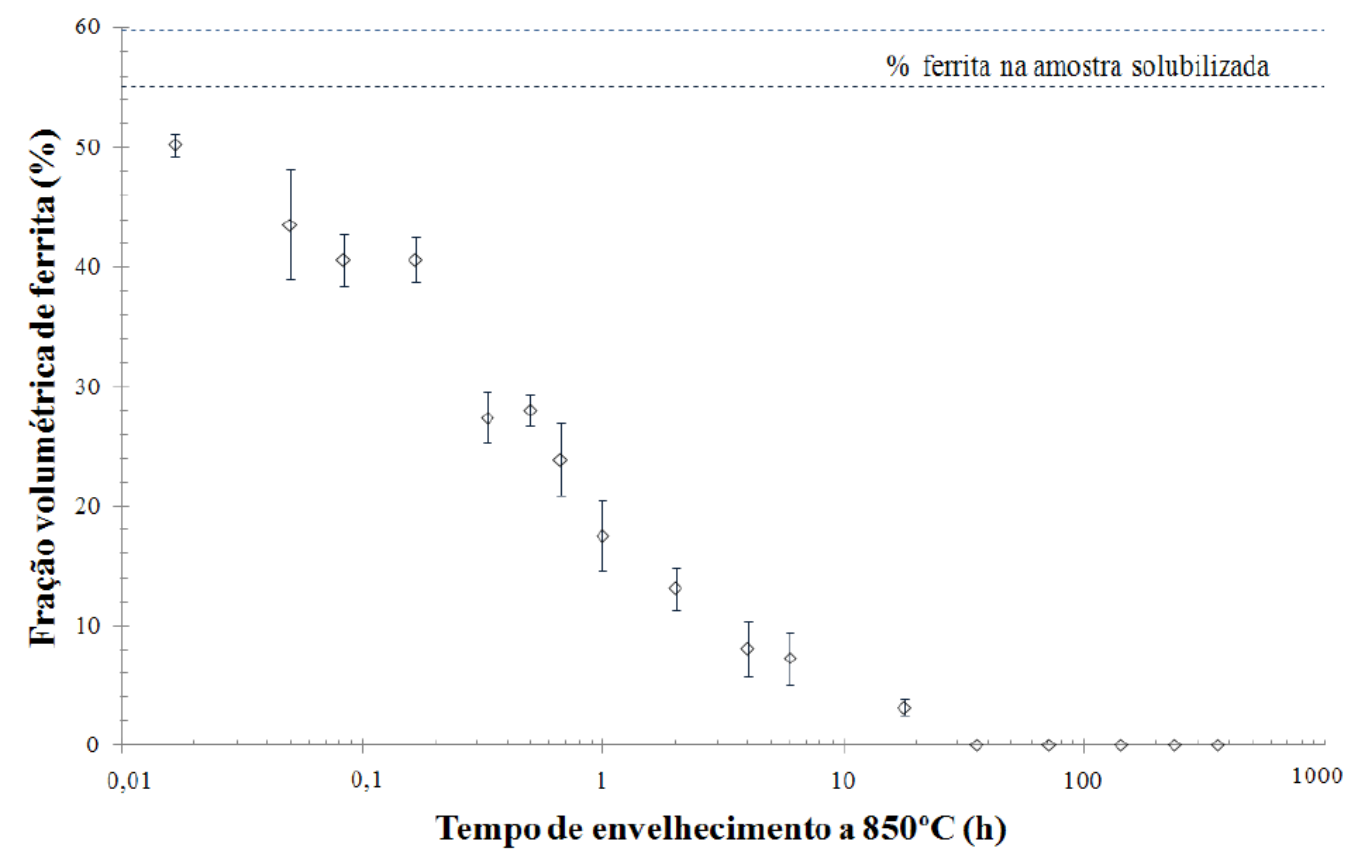

Fonte: Santos, 2013

Nota-se que tanto os autores grupo de pesquisa em que esta dissertação se insere quanto Elmer, Palmer e Specht, (2007) obtiveram máxima cinética de formação de sigma no aço dúplex UNS 31803 em temperaturas entre $800{ }^{\circ} \mathrm{C}$ e $850{ }^{\circ} \mathrm{C}$, assim como Maehara et al. (1983) já haviam verificado em 1980 , obtendo $820^{\circ} \mathrm{C}$, valor próximo ao encontrado pelos demais autores 
já citados, conforme diagrama TTP da Figura 16. Comparando os valores do expoente ' $\mathrm{n}$ ' obtidos por este grupo de pesquisa e Elmer, Palmer e Specht (2007), nota-se que apesar de divergirem entre si, mostram que a formação de sigma é controlada inicialmente por nucleação heterogênea e é finalizada com crescimento controlado por difusão, o que também foi constatado experimentalmente por Melo e Magnabosco (2017), vide item 2.2.1. Os valores do expoente ' $n$ ' serem distintos devem-se provavelmente às diferentes temperaturas e tempos de solubilização usados, os quais geram diferentes condições iniciais de nucleação e crescimento de fase sigma.

Figura 16 - Diagrama de precipitação isotérmica de fase sigma no aço UNS S31803

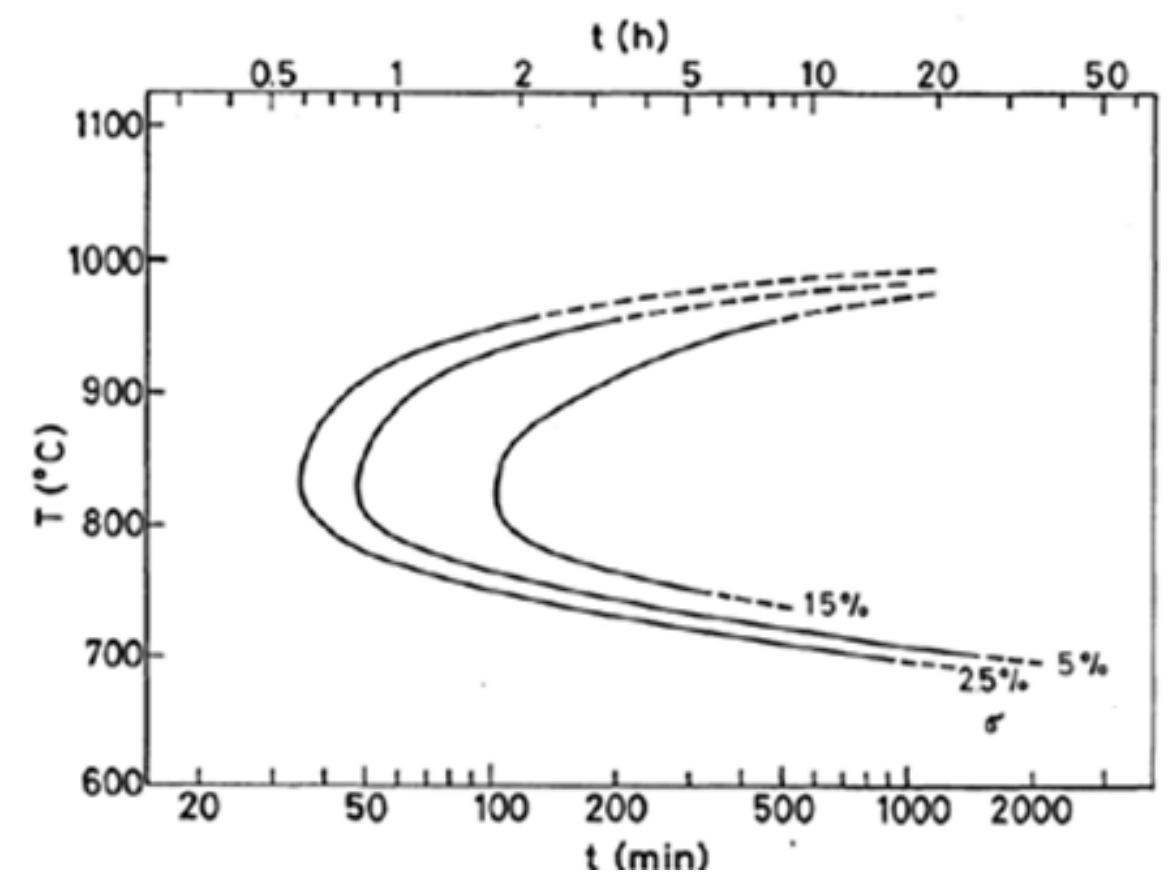

Fonte: Maehara et al., 1983

Nilsson e Wilson (1993) investigaram a cinética de transformação de fases do aço superdúplex UNS S32750 de composição química $\mathrm{Fe}-22,9 \% \mathrm{Cr}-6,9 \% \mathrm{Ni}-3,8 \% \mathrm{Mo}-$ $0,27 \% \mathrm{~N}$, efetuando envelhecimento entre $700{ }^{\circ} \mathrm{C}$ e $1030^{\circ} \mathrm{C}$ por um faixa de tempo de 1 min a $72 \mathrm{~h}$, após solubilização a $1060^{\circ} \mathrm{C}$. Os autores reportaram o aparecimento de chi a partir de 10 minutos a $800{ }^{\circ} \mathrm{C}, 3$ minutos a $900{ }^{\circ} \mathrm{C}$ e de apenas 1 minuto em $850{ }^{\circ} \mathrm{C}$, indicando também que a máxima cinética da fase chi se dá em $850^{\circ} \mathrm{C}$, conforme mostra o diagrama TTP da Figura 17. $\mathrm{O}$ autor cita uma possível transformação de fase chi em sigma, uma vez que em $850{ }^{\circ} \mathrm{C}$ por $72 \mathrm{~h}$ não se observa mais a fase chi. Além disso, a máxima cinética de formação de sigma se dá em $950{ }^{\circ} \mathrm{C}$, temperatura superior à de chi, em 1 min de tratamento térmico. Nota-se ainda que se 
inicia a precipitação de nitretos de cromo simultaneamente à precipitação de chi e austenita secundária até atingir a temperatura de $820{ }^{\circ} \mathrm{C}$. Nitretos de cromo e austenita secundária precipitam simultaneamente o tempo todo entre $750{ }^{\circ} \mathrm{C}$ e $950{ }^{\circ} \mathrm{C}$ e a máxima cinética de formação destas fases se dá em $850{ }^{\circ} \mathrm{C}$.

Por conta da rápida formação de chi a $850^{\circ} \mathrm{C}$ e de sigma a $950{ }^{\circ} \mathrm{C}$ em apenas 1 min de tratamento térmico, indicado no diagrama TTP da Figura 17, necessita-se de taxas de resfriamento ainda maiores para o aço superdúplex, se comparados aos dúplex apresentados, para obtenção do balanço de apenas ferrita e austenita na estrutura.

Figura 17 - Diagrama de precipitação isotérmica do aço UNS S32750, solubilizado a $1060^{\circ} \mathrm{C}$

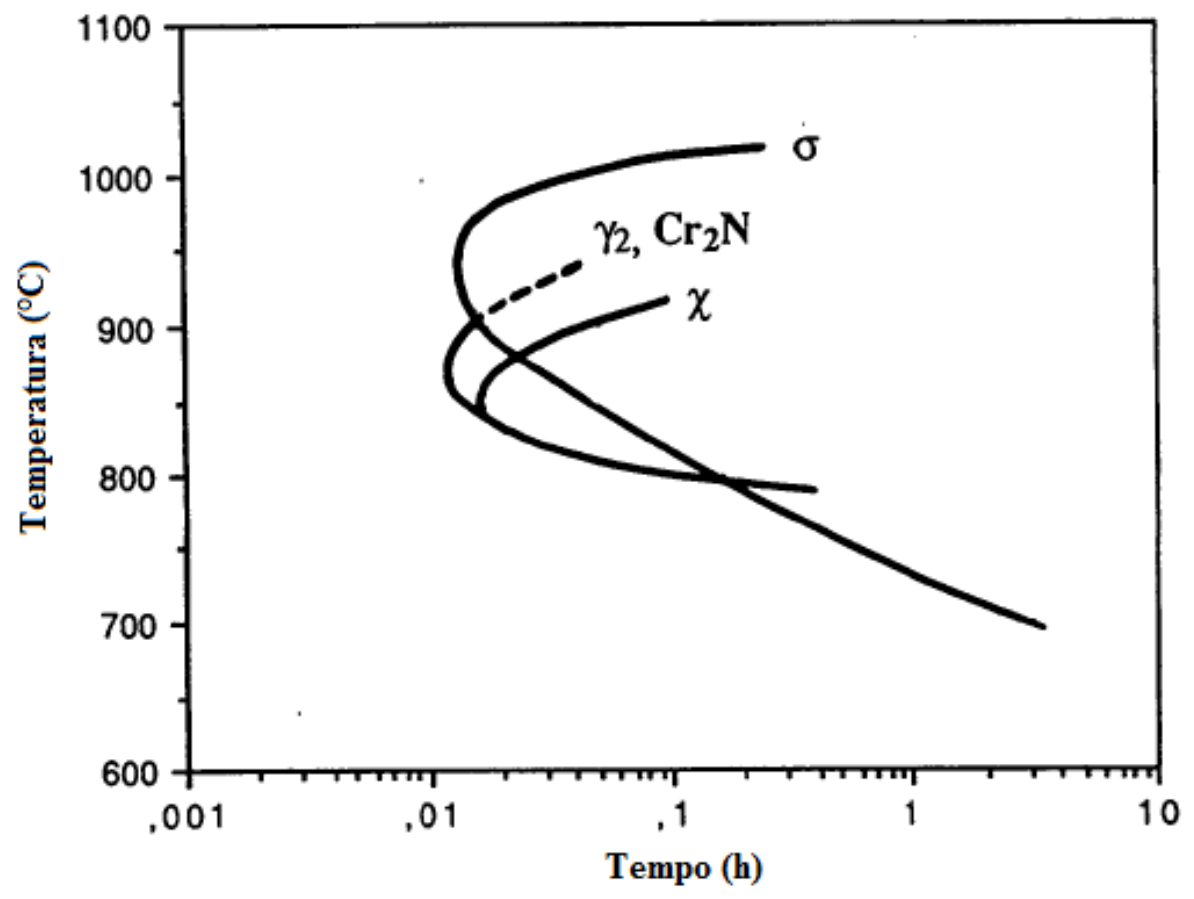

Fonte: Autora “adaptado de” Nilsson e Wilson, 1993, p. 549

Thorvaldsson et al. (1985) e Magnabosco e Alonso-Falleiros (2003) estudaram a cinética de formação de nitretos de cromo para o aço dúplex UNS S31803, de composição química média $\mathrm{Fe}-22 \% \mathrm{Cr}-5,6 \% \mathrm{Ni}-2,9 \% \mathrm{Mo}$. Ambos os grupos de pesquisa obtiveram tempos longos de precipitação de nitretos de cromo a $850{ }^{\circ} \mathrm{C}: 300 \mathrm{~h}$ mínimo para Thorvaldsson et al., (1985) nas interfaces austenita/sigma e 1000 h mínimo para Magnabosco e AlonsoFalleiros (2003). Ambos os trabalhos iniciaram os tratamentos isotérmicos sobre estruturas solubilizadas, ou seja, onde não há possibilidade de supersaturação de $\mathrm{N}$ na ferrita.

Calliari, Ramous e Bassani, (2010), avaliando o efeito de tratamentos isotérmicos de $800{ }^{\circ} \mathrm{C}$ a $1000{ }^{\circ} \mathrm{C}$ no aço superdúplex UNS S32750 de composição química $\mathrm{Fe}-24,5 \% \mathrm{Cr}$ - 
$6,36 \% \mathrm{Ni}-4 \% \mathrm{Mo}-0,26 \% \mathrm{~N}$, notaram que a $800{ }^{\circ} \mathrm{C}$ nenhuma precipitação foi detectada, ao passo que a $850{ }^{\circ} \mathrm{C}$ encontraram chi a uma fração inferior a $0,1 \%$ nos contornos de ferrita e austenita. Já a $900{ }^{\circ} \mathrm{C}$ os autores encontraram tanto chi quanto sigma e a $950{ }^{\circ} \mathrm{C}$ detectou-se chi em apenas 3 min de tratamento e sigma em $2400 \mathrm{~s}$ (40 min), a qual cresce dos contornos para o interior da ferrita, englobando algumas partículas da fase chi. Ainda entre $900{ }^{\circ} \mathrm{C}$ e $950{ }^{\circ} \mathrm{C}$, nitretos de cromo também precipitaram nos contornos de grãos, em menor fração que as outras duas fases. Por fim, a $1000{ }^{\circ} \mathrm{C}$ observaram o aparecimento de chi e sigma tanto em contornos de grãos quanto dentro da ferrita após $300 \mathrm{~s}$, ao passo que em tempos mais longos, acima de 900 s, a fração de chi descresce enquanto a fração de sigma atinge o valor máximo de 4\%. Desta forma, Calliari et al. (2010) comprovam que o aço UNS S32750 é susceptível à precipitação de chi e sigma devendo ser solubilizado a temperaturas superiores a $1050{ }^{\circ} \mathrm{C}$, seguido de um rápido resfriamento que não cruze com a curva TTP, evitando-se o surgimento de tais fases secundárias. As micrografias da Figura 18 mostram o tratamento isotérmico do aço em questão a $950{ }^{\circ} \mathrm{C}$ por $300 \mathrm{~s}(\mathrm{a})$ e $2400 \mathrm{~s}$ (b), com chi e nitretos de cromo presentes em mais destaque no tempo mais curto, Figura 18 a, e predomínio de sigma no tempo mais longo, Figura 18 b.

Figura 18 - Precipitação de fases secundárias no aço superdúplex UNS S32750 a $950^{\circ} \mathrm{C}$ por 300 s (a) e 2400 s (b)
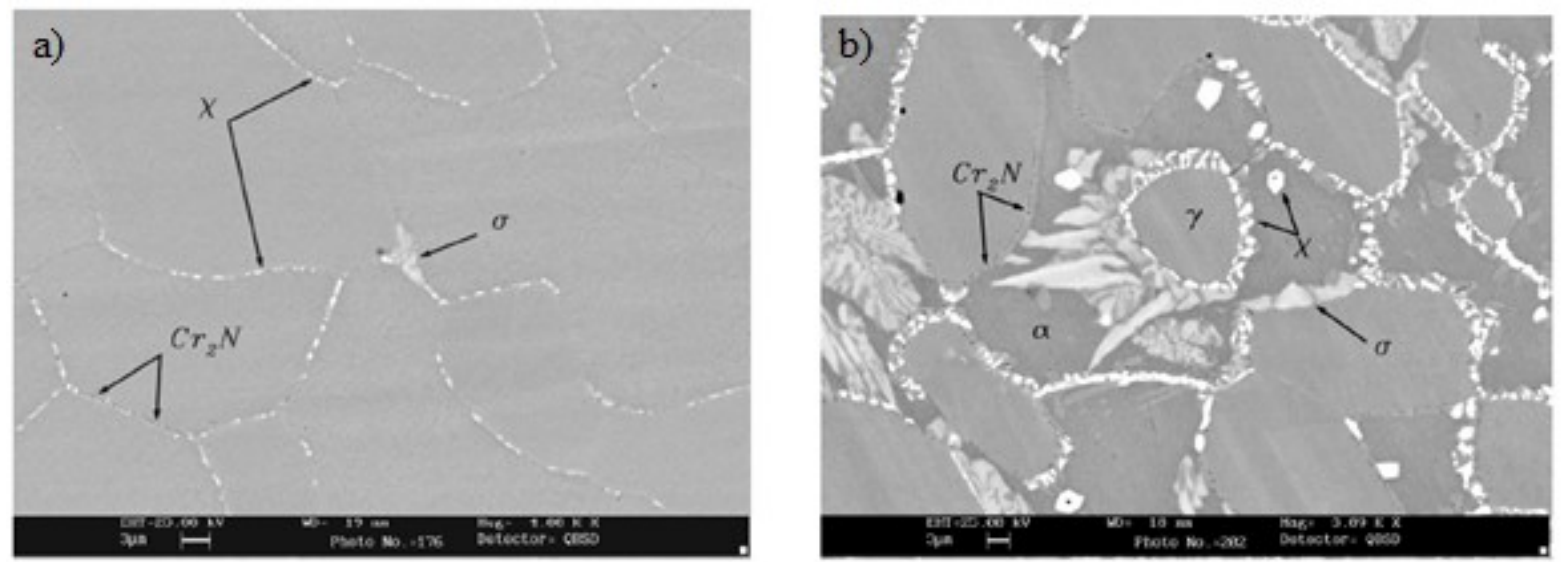

Fonte: Calliari, Ramous e Bassani, 2010

Diante dos exemplos de aços dúplex e superdúplex expostos, gerou-se a Tabela 5 com o intuito de comparar as temperaturas e tempos de máxima cinética de formação de sigma, por exemplo, obtida pelos diferentes autores, sendo possível notar que esta é sempre superior no aço inoxidável superdúplex em detrimento do dúplex, o que provavelmente se deve à composição química mais rica em cromo e molibdênio, os quais aumentam tanto a taxa de 
precipitação quanto a fração volumétrica desta fase e, portanto, os superdúplex também requerem um resfriamento mais rápido que os dúplex a partir da temperatura de solubilização para manterem a estrutura metaestável de ferrita e austenita na temperatura ambiente (NILSSON, 1992).

Além da composição química, a cinética de sigma também pode ser influenciada pela temperatura de solubilização, uma vez que o aumento desta implica em maior fração volumétrica de ferrita e, consequentemente, diluição dos principais formadores de sigma na ferrita, o que inibe e retarda a formação desta fase. Além disso, a maior fração volumétrica de ferrita reduz a quantidade de sítios heterogêneos de precipitação, ou seja, as interfaces ferrita/austenita (MAGNABOSCO; 2009).

Tabela 5 - Comparativo entre a temperatura de cinética máxima de formação de fase sigma entre os aços dúplex e superdúplex

\begin{tabular}{|c|c|c|c|c|}
\hline Aço inoxidável & $\begin{array}{l}\text { Temperatura } \\
\text { de } \\
\text { solubilização }\end{array}$ & $\begin{array}{l}\text { Temperatura } \\
\text { de cinética } \\
\text { máxima }\end{array}$ & $\begin{array}{l}\text { Tempo de } \\
\text { cinética } \\
\text { máxima }\end{array}$ & Autor \\
\hline $\begin{array}{c}\text { UNS S31803 } \\
\mathrm{Fe}-22,4 \% \mathrm{Cr}-4,88 \% \mathrm{Ni}- \\
3 \% \mathrm{Mo}\end{array}$ & $1065^{\circ} \mathrm{C}$ & $800^{\circ} \mathrm{C}$ & $\begin{array}{c}100 \mathrm{~s} \\
1,67 \mathrm{~min}\end{array}$ & $\begin{array}{c}\text { Elmer et. al } \\
(2007)\end{array}$ \\
\hline $\begin{array}{c}\text { UNS S31803 } \\
\mathrm{Fe}-22 \% \mathrm{Cr}-5,7 \% \mathrm{Ni}- \\
3 \% \mathrm{Mo}\end{array}$ & $1120^{\circ} \mathrm{C}$ & $850^{\circ} \mathrm{C}$ & $\begin{array}{c}288 \mathrm{~s} \\
4,8 \mathrm{~min}\end{array}$ & $\begin{array}{c}\text { Magnabosco } \\
\text { (2009) }\end{array}$ \\
\hline $\begin{array}{c}\text { UNS S31803 } \\
\mathrm{Fe}-22 \% \mathrm{Cr}-5,68 \% \mathrm{Ni}- \\
3,2 \% \mathrm{Mo}\end{array}$ & $1175^{\circ} \mathrm{C}$ & $850^{\circ} \mathrm{C}$ & $\begin{array}{c}288 \mathrm{~s} \\
4,8 \mathrm{~min}\end{array}$ & $\begin{array}{l}\text { Santos } \\
(2013)\end{array}$ \\
\hline $\begin{array}{c}\text { UNS S32750 } \\
\mathrm{Fe}-22,9 \% \mathrm{Cr}-6,9 \% \mathrm{Ni}- \\
3,8 \% \mathrm{Mo}\end{array}$ & $1060^{\circ} \mathrm{C}$ & $950^{\circ} \mathrm{C}$ & $\begin{array}{l}420 \mathrm{~s} \\
7 \mathrm{~min}\end{array}$ & $\begin{array}{l}\text { Nilsson e } \\
\text { Wilson } \\
\text { (1993) }\end{array}$ \\
\hline $\begin{array}{c}\text { UNS S32750 } \\
\mathrm{Fe}-24,5 \% \mathrm{Cr}-6,36 \% \mathrm{Ni}- \\
4 \% \mathrm{Mo}\end{array}$ & $1120^{\circ} \mathrm{C}$ & $900^{\circ} \mathrm{C}$ & $\begin{array}{l}300 \mathrm{~s} \\
5 \mathrm{~min}\end{array}$ & $\begin{array}{l}\text { Calliari et. } \\
\text { al (2010) }\end{array}$ \\
\hline
\end{tabular}


Pelo cenário exposto, é possível notar que a maioria dos trabalhos preocupa-se apenas com a formação isotérmica de fases deletérias, sem levar em consideração a taxa de aquecimento e/ou resfriamento, as quais desempenham um papel importante tanto na metalurgia física do aço (visando o balanço entre ferrita e austenita, evitando ou dissolvendo as fases secundárias), quanto em aspectos tecnológicos (uma vez que o próprio processo de processamento sofre aquecimentos e resfriamentos), evidenciando a necessidade de investigações teóricas e experimentais que levem tais taxas em consideração, como fizeram os autores dos trabalhos que serão discutidos na sequência, em relação ao resfriamento.

Estudos experimentais do aço UNS S32750 elaborados por Nilsson (1992) mostraram que uma taxa de resfriamento crítica de $0,4 \mathrm{~K} / \mathrm{s}(24 \mathrm{~K} / \mathrm{min})$ leva a formação de apenas $1 \%$ de sigma quando a temperatura de solubilização é de $1060{ }^{\circ} \mathrm{C}$, vide diagrama TRC da Figura 19, informação valiosa quando não se deseja a precipitação desta fase no resfriamento do aço.

Figura 19 - Diagrama TRC do aço UNS S32750

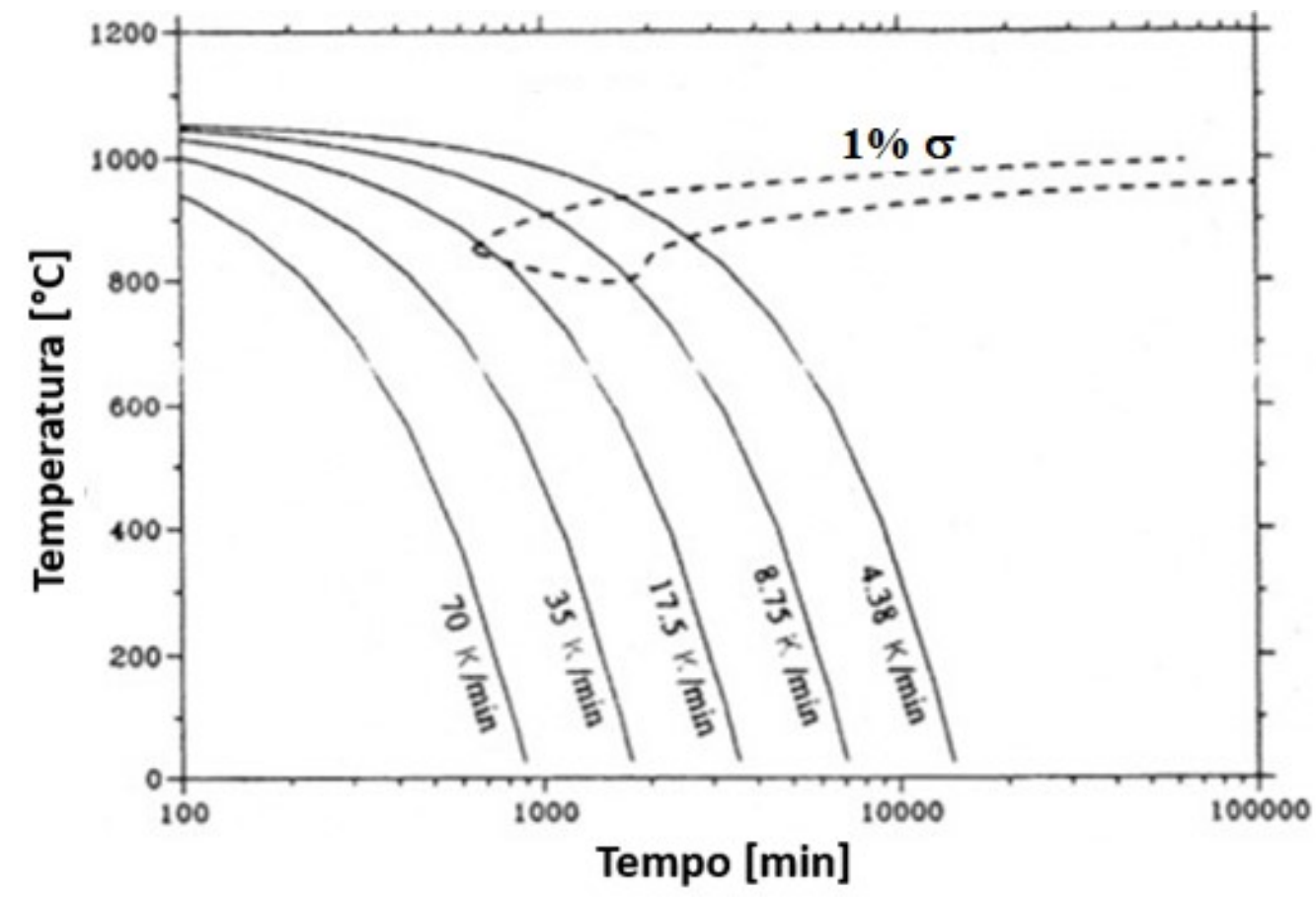

Fonte: Autora "adaptado de" Nilsson, 1992, p. 693

Calliari, Ramous e Bassani, (2010) também investigaram quais os efeitos de um resfriamento contínuo a partir da temperatura de solubilização de $1120{ }^{\circ} \mathrm{C}$ na precipitação de fases secundárias do aço superdúplex UNS S32750. Os autores verificaram que não houve formação de nitretos de cromo e não conseguiram determinar a taxa de resfriamento máxima que promove menos que $1 \%$ de precipitação, mas estimam que esteja entre 0,8 e $0,9{ }^{\circ} \mathrm{C} / \mathrm{s}$. 
Pardal et al. (2012) investigaram a precipitação de fases deletérias do aço superdúplex UNS S32750 de composição química $\mathrm{Fe}-24,8 \% \mathrm{Cr}-6,7 \% \mathrm{Ni}-3,7 \% \mathrm{Mo}-0,27 \% \mathrm{~N}$ durante o resfriamento contínuo a partir da temperatura de solubilização de $1100{ }^{\circ} \mathrm{C}$ por 40 minutos, para três diferentes taxas de resfriamento, classificadas como rápida $\left(0,140{ }^{\circ} \mathrm{C} / \mathrm{s}\right)$, moderada $(0,080$ $\left.{ }^{\circ} \mathrm{C} / \mathrm{s}\right)$ e lenta $\left(0,054{ }^{\circ} \mathrm{C} / \mathrm{s}\right)$, conforme mostra a Figura 20 . As amostras foram resfriadas em água assim que atingiram $580^{\circ} \mathrm{C}$, com intuito de evitar a precipitação da fase alfa linha.

$\mathrm{Na}$ amostra de maior taxa de resfriamento $\left(0,140{ }^{\circ} \mathrm{C} / \mathrm{s}\right)$, a fase que precipitou em maior fração volumétrica foi a sigma, preferencialmente nos contornos entre ferrita/ferrita e nas interfaces ferrita/austenita. Já a taxa de resfriamento moderada $\left(0,080{ }^{\circ} \mathrm{C} / \mathrm{s}\right)$ produziu coalescimento de placas de sigma e formação de austenita secundária e, por fim, houve ainda mais coalescimento das placas de sigma para a menor taxa de resfriamento $\left(0,054{ }^{\circ} \mathrm{C} / \mathrm{s}\right)$. As micrografias das amostras resfriadas às três diferentes taxas podem ser vistas na Figura 21 (PARDAL et al., 2012). Os autores notaram que as fases secundárias que precipitaram não influenciaram na dureza das amostras, contudo, influenciaram na fragilidade e em uma drástica queda na resistência à corrosão. Ainda, reportaram que uma fração volumétrica de $5 \%$ de fase sigma promove uma queda na resistência abaixo do aceitável e, portanto, deve ser evitada (PARDAL et al., 2012).

Figura 20 - Taxas de resfriamento do aço superdúplex UNS S32750 a partir da temperatura de solubilização de $1100^{\circ} \mathrm{C}$

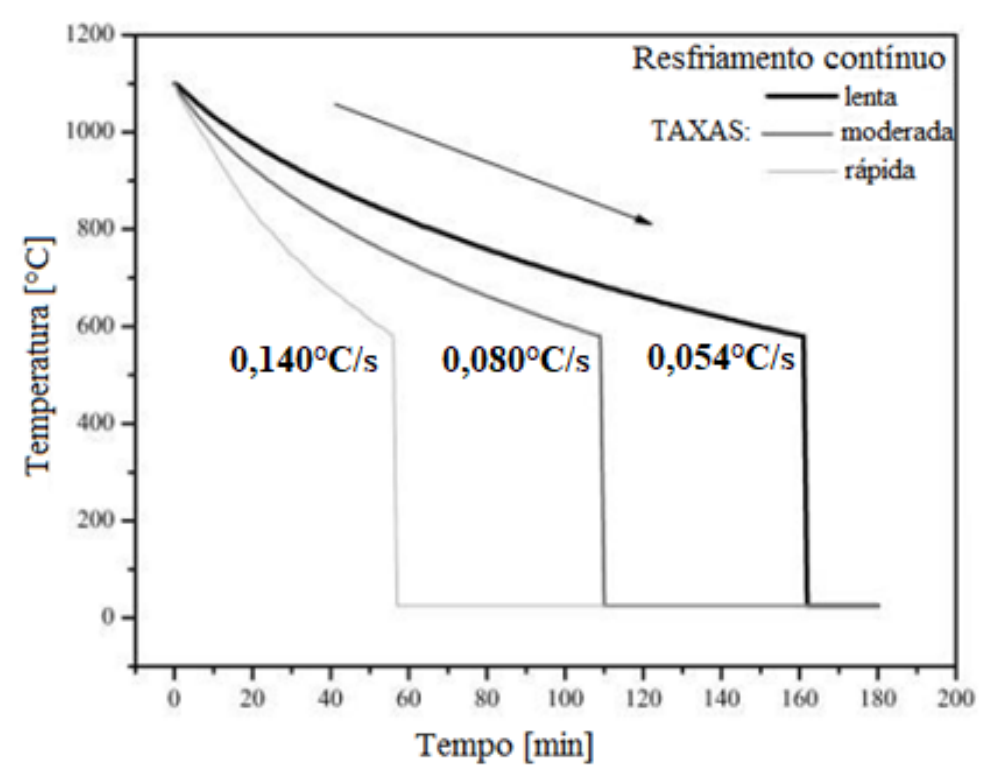

Fonte: Autora “adaptado de” Pardal et al., 2012, p. 297 
Figura 21 - Micrografias da amostra do aço superdúplex UNS S32750 resfriado a três diferentes taxas de resfriamento: a) rápida; b) moderada; c) lenta
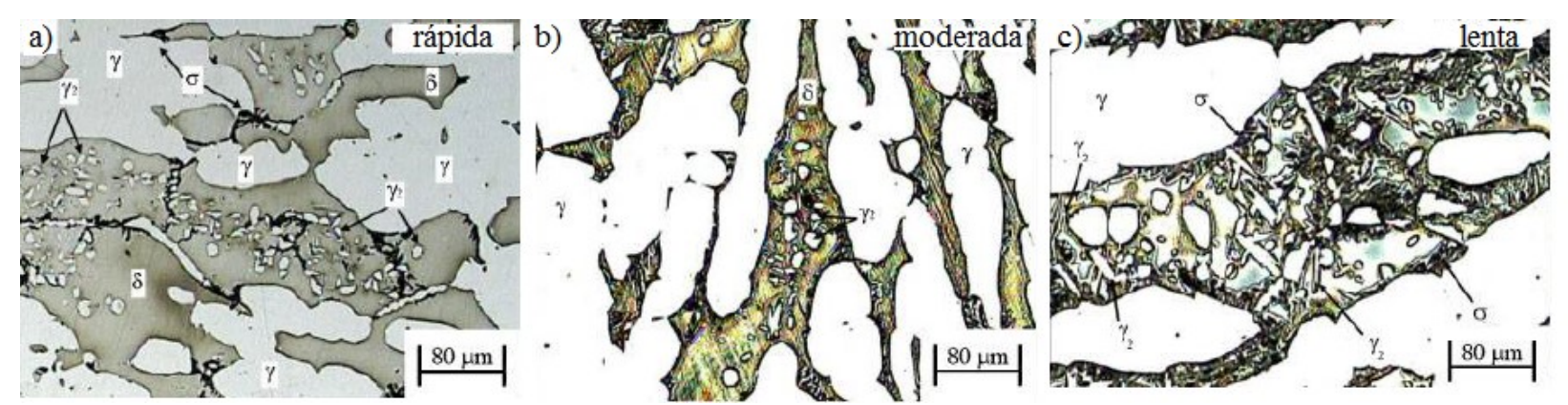

Fonte: Pardal et al., 2012

Shin et al. (2018) também verificaram a cinética de formação de fases deletérias no aço superdúplex UNS S32750 a três diferentes taxas de resfriamento: água $(5600 \mathrm{~J} / \mathrm{s})$, ar $(1,9 \mathrm{~J} / \mathrm{s}) \mathrm{e}$ forno $(0,4 \mathrm{~J} / \mathrm{s})$ para temperaturas de solubilização que variam entre $1000{ }^{\circ} \mathrm{C}$ e $1300{ }^{\circ} \mathrm{C}$ durante 1 hora. $\mathrm{O}$ autor notou que os resfriamentos em água $(5600 \mathrm{~J} / \mathrm{s})$ e ar $(1,9 \mathrm{~J} / \mathrm{s})$ não levam a precipitação de fases deletérias, exceto $5 \%$ entre $1000{ }^{\circ} \mathrm{C}$ e $1050{ }^{\circ} \mathrm{C}$ e ainda encontrou as temperaturas ideais de solubilização para obtenção da condição dúplex, de $1120{ }^{\circ} \mathrm{C}$ para 5600 $\mathrm{J} / \mathrm{s}$ e $1180^{\circ} \mathrm{C}$ para $1,9 \mathrm{~J} / \mathrm{s}$, como mostram os gráficos da Figura 22, evitando a faixa em que há o mínimo de fase deletéria formada. Já no resfriamento ao forno a uma taxa de $0,4 \mathrm{~J} / \mathrm{s}$, há precipitação de fases secundárias por toda a faixa de temperatura, com menor precipitação em $1300{ }^{\circ} \mathrm{C}$. Observa-se que em $1300^{\circ} \mathrm{C}$, a fração volumétrica de ferrita supera $70 \%$, como obtido nas simulações de Thermo-Calc ${ }^{\circledR}$ por Magnabosco e Fiorante (2019) indicado na Figura 5. Diante dos resultados de Shin et al. (2018), conclui-se que taxas de resfriamento superiores a 1,9J/s são ideais para evitar-se precipitação de fases secundárias. Os autores, no entanto, não forneceram dados sobre o tamanho dos corpos de prova, nem a temperatura anterior ao resfriamento indicado em $\mathrm{J} / \mathrm{s}$, impedindo a conversão destes valores para taxas de resfriamento em K/s, por exemplo. 
Figura 22 - Fração volumétrica das fases em função da temperatura de solubilização para diferentes taxas de resfriamento
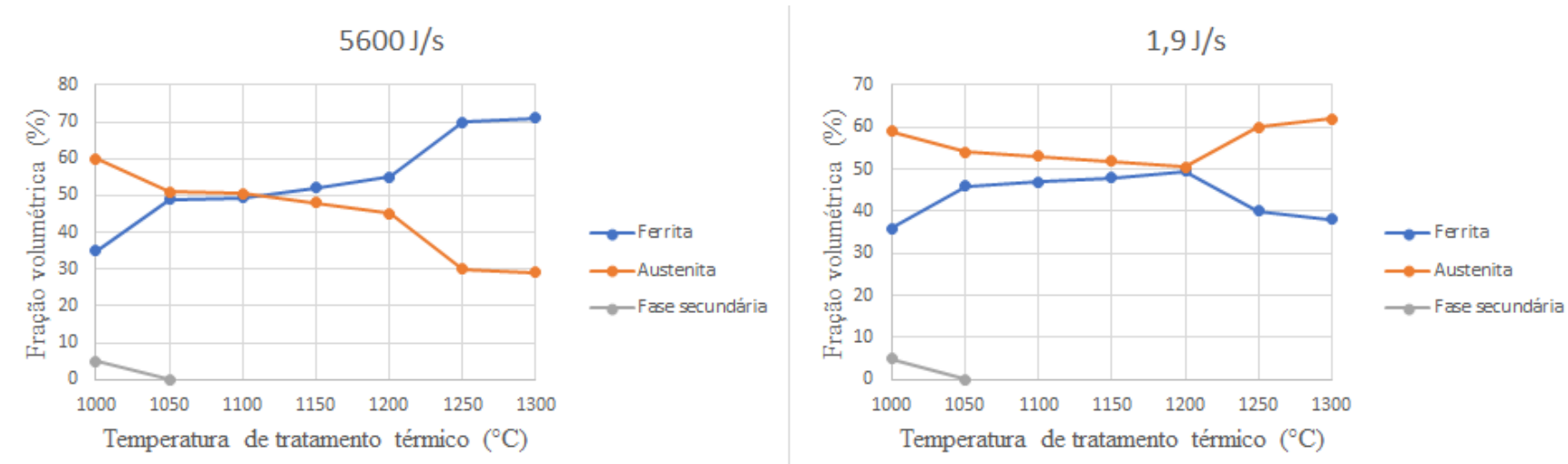

$0,4 \mathrm{~J} / \mathrm{s}$

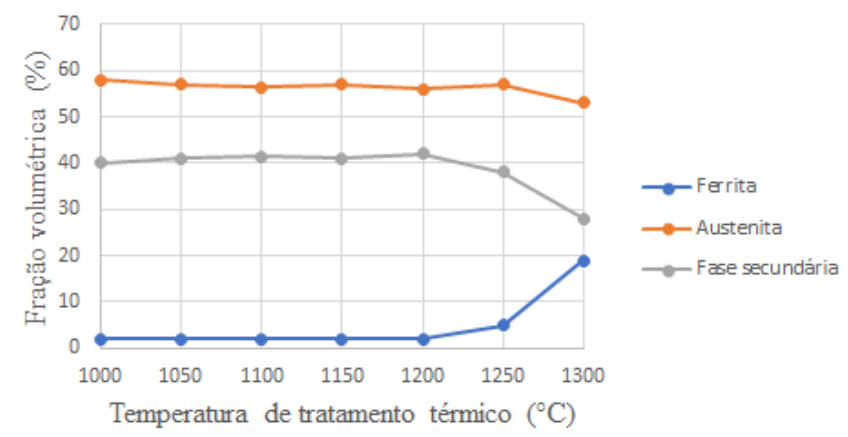

Fonte: Autora "adaptado de" Shin et al., 2018

Com foco em verificar a precipitação de nitretos de cromo $\left(\mathrm{Cr}_{2} \mathrm{~N}\right)$ no aço superdúplex UNS S32750 de composição química $\mathrm{Fe}-24,80 \% \mathrm{Cr}-6,89 \% \mathrm{Ni}-3,83 \% \mathrm{Mo}-0,27 \% \mathrm{~N}$, os autores Pettersson, N.; Pettersson, R.; Wessman (2015) realizaram tratamentos térmicos de solubilização a $1250{ }^{\circ} \mathrm{C}$ por $10 \mathrm{~s}$, seguido de resfriamentos controlados a taxas de $20 \mathrm{~K} / \mathrm{s}, 50$ $\mathrm{K} / \mathrm{s}$ e $100 \mathrm{~K} / \mathrm{s}$, além de solubilização a $1250{ }^{\circ} \mathrm{C}$ por 5 min e resfriamento em água e ao ar calmo.

Todas as amostras apresentaram precipitação de nitretos de cromo $\left(\mathrm{Cr}_{2} \mathrm{~N}\right)$ na ferrita para as taxas de resfriamento superiores a $20 \mathrm{~K} / \mathrm{s}$ e resfriamento em água, exceto para resfriamento ao ar calmo, em que há aparecimento de fase sigma; entretanto, os autores não informaram a porcentagem precipitada. A Tabela 6 contém a composição química dos nitretos de cromo formados $\left(\mathrm{Cr}_{2} \mathrm{~N}\right)$ às diferentes taxas de resfriamento, exceto no resfriamento em água e ao ar calmo, os quais também não foram informados (Pettersson, N.; Pettersson, R.; Wessman, 2015).

Nesta condição de elevada temperatura de solubilização, com alta fração de ferrita e maior concentração de $\mathrm{N}$ nesta fase, notou-se também que taxas de resfriamento mais altas produzem maior concentração de nitretos, uma vez que os grãos de ferrita estão supersaturados 
em $\mathrm{N}$, além de produzir nitretos mais largos: a alta taxa de resfriamento impede o $\mathrm{N}$ de difundir para a austenita presente, supersaturado a ferrita e levando a precipitação do nitreto nesta fase. Para a taxa de resfriamento mais alta, $100 \mathrm{~K} / \mathrm{s}$, também observaram precipitação de nitreto de cromo metaestável (CrN). Taxas de resfriamento mais lentas permitem a partição do nitrogênio, levando a precipitação de nitretos menos largos, como a $20 \mathrm{~K} / \mathrm{s}$, ou ainda que outras fases intermetálicas formem, como é o caso do aparecimento de sigma no resfriamento ao ar calmo. Ainda, os autores verificaram que a taxa de resfriamento teve menor efeito no equilíbrio ferritaaustenita, uma vez que o teor de ferrita manteve-se em torno de 50\% em todos os casos após os resfriamentos controlados (Pettersson, N.; Pettersson, R.; Wessman, 2015).

Tabela 6 - Composição química dos niretos de cromo a diferentes taxas de resfriamento

\begin{tabular}{ccccc}
\hline $\begin{array}{c}\text { Taxas de } \\
\text { resfriamento }\end{array}$ & Fe & Cr & Mo & $\mathrm{N}$ \\
\hline $20 \mathrm{~K} / \mathrm{s}$ & $4,0 \%$ & $61,2 \%$ & $3,8 \%$ & $28,8 \%$ \\
\hline $50 \mathrm{~K} / \mathrm{s}$ & $3,2 \%$ & $54,9 \%$ & $4,4 \%$ & $36,7 \%$ \\
\hline $100 \mathrm{~K} / \mathrm{s}$ & $3,9 \%$ & $52,2 \%$ & $1,8 \%$ & $40,9 \%$ \\
\hline
\end{tabular}

Fonte: Petterson N., Petterson, R., Wessman, 2015

Em resumo, as taxas de resfriamento críticas que cada autor encontrou a partir da qual também se forma o mínimo de fases deletérias, foram resumidas na Tabela 7. É possível concluir que para o aço inoxidável superdúplex UNS S32750, a taxa crítica de resfriamento é de $0,4{ }^{\circ} \mathrm{C} / \mathrm{s}$, em que forma no máximo $1 \%$ de fase deletéria, valor desejável para o produto final, e taxas de resfriamento na ordem de $20{ }^{\circ} \mathrm{C} / \mathrm{s}$ ou superiores, a partir da temperatura de solubilização de $1250{ }^{\circ} \mathrm{C}$, levam a formação de nitretos de cromo. Estes dados sumarizados na Tabela 7 serão usados na determinação de condição inicial que será utilizada nas simulações computacionais do resfriamento do presente estudo. 
Tabela 7 - Taxas de resfriamento contínuo críticas para evitar a formação de fases deletérias no aço UNS S32750

\begin{tabular}{cccc}
\hline Autor & $\begin{array}{c}\text { Taxa de resfriamento } \\
\text { crítica }\end{array}$ & $\begin{array}{c}\text { Taxa de resfriamento } \\
\text { convertida }\end{array}$ & Fase formada \\
\hline Nilsson, 1992 & $<0,400 \mathrm{~K} / \mathrm{s}$ & $<0,400{ }^{\circ} \mathrm{C} / \mathrm{s}$ & $\sigma(1 \% \mathrm{v})$ \\
\hline $\begin{array}{c}\text { Calliari; Ramous; } \\
\text { Bassani, 2010 }\end{array}$ & $<0,900{ }^{\circ} \mathrm{C} / \mathrm{s}$ & $<0,900{ }^{\circ} \mathrm{C} / \mathrm{s}$ & $\sigma(1 \% \mathrm{v})$ \\
\hline Pardal et al., 2012 & $<9,235^{\circ} \mathrm{C} / \mathrm{min}$ & $<0,140{ }^{\circ} \mathrm{C} / \mathrm{s}$ & $\sigma(5 \% \mathrm{v})$ \\
\hline $\begin{array}{c}\text { Petterson, N.; } \\
\text { Petterson, R.; } \\
\text { Wessman, 2015 }\end{array}$ & $>20 \mathrm{~K} / \mathrm{s}$ & $>20^{\circ} \mathrm{C} / \mathrm{s}$ & $\mathrm{Cr}_{2} \mathrm{~N}$ \\
\end{tabular}

Fonte: Nilsson, 1992; Calliari, Ramous e Bassani, 2010; Petterson, N.; Petterson, R.; Wessman, 2015

Diante do exposto na Tabela 7, uma forma de suprimir a presença de fases secundárias como a sigma e nitretos de cromo no aço superdúplex UNS S32750 está em promover a solubilização, garantindo a condição dúplex diluída de elementos formadores destas fases deletérias, seguido de resfriamento a taxa controlada, isto é, superior à $0,4{ }^{\circ} \mathrm{C} / \mathrm{s}$ para evitar-se sigma e inferior a $20{ }^{\circ} \mathrm{C} / \mathrm{s}$ para evitar-se nitreto de cromo em condições de supersaturação de nitrogênio na ferrita acima de $1250{ }^{\circ} \mathrm{C}$, assim, a microestrutura bifásica de ferrita e austenita continua coexistindo, agora na condição de solução sólida supersaturada, isto é, de microestrutura metaestável.

Por conta da condição metaestável, qualquer insumo de energia ao qual este aço for submetido, levará a uma reestruturação da microestrutura, com o intuito de atingir novamente a condição de equilíbrio estável, estando suscetível a formação de tais fases indesejáveis e a perda da condição dúplex, o que mostra a importância de se conhecer e prever o comportamento microestrutural do material durante os ciclos térmicos de processamento, principalmente por meio de modelamentos computacionais.

\subsection{SIMULAÇÕES COMPUTACIONAIS}

Resultados experimentais podem descrever a termodinâmica e a cinética de transformação de fases e são essenciais para a determinação dos ciclos térmicos que o aço inoxidável superdúplex deve ser processado sem que fases indesejáveis sejam formadas. Porém, 
é inviável que tais dados sejam o único meio de prever as transformações, uma vez que existem diferentes mecanismos de formação de fases. Sendo assim, as simulações computacionais são ferramentas poderosas para se prever as possibilidades de transformações e validar as já previstas.

\subsubsection{Thermo-Calc}

Desenvolvido há mais de 30 anos pelo Royal Institute of Technology de Estocolmo, na Suécia, o software Thermo-Calc ${ }^{\circledR}$ é capaz de simular os mais diversos cálculos termodinâmicos graças a uma ampla e precisa base de dados, apresentando-se extremamente útil e atual (THERMO-CALC, 2019). Os usuários têm a possibilidade de gerar um projeto especificando e configurando uma sequência de atividades individualmente, como definir um sistema, as condições para um cálculo de equilíbrio e até mesmo para traçar os resultados. O software é capaz de calcular o equilíbrio entre as fases de um material, as temperaturas de transformações de fases, o modelo de solidificação de Scheil-Gulliver, além de obter dados termodinâmicos como entalpia, energia livre de Gibbs, entre outros (THERMO-CALC, 2019).

Nesta dissertação, o Thermo-Calc ${ }^{\circledR}$ foi utilizado para obter-se diagramas de equilíbrio, verificando quais fases coexistem em determinados intervalos de temperatura de interesse e, sobretudo, encontrar a temperatura de solubilização necessária para atingir-se a condição dúplex desejada, como mostraram os exemplos do item 2.1 com o diagrama de equilíbrio do aço superdúplex UNS S32750 na Figura 5 e do aço dúplex UNS S31803 na Figura 6.

Outros autores como Forgas (2016) e Morais (2016) também simularam a variação da fração de fases em função da temperatura para o aço dúplex UNS S31803, com bases de dados distintas, TCFE7 e TCFE8, conforme mostrado a seguir.

A Figura 23 mostra o diagrama de equilíbrio obtido por Forgas (2016) com base de dados TCFE7, verificando que a temperatura de solubilização necessária para atingir-se a condição dúplex desejada é de aproximadamente $1090^{\circ} \mathrm{C}$, para a composição química simulada $\mathrm{Fe}-22 \% \mathrm{Cr}-5,4 \% \mathrm{Ni}-3,15 \% \mathrm{Mo}-0,18 \% \mathrm{~N}$. 
Figura 23 - Fração das fases em função da temperatura para o aço UNS S31803

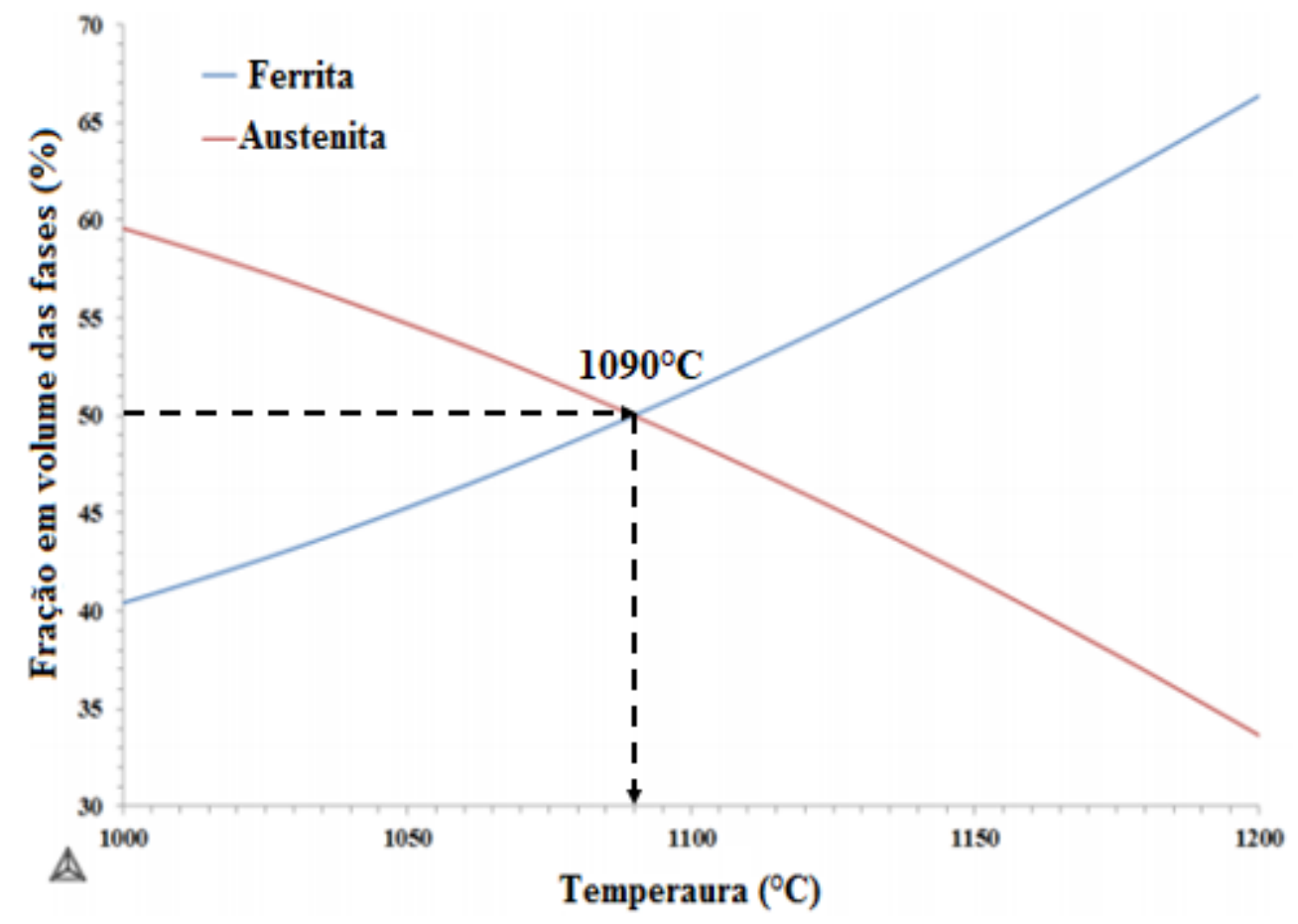

Fonte: Autora "adaptado de" Forgas, 2016, p.26

Morais (2017) simulou o equilíbrio do aço dúplex UNS S31803 com a base de dados TCFE8, para duas diferentes composições químicas: completa (com todos os elementos químicos presentes na composição) e reduzida (com os principais elementos de interesse: FeCr-Ni-Mo-N), vide Figura 24. Para a composição química completa $\mathrm{Fe}-22 \% \mathrm{Cr}-5,68 \% \mathrm{Ni}$ $3,20 \% \mathrm{Mo}-1,38 \% \mathrm{Mn}-0,17 \% \mathrm{~N}-0,017 \% \mathrm{C}-0,34 \% \mathrm{Si}-0,15 \% \mathrm{Cu}-0,13 \% \mathrm{~V}$, a autora obteve temperatura de solubilização de $1120^{\circ} \mathrm{C}$, Figura 24 (a). Já ao simular apenas com os principais elementos de interesse, $\mathrm{Fe}-22,07 \% \mathrm{Cr}-5,68 \% \mathrm{Ni}-3,20 \% \mathrm{Mo}-0,17 \% \mathrm{~N}$, a temperatura de solubilização passa a ser um pouco menor, de $1090{ }^{\circ} \mathrm{C}$, Figura 24 (b). Para a composição reduzida, a temperatura de $1120{ }^{\circ} \mathrm{C}$ representa uma condição de $53 \%$ de ferrita e $47 \%$ de austenita, condição levemente diferente da situação encontrada para a composição química completa.

Comparando-se os diagramas obtidos pelos autores das Figura 6, 23 e 24, todos para o aço dúplex UNS S31803, apesar de utilizarem diferentes atualizações da base de dados e variações de composições químicas do aço, o equilíbrio entre as fases e as temperaturas de 
solubilização obtidas são similires, o que mostra confiabilidade e reprodutibilidade dos resultados simulados no Thermo-Calc ${ }^{\circledR}$.

Figura 24 - Comparação entre a temperatura de solubilização para o aço UNS 31803 de composição química completa em a) e composição química reduzida em b)
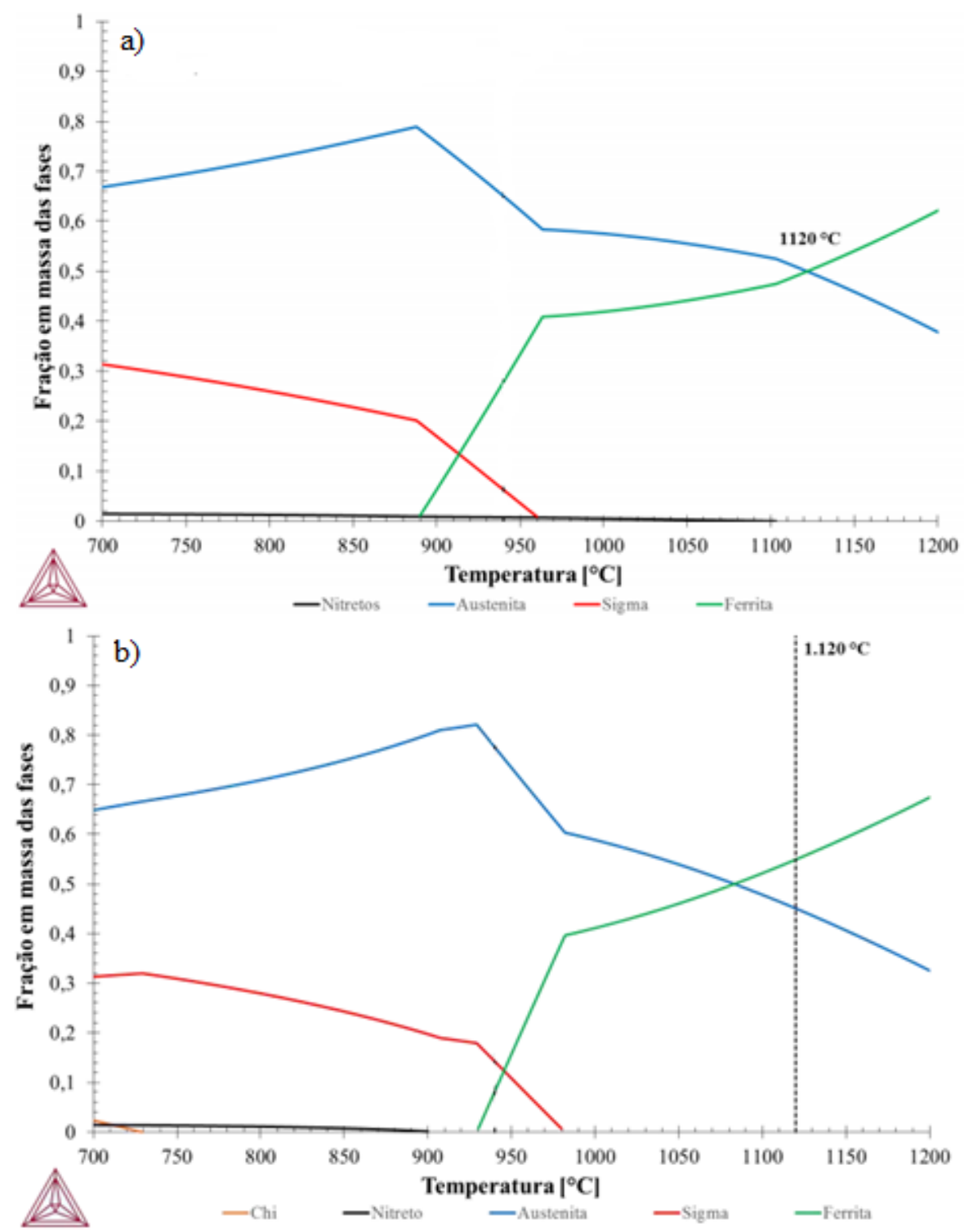

Fonte: Autora “adaptado de" Morais, 2017, p. 41

A mesma análise foi feita por Fiorante (2019) ao simular o equilíbrio do aço superdúplex UNS S32750 com base de dados TCFE8, para duas composições químicas: reduzida e completa. Simulando-se apenas com os principais elementos de interesse, $\mathrm{Fe}-25,17 \% \mathrm{Cr}-$ $6,88 \% \mathrm{Ni}-3,61 \% \mathrm{Mo}-0,27 \% \mathrm{Ni}$, a autora obteve temperatura de solubilização de $1088{ }^{\circ} \mathrm{C}$ e fração de $70 \%$ de ferrita e $30 \%$ de austenita em $1250^{\circ} \mathrm{C}$ (Figura 5), enquanto que para 
composição química completa $\mathrm{Fe}-22 \% \mathrm{Cr}-5,68 \% \mathrm{Ni}-3,20 \% \mathrm{Mo}-1,38 \% \mathrm{Mn}-0,17 \% \mathrm{~N}-$ $0,017 \% \mathrm{C}-0,34 \% \mathrm{Si}-0,15 \% \mathrm{Cu}-0,13 \% \mathrm{~V}$, obteve-se temperatura de solubilização de $1115{ }^{\circ} \mathrm{C}$ e fração de $68 \%$ de ferrita e $32 \%$ de austenita em $1250{ }^{\circ} \mathrm{C}$ (Figura 25).

Comparando-se os resultados obtidos, percebe-se que para a composição química completa, a temperatura de solubilização é $27^{\circ} \mathrm{C}$ maior, mas a diferença de frações de ferrita e austenita nesta temperatura é pequena, apenas $2 \%$ a menos de ferrita e $2 \%$ a mais de austenita. Isso se deve ao maior número de elementos inseridos na simulação, o que também a torna mais lenta (FIORANTE, 2019). Considerando que a diferença de resultados é mínima, a autora optou por utilizar nesta dissertação apenas os principais elementos do aço superdúplex em questão, reduzindo tempo de simulação, o que será uma característica desejável nas simulações de DICTRA $^{\circledR}$ que serão descritas em próximo item.

Figura 25 - Diagrama de fases do aço inoxidável superdúplex UNS S32750 com base de dados TCFE8 e composição química completa

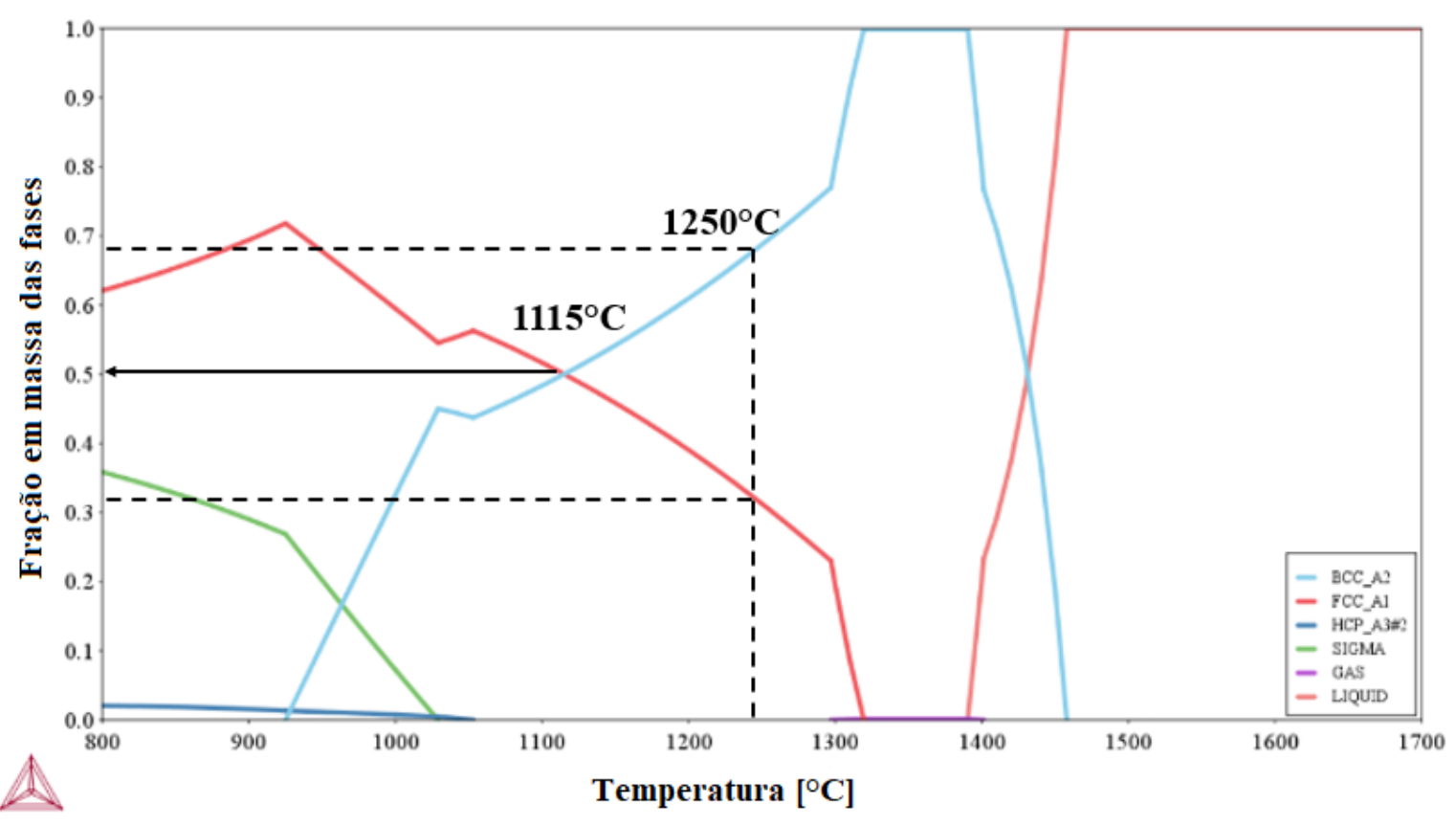

Fonte: Fiorante, 2019

\subsubsection{DICTRA}

O software DICTRA ${ }^{\circledR}$ (diffusion-controlled transformations) simula transformações de fase controladas por difusão em sistemas multicomponentes, permitindo simulações em condições reais por meio de modelos fundamentados em dados termodinâmicos e cinéticos. A 
base de dados termodinâmica é a mesma do Thermo-Calc ${ }^{\circledR}$, enquanto que a cinética é adicional e contém informações de coeficientes de difusão para cada elemento químico. Os usuários têm a possibilidade de simular a homogeneização de ligas, crescimento e solubilização de segundas fases, cementação, descarbonetação e nitrocarbonetação de aços, microsegregação durante a solidificação, coalescimento, gradientes de composição, entre outros (THERMO-CALC, 2019).

As simulações realizadas pelo DICTRA ${ }^{\circledR}$ são unidimensionais e a geometria da interface entre regiões é limitada a planar, esférica ou cilíndrica, que devem ser escolhidas e baseadas no estudo a ser realizado. Utiliza-se a geometria planar, ou de interface perpendicular ao fluxo difusional, para verificar como se dá a migração de interfaces entre fases, enquanto a geometria esférica é utilizada no estudo de precipitação e solubilização de fases secundárias, e a geometria cilíndrica na análise de precipitados com tal morfologia (ANDERSSON et al., 2002). No caso desta dissertação, optou-se por modelar o sistema com geometria planar, conforme Figura 26, considerando a interface ferrita/austenita como região preferencial de formação de fases deletérias, por onde se dá a difusão entre as fases, como mostrado pela literatura e confirmado experimentalmente por Melo e Magnabosco (2017) tanto para a precipitação de sigma, já discutida no item 2.2.1 quanto de nitretos de cromo, discutida no item 2.2.2.

Figura 26 - Modelo geométrico utilizado na simulação computacional

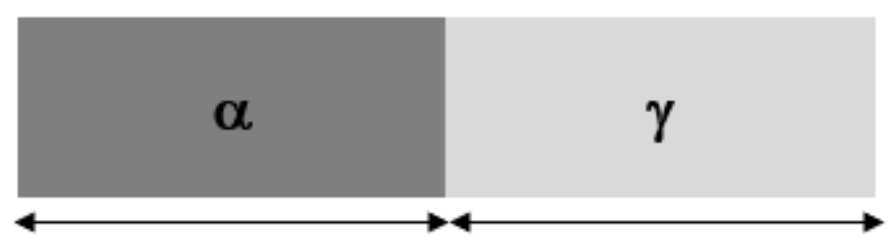

Comprimento útil de difusão

Fonte: Autora

A primeira Lei de Fick, Equação 3, equaciona o fenômeno da difusão, o qual ocorre em estado estacionário, visto que os gradientes composicionais não variam ao longo do tempo. Já em sistemas onde as concentrações variam tanto com a distância quanto com o tempo, a difusão ocorre em estado não estacionário conforme descreve a segunda Lei de Fick, Equação 4 (PORTER; EASTERLING, 1992). A difusão ocorre por conta do gradiente de composição química existente no sistema, buscando igualar o potencial termodinâmico que os diferentes elementos possuem e, consequentemente, reduzindo a energia livre (PORTER; EASTERLING, 2004; ANDERSSON et al., 2002). O potencial termodinâmico é calculado, para instantes 
infinitesimais de tempo, usando-se o Thermo-Calc ${ }^{\circledR}$, e o DICTRA ${ }^{\circledR}$ resolve as equações de difusão naquele intervalo de tempo usando a base de dados de mobilidade como referência.

$$
\begin{aligned}
& J=-D \cdot \frac{\partial C}{\partial x} \\
& \frac{\partial C}{\partial t}=\frac{\partial}{\partial x} \cdot\left(D \cdot \frac{\partial C}{\partial x}\right)
\end{aligned}
$$

Nas equações 3 e 4, J refere-se ao fluxo de difusão do elemento químico $\left[\mathrm{kg} /\left(\mathrm{m}^{2} . \mathrm{s}\right)\right]$, D refere-se ao coeficiente de difusão $\left[\mathrm{m}^{2} / \mathrm{s}\right], \partial \mathrm{C} / \partial \mathrm{x}$ é o gradiente de composição do elemento químico em função da distância $\left[\mathrm{kg} / \mathrm{m}^{4}\right]$ e $\partial \mathrm{C} / \partial \mathrm{t}$ é o gradiente de composição do elemento químico em função do tempo $\left[\mathrm{kg} /\left(\mathrm{m}^{3} . \mathrm{s}\right)\right]$.

Alimentando-se o software com dados como a geometria do modelo, as fases que se deseja avaliar, o comprimento útil de difusão de cada fase, o tempo e temperatura de tratamento térmico e bases de dados necessárias, o Thermo-Calc ${ }^{\circledR}$, comandado pelo DICTRA $^{\circledR}$, realiza o cálculo do equilíbrio local do sistema para um intervalo de tempo desejado, assumindo dados de equilíbrio termodinâmico na interface entre as fases (BORGENSTAM et al., 2000). Assim, é possível obter importantes propriedades do aço em estudo como o perfil de composição de determinado elemento químico ao longo do comprimento do modelo e tempo de tratamento térmico, a fração de fases presentes a determinado tempo e temperatura, a posição da interface entre as fases e o seu equilíbrio, entre outros, como foi obtido pelos trabalhos discutidos na sequência.

Um artigo publicado por Liu et al. (2010) avalia o comportamento difusional do cromo na interface da ferrita e austenita ao longo do tempo sob a influência de diferentes temperaturas, para o aço dúplex UNS S31803, utilizando-se o software DICTRA ${ }^{\circledR}$ e base de dados SSOL4 e MOB2. O resultado obtido está na Figura 27, cuja linha vertical é a interface entre as fases austenítica (à esquerda) e ferrítica (à direita), pelas quais o cromo se difunde. Considera-se que as fases austenítica e ferrítica estão em equilíbrio e que o comprimento inicial de cada fase é, respectivamente, $4 \mu \mathrm{m}$ e 2,6 $\mu \mathrm{m}$, obtidos por microscopia óptica.

Pela análise da Figura 27, é interessante mencionar que a fração volumétrica de ferrita reduz com o aumento do tempo de envelhecimento a $1000{ }^{\circ} \mathrm{C}$ e $1050{ }^{\circ} \mathrm{C}$, uma vez que a interface migra da austenita para a ferrita, visto que o potencial químico do cromo é maior na ferrita para tais temperaturas, como calculado pelo software. Para as temperaturas de $1100{ }^{\circ} \mathrm{C}$ 
a $1200^{\circ} \mathrm{C}$, a fração de ferrita aumenta com o tempo, uma vez que a difusão se dá da austenita para a ferrita, visto que em maiores temperaturas, o potencial químico do cromo passa a ser maior na austenita. Os autores confirmaram a validade dos resultados do software através de experimentos laboratoriais (LIU et al., 2010).

Figura 27 - Perfil de Cr na interface ferrita/austenita do aço UNS S31803 a diferentes temperaturas
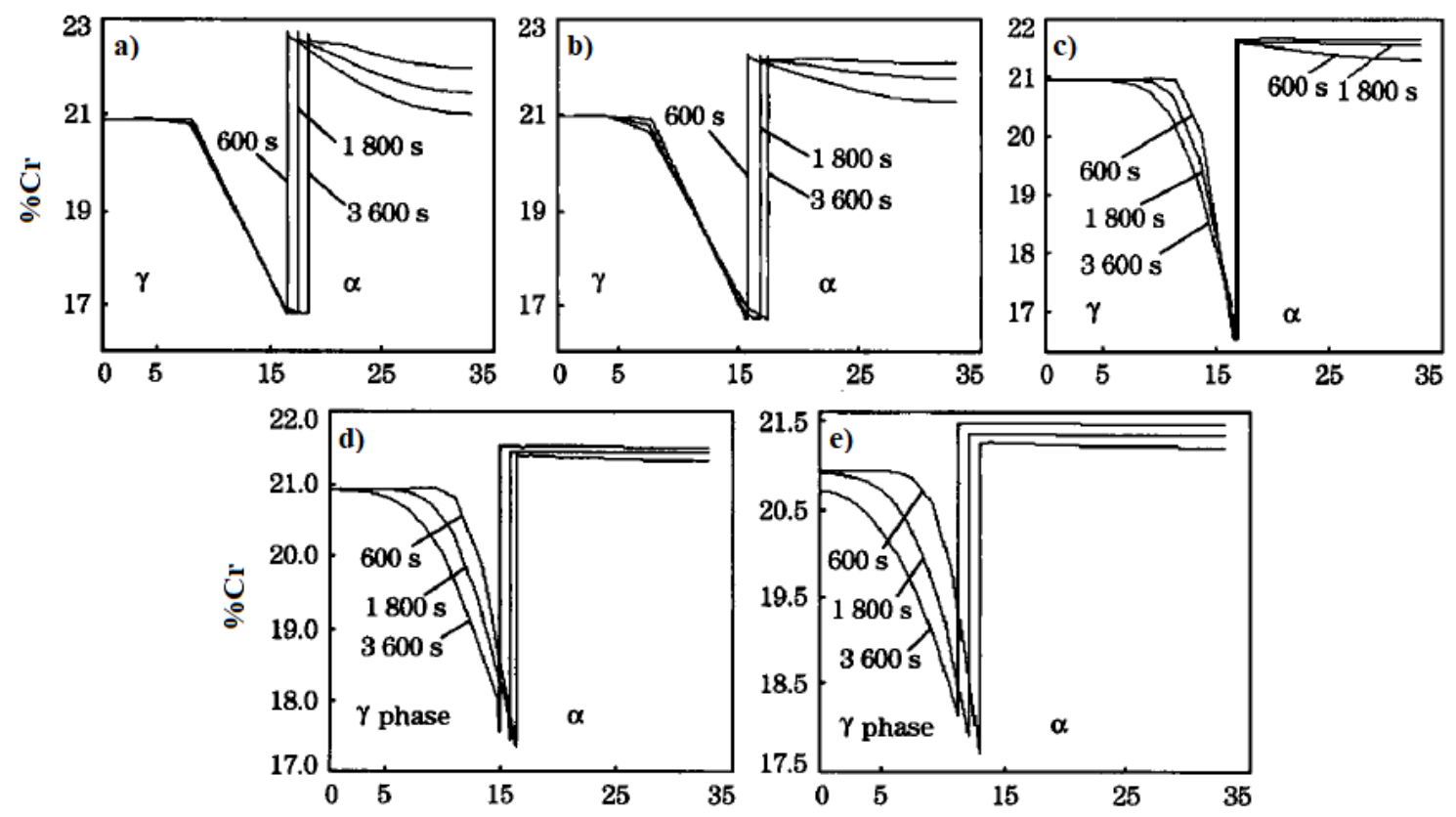

Distância das fases $(\mu \mathrm{m})$
(a) $1000 \mathrm{C}$;
(b) $1050^{\circ} \mathrm{C}$;
(c) $1100{ }^{\circ} \mathrm{C}$;
(d) $11500^{\circ}$;
(e) $1200{ }^{\circ} \mathrm{C}$.

Fonte: Autora “adaptado de” Liu et al., 2010, p. 47

Considerando um modelo de fases em que sigma está entre a ferrita e austenita, Magnabosco (2015) também utilizou o módulo de difusão DICTRA ${ }^{\circledR}$ para avaliar de que maneira o cromo se difunde nesta interface a uma temperatura de envelhecimento de $950{ }^{\circ} \mathrm{C}$, por diferentes tempos no aço superdúplex UNS S32750, como mostra a Figura 28. O autor pode notar que acima de $1800 \mathrm{~s}$ (30 $\mathrm{min})$, há gradiente de cromo na ferrita concomitante ao desenvolvimento de sigma na interface ferrita/austenita, consumindo preferencialmente a ferrita existente. Ainda, nota-se que apesar da diferença de composição entre a ferrita e austenita, não há desenvolvimento de sigma na austenita, como era de se esperar. Além disso, observa-se que somente após $7200 \mathrm{~s}(2 \mathrm{~h})$ de tratamento térmico ocorre a estabilização do cromo na ferrita, mostrando o fim da difusão nesta fase. 
Figura 28 - Perfil de Cr em função do tempo a $950^{\circ} \mathrm{C}$ do aço UNS S32750

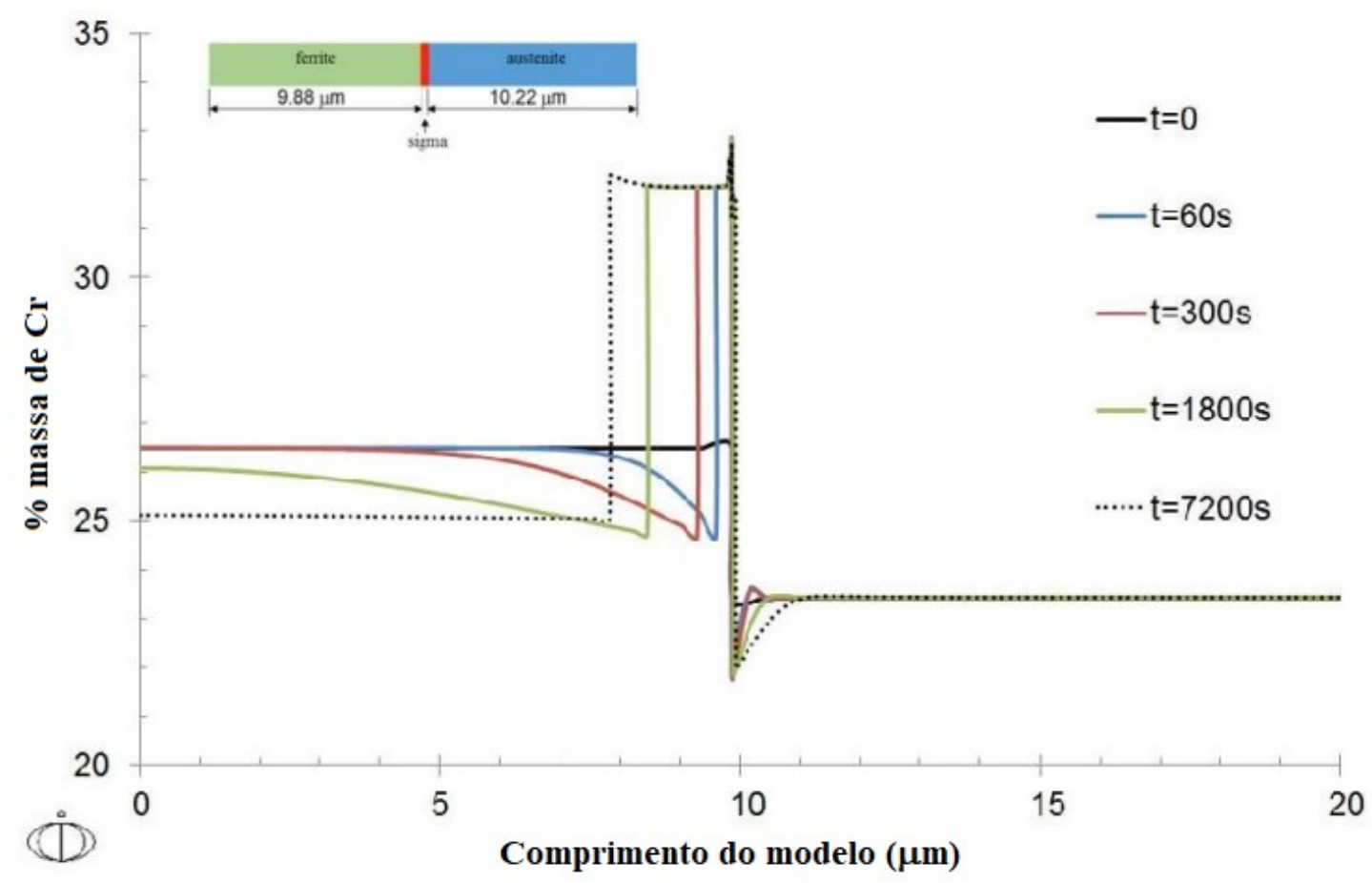

Fonte: Autora "adaptado de" Magnabosco, 2015, fig. 4

O DICTRA ${ }^{\circledR}$ também é capaz de avaliar a cinética de formação de fases, isto é, a fração volumétrica que se pode atingir em função do tempo de tratamento térmico sob influência de certa temperatura. Magnabosco (2015) realizou a simulação computacional da cinética de formação da fase sigma para o aço dúplex UNS S31803 e base de dados TCFE8, na temperatura de envelhecimento de $950{ }^{\circ} \mathrm{C}$, para dois modelos de simulação que representam a fase sigma entre ferrita e austenita, variando apenas o comprimento das fases, e para um terceiro modelo representando a fase sigma à esquerda da ferrita e austenita, conforme Figura 29. Nota-se que nenhum dos modelos estudados se mostraram capazes de descrever corretamente os resultados experimentais da evolução da fração de sigma a $950{ }^{\circ} \mathrm{C}$. 
Figura 29 - Fração volumétrica de sigma em função do tempo a $950^{\circ} \mathrm{C}$ do aço UNS S31803

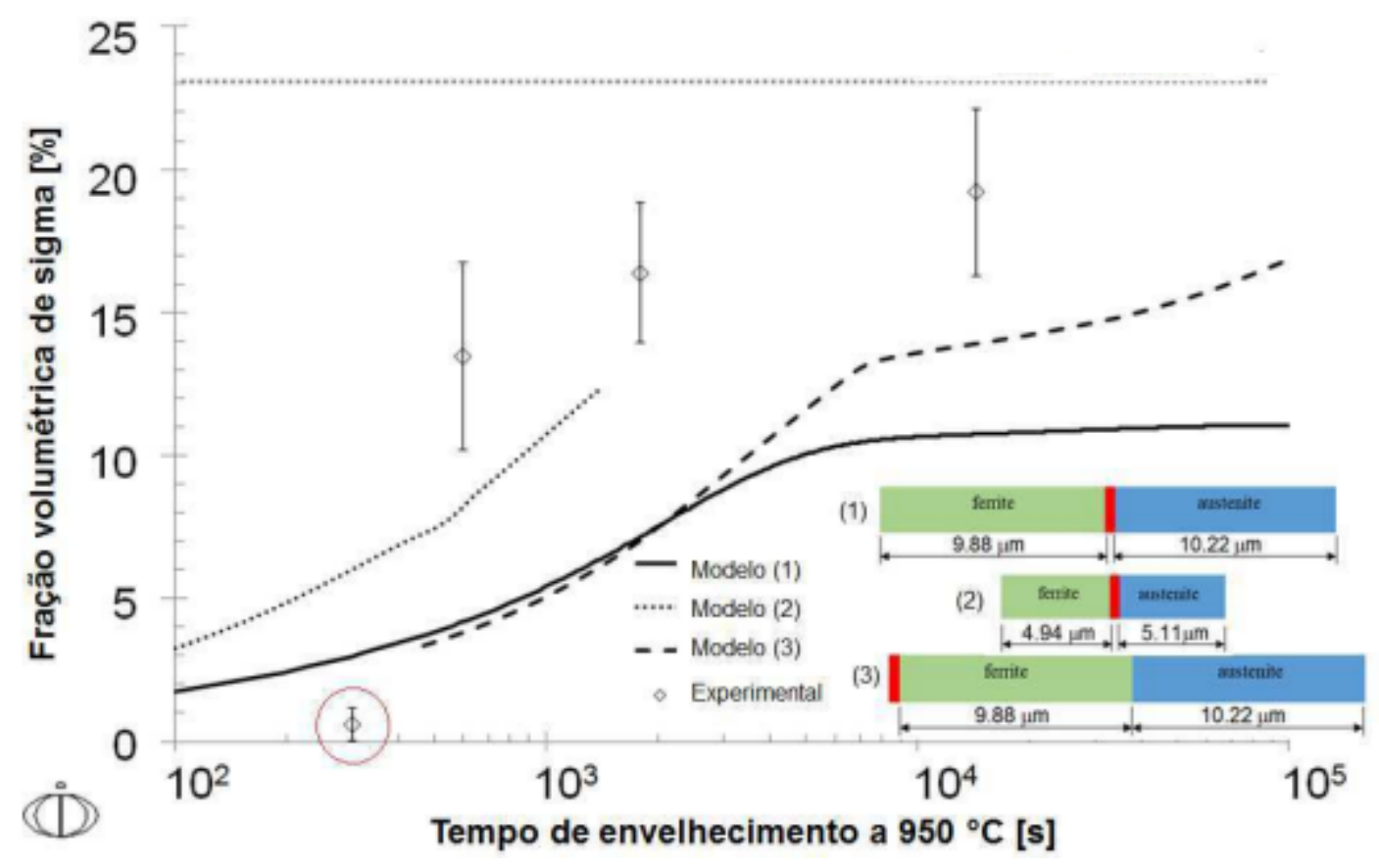

Fonte: Morais, 2015

Ainda buscando avaliar o comportamento de formação de sigma, Morais e Magnabosco (2017) propuseram outros dois modelos de simulação, um em que há fase sigma inativa entre a interface ferrita/austenita para que o DICTRA ${ }^{\circledR}$ calcule o momento que haverá potencial químico para o surgimento da fase deletéria (chamado de modelo 1), e outro com fase sigma já ativa crescendo próxima a fase ferrítica e permitindo que os elementos de liga particionem entre as fases ao longo do tempo (chamado de modelo 2), ambos a uma temperatura de envelhecimento de $940^{\circ} \mathrm{C}$, susceptível a precipitação de sigma.

Dos resultados obtidos pelos autores, tem-se como exemplo os perfis de molibdênio ao longo do tempo, na Figura 30 para o modelo 1 e na Figura 31 para o modelo 2. O perfil de Mo obtido para o modelo 1 mostra qualitativamente o empobrecimento do elemento nas regiões próximas a sigma nos estágios iniciais da transformação, enquanto que o modelo 2 mostra que o principal mecanismo após 3600s é a partição de elemento entre as fases (Morais e Magnabosco, 2017). 
Figura 30 - Perfil de Mo em função do tempo a $940^{\circ} \mathrm{C}$ para o modelo 1 do aço UNS S31803

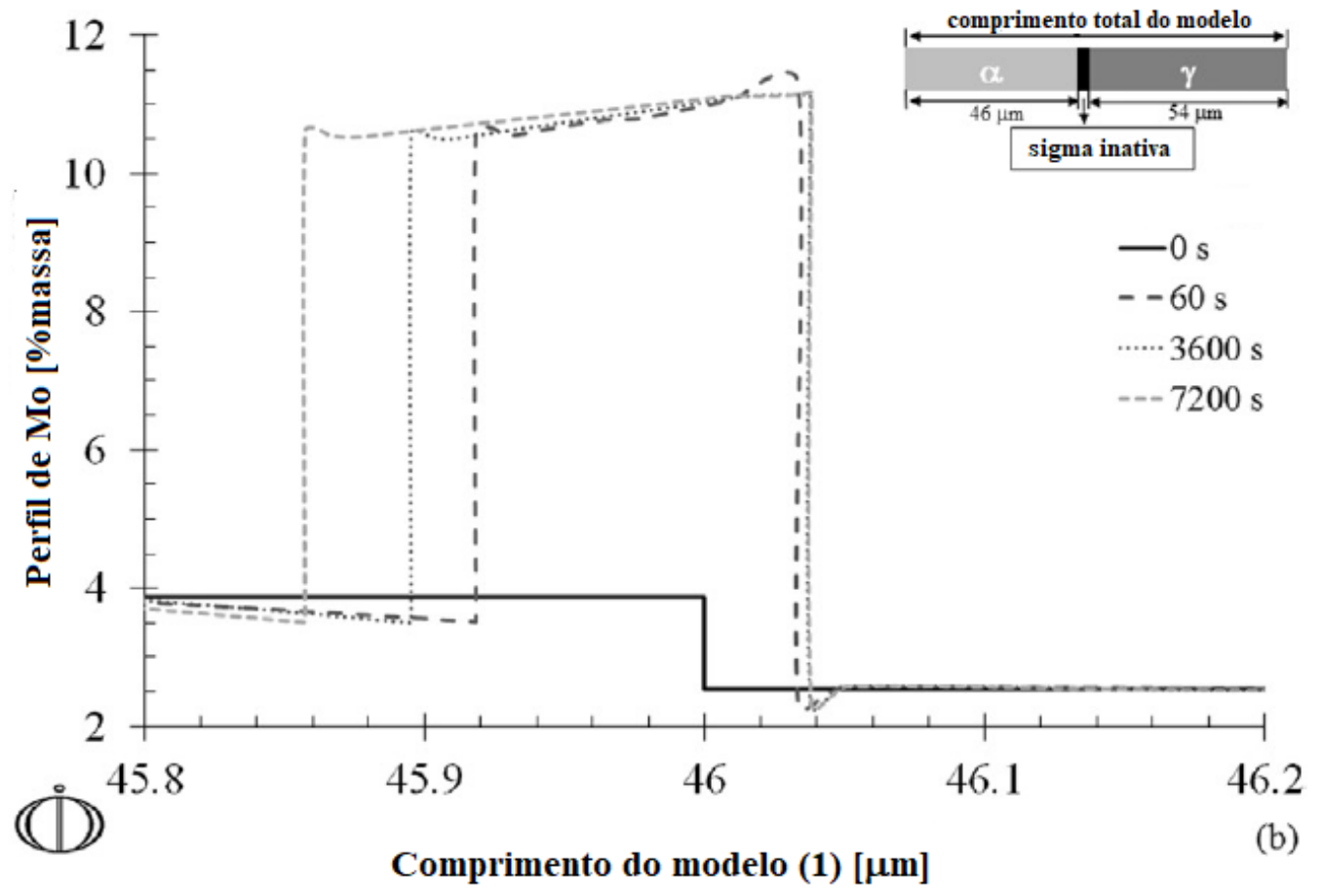

Fonte: Autora "adaptado de" Morais e Magnabosco, 2017, p. 217

Figura 31 - Perfil de Mo em função do tempo a $940^{\circ} \mathrm{C}$ para o modelo 2 do aço UNS S31803

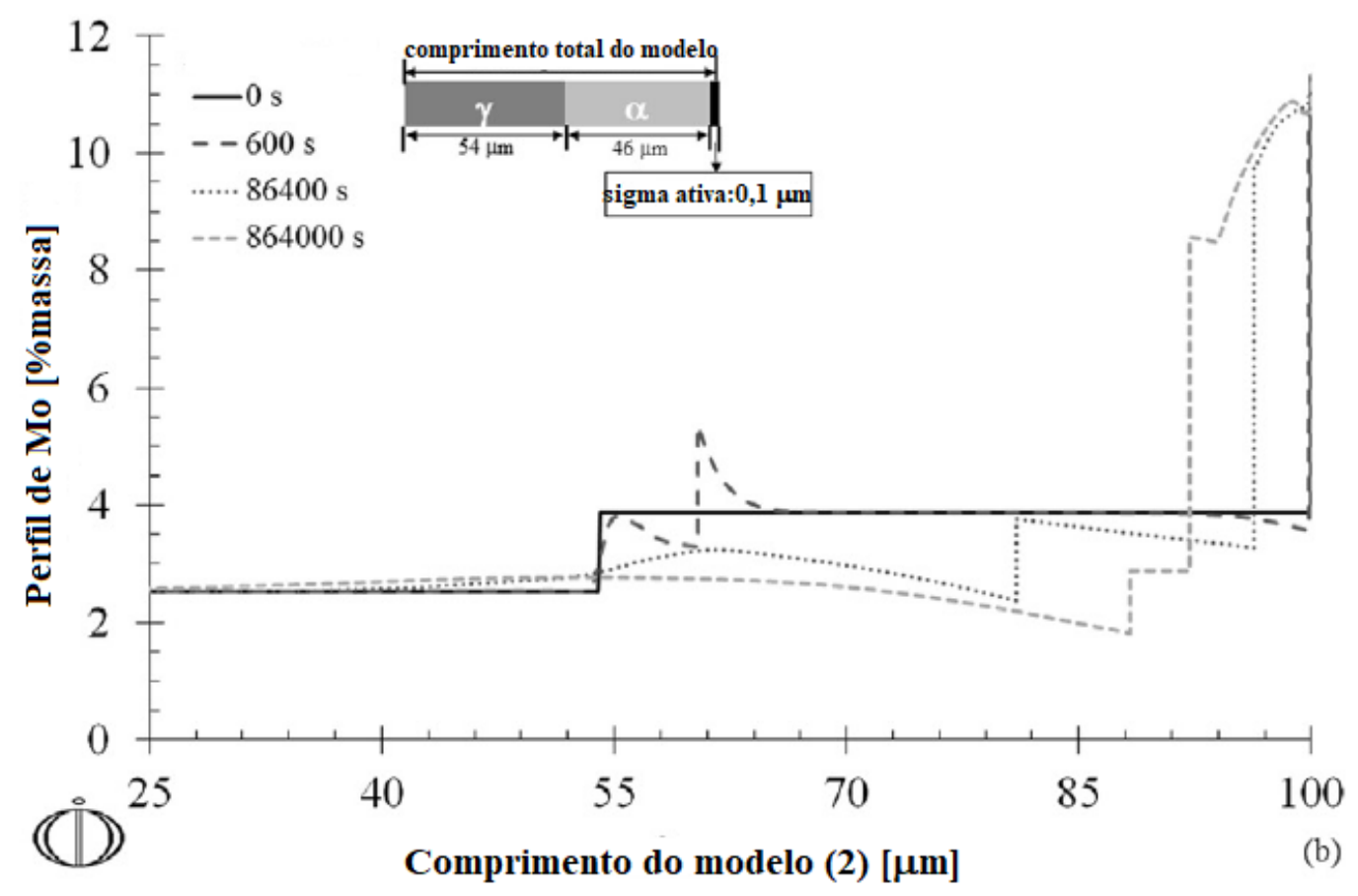

Fonte: Autora “adaptado de” Morais e Magnabosco, 2017, p. 127 
Dando sequência, Morais e Magnabosco (2017) realizaram a simulação computacional da cinética de envelhecimento do aço dúplex UNS S31808 a $940{ }^{\circ} \mathrm{C}$, para os dois modelos de fases já discutidos, cujo modelo 1 representa a fase sigma entre as fases ferrita e austenita, enquanto que o modelo 2 é dado pela fase sigma à direita das fases ferrita e austenita, utilizandose as bases de dados TCFE8 e MOB2. A Figura 32 mostra a evolução da fração volumétrica de sigma para cada modelo de simulação somado aos resultados experimentais reproduzidos em laboratório, permitindo a comparação entre si. A fração máxima de sigma obtida na simulação do modelo 1 equivale a 1,32\% após $100 \mathrm{~h}$ de tratamento térmico e 7,89\% após $240 \mathrm{~h}$ para o modelo 2. Nota-se que apenas a fração volumétrica de sigma obtida no modelo 1 mostrou aderência aos resultados experimentais até $2 \mathrm{~h}$ de simulação, indicando a incapacidade deste modelo na descrição dos estágios finais da formação do sigma (MORAIS; MAGNABOSCO, 2017). Além disso, observa-se a necessidade de tempos longos para que haja precipitação de sigma no aço dúplex a $940{ }^{\circ} \mathrm{C}$. Contudo, o modelo 1 é o ideal para detectar os instantes iniciais da formação de sigma, preponderantes nos ciclos de aquecimento e resfriamento, dada a maior aderência aos resultados iniciais de início de formação de sigma.

Figura 32 - Fração volumétrica de sigma em função do tempo a $940^{\circ} \mathrm{C}$ do aço UNS S31803

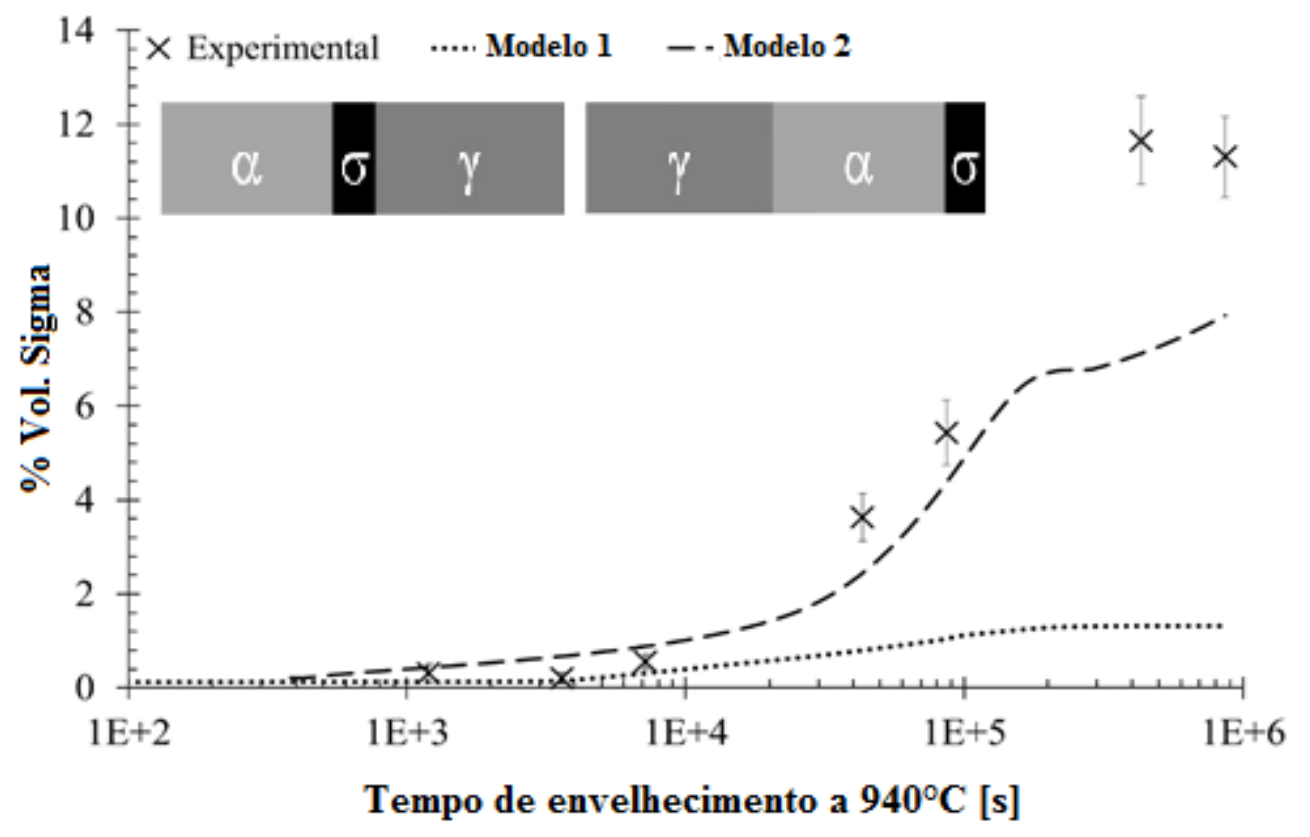

Fonte: Autora “adaptado de" Morais e Magnabosco, 2017, p. 217 
Do mesmo grupo de pesquisa, Magnabosco, Morais e Santos (2019), utilizaram da simulação do DICTRA ${ }^{\circledR}$ para avaliar o potencial de pite que o aço dúplex UNS S31803 possui, baseado na diminuição de $\mathrm{Cr}$ e Mo de áreas próximas as interfaces sigma/ferrita e sigma/austenita, utilizando-se de um modelo de fases que assume geometria esférica de austenita cercada por ferrita. Como exemplo de resultado, tem-se o perfil de Mo na Figura 33 e a evolução de sigma na Figura 34, ambos em função do tempo a $800^{\circ} \mathrm{C}$.

Tanto na interface sigma/ferrita quanto na interface sigma/austenita, houve empobrecimento de Mo, dada pela formação de sigma, o qual pode ser visto no perfil de composição. Além disso, obteve-se experimentalmente a fração de sigma formada no sistema, a qual foi comparada a fração simulada em DICTRA ${ }^{\circledR}$, mostrando que o modelo é capaz de descrever os resultados laboratoriais.

Figura 33 - Perfil de Mo em função do tempo a $800^{\circ} \mathrm{C}$

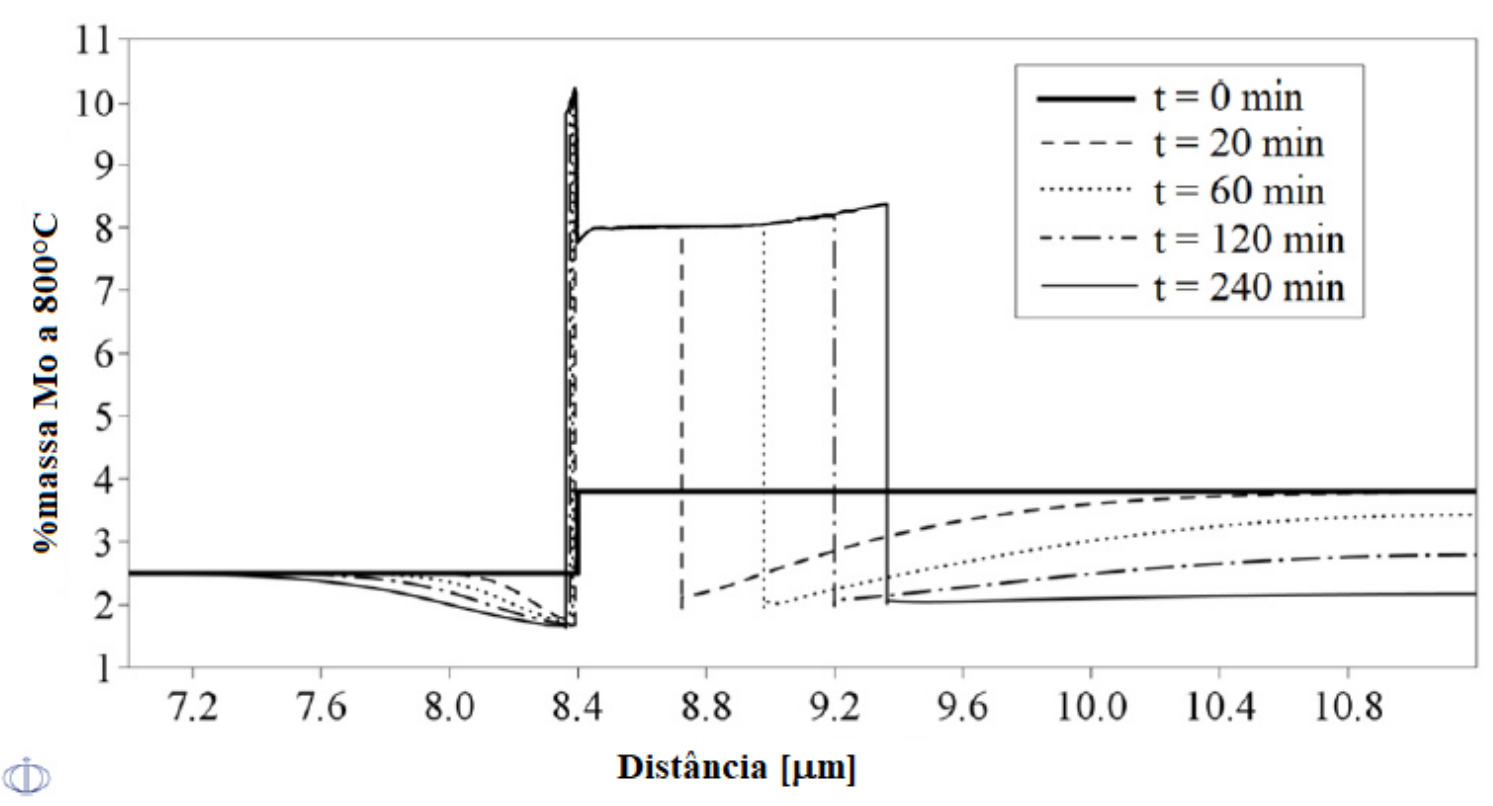

Fonte: Autora “adaptado de” Magnabosco, Morais e Santos (2019) 
Figura 34 - Fração volumétrica de sigma em função do tempo a $800^{\circ} \mathrm{C}$

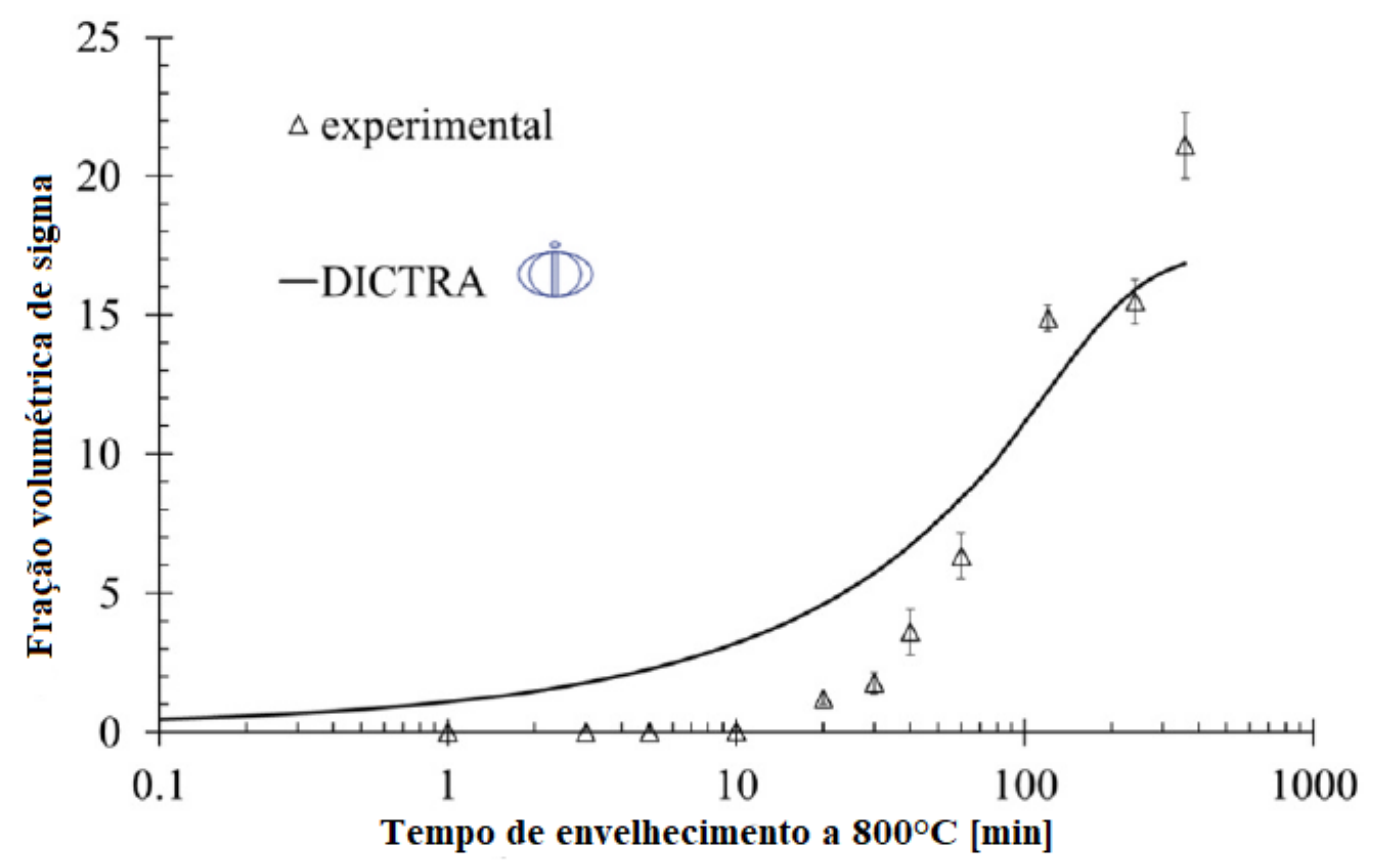

Fonte: Autora “adaptado de” Magnabosco, Morais e Santos (2019), p. 128

Nota-se que a maioria dos trabalhos expostos atentam-se na fração de sigma formada em tratamentos isotérmicos, uma vez que é a fase deletéria de maior fração volumétrica que pode precipitar nos aços inoxidáveis e, portanto, merece atenção. Entretanto, quando o objetivo é a manutenção da condição dúplex deste aço, a avaliação da evolução da ferrita e austenita também são valiosas e pouco encontradas na literatura, sendo a principal motivação desta dissertação.

Em trabalho anterior a este, Magnabosco e Fiorante (2019) avaliaram a evolução de ferrita ao longo do tempo do aço superdúplex UNS S32750 na temperatura típica de forjamento de $1250{ }^{\circ} \mathrm{C}$, conforme mostra a Figura 35, para um modelo de fases de ferrita e austenita. Notase que a curva obtida segue o formato sigmoidal de acordo com a equação de KJMA, partindose da condição microestrutural dúplex, com 50\% de ferrita (e 50\% de austenita) e atingindo-se fração máxima de 70\% de ferrita (e 30\% de austenita) após $1000 \mathrm{~s}$ (16 min) de tratamento térmico. 
Figura 35 - Fração volumétrica de ferrita a $1250^{\circ} \mathrm{C}$ com base de dados TCFE8 e MOBFE3

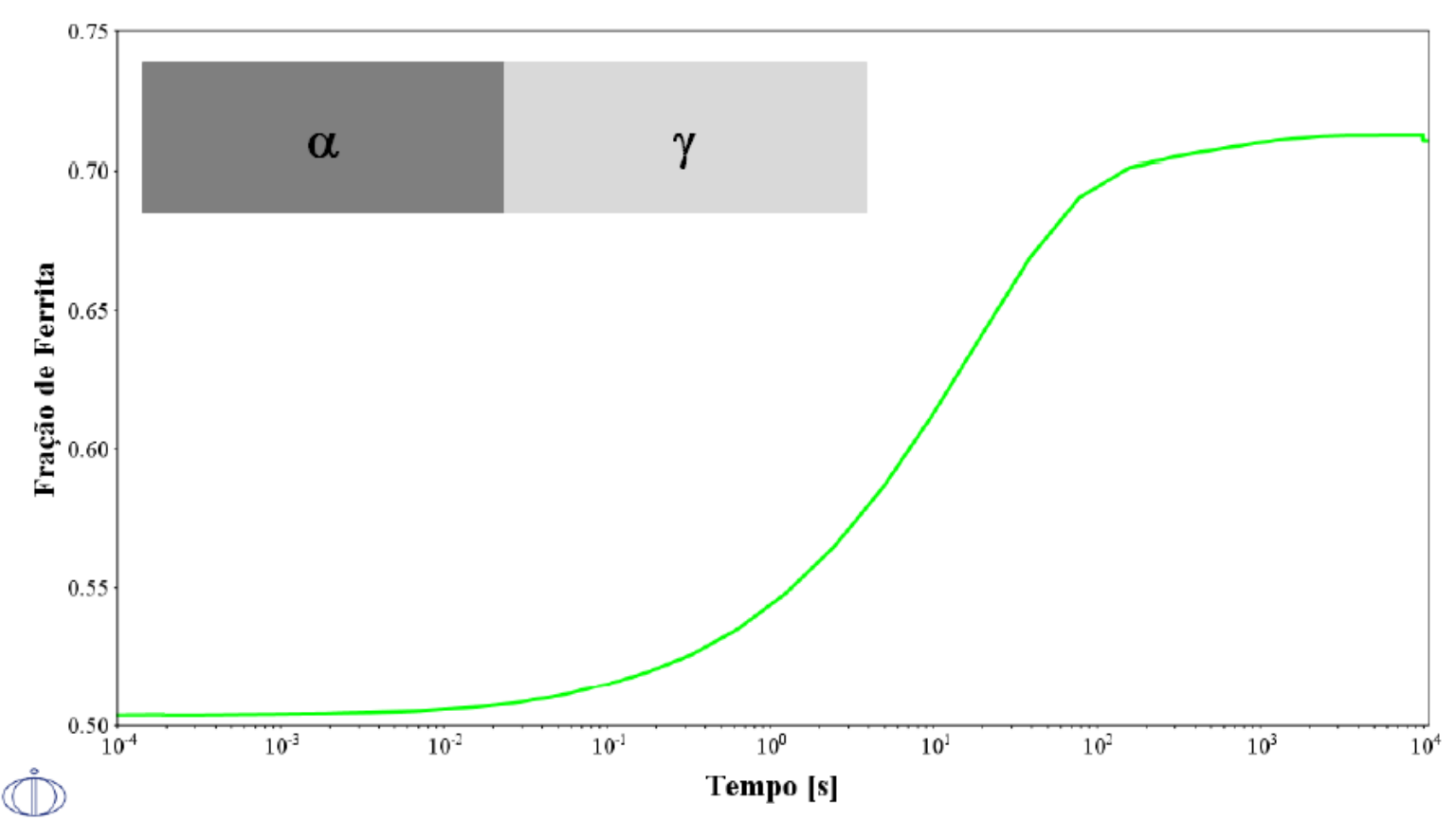

Fonte: Magnabosco e Fiorante, 2019

Através do diagrama de equilíbrio simulado para o aço em questão por Magnabosco e Fiorante (2019), exposto na Figura 5, nota-se que a temperatura de solubilização necessária para se recuperar o equilíbrio entre ferrita e austenita, de $50 \%$ de cada fase, é de $1088{ }^{\circ} \mathrm{C}$. Portanto, ao simular a evolução da austenita nesta temperatura com o DICTRA ${ }^{\circledR}$, vide Figura 36, além de recuperar o equilíbrio termodinâmico, determina-se o tempo necessário para que isto aconteça, sendo possível verificar que a estabilização da fase austenítica somente ocorre após $20000 \mathrm{~s}(5,5 \mathrm{~h})$ de tratamento térmico. 
Figura 36 - Fração volumétrica de austenita a $1088^{\circ} \mathrm{C}$

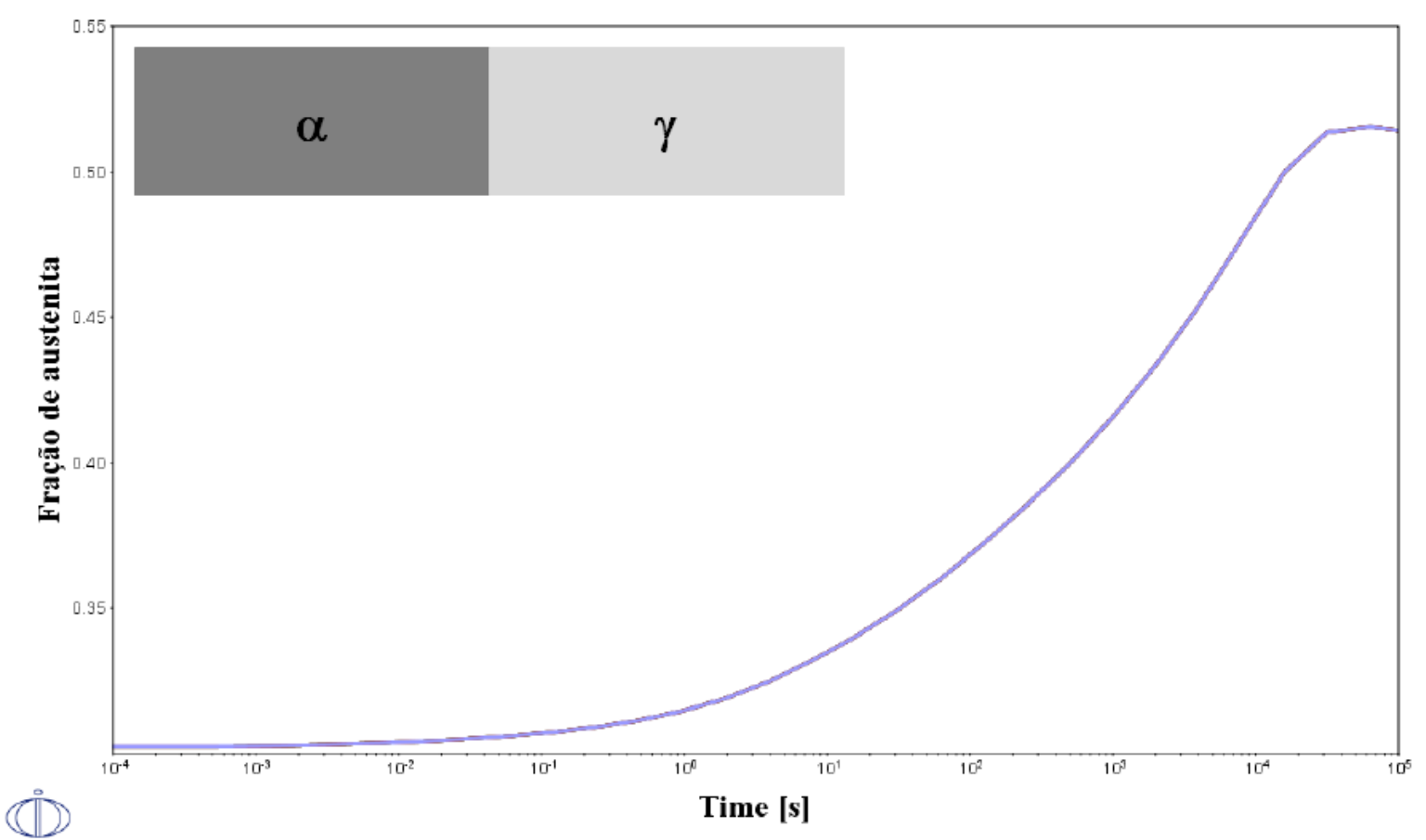

Fonte: Magnabosco e Fiorante, 2019

Nota-se que não há simulações na literatura descrevendo as transformações de fases que ocorrem no aquecimento e resfriamento dos aços inoxidáveis dúplex e superdúplex durante o processo produtivo, tampouco que considerem o efeito das taxas envolvidas, uma vez que a obtenção de curvas TRC (Transformação sob Resfriamento Contínuo) exige o levantamento de parâmetros de aquecimento e/ou resfriamento altamente precisos, e para tanto, dever-se-ia garantir que toda extensão da peça sofra variação temperatura de maneira contínua e homogênea.

Por isso, o DICTRA ${ }^{\circledR}$ mostra-se a melhor alternativa para prever as transformações de fases durante o tratamento térmico contínuo, pois além de possuir uma vasta base de dados termodinâmica e cinética, permite a quantificação de fases formadas sob as condições de taxas de aquecimento e resfriamento e, portanto, é a principal contribuição desta dissertação. 


\section{METODOLOGIA}

A seguir será apresentada a metodologia empregada nas simulações computacionais do equilíbrio e das transformações de fases do aço UNS S32750 por meio dos softwares ThermoCalc $^{\circledR}$ e DICTRA $^{\circledR}$.

\subsection{MATERIAL}

O aço inoxidável superdúplex em estudo, UNS S32750, foi fornecido pela Villares Metals como uma barra de $82 \mathrm{~mm}$ de diâmetro e $3 \mathrm{~m}$ de comprimento, laminada a quente, solubilizada a $1120{ }^{\circ} \mathrm{C}$ por 1 h e 30 min e resfriada em água, cuja composição química $(\%$ em massa) está apresentada na Tabela 8 .

Tabela 8 - Composição química do aço superdúplex UNS S32750 de análise química realizada pela Villares Metals

\begin{tabular}{cccccccccc}
\hline $\mathrm{Cr}$ & $\mathrm{Ni}$ & $\mathrm{Mo}$ & $\mathrm{N}$ & $\mathrm{Mn}$ & $\mathrm{Si}$ & $\mathrm{Cu}$ & $\mathrm{W}$ & $\mathrm{C}$ & $\mathrm{Fe}$ \\
\hline 25,17 & 6,88 & 3,61 & 0,25 & 0,60 & 0,40 & 0,58 & 0,69 & 0,01 & Bal. \\
\hline
\end{tabular}

Fonte: Autora

\subsection{SIMULAÇÃO DE EQUILÍBRIO}

A primeira etapa de simulação computacional consiste em obter o equilíbrio termodinâmico das fases em função da temperatura, por meio do software Thermo-Calc ${ }^{\circledR}$, utilizando-se a base de dados termodinâmica TCFE9. Com isso, é possível determinar não somente as faixas de temperaturas em que as fases desejadas e deletérias aparecem no sistema, como também a temperatura de solubilização correspondente a condição dúplex de $50 \%$ de ferrita e 50\% de austenita, além da composição química destas fases a $1250{ }^{\circ} \mathrm{C}$.

Os parâmetros de entrada para a simulação em Thermo-Calc ${ }^{\circledR}$ foram a composição química do aço superdúplex UNS S32750, base de dados TCFE9 e faixa de temperatura de 600 ${ }^{\circ} \mathrm{C}$ a $1600{ }^{\circ} \mathrm{C}$ para cálculo do equilíbrio. Como Magnabosco e Fiorante (2019) verificaram em trabalho anterior que o uso da composição química reduzida é mais vantajoso por trazer resultados muito semelhantes aos da simulação com composição completa, e ainda levar menos tempo para executar a simulação, foi utilizada nesta dissertação a composição química reduzida, considerando-se a presença apenas de $\mathrm{Fe}, \mathrm{Cr}, \mathrm{Ni}$, Mo e N. 
A segunda etapa de simulação computacional foi feita por meio do software DICTRA ${ }^{\circledR}$ e consiste em obter a cinética de transformação de fases e a evolução da ferrita, austenita, nitretos de cromo e sigma que o aço superdúplex sofre durante os ciclos térmicos de processamento, incluindo as etapas de aquecimento e resfriamento a diferentes taxas como mostra o esquema da Figura 37. Os parâmetros inicialmente utilizados para a simulação

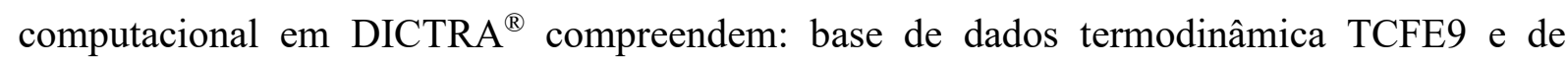
mobilidade atômica MOBFE4, tempo inicial e final, geometria planar, largura inicial de $20 \mu \mathrm{m}$ tanto para a ferrita quanto para a austenita, composição química dos elementos constante em tais fases determinadas na simulação de Thermo-Calc ${ }^{\circledR}$ na temperatura de solubilização que garante $50 \%$ em volume de cada fase, e número de pontos de cálculo dentro de cada fase igual a 50. Em seguida, selecionou-se o perfil térmico não-isotérmico inserindo as faixas de tempo e temperatura para simular as taxas de aquecimento e resfriamento. A simulação de cada etapa do trabalho a quente levou aproximadamente 20 min para ser completada, utilizando-se um computador com processador do tipo Intel® CoreTM i7-4770 CPU @ 3.40 GHz e 8 núcleos.

O esquema da Figura 37 é dividido em 6 partes correspondentes ao ciclo térmico real de processamento, partes estas que serão explanadas a seguir.

Figura 37 - Modelo esquemático das transformações de fases que serão simuladas

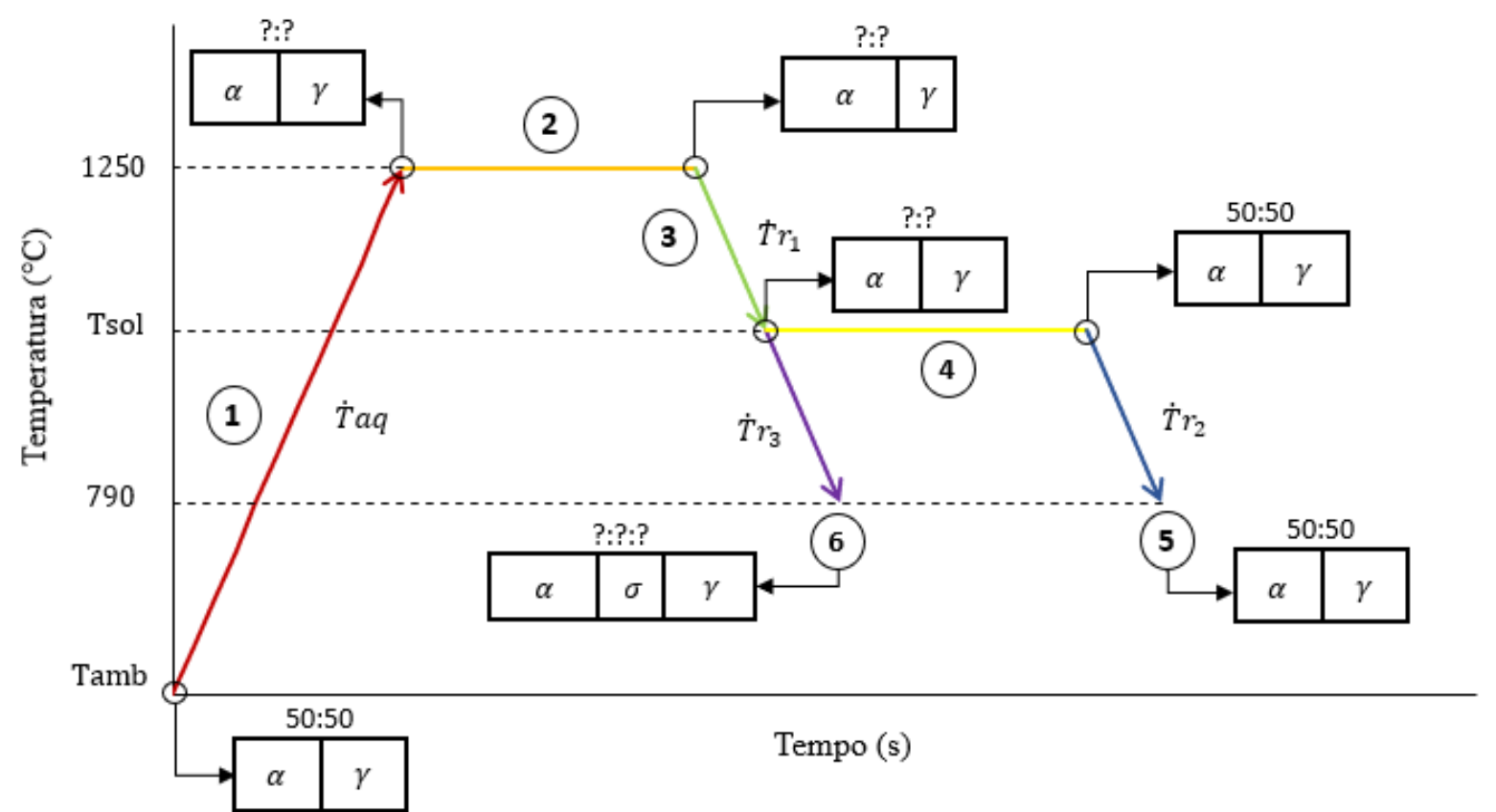

Fonte: Autora 


\subsubsection{Descrição do trecho 1}

O trecho 1 da Figura 37 (indicado pela seta vermelha) corresponde ao aquecimento do aço superdúplex para ser conformado plasticamente, que parte da temperatura ambiente e condição microestrutural de $50 \%$ de cada fase até a temperatura típica de trabalho a quente, de $1250{ }^{\circ} \mathrm{C}$, atingindo-se uma fração volumétrica de fases desconhecida e que deve ser determinada pela simulação, bem como o perfil de composição química das fases ao longo do modelo. Os parâmetros utilizados seguem descritos na Tabela 9, com as composições químicas de ferrita e austenita obtidas do diagrama de equilíbrio simulado em Thermocalc ${ }^{\circledR}$ e com comprimento inicial das fases de $20 \mu \mathrm{m}$, baseado nos resultados obtidos por Magnabosco e Fiorante (2019) e que representam o balanço de $50 \%$ de cada fase.

Tabela 9 - Parâmetros utilizados para simulação do trecho 1

\begin{tabular}{cc}
\hline Bases de dados & TCFE9 / MOBFE4 \\
\hline Comprimento inicial da ferrita & $20 \mu \mathrm{m}$ \\
\hline Comprimento inicial da austenita & $20 \mu \mathrm{m}$ \\
\hline Perfil térmico & $\mathrm{Não}-$ isotérmico \\
\hline Composição da ferrita & $\mathrm{Fe}-26.826 \% \mathrm{Cr}-4,422 \% \mathrm{Mo}-5,223 \% \mathrm{Ni}-$ \\
& $0,039 \% \mathrm{~N}$ \\
\hline Composição da austenita & $\mathrm{Fe}-23.518 \% \mathrm{Cr}-2,801 \% \mathrm{Mo}-8,533 \% \mathrm{Ni}-$ \\
& $0,461 \% \mathrm{~N}$ \\
\hline
\end{tabular}

Fonte: Autora

\subsubsection{Descrição do trecho 2}

O trecho 2 (indicado pela reta laranja), corresponde ao tempo de patamar necessário para se realizar o trabalho a quente bem como para que se atinja as frações de equilíbrio a $1250^{\circ} \mathrm{C}$, considerando-se as frações de fases e composições químicas ao final do tempo de tratamento térmico do trecho 1 . Os parâmetros utilizados seguem descritos na Tabela 10, com comprimento inicial de ferrita e austenita proporcionais à frações obtidas na simulação do trecho em questão, visto que $20 \mu \mathrm{m}$ corresponde a $50 \%$ de ferrita, por exemplo, então o novo comprimento desta fase corresponderia à fração final atingida ao final do trecho 2 . 
Tabela 10 - Parâmetros utilizados para simulação do trecho 2

\begin{tabular}{cc}
\hline Bases de dados & TCFE9 / MOBFE4 \\
\hline Comprimento inicial da ferrita & $26,8 \mu \mathrm{m}$ \\
\hline Comprimento inicial da austenita & $13,2 \mu \mathrm{m}$ \\
\hline Perfil térmico & Isotérmico \\
\hline Composição da ferrita & Tabela 19, Apêndice I \\
\hline Composição da austenita & Tabela 19, Apêndice I \\
\hline
\end{tabular}

Fonte: Autora

\subsubsection{Descrição do trecho 3}

Depois da simulação do trabalho a quente na temperatura estimada de $1250{ }^{\circ} \mathrm{C}$, tornase necessário recuperar a condição microestrutural dúplex de $50 \%$ de cada fase e, para tanto, deve-se realizar um tratamento térmico na temperatura de solubilização, Tsol. Antes do tratamento térmico em si, o ciclo térmico de processamento conta com o resfriamento do aço de $1250{ }^{\circ} \mathrm{C}$ até a temperatura de solubilização, conforme mostra o trecho 3 (indicado pela seta verde) da Figura 37.

Desta forma, simulou-se o trecho 3 à diferentes taxas de resfriamento até que se encontre a ideal, nomeada de $\operatorname{Tr}_{1}$, considerando as frações de fase e perfis de composição química obtidos ao final da etapa 2. Os parâmetros utilizados seguem descritos na Tabela 11.

Tabela 11 - Parâmetros utilizados para simulação do trecho 3

\begin{tabular}{cc}
\hline Bases de dados & TCFE9 / MOBFE4 \\
\hline Comprimento inicial da ferrita & $28,5 \mu \mathrm{m}$ \\
\hline Comprimento inicial da austenita & $11,5 \mu \mathrm{m}$ \\
\hline Perfil térmico & Não-isotérmico \\
\hline Composição da ferrita & Tabela 20, Apêndice I \\
\hline Composição da austenita & Tabela 20, Apêndice I \\
\hline
\end{tabular}

Fonte: Autora 


\subsubsection{Descrição do trecho 4}

Sabendo-se que a fração de equilíbrio não será atingida imediatamente ao chegar em Tsol, torna-se necessário realizar o tratamento térmico de solubilização para recuperar a estrutura dúplex desejada. Desta forma, simulou-se o menor tempo de patamar capaz de recuperar as frações volumétricas de $50 \%$ de cada fase, realizando-se a simulação do trecho 4 (indicado na reta amarela) da Figura 37. Para tanto, deve-se utilizar as funções matemáticas que descrevem a composição química do final do trecho 3. Os parâmetros utilizados seguem descritos na Tabela 12.

Tabela 12 - Parâmetros utilizados para simulação do trecho 4

\begin{tabular}{cc}
\hline Bases de dados & TCFE9 / MOBFE4 \\
\hline Comprimento inicial da ferrita & $22,3 \mu \mathrm{m}$ \\
\hline Comprimento inicial da austenita & $17,7 \mu \mathrm{m}$ \\
\hline Perfil térmico & Isotérmico \\
\hline Composição da ferrita & Tabela 21, Apêndice I \\
\hline Composição da austenita & Tabela 21, Apêndice I \\
\hline
\end{tabular}

Fonte: Autora

\subsubsection{Descrição do trecho 5}

Assim que o sistema atinge a fração de 50\% de ferrita e 50\% de austenita ao final do trecho 4, deve-se realizar um resfriamento a uma determinada taxa, $\operatorname{Tr}_{2}$, até $790^{\circ} \mathrm{C}$, temperatura na qual a cinética no TTP é lenta o suficiente pra não ocorrer transformações de fase, mantendo a microestrutura dúplex metaestável conforme discutido no item 2.3, constituindo-se o trecho 5 (indicado pela seta azul) da Figura 37. Levando em conta que fases indesejáveis como a sigma poderiam precipitar no resfriamento do trecho 5 , considerou-se sigma inativa na interface à direita da ferrita, o que significa que para um tempo $\mathrm{t}=0$ a mesma não está presente na simulação. Além disso, como há possibilidade de precipitação de sigma na interface ferrita/austenita, removeu-se o $\mathrm{N}$ da composição química das fases, pois as bases de dados não definem $\mathrm{N}$ como elemento constituinte da fase sigma.

Utilizando as funções matemáticas que descrevem a composição química ao final do trecho 4, simulou-se diferentes taxas de resfriamento até encontrar a crítica, isto é, a taxa em 
que há alguma fração de sigma formada, como pode ser visto no item 4. Os parâmetros utilizados para a simulação do trecho em questão seguem descritos na Tabela 13.

Tabela 13 - Parâmetros utilizados para simulação do trecho 5

\begin{tabular}{cc}
\hline Bases de dados & TCFE9 / MOBFE4 \\
\hline Comprimento inicial da ferrita & $22,2 \mu \mathrm{m}$ \\
\hline Comprimento inicial da austenita & $17,8 \mu \mathrm{m}$ \\
\hline Perfil térmico & Não-isotérmico \\
\hline Composição da ferrita & Tabela 22, Apêndice I \\
\hline Composição da austenita & Tabela 22, Apêndice I
\end{tabular}

Fonte: Autora

\subsubsection{Descrição do trecho 6}

Semelhante ao trecho 5, o mesmo resfriamento pode ser feito ao final do trecho 3 , isto é, assim que se atinge a temperatura de solubilização, Tsol, sem levar em consideração o tempo de patamar e a uma taxa, $\operatorname{Tr}_{3}$, como mostra o trecho 6 (indicado pela seta roxa) da Figura 37, podendo levar a formação de fases indesejáveis como a sigma, também a frações volumétricas ainda desconhecidas. Neste caso, também simulou-se inicialmente as taxas em que aparecem a fase sigma, obtendo-se a taxa necessária para evitar o surgimento desta fase.

Tabela 14 - Parâmetros utilizados para simulação do trecho 6

\begin{tabular}{cc}
\hline Bases de dados & TCFE9 / MOBFE4 \\
\hline Comprimento inicial da ferrita & $23,5 \mu \mathrm{m}$ \\
\hline Comprimento inicial da austenita & $16,5 \mu \mathrm{m}$ \\
\hline Perfil térmico & Não-isotérmico \\
\hline Composição da ferrita & Tabela 21, Apêndice I \\
\hline Composição da austenita & Tabela 21, Apêndice I \\
\hline
\end{tabular}




\section{RESULTADOS E DISCUSSÃO}

Utilizando-se a composição química reduzida, isto é, apenas os principais elementos de interesse da Tabela 8, Fe-Cr-Ni-Mo-N, obteve-se a simulação de equilíbrio do aço UNS S32750 entre $600{ }^{\circ} \mathrm{C}$ e $1300{ }^{\circ} \mathrm{C}$, exposta na Figura 38, com base de dados TCFE9 do Thermo-Calc ${ }^{\circledR}$. Percebe-se que a condição para haver apenas ferrita e austenita ocorre entre $1050{ }^{\circ} \mathrm{C}$ e $1300{ }^{\circ} \mathrm{C}$, com fração de ferrita aumentando com a temperatura e atingindo-se o balanço de $50 \%$ de cada fase em $1090{ }^{\circ} \mathrm{C}$. A temperaturas inferiores a $1050{ }^{\circ} \mathrm{C}$ inicia-se a formação da fase sigma e abaixo de $950{ }^{\circ} \mathrm{C}$ precipitam nitretos de cromo, $\mathrm{Cr}_{2} \mathrm{~N}$ (HCP_A3\#2), em conformidade com o encontrado na literatura para aços superdúplex. Nota-se também, que na temperatura escolhida de $1250{ }^{\circ} \mathrm{C}$ para simular o trabalho a quente, estima-se atingir uma fração volumétrica de $70 \%$ de ferrita e $30 \%$ de austenita.

Figura 38 - Diagrama de equilíbrio do aço UNS S32750 com base de dados TCFE9

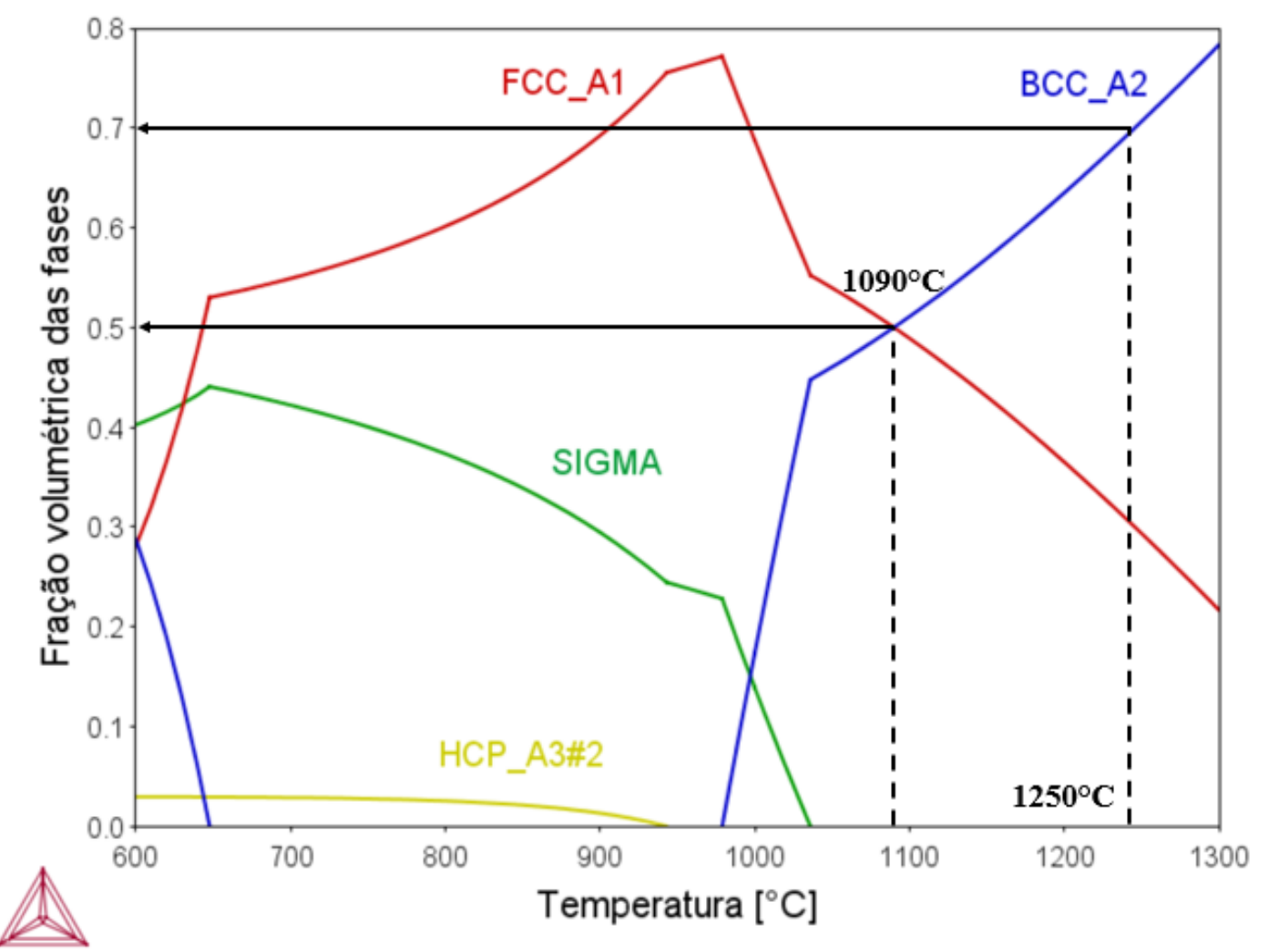

Fonte: Autora

Utilizando-se o software DICTRA ${ }^{\circledR}$, foi possível simular o ciclo térmico de processamento do aço superdúplex UNS S32750, isto é, de cada um dos 6 trechos apresentados no gráfico esquemático da Figura 37. 


\subsection{SIMULAÇÃO COMPUTACIONAL DO TRECHO 1}

Realizou-se a simulação computacional do trecho 1 (indicado pela seta vermelha da Figura 37), utilizando-se os parâmetros expostos na Tabela 9, que corresponde ao aquecimento do aço superdúplex para trabalho a quente, ou seja, da temperatura ambiente até $1250{ }^{\circ} \mathrm{C}$, considerando-se diversas taxas de aquecimento, de modo que a microestrutura parta de $50 \%$ de cada fase para uma fração ainda não determinada. Os resultados podem ser vistos na sequência, da Figura 39 a 46. Deve se destacar que o DICTRA ${ }^{\circledR}$ mostrou-se incapaz de simular o aquecimento a partir da temperatura ambiente, uma vez que são gerados erros de cálculos no software, por não existir ferrita e austenita com as composições e potenciais químicos de $\mathrm{Cr}$, Mo, Ni e $\mathrm{N}$ nesta duas fases em tais temperaturas, somente sendo possível simular a partir de $950{ }^{\circ} \mathrm{C}$, mostrando que há um problema de definição da base de dados. Portanto, assume-se que não há transformações de fases até $950{ }^{\circ} \mathrm{C}$ para as taxas de aquecimento simuladas. Os resultados, deste modo, contêm a fração volumétrica de ferrita formada em função do tempo em segundos (em azul) e a taxa de aquecimento utilizada (em vermelho) partindo-se de $950{ }^{\circ} \mathrm{C}$ até $1250^{\circ} \mathrm{C}$, nas taxas de aquecimento especificadas em cada figura.

Figura 39 - Fração de ferrita no aquecimento de $950^{\circ} \mathrm{C}$ até $1250^{\circ} \mathrm{C}$ (trecho 1 ) à taxa de $2{ }^{\circ} \mathrm{C} / \mathrm{s}$

Taxa de aquecimento: $2^{\circ} \mathrm{C} / \mathrm{s}$

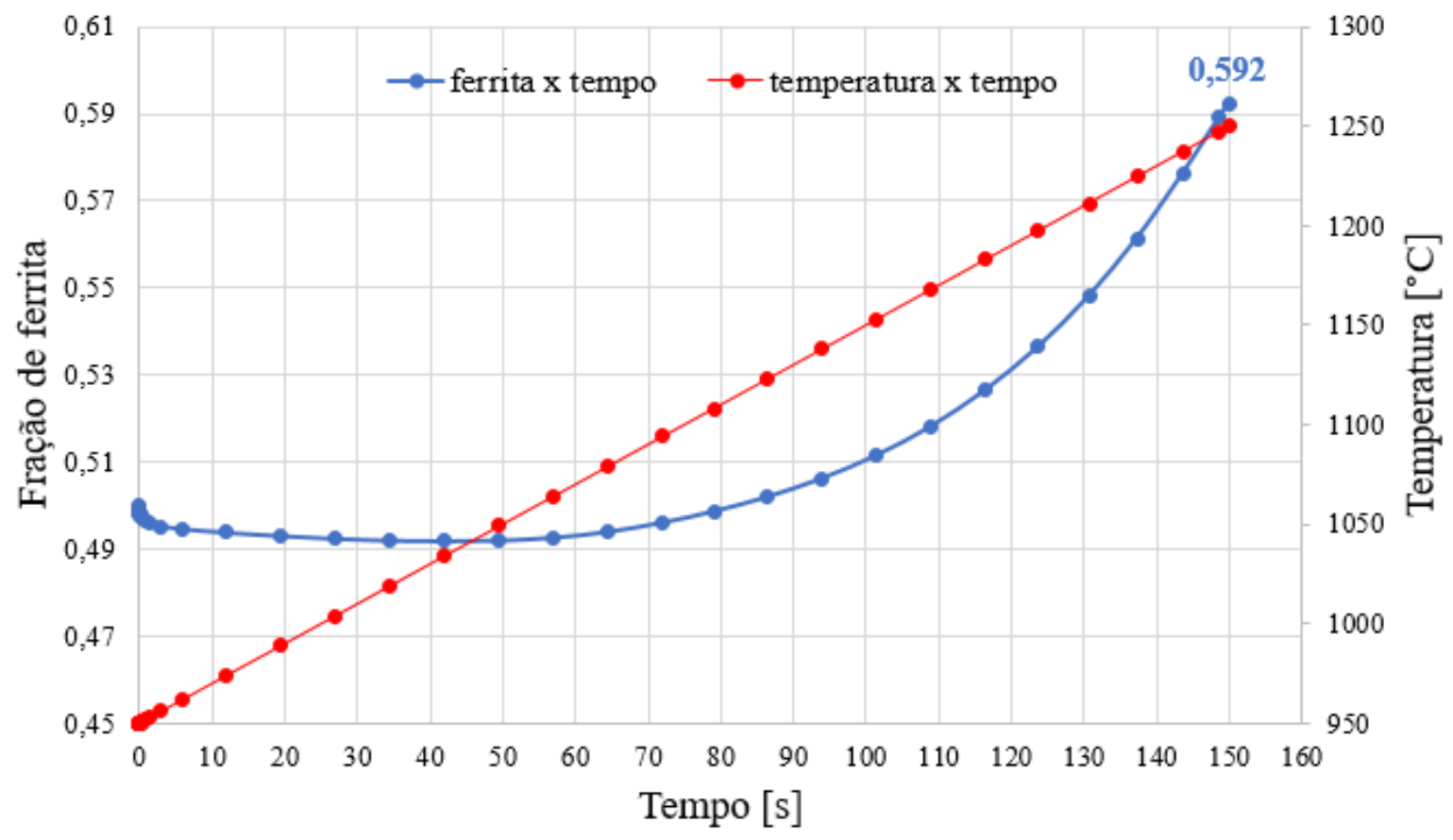

Fonte: Autora 
Figura 40 - Fração de ferrita no aquecimento de $950^{\circ} \mathrm{C}$ até $1250^{\circ} \mathrm{C}$ (trecho 1 ) à taxa de $1,2^{\circ} \mathrm{C} / \mathrm{s}$

Taxa de aquecimento: $1,2^{\circ} \mathrm{C} / \mathrm{s}$

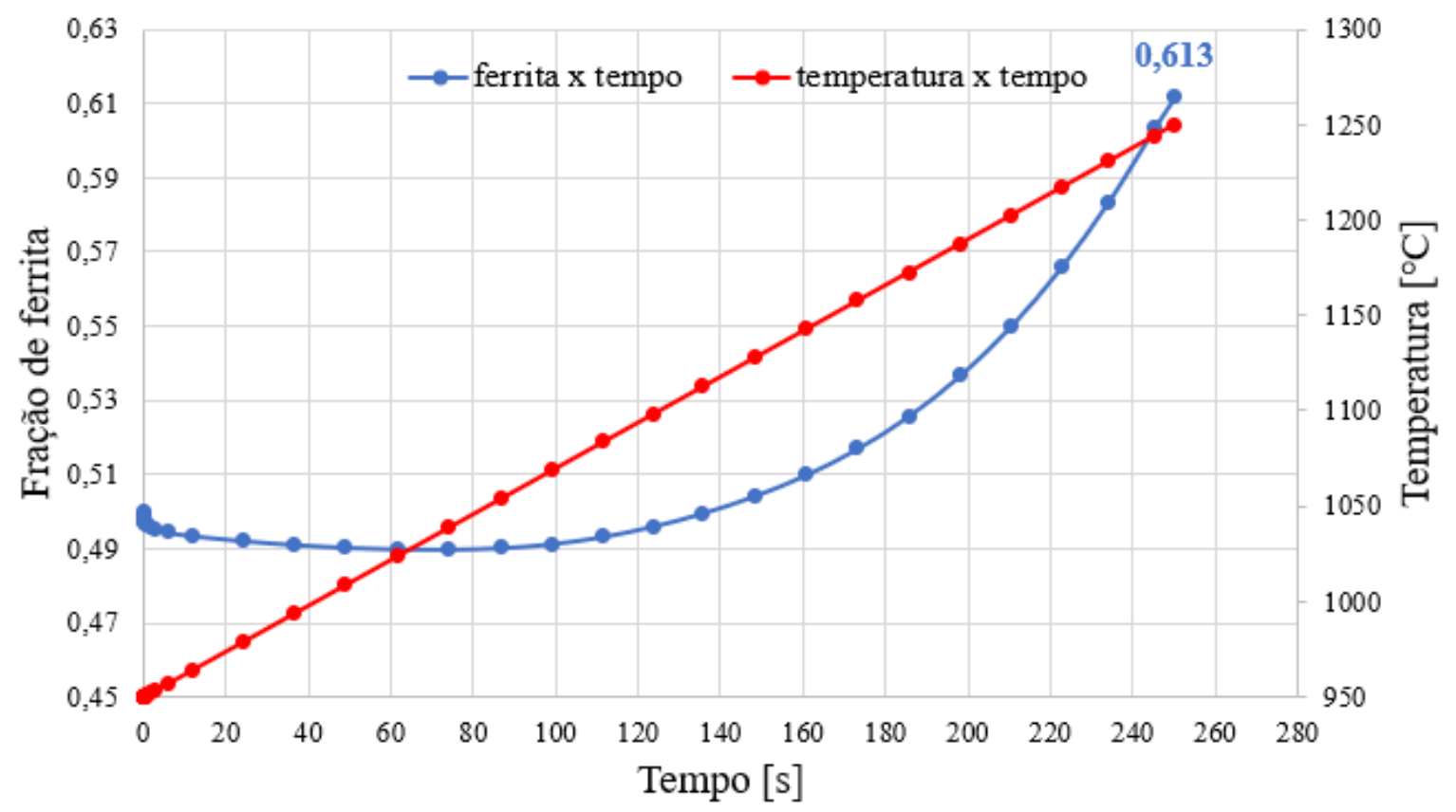

Fonte: Autora

Figura 41 - Fração de ferrita no aquecimento de $950^{\circ} \mathrm{C}$ até $1250^{\circ} \mathrm{C}$ (trecho 1 ) à taxa de $1,0^{\circ} \mathrm{C} / \mathrm{s}$

Taxa de aquecimento: $1^{\circ} \mathrm{C} / \mathrm{s}$

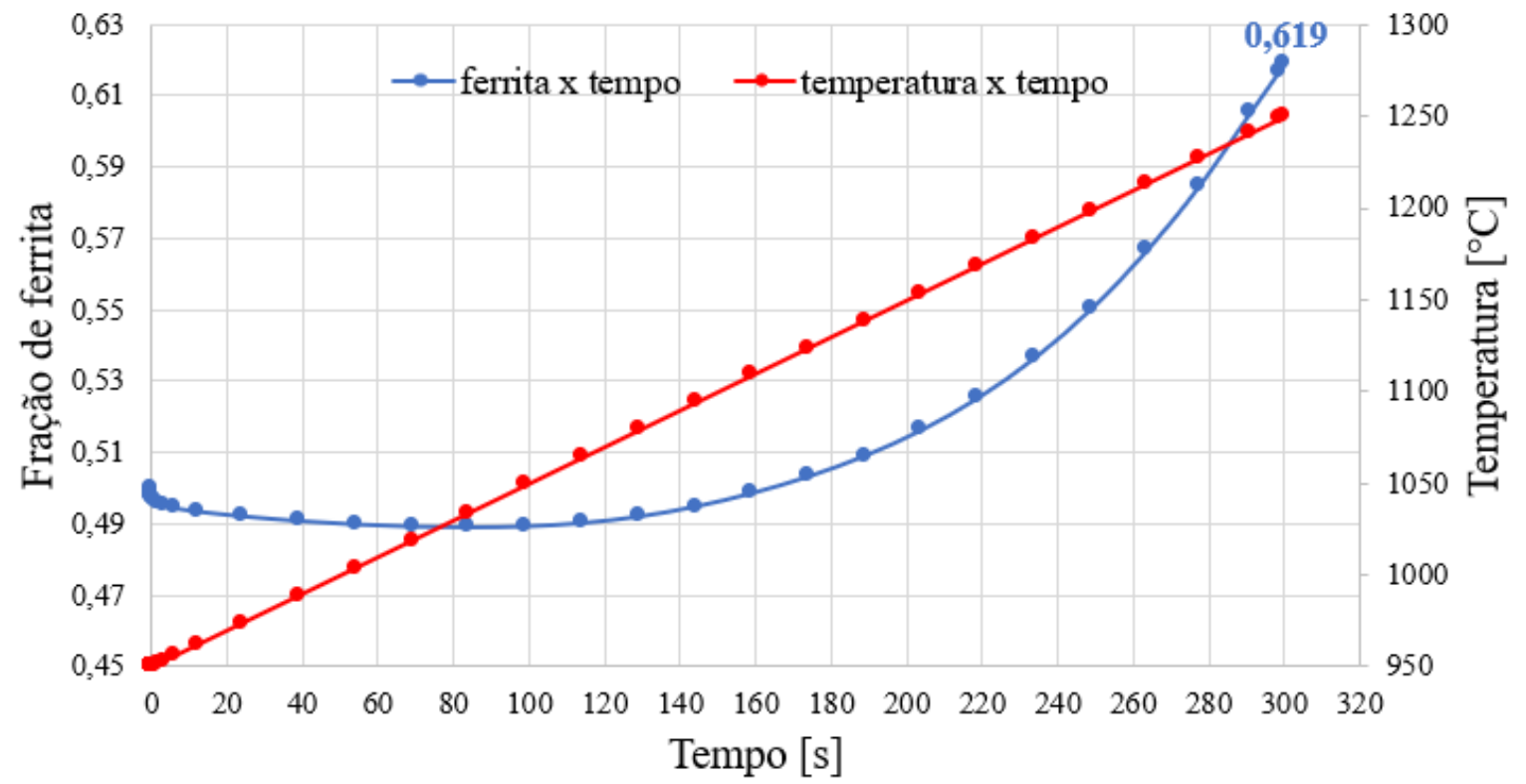

Fonte: Autora 
Figura 42 - Fração de ferrita no aquecimento de $950^{\circ} \mathrm{C}$ até $1250^{\circ} \mathrm{C}$ (trecho 1 ) à taxa de $0,86^{\circ} \mathrm{C} / \mathrm{s}$

Taxa de aquecimento: $0,86^{\circ} \mathrm{C} / \mathrm{s}$

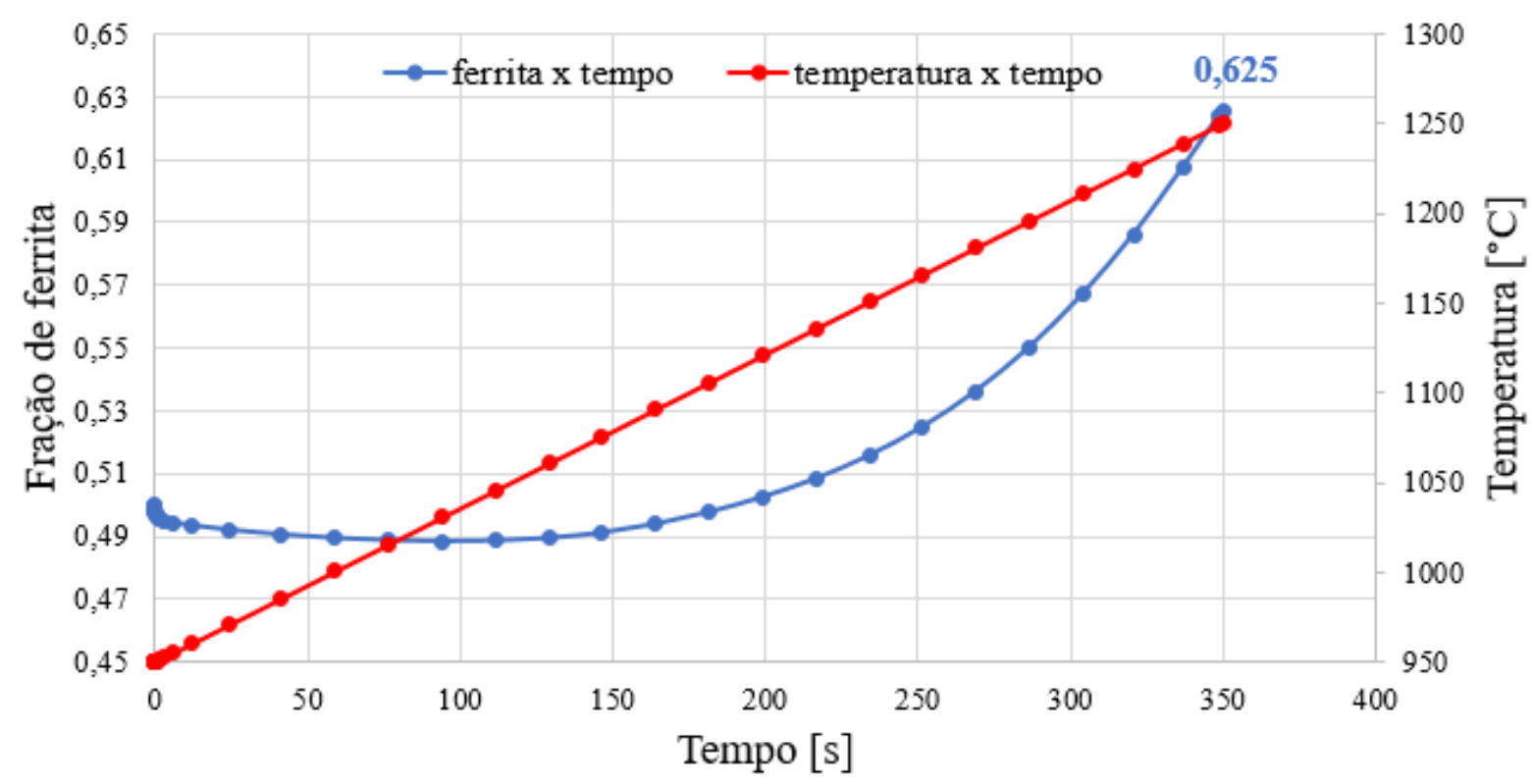

Fonte: Autora

Figura 43 - Fração de ferrita no aquecimento de $950^{\circ} \mathrm{C}$ até $1250^{\circ} \mathrm{C}$ (trecho 1 ) à taxa de $0,75^{\circ} \mathrm{C} / \mathrm{s}$

Taxa de aquecimento: $0,75^{\circ} \mathrm{C} / \mathrm{s}$

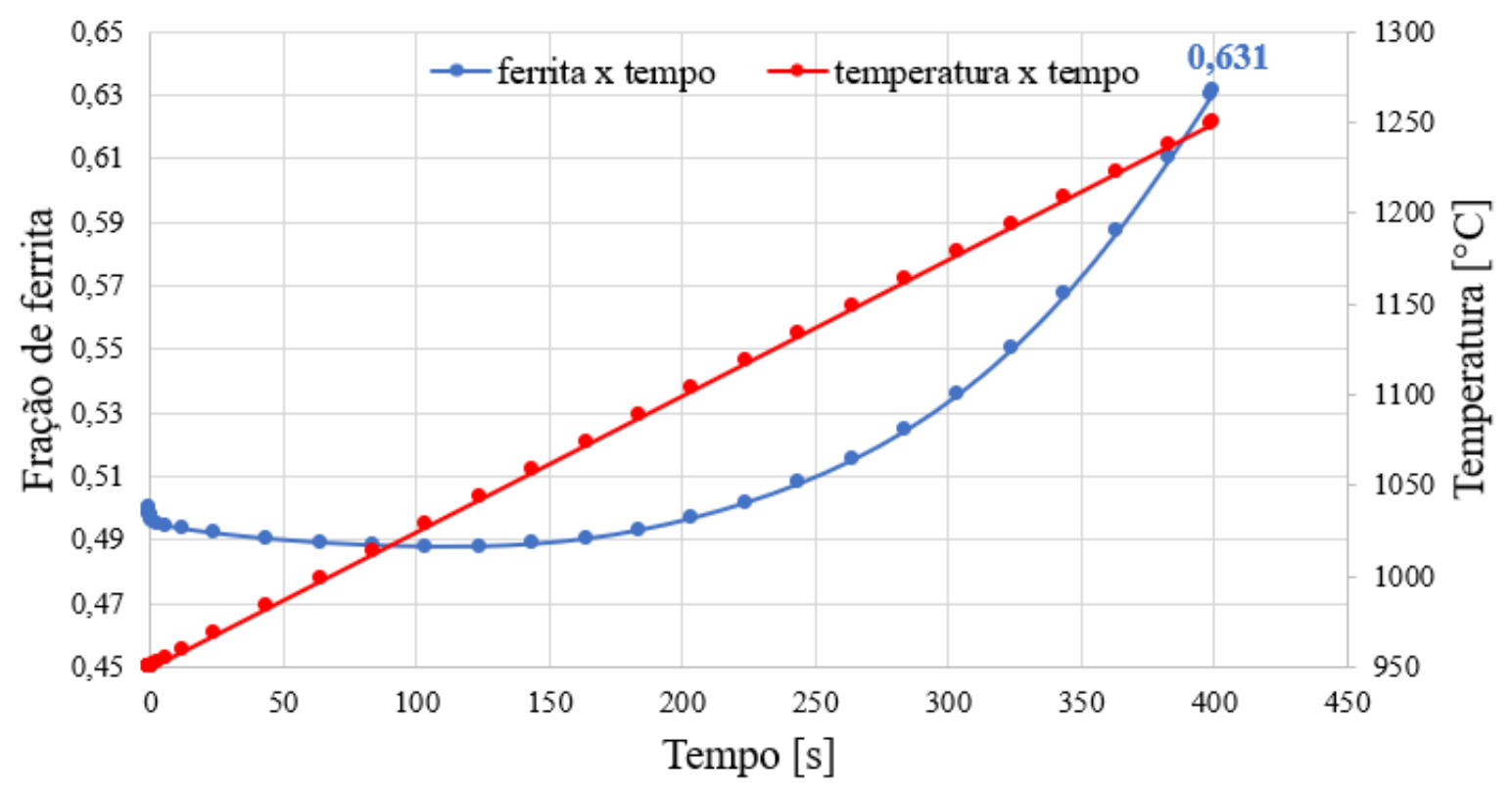

Fonte: Autora 
Figura 44 - Fração de ferrita no aquecimento de $950^{\circ} \mathrm{C}$ até $1250^{\circ} \mathrm{C}$ (trecho 1 ) à taxa de $0,50^{\circ} \mathrm{C} / \mathrm{s}$

Taxa de aquecimento: $0,5^{\circ} \mathrm{C} / \mathrm{s}$

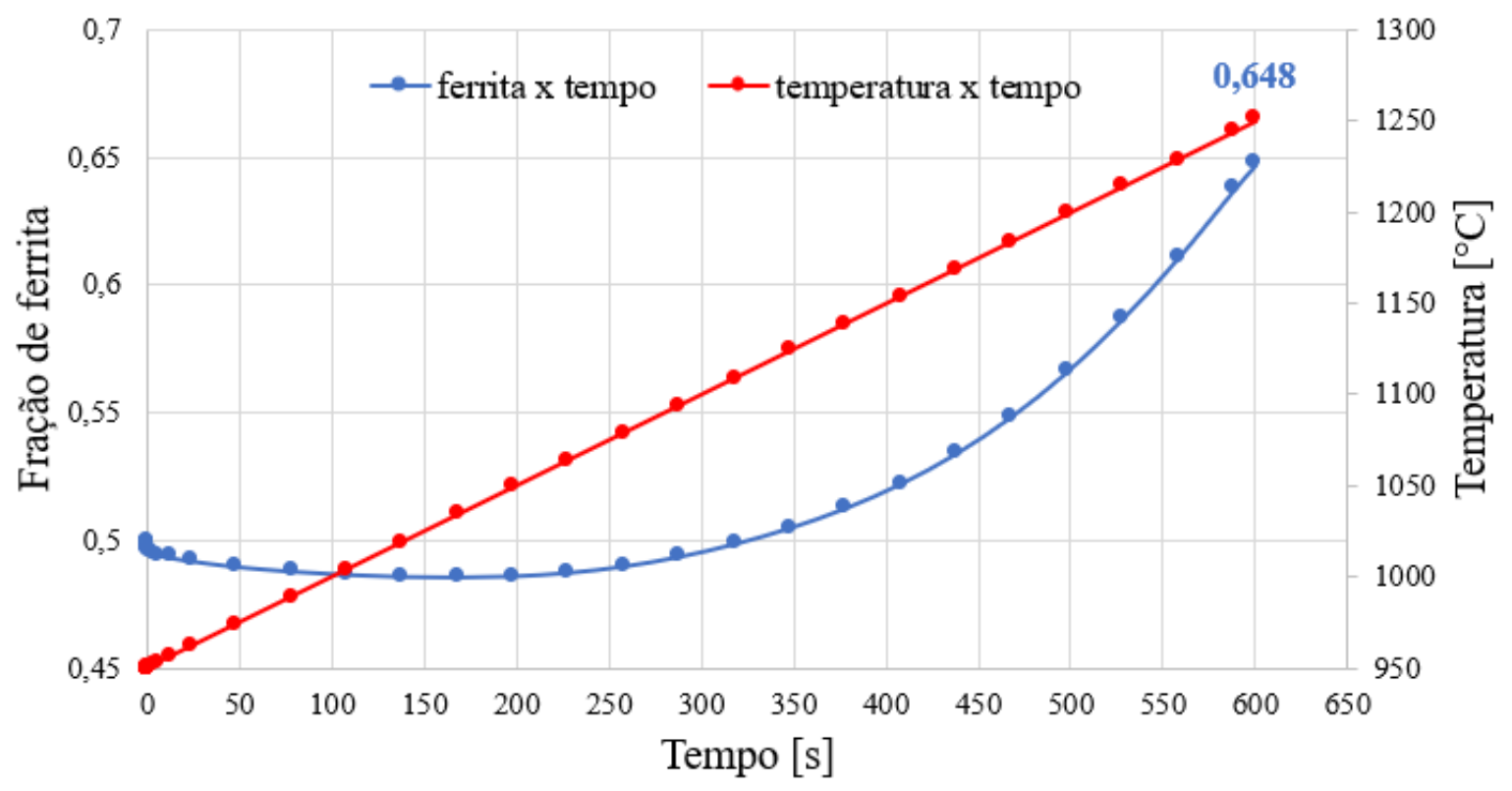

Fonte: Autora

Figura 45 - Fração de ferrita no aquecimento de $950^{\circ} \mathrm{C}$ até $1250^{\circ} \mathrm{C}$ (trecho 1 ) à taxa de $0,40^{\circ} \mathrm{C} / \mathrm{s}$

Taxa de aquecimento: $0,4^{\circ} \mathrm{C} / \mathrm{s}$

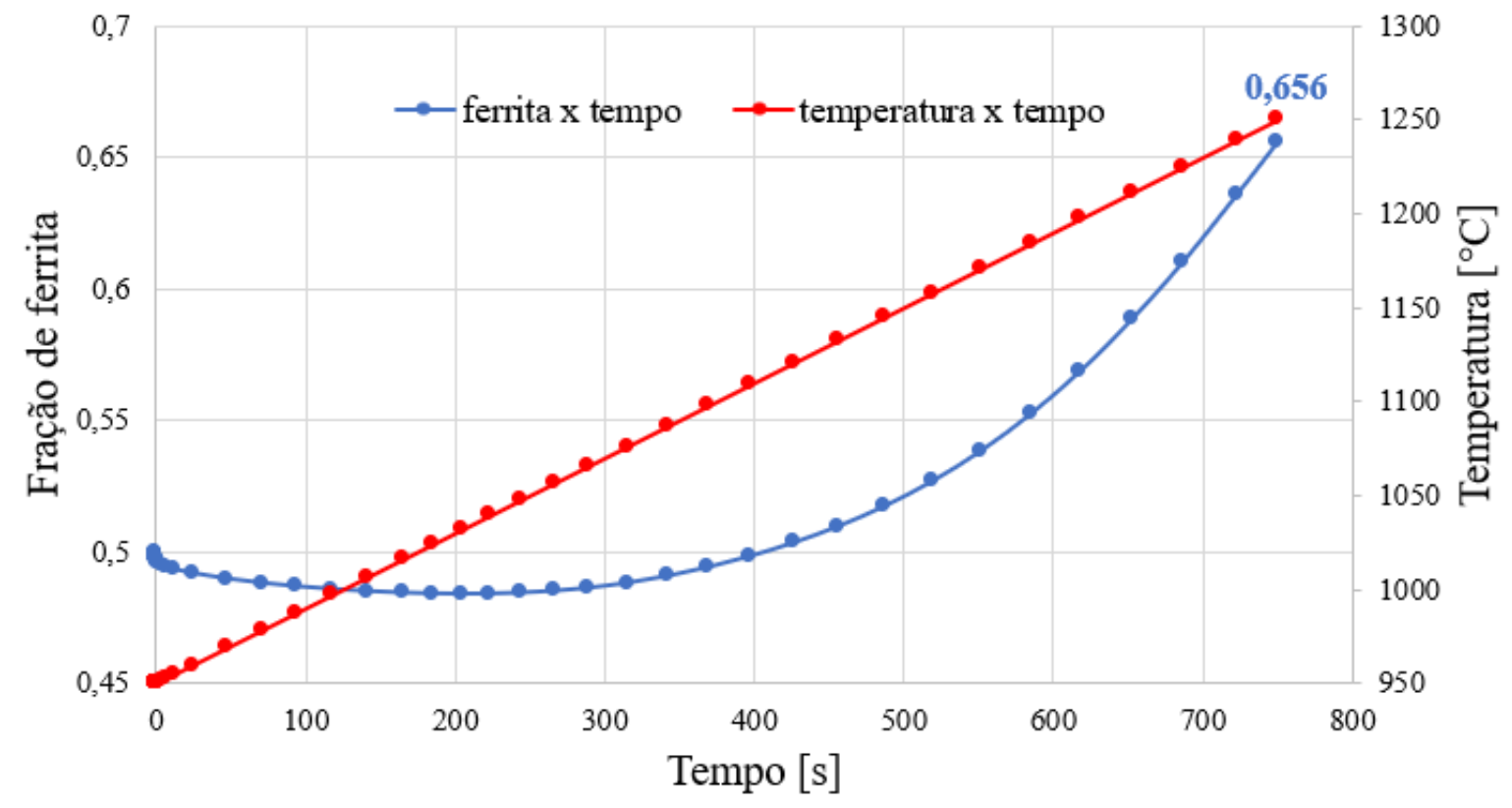

Fonte: Autora 
Figura 46 - Fração de ferrita no aquecimento de $950^{\circ} \mathrm{C}$ até $1250^{\circ} \mathrm{C}$ (trecho 1 ) à taxa de $0,30^{\circ} \mathrm{C} / \mathrm{s}$

Taxa de aquecimento: $0,30^{\circ} \mathrm{C} / \mathrm{s}$

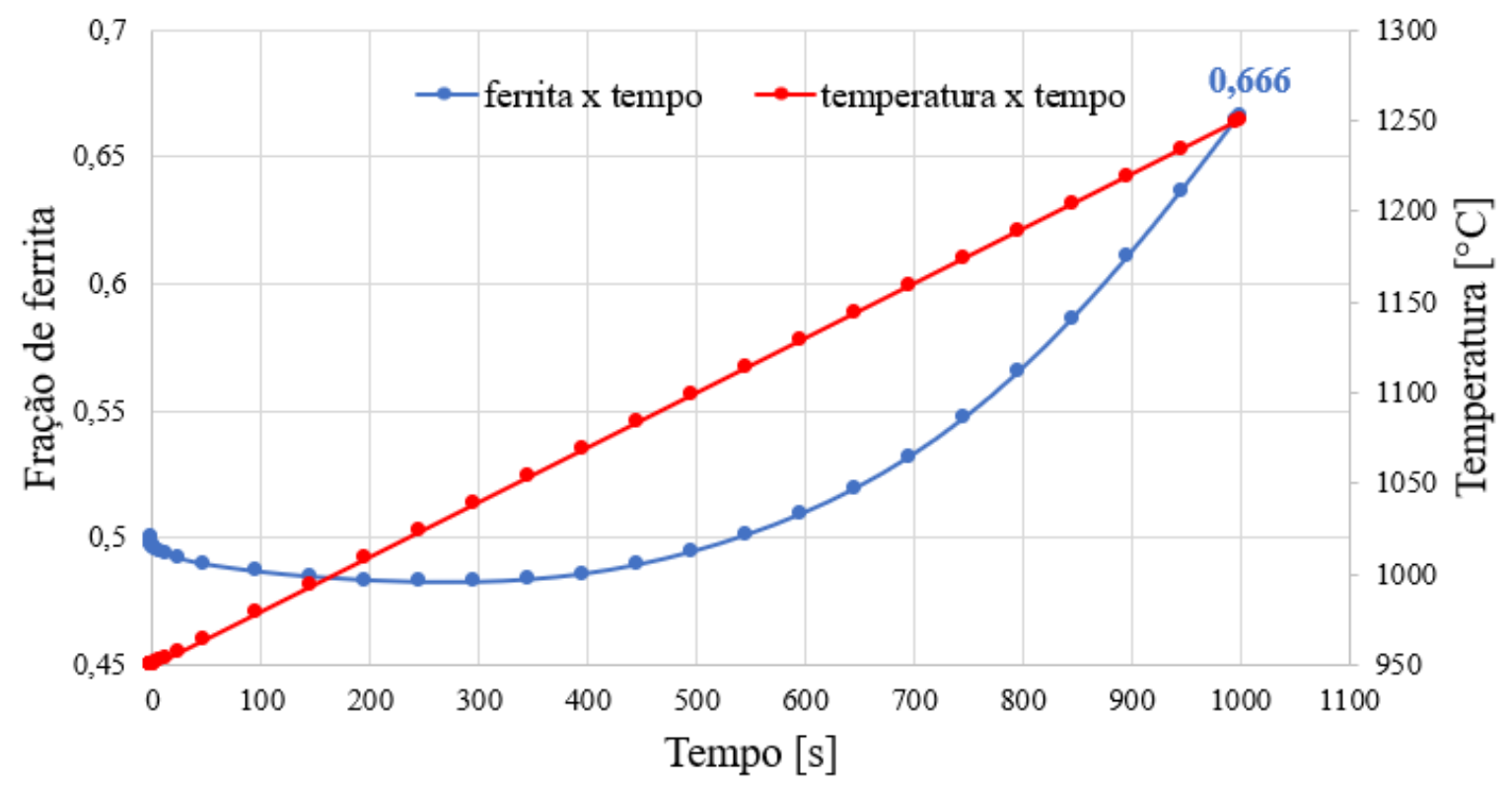

Fonte: Autora

A comparação entre as frações volumétricas de ferrita formada em função do tempo pode ser vista na Figura 47. Nota-se que em todos os casos, a fração de ferrita cai sutilmente no início do aquecimento, indicando que há redistribuição dos elementos entre a fase ferrítica e austenítica. As maiores taxas de aquecimento apresentam menor queda da fração de ferrita e, consequentemente, atinge-se o equilíbrio de fração máxima da fase em menor tempo.

Conforme diminui-se a taxa de aquecimento, maior é a fração de ferrita formada, uma vez que há mais tempo para a difusão dos elementos, sobretudo os alfagênicos, atingindo-se fração volumétrica de ferrita que varia desde $59,2 \%$ em $150 \mathrm{~s}$ e taxa de $2{ }^{\circ} \mathrm{C} / \mathrm{s}$ até $66,6 \% \mathrm{em}$ $1000 \mathrm{~s}$ e taxa de $0,30^{\circ} \mathrm{C} / \mathrm{s}$, valor próximo ao esperado pela simulação de equilíbrio, isto é $70 \%$ de ferrita em $1250{ }^{\circ} \mathrm{C}$. A comparação da fração máxima obtida em função da taxa de aquecimento está resumida na Tabela 15. 
Figura 47 - Frações de ferrita em função da taxa de aquecimento no trecho 1

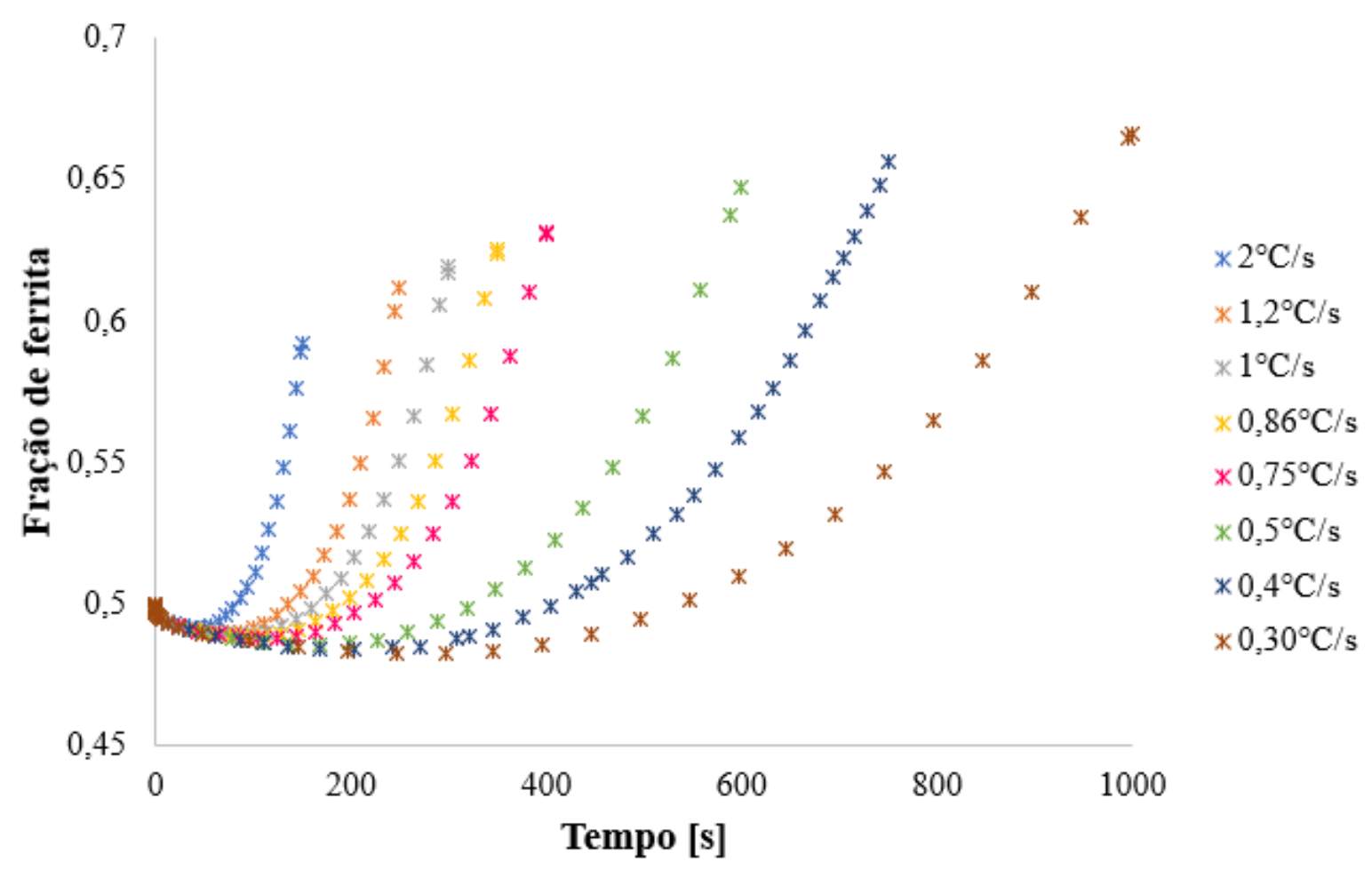

Fonte: Autora

Tabela 15 - Fração máxima de ferrita formada em função da taxa de aquecimento no trecho 1

\begin{tabular}{ccc}
\hline & $\begin{array}{c}\text { Taxa de } \\
\text { aquecimento }\end{array}$ & $\begin{array}{c}\text { Fração máxima } \\
\text { de ferrita }\end{array}$ \\
\hline & $2,00^{\circ} \mathrm{C} / \mathrm{s}$ & $59,2 \%$ \\
\hline $1,20{ }^{\circ} \mathrm{C} / \mathrm{s}$ & $61,3 \%$ \\
\hline \multirow{2}{*}{ Trecho 1} & $1,00^{\circ} \mathrm{C} / \mathrm{s}$ & $61,9 \%$ \\
\cline { 2 - 3 } & $0,86{ }^{\circ} \mathrm{C} / \mathrm{s}$ & $62,5 \%$ \\
\hline $0,75^{\circ} \mathrm{C} / \mathrm{s}$ & $63,1 \%$ \\
\hline $0,50{ }^{\circ} \mathrm{C} / \mathrm{s}$ & $64,8 \%$ \\
\hline $0,40{ }^{\circ} \mathrm{C} / \mathrm{s}$ & $65,6 \%$ \\
\hline $0,30{ }^{\circ} \mathrm{C} / \mathrm{s}$ & $66,6 \%$ \\
\hline
\end{tabular}

Fonte: Autora

Em seguida, obteve-se os perfis de composição química dos principais elementos ao longo do tempo (em segundos) em função da distância, isto é, do comprimento do modelo planar de fases exposto na Figura 26, para cada taxa de aquecimento simulada. Considerando que para a menor taxa de aquecimento simulada, $0,30^{\circ} \mathrm{C} / \mathrm{s}$, atingiu-se a maior fração de ferrita, 
$66,6 \%$, e que mais se aproxima dos $70 \%$ obtidos no equilíbrio, esta será a taxa utilizada para dar sequência às simulações do trecho 2.

Nota-se nas simulações à taxa de $0,30^{\circ} \mathrm{C} / \mathrm{s}$ a seguir que, para um tempo de simulação $\mathrm{t}=0$, tem-se uma linha vertical representando a interface entre as fases ferrita $(\alpha)$ e austenita $(\gamma)$ exatamente no meio do modelo, indicando a presença de $50 \%$ de cada fase, além de um patamar à esquerda que representa o perfil do elemento na ferrita e um patamar à direita que representa o perfil do elemento na austenita.

Na Figura 48, é possível observar o perfil de $\mathrm{Cr}$ em função da distância para a taxa de aquecimento simulada de $0,30^{\circ} \mathrm{C} / \mathrm{s}$. Nota-se com o passar do tempo que a fase $\alpha$ avança por difusão em direção a fase $\gamma$, uma vez que a interface $\alpha / \gamma$ se desloca para direita, e a fração inicial de $\mathrm{Cr}$ na ferrita cai de $26,8 \%$ para $26,4 \%$, ao passo em que permanece em torno de $23,5 \%$ na austenita.

O comportamento do Mo observado na Figura 49 também indica que a fase $\alpha$ avança por difusão em direção a fase $\gamma$, visto que a porcentagem inicial de 4,4\% de Mo em $\alpha$ cai para $4,2 \%$ e a interface $\alpha / \gamma$ se desloca para direita, enquanto que em $\gamma$ praticamente permanece a mesma, de 2,8\% de Mo até o final do tratamento térmico em $1000 \mathrm{~s}$.

Figura 48 - Perfil de composição de $\mathrm{Cr}$ no aquecimento de $950^{\circ} \mathrm{C}$ a $1250^{\circ} \mathrm{C}$ (trecho 1 ) em função da distância à taxa de $0,30^{\circ} \mathrm{C} / \mathrm{s}$

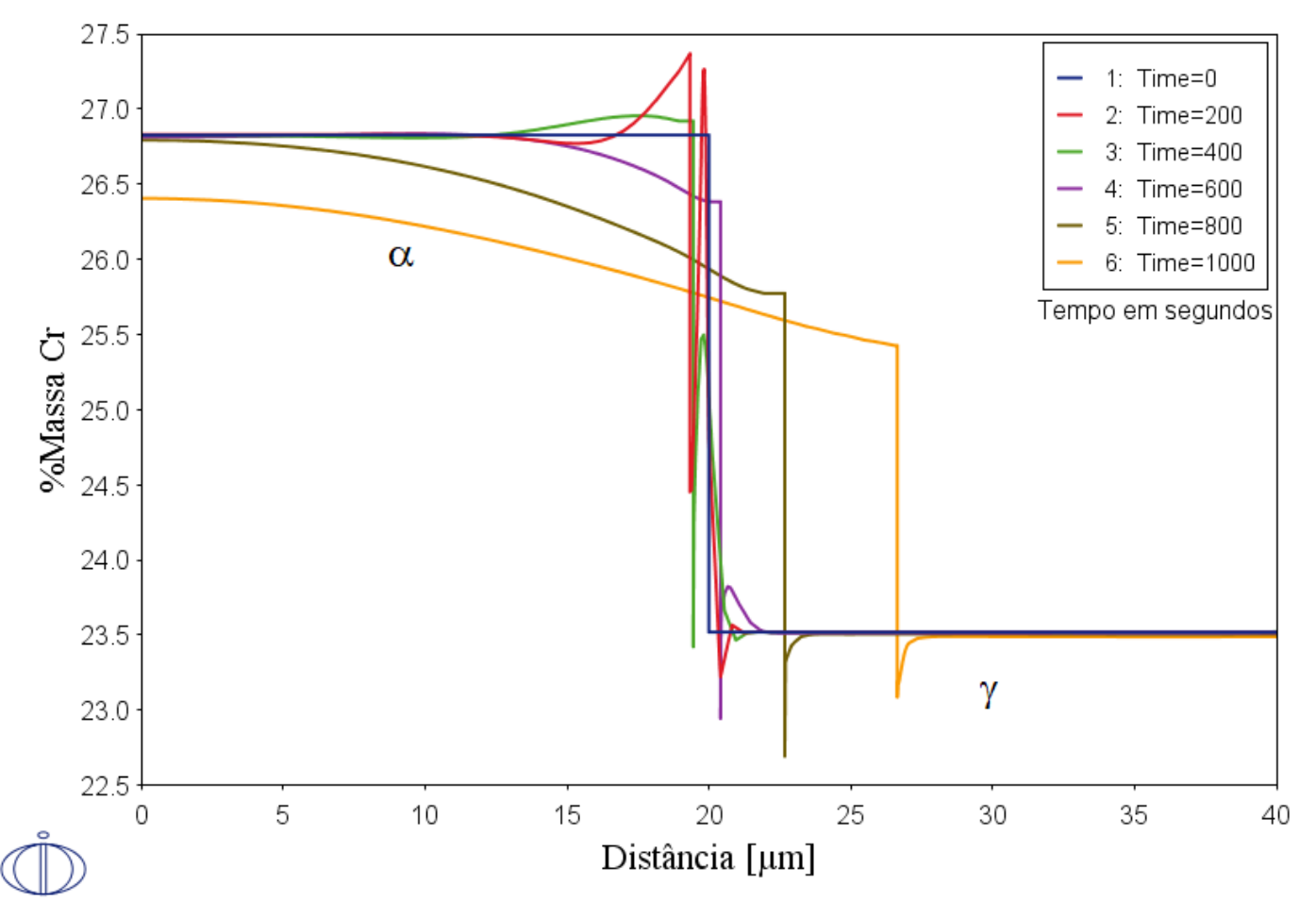

Fonte: Autora 
Figura 49 - Perfil de composição de Mo no aquecimento de $950^{\circ} \mathrm{C}$ a $1250^{\circ} \mathrm{C}$ (trecho 1 ) em função da distância à taxa de $0,30^{\circ} \mathrm{C} / \mathrm{s}$

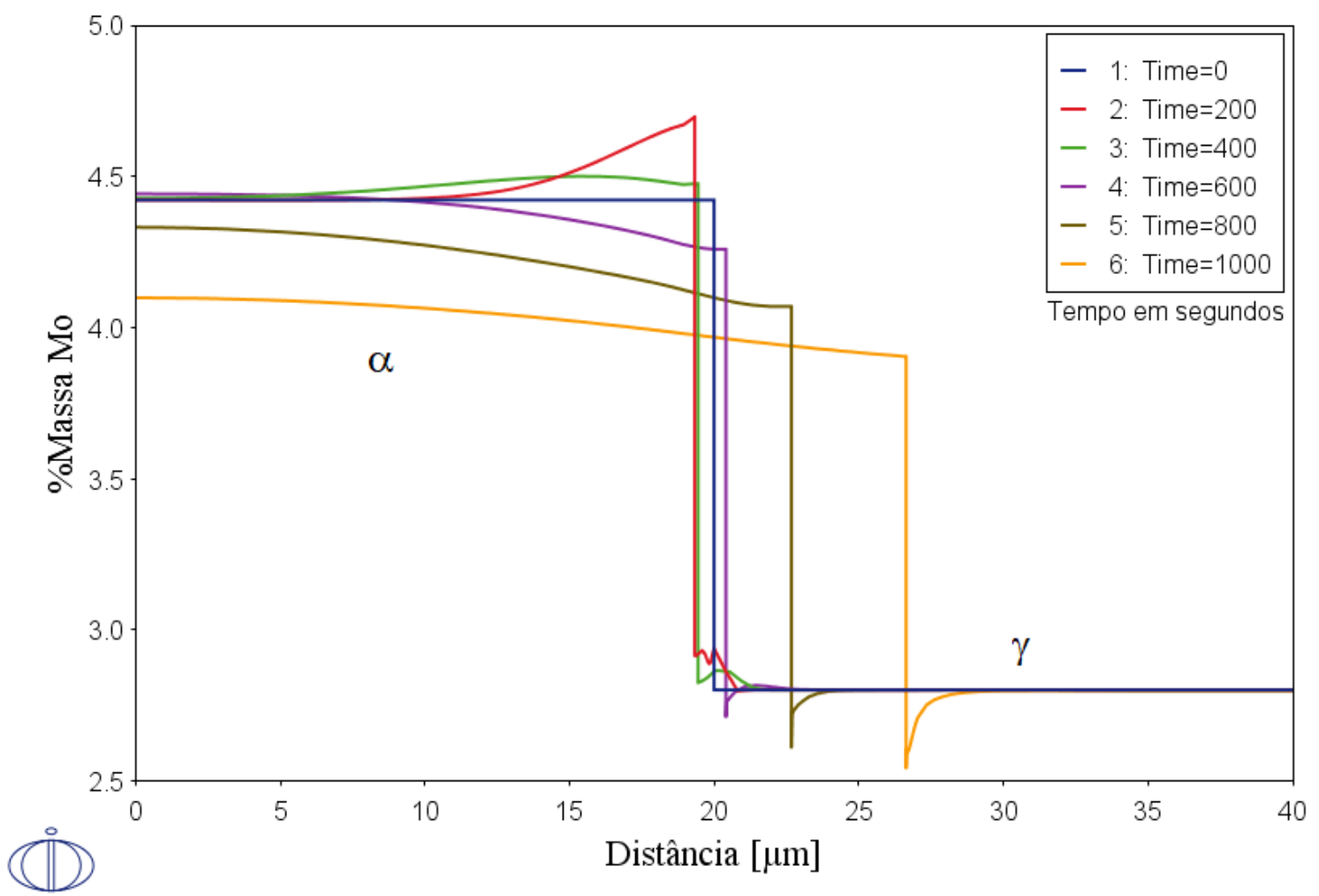

Fonte: Autora

O perfil de Ni em função da distância na Figura 50 mostra que, assim como o $\mathrm{Cr}$ e o Mo, a difusão se dá de $\alpha$ para $\gamma$, uma vez que a interface se move para a direita, com a diferença que o Ni se concentra na austenita, em torno de $8,5 \%$, enquanto que a fração deste elemento na ferrita sobe de $5,25 \%$ para $5,8 \%$ ao final dos 1000 s de tratamento térmico.

Por fim, a análise do perfil de $\mathrm{N}$ exposta na Figura 51, mostra que a fração inicial de $\mathrm{N}$ em $\alpha$ é de $0,05 \%$ e sobe para $0,1 \%$ após 1000 s de tratamento térmico (linha amarela), valor este considerado alto para o aço superdúplex UNS S32750, visto que pode haver precipitação de nitretos de cromo na interface $\alpha / \gamma$ durante o resfriamento. Nota-se que a fração de $\mathrm{N}$ em $\gamma$ também sobe, de $0,46 \%$ para $0,57 \%$. Este comportamento se deve ao fato de que há diferentes solubilidades de $\mathrm{N}$ em função da temperatura e, quanto maior for a temperatura, maior quantidade do elemento pode ser dissolvida na ferrita. Logo, pode-se afirmar que diferentemente dos demais elementos, o valor de $\mathrm{N}$ é enriquecido em ambas as fases. 
Figura 50 - Perfil de composição de Ni no aquecimento de $950^{\circ} \mathrm{C}$ a $1250^{\circ} \mathrm{C}$ (trecho 1 ) em função da distância à taxa de $0,30^{\circ} \mathrm{C} / \mathrm{s}$

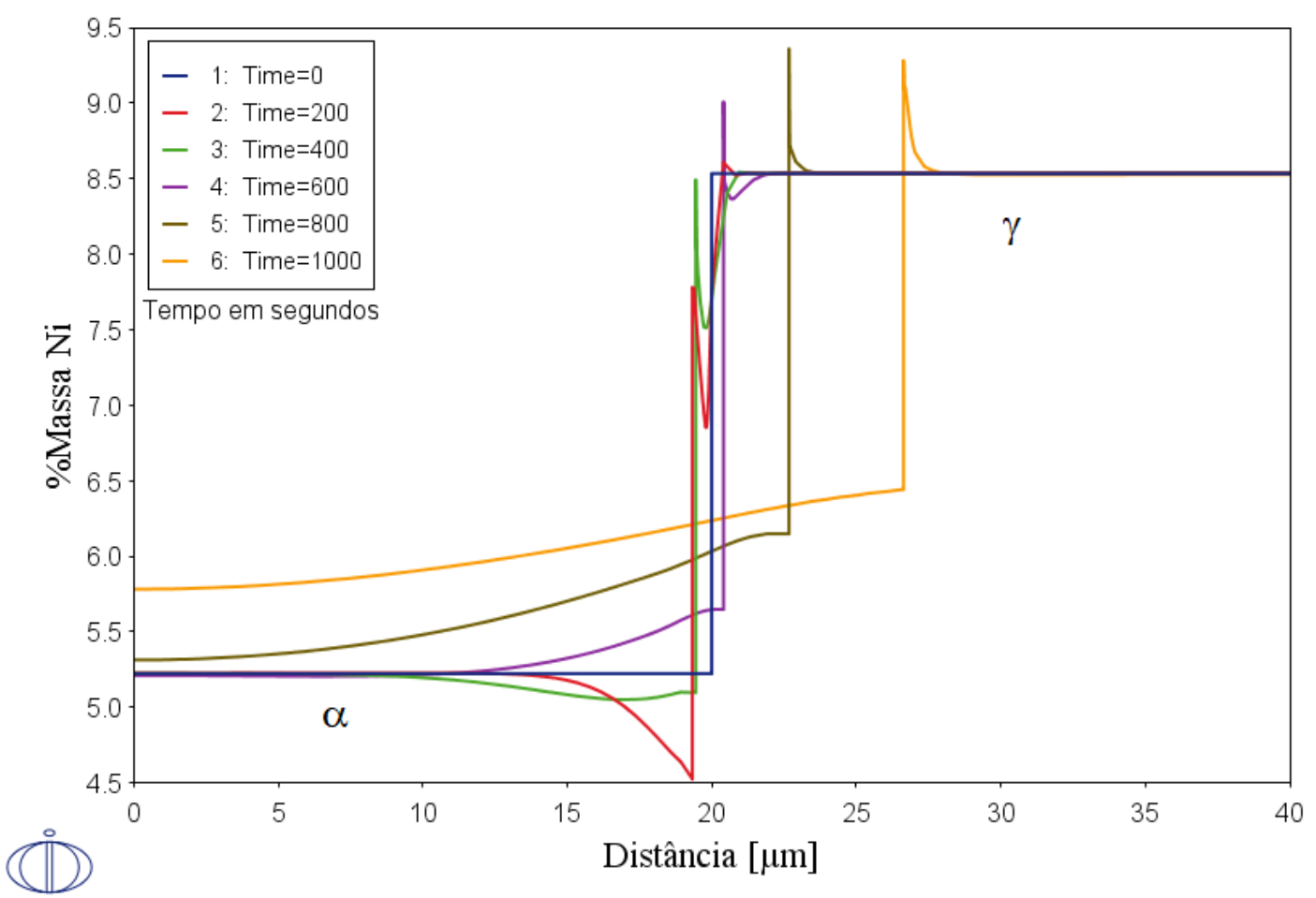

Fonte: Autora

Figura 51 - Perfil de composição de $\mathrm{N}$ no aquecimento de $950^{\circ} \mathrm{C}$ a $1250^{\circ} \mathrm{C}$ (trecho 1 ) em função da distância à taxa de $0,30^{\circ} \mathrm{C} / \mathrm{s}$

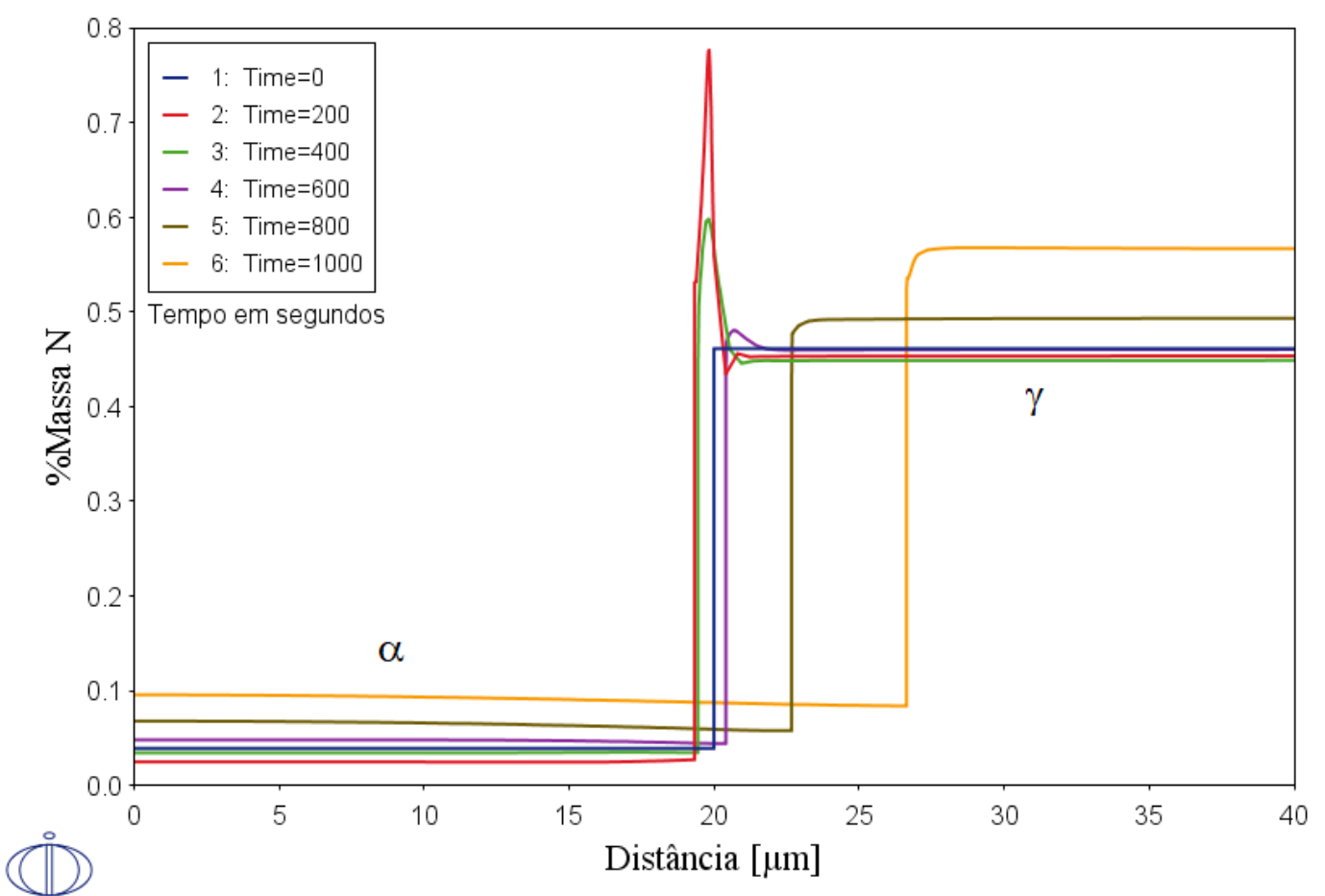

Fonte: Autora 


\subsection{SIMULAÇÃO COMPUTACIONAL DO TRECHO 2}

Considerando-se que a simulação do trecho 2 somente se inicia ao final dos $1000 \mathrm{~s}$ em que se encerra o tratamento térmico do trecho $1 \mathrm{e}$, que neste tempo tem-se a composição química final e exata ao atingir-se $1250{ }^{\circ} \mathrm{C}$, obteve-se separadamente a curva de $1000 \mathrm{~s}$ de cada elemento, como dado de entrada para as simulações de trecho 2, vide exemplo do Cr na Figura 52.

Figura 52 - Perfil de composição de $\mathrm{Cr}$ no aquecimento de $950^{\circ} \mathrm{C}$ a $1250^{\circ} \mathrm{C}$ (trecho 1 ) em função da distância à taxa de $0,30^{\circ} \mathrm{C} / \mathrm{s}$ em $1000 \mathrm{~s}$

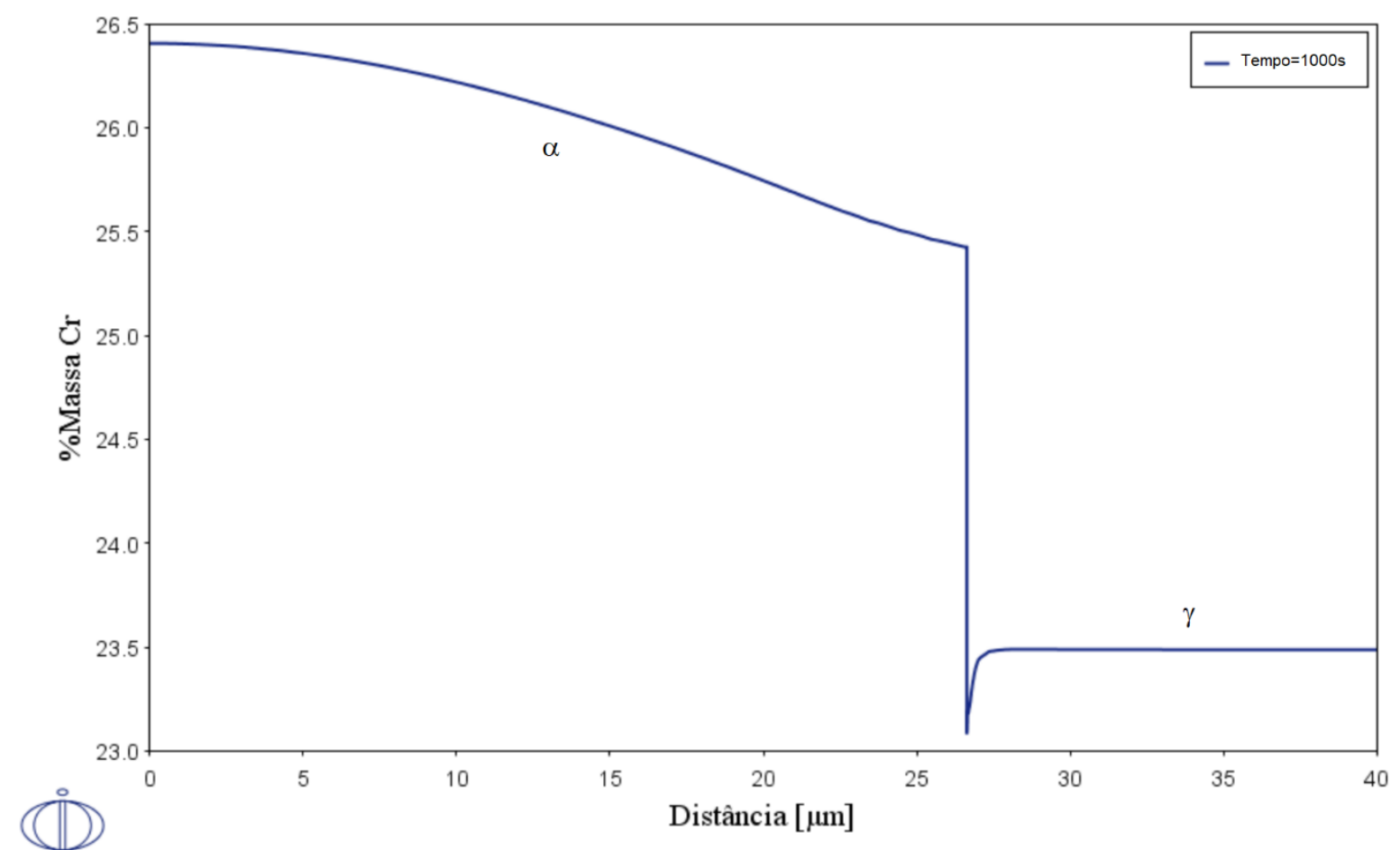

Fonte: Autora

Com a finalidade de obter-se as funções matemáticas que descrevem a composição química da ferrita e da austenita para cada elemento, $\mathrm{Cr}$, Mo, Ni e N, os resultados foram exportados para o Excel, separando-se o trecho de cada fase e traçando a linha de tendência cujo R quadrático mais se aproxima de 1 , e inserindo-as no DICTRA ${ }^{\circledR}$. As funções matemáticas de cada elemento encontram-se na Tabela 19 do Apêndice I.

Desta forma, foi possível simular o trecho de número 2 (indicado pela reta amarela) da Figura 37, que corresponde ao tempo de patamar (em segundos) na temperatura de conformação plástica de $1250{ }^{\circ} \mathrm{C}$, de modo que a microestrutura atinja novos valores de equilíbrio para a 
ferrita e austenita. Os resultados podem ser vistos na sequência da Figura 53 e 54, considerando um tempo de $1000 \mathrm{~s}$ de tratamento térmico, suficiente para que a ferrita atinja fração de 70,7\% esperados pela simulação de Thermo-Calc ${ }^{\circledR}$ e que a austenita atinja fração de $28,3 \%$. Também se obteve os perfis de composição química dos elementos em função da distância no tempo de patamar a $1250{ }^{\circ} \mathrm{C}$, como podem ser vistos da Figura 55 a 58.

Figura 53 - Fração de ferrita em função do tempo no patamar a $1250^{\circ} \mathrm{C}$ (trecho 2)

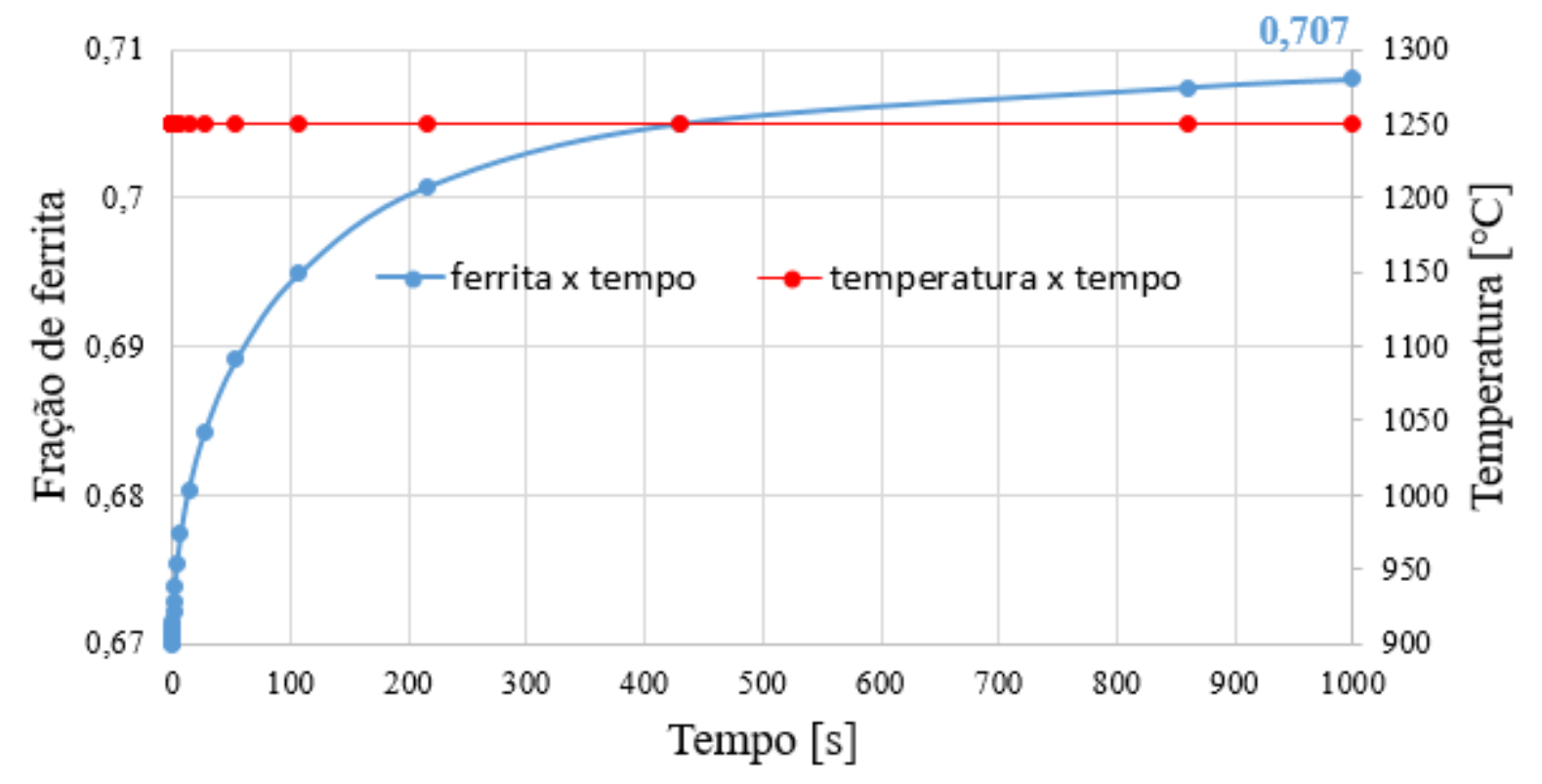

Fonte: Autora

Figura 54 - Fração de austenita em função do tempo no patamar a $1250^{\circ} \mathrm{C}$ (trecho 2)

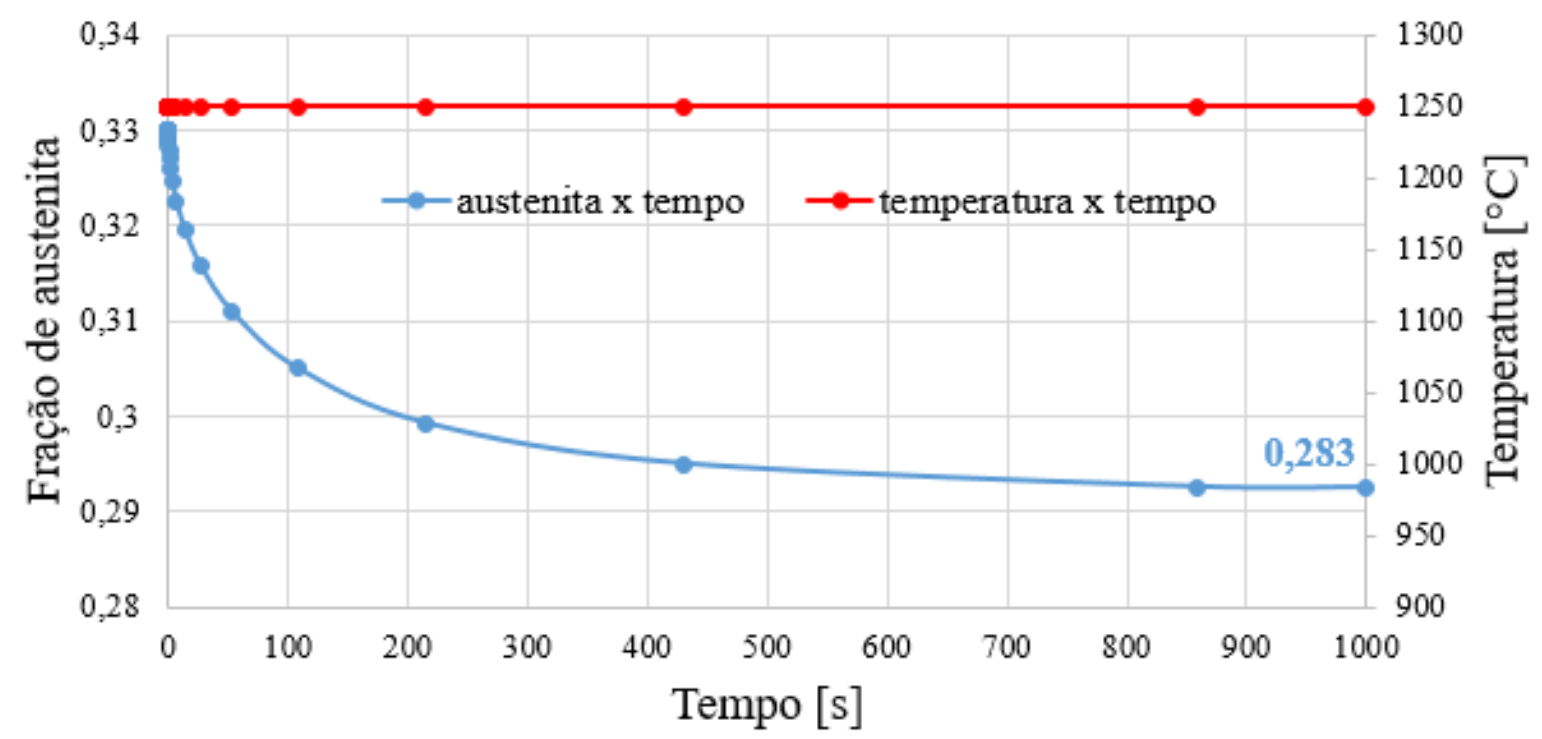

Fonte: Autora 
Analisando-se os perfis de composição química obtidos, nota-se que tanto o Cr, Figura 55, quanto o Mo, Figura 56, difundem da ferrita para austenita, uma vez que os teores de ambos elementos diminuem na ferrita e aumentam na austenita com o passar do tempo, com interface entre as fases se deslocando para a direita.

Já o Ni, Figura 57, tem comportamento contrário ao Cr e Mo, visto que seu teor aumenta na ferrita e diminui na austenita. Entretanto, a interface entre as fases também se desloca para a direita. O N, por sua vez, Figura 58, mantém um valor constante na ferrita durante todo o tempo de tratamento, ao passo em que acresce até 0.12 pontos percentuais na austenita.

Em todos os casos, a fração em massa dos elementos em ambas as fases são aproximadamente iguais na simulação dos trechos 1 e 2 .

Figura 55 - Perfil de composição de $\mathrm{Cr}$ no patamar à $1250^{\circ} \mathrm{C}$ (trecho 2 ) em função da distância

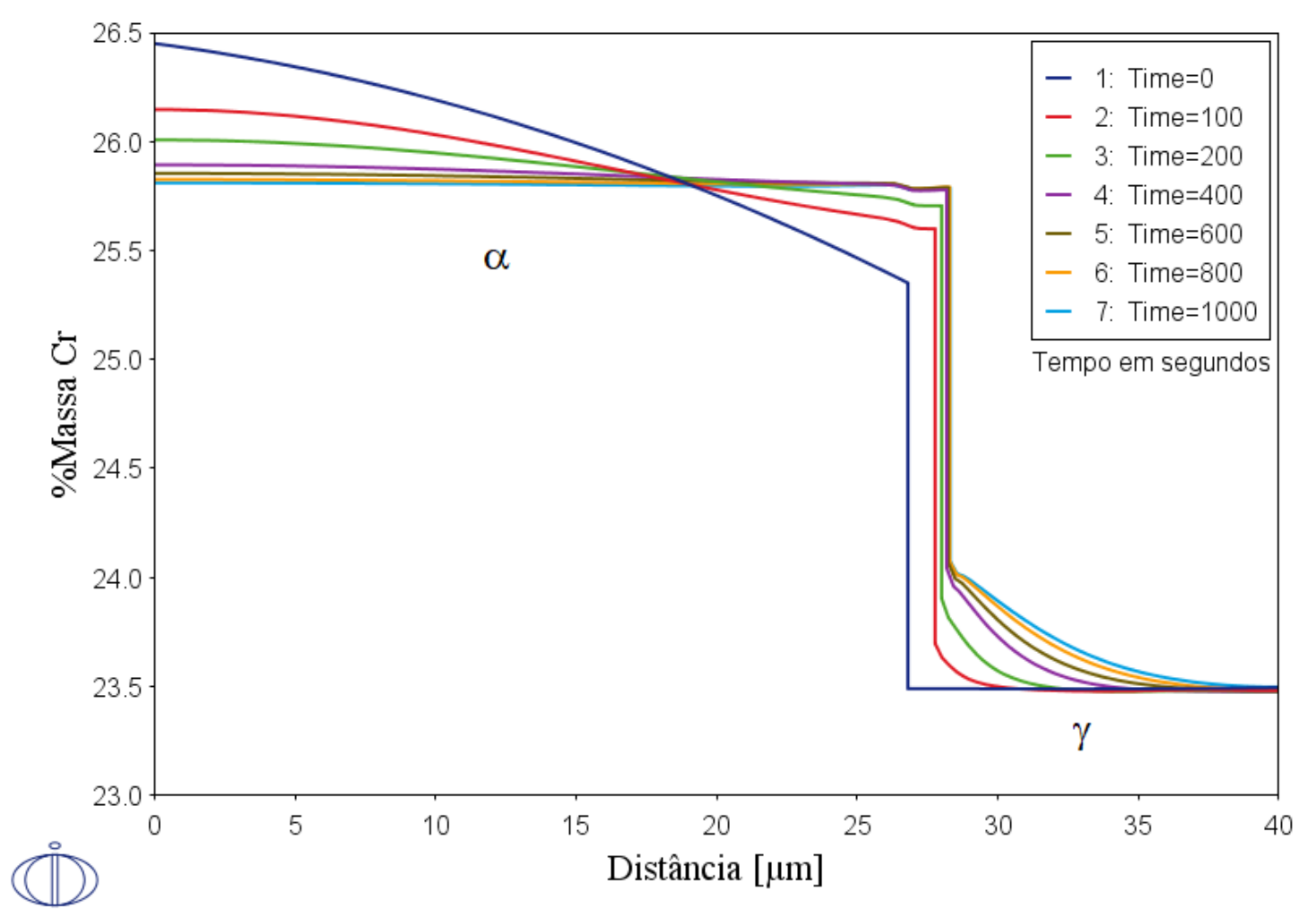

Fonte: Autora 
Figura 56 - Perfil de composição de Mo no patamar à $1250^{\circ} \mathrm{C}$ (trecho 2 ) em função da distância

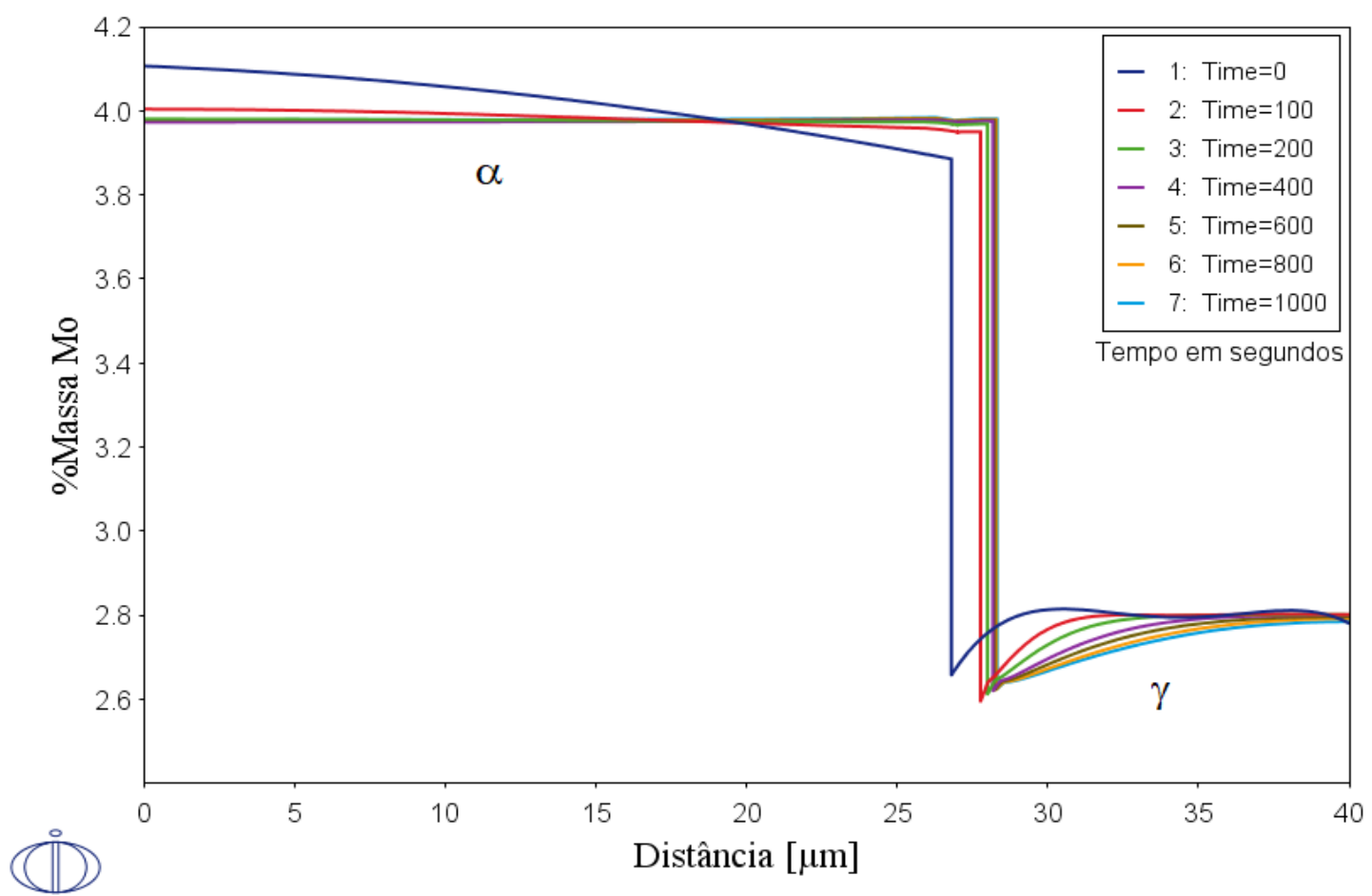

Fonte: Autora

Figura 57 - Perfil de composição de Ni no patamar à $1250^{\circ} \mathrm{C}$ (trecho 2 ) em função da distância

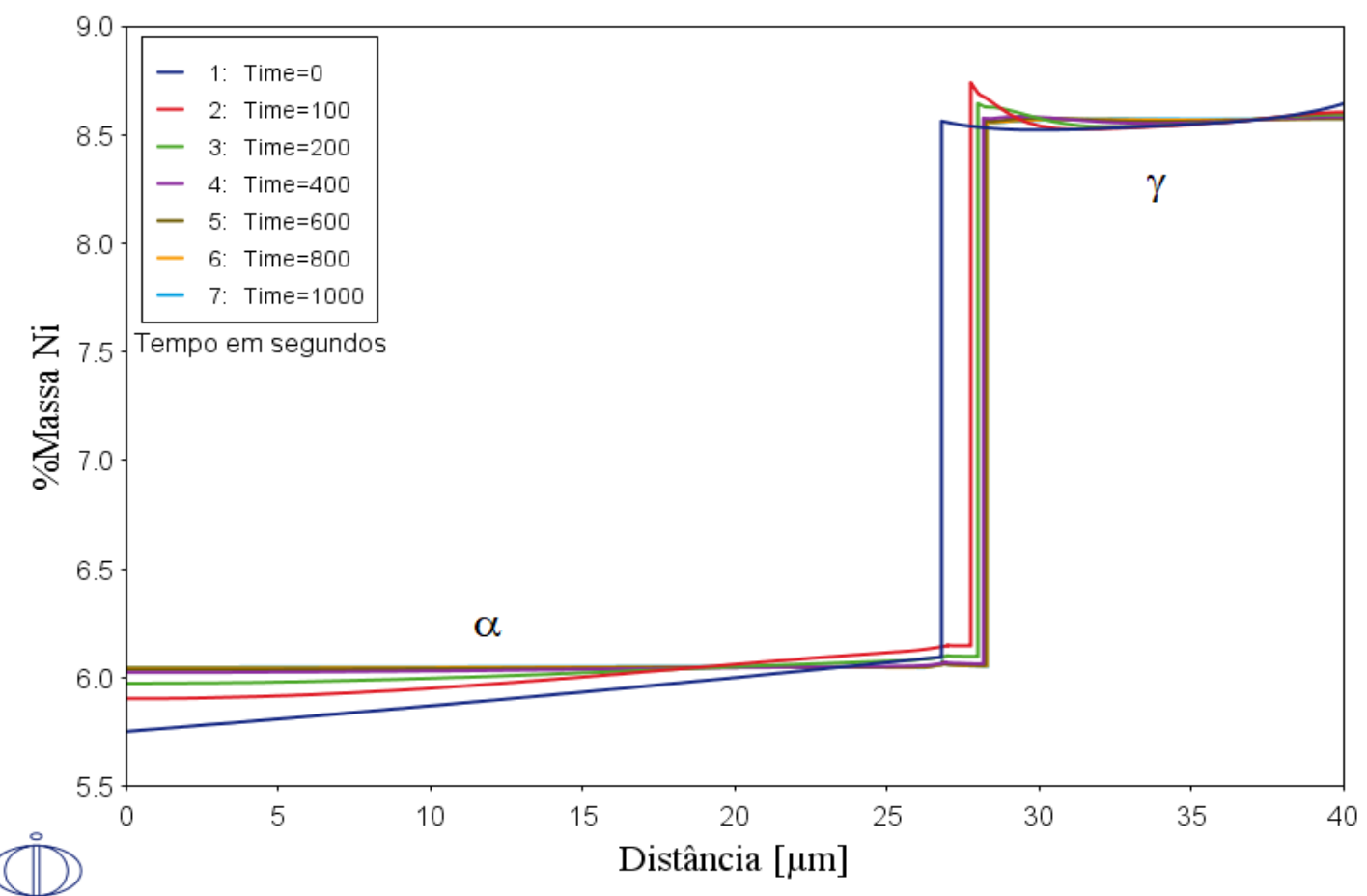

Fonte: Autora 
Figura 58 - Perfil de composição de $\mathrm{N}$ no patamar à $1250^{\circ} \mathrm{C}$ (trecho 2) em função da distância

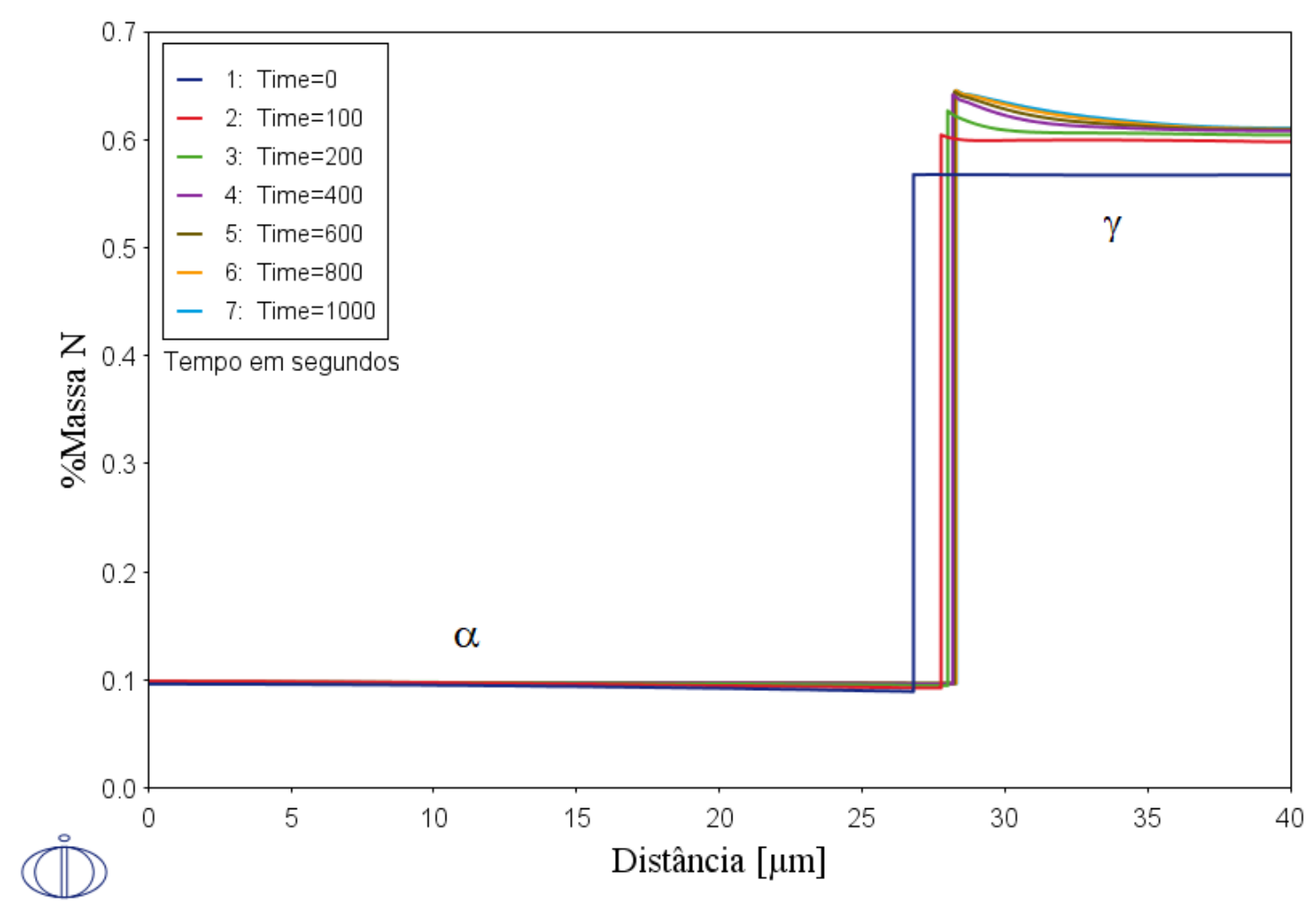

Fonte: Autora

\subsection{SIMULAÇÃO COMPUTACIONAL DO TRECHO 3}

Sabendo-se que $1000 \mathrm{~s}$ é o tempo final de tratamento térmico do trecho 2, obteve-se então as funções matemáticas que descrevem a composição química da ferrita e da austenita para cada elemento neste tempo, como mostra a Tabela 20 do Apêndice I, com a finalidade de inserir no DICTRA ${ }^{\circledR}$ como dado de entrada para a simulação do trecho 3.

Desta forma, simulou-se o trecho de número 3 (indicado pela seta verde) da Figura 37, que corresponde ao resfriamento subsequente à conformação plástica até a temperatura de equilíbrio entre as fases, isto é, de $1250{ }^{\circ} \mathrm{C}$ à $1090^{\circ} \mathrm{C}$, atingindo-se novos valores de equilíbrio para a ferrita e austenita, à duas diferentes taxas, de $0,30^{\circ} \mathrm{C} / \mathrm{s}$ (para que o forno resfrie na mesma taxa em que aqueceu) e $0,10{ }^{\circ} \mathrm{C} / \mathrm{s}$ (menor taxa para fins de comparação e que formaria sigma se houvesse esta fase no sistema).

Simulando-se o trecho 3 a uma taxa de resfriamento de $0,30^{\circ} \mathrm{C} / \mathrm{s}$, tem-se uma fração de ferrita partindo de $70,7 \%$ a $1250{ }^{\circ} \mathrm{C}$ e atingindo $58,7 \%$ em $1090{ }^{\circ} \mathrm{C}$ e $500 \mathrm{~s}$, enquanto que a 
fração de austenita parte de 28,3\% atingindo 41,3\% nas mesmas condições, Figura 59 e 60, respectivamente.

Figura 59 - Fração de ferrita no resfriamento do aço de $1250^{\circ} \mathrm{C}$ até $1090^{\circ} \mathrm{C}$ (trecho 3 ) à taxa de $0,30^{\circ} \mathrm{C} / \mathrm{s}$

Taxa de resfriamento: $0,30^{\circ} \mathrm{C} / \mathrm{s}$

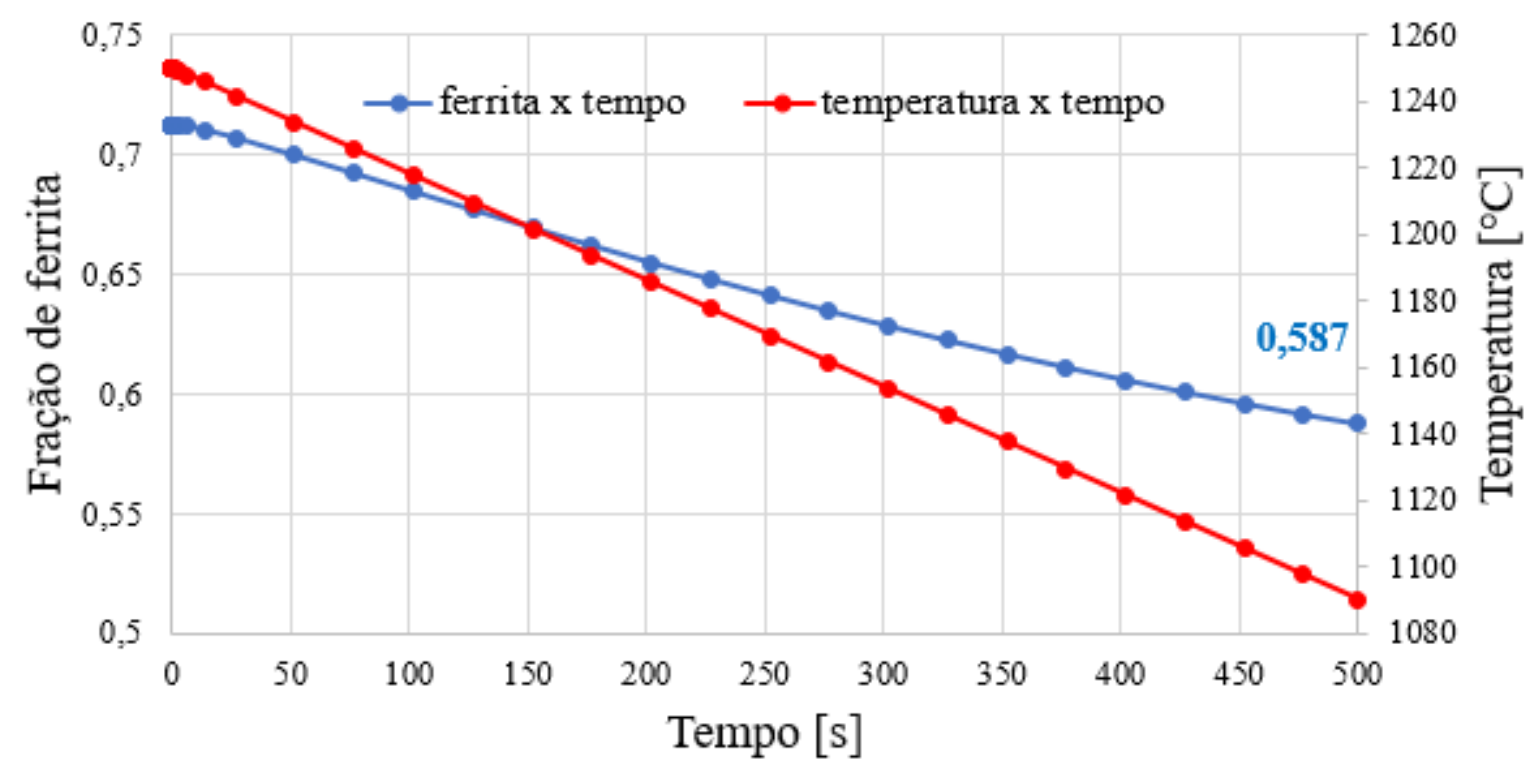

Fonte: Autora

Figura 60 - Fração de austenita no resfriamento do aço de $1250^{\circ} \mathrm{C}$ até $1090^{\circ} \mathrm{C}$ (trecho 3 ) à taxa de $0,30^{\circ} \mathrm{C} / \mathrm{s}$

Taxa de resfriamento: $0,30^{\circ} \mathrm{C} / \mathrm{s}$

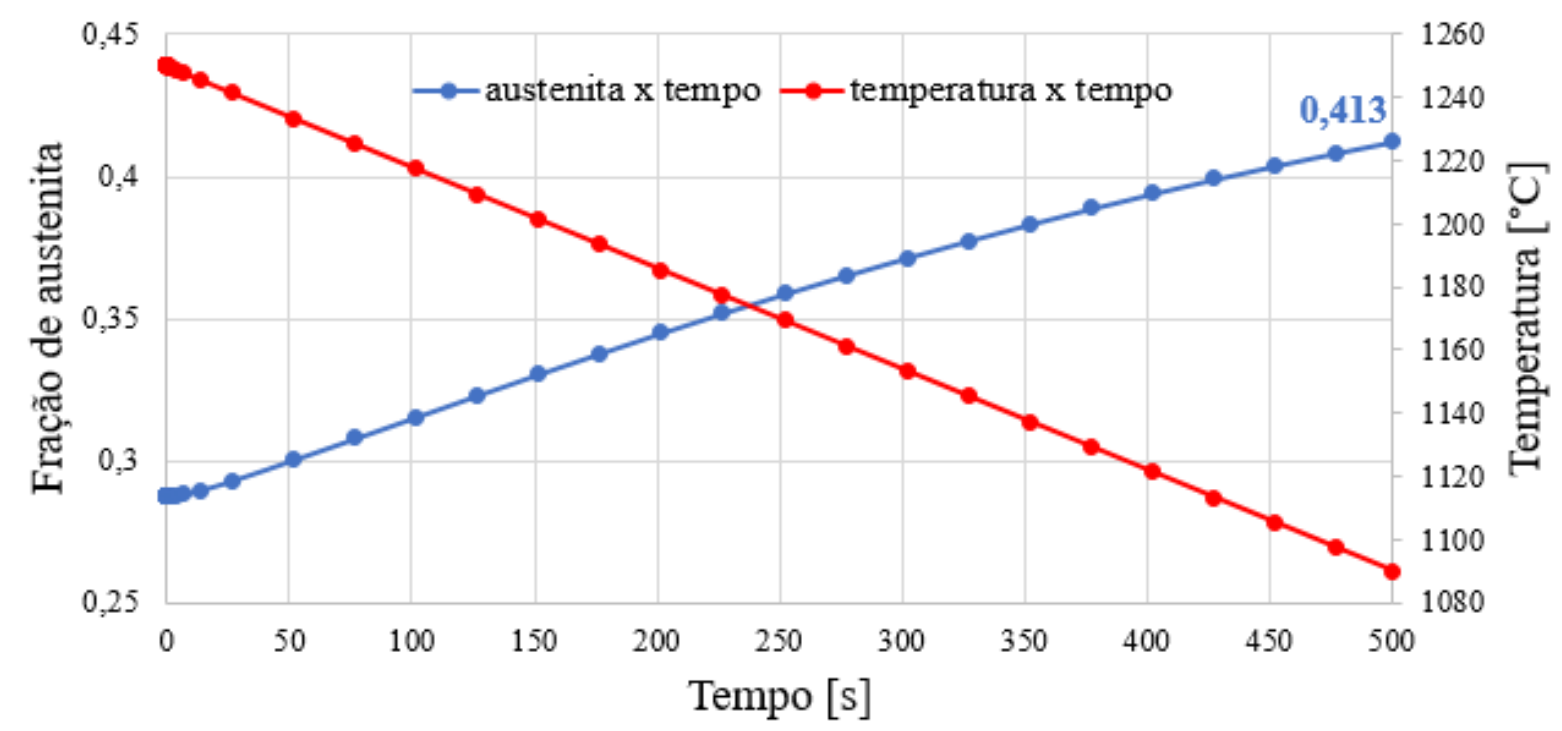

Fonte: Autora 
Em seguida, obteve-se os perfis de composição química dos elementos ao longo do tempo (em segundos) em função da distância, para a taxa de resfriamento de $0,30{ }^{\circ} \mathrm{C} / \mathrm{s}$. Os resultados podem ser vistos da Figura 61 a 64. Nota-se que a curva de tempo inicial zero para cada um dos elementos químicos corresponde exatamente à curva de tempo final do trecho 2 , obtida através das funções matemáticas.

Neste resfriamento tanto o Cr, Figura 61, quanto o Mo, Figura 62, são enriquecidos na ferrita ao longo do tempo, uma vez que a interface $\alpha / \gamma$ se desloca da direta para a esquerda, indicando que a difusão se dá da austenita para a ferrita, enquanto que o teor de ambos os elementos na austenita se mantém constante, isto é, sem gradiente de composição química.

O Ni por sua vez, Figura 63, tem fração volumétrica empobrecida na ferrita ao longo tempo, mesmo que a interface $\alpha / \gamma$ indique que a difusão acontece em direção à ferrita. Nota-se que o teor do elemento na austenita também se mantém praticamente constante. Por fim, o N é empobrecido em ambas as fases, Figura 64, mostrando que a difusão também ocorre da austenita para a ferrita, como visto nas simulações dos outros elementos químicos. Neste caso, há gradiente de composição na austenita em função do tempo de tratamento térmico.

Figura 61 - Perfil de composição de $\mathrm{Cr}$ no resfriamento de $1250^{\circ} \mathrm{C}$ a $1090^{\circ} \mathrm{C}$ (trecho 3) em função da distância à taxa de $0,30^{\circ} \mathrm{C} / \mathrm{s}$

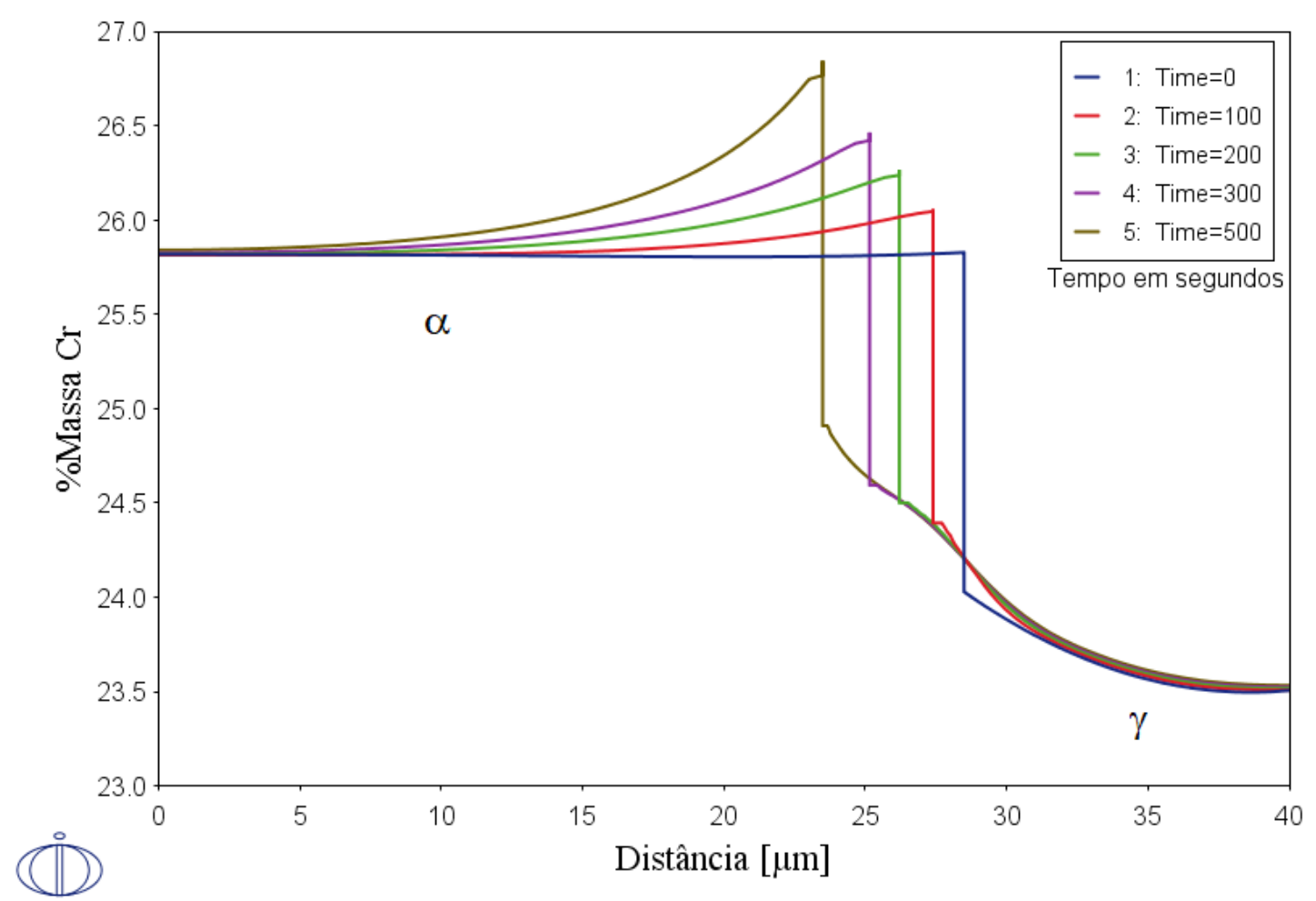

Fonte: Autora 
Figura 62 - Perfil de composição de Mo no resfriamento de $1250^{\circ} \mathrm{C}$ a $1090^{\circ} \mathrm{C}$ (trecho 3) em função da distância à taxa de $0,30^{\circ} \mathrm{C} / \mathrm{s}$

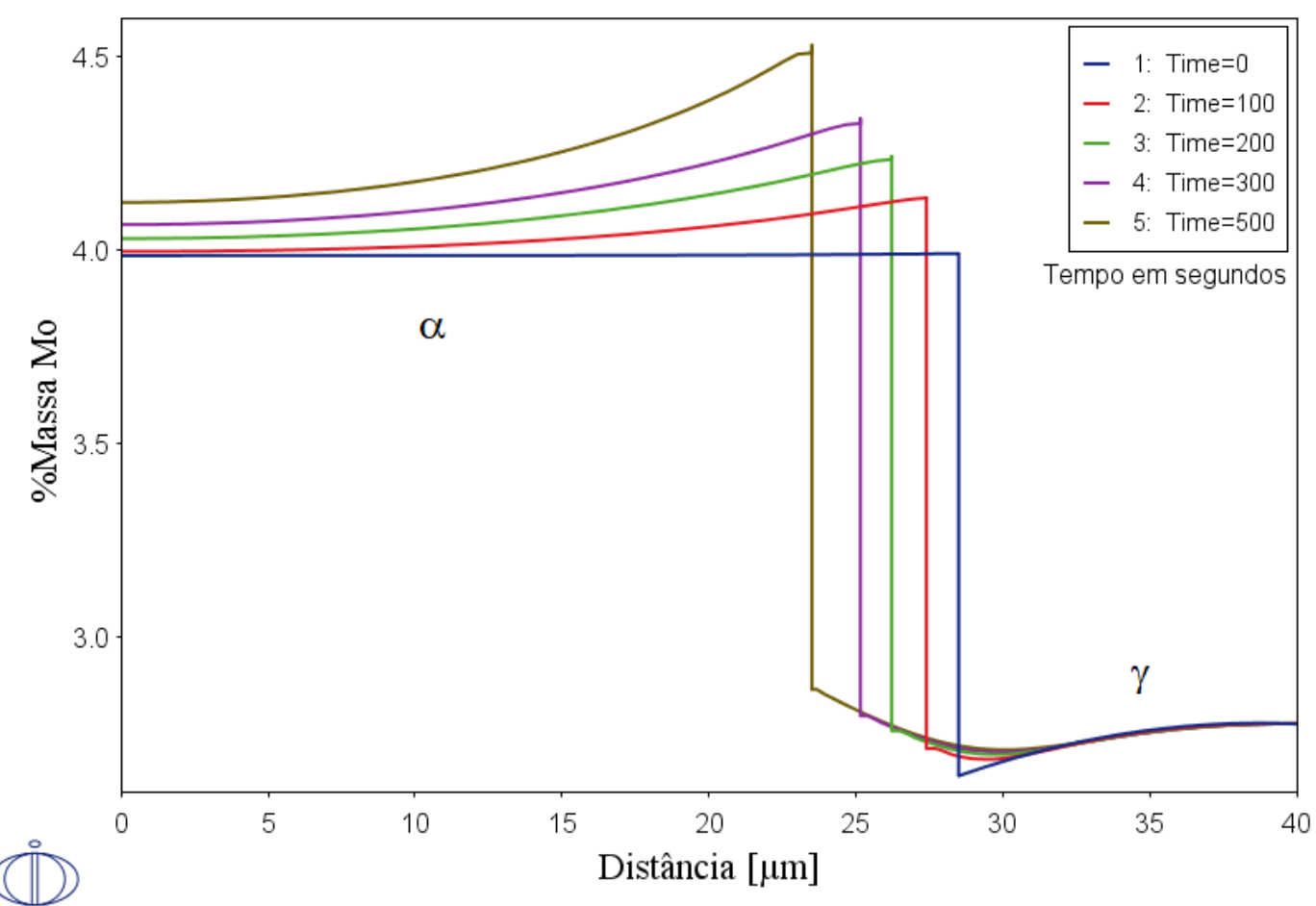

Fonte: Autora

Figura 63 - Perfil de composição de Ni no resfriamento de $1250^{\circ} \mathrm{C}$ a $1090^{\circ} \mathrm{C}$ (trecho 3) em função da distância à taxa de $0,30^{\circ} \mathrm{C} / \mathrm{s}$

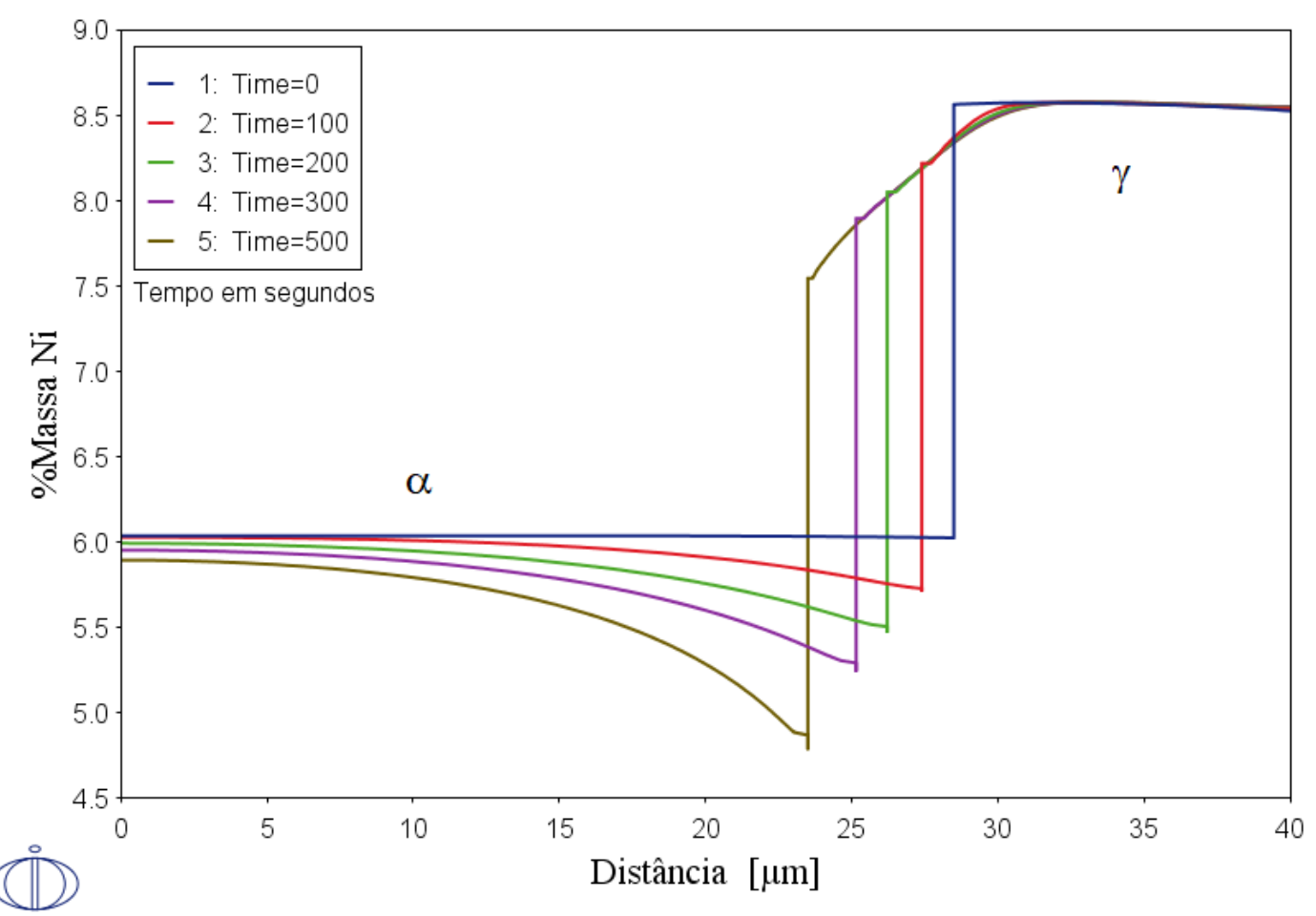

Fonte: Autora 
Figura 64 - Perfil de composição de $\mathrm{N}$ no resfriamento de $1250^{\circ} \mathrm{C}$ a $1090^{\circ} \mathrm{C}$ (trecho 3 ) em função da distância à taxa de $0,30^{\circ} \mathrm{C} / \mathrm{s}$

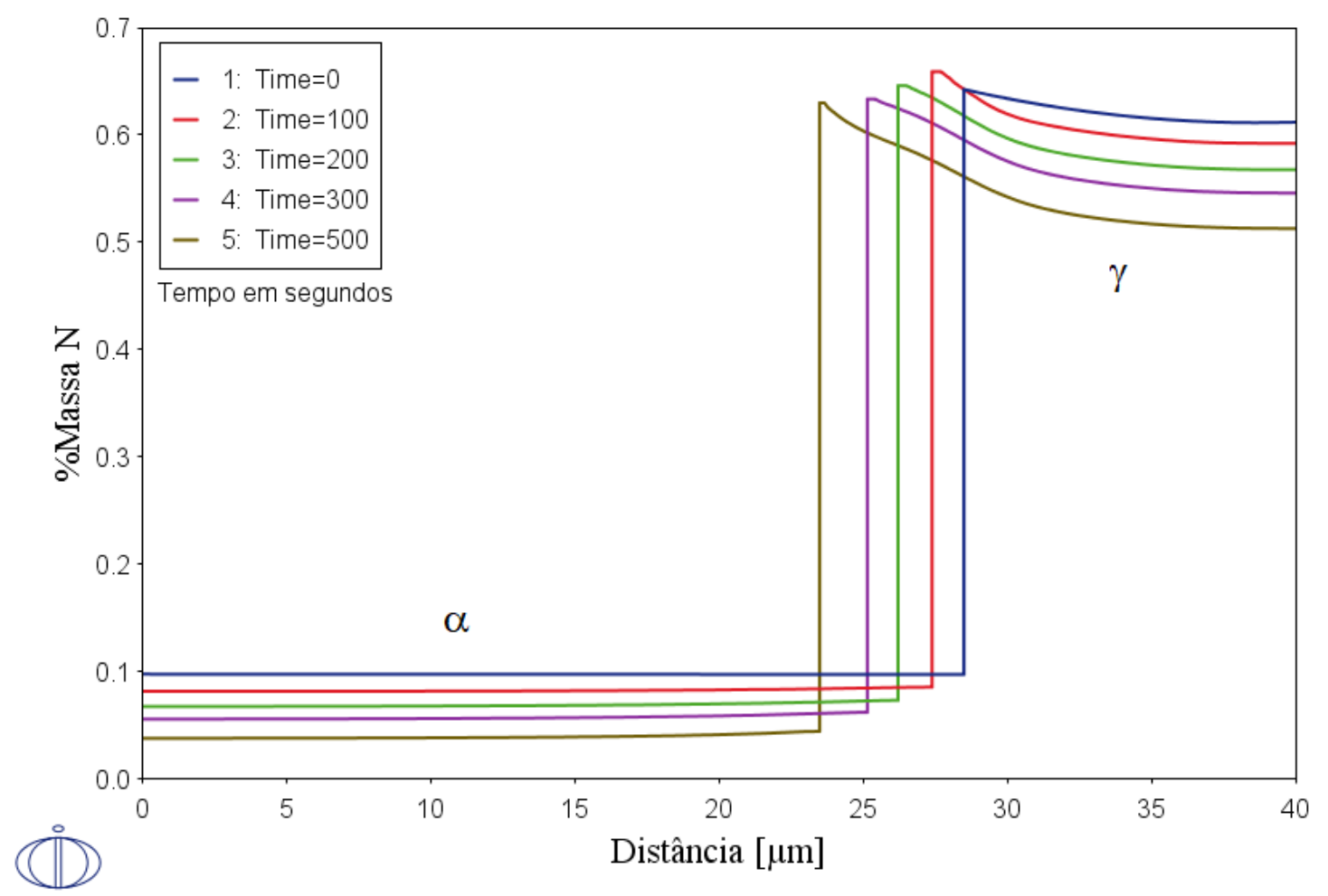

Fonte: Autora

Para fins de comparação, também foi feita a simulação do trecho 3 a uma taxa de resfriamento de $0,10^{\circ} \mathrm{C} / \mathrm{s}$ utilizando-se as mesmas funções matemáticas da Tabela 20 . Tem-se que a fração de ferrita de $70,7 \%$ a $1250{ }^{\circ} \mathrm{C}$ atinge fração de $58,2 \%$ em $1090{ }^{\circ} \mathrm{C}$ e $1600 \mathrm{~s}$, enquanto que a fração de austenita de 28,3\% atinge 41,8\% nas mesmas condições, Figura 65 e 66 , respectivamente. Comparando-se com a taxa de resfriamento de $0,30{ }^{\circ} \mathrm{C} / \mathrm{s}$ simulada anteriormente, as frações de ferrita e austenita obtidas no resfriamento à taxa de $0,10{ }^{\circ} \mathrm{C} / \mathrm{s}$ são próximas. Entretanto, por haver um pouco mais de tempo para que ocorra difusão dos elementos químicos, atinge-se frações de ferrita e austenita mais próximas ao equilíbrio de $50 \%$ de cada fase esperados a $1090^{\circ} \mathrm{C}$, conforme obtido no Thermo-Calc $\AA$ e mostrado na Figura 38. 
Figura 65 - Fração de ferrita no resfriamento do aço de $1250^{\circ} \mathrm{C}$ até $1090^{\circ} \mathrm{C}$ (trecho 3 ) à taxa de $0,10^{\circ} \mathrm{C} / \mathrm{s}$

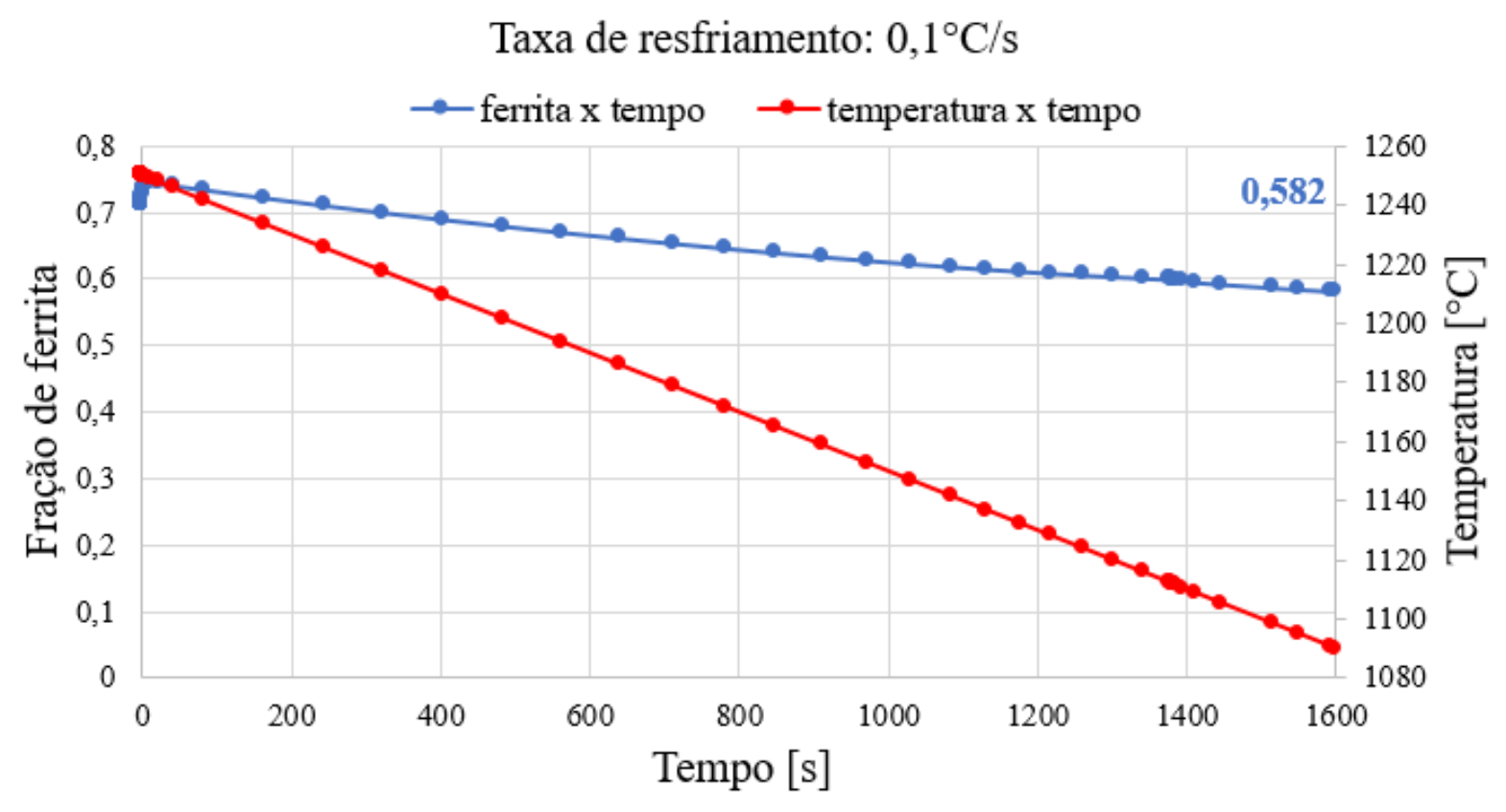

Fonte: Autora

Figura 66 - Fração de ferrita no resfriamento do aço de $1250^{\circ} \mathrm{C}$ até $1090^{\circ} \mathrm{C}$ (trecho 3 ) à taxa de $0,10^{\circ} \mathrm{C} / \mathrm{s}$

Taxa de resfriamento: $0,1^{\circ} \mathrm{C} / \mathrm{s}$

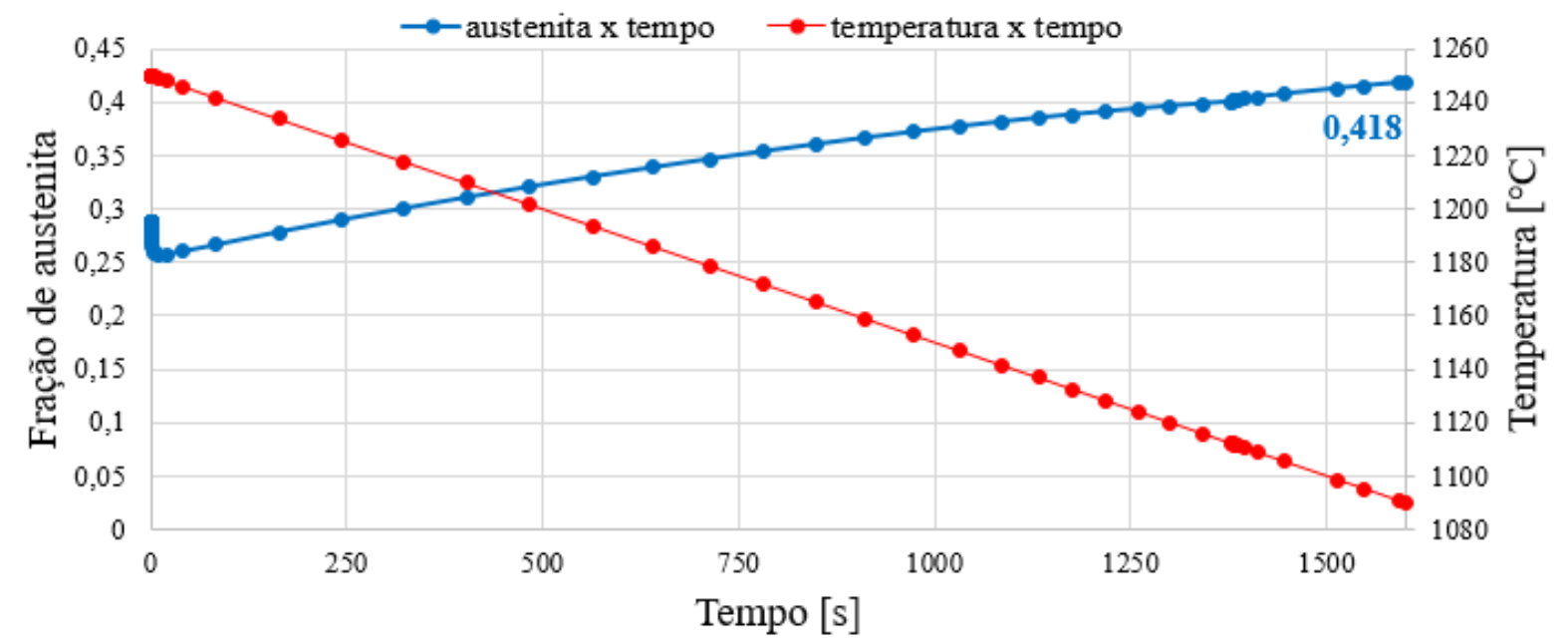

Fonte: Autora

Simulou-se também os perfis de composição química para a taxa de resfriamento de 0,1 ${ }^{\circ} \mathrm{C} / \mathrm{s}$, que por serem semelhantes aos perfis simulados a $0,3{ }^{\circ} \mathrm{C} / \mathrm{s}$, encontram-se expostos para consulta somente no Apêndice II. 
Considerando que os resultados obtidos pelas simulações dos resfriamentos à taxa de $0,3{ }^{\circ} \mathrm{C} / \mathrm{s}$ e $0,1{ }^{\circ} \mathrm{C} / \mathrm{s}$ são similares, optou-se por utilizar a taxa de $0,3{ }^{\circ} \mathrm{C} / \mathrm{s}$ para dar sequência às simulações, já que esta é a que mais se aproxima da taxa de resfriamento crítica de $0,40{ }^{\circ} \mathrm{C} / \mathrm{s}$ proposta por Nilsson (1992), cuja formação de sigma não excederia 1\%.

Sendo assim, obteve-se as funções matemáticas que descrevem a composição química da ferrita e da austenita para cada elemento, $\mathrm{Cr}$, Mo, Ni e N, no tempo final de tratamento térmico do trecho $3,500 \mathrm{~s}$, a uma taxa de resfriamento de $0,30{ }^{\circ} \mathrm{C} / \mathrm{s}$, conforme Tabela 21 do Apêndice I, possibilitando simular o próximo trecho do ciclo térmico de processamento do aço em estudo.

\subsection{SIMULAÇÃO COMPUTACIONAL DO TRECHO 4}

O trecho de número 4 (indicado pela reta laranja) da Figura 37, corresponde ao patamar na temperatura de equilíbrio de $1090^{\circ} \mathrm{C}$, para que se atinja a microestrutura dúplex. Pensando em um processo industrial, considerou-se um tempo de processamento de $3600 \mathrm{~s}$, visto que comumente se utiliza tempo de encharque de $1 \mathrm{~h} /$ polegada de espessura de tratamento térmico. A simulação do tratamento térmico na temperatura de equilíbrio de $1090{ }^{\circ} \mathrm{C}$, com tempo de patamar de 3600 s, mostra por meio das Figura 67 e 68, a fração de ferrita partindo de 58,7\% e atingindo a estabilidade em 55,5\%, e a fração de austenita partindo de 41,3\% e atingindo fração de $44,5 \%$, ao contrário dos $50 \%$ esperados em cada fase pela simulação de equilíbrio do Thermo-Calc ${ }^{\circledR}$ no tempo de processamento escolhido para o processo definido.

Entretanto, conforme já discutido no item 2, aços inoxidáveis superdúplex possuem fração volumétrica de ferrita variando entre 35 e 55\%, o que mostra que para os dados de entrada e condições utilizados nas simulações, o aço superdúplex UNS S32750 pode ser considerado como dúplex se solubilizado à $1090^{\circ} \mathrm{C}$ por $3600 \mathrm{~s}$, após os ciclos anteriormente impostos. 
Figura 67 - Fração de ferrita em função do tempo no patamar a $1090^{\circ} \mathrm{C}$ (trecho 4)

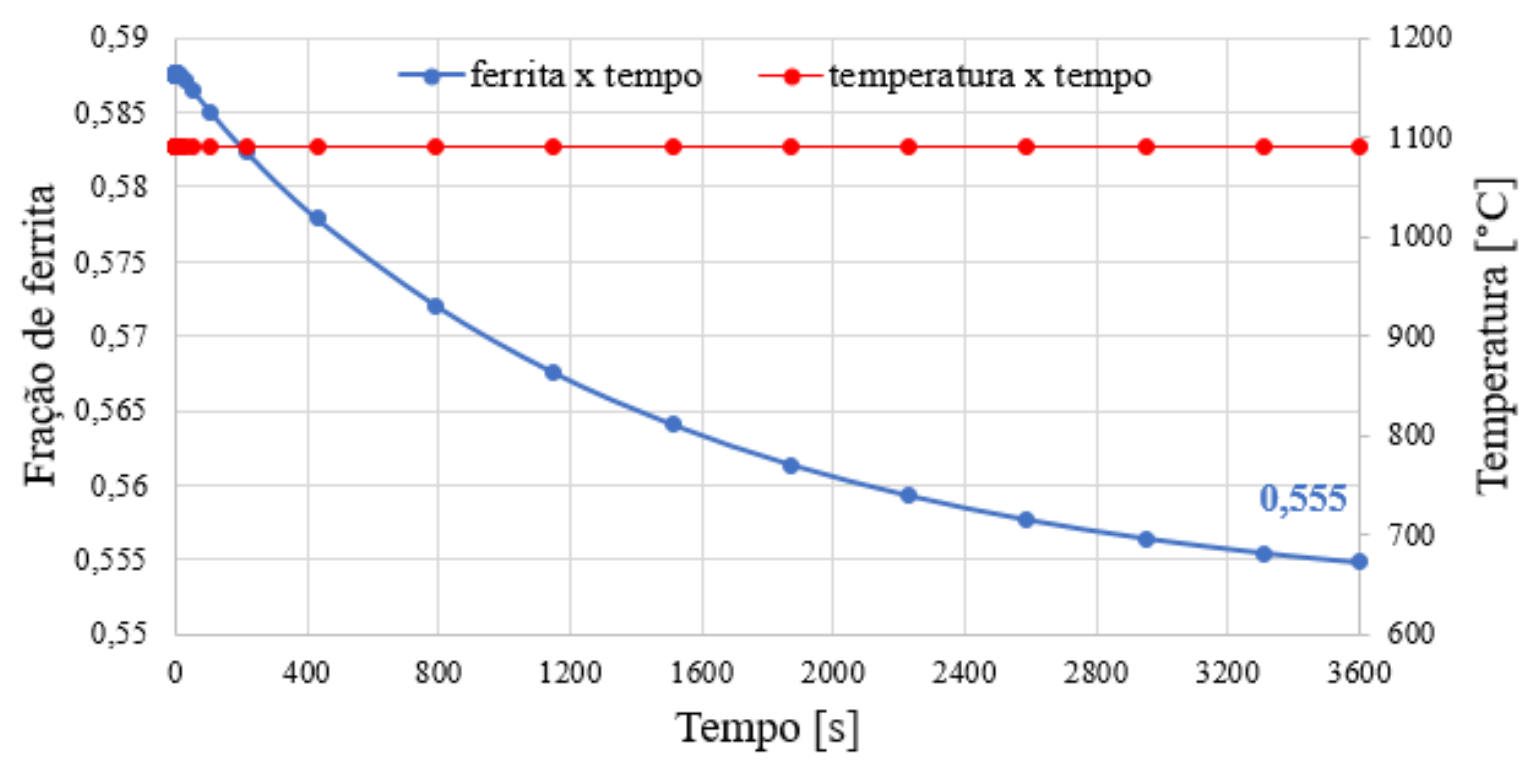

Fonte: Autora

Figura 68 - Fração de austenita em função do tempo no patamar a $1090^{\circ} \mathrm{C}$ (trecho 4)

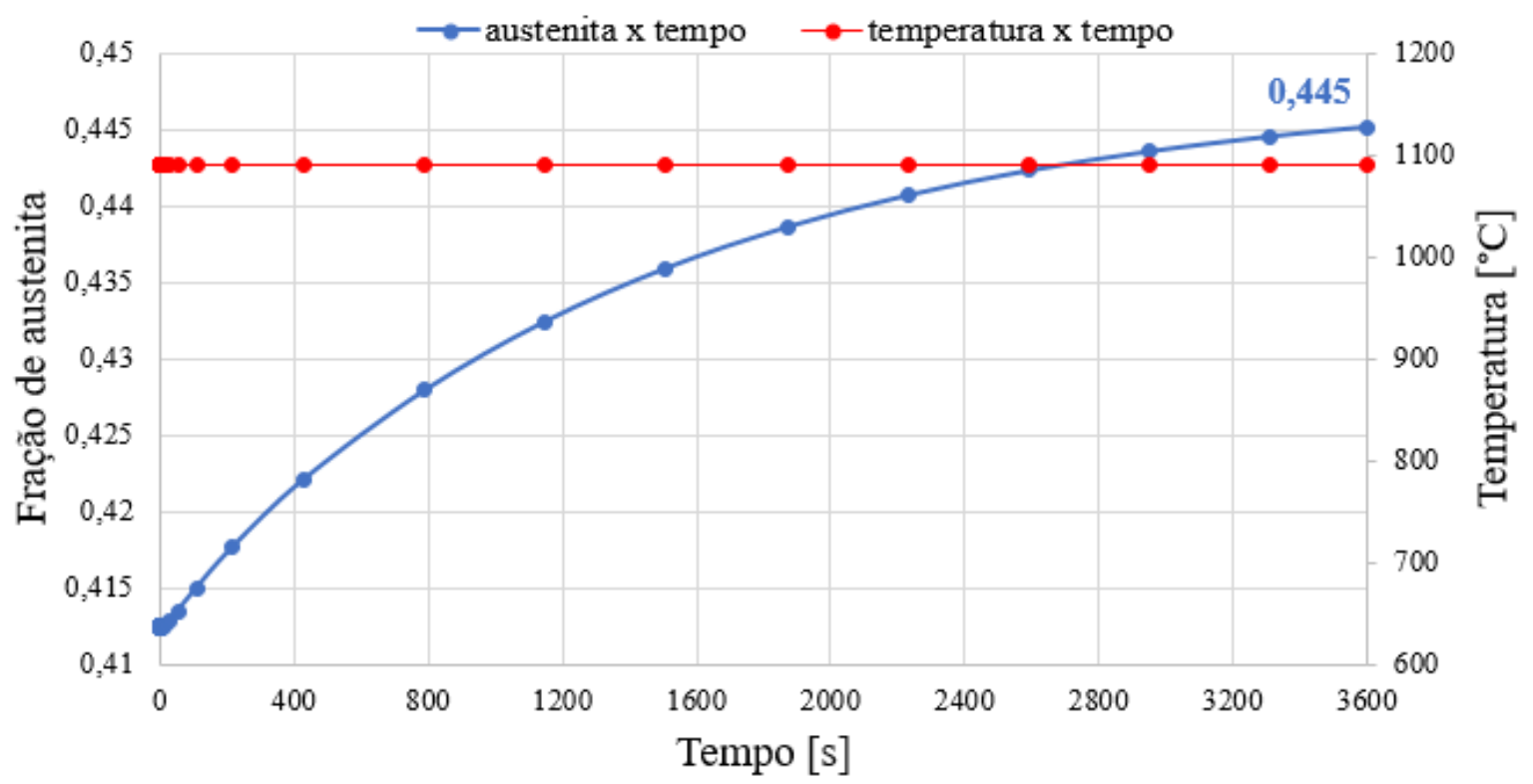

Fonte: Autora

Os perfis de composição química a $1090{ }^{\circ} \mathrm{C}$ para os elementos químicos expostos nas Figura 69 a 72, mostram, mais uma vez, a semelhança de comportamento entre o Cr e Mo, cujos teores são maiores na ferrita, e entre o $\mathrm{Ni}$ e $\mathrm{N}$, os quais predominam na austenita, sendo que em todos os casos, a difusão acontece da austenita para a ferrita, visto que a interface $\alpha / \gamma$ se desloca da direita para a esquerda em função do tempo. Além disso, a variação das frações dos elementos em cada fase é semelhante às simulações anteriores. 
Entretanto, deve-se destacar que mesmo realizando-se o tratamento térmico na temperatura de solubilização de $1090^{\circ} \mathrm{C}$ por $3600 \mathrm{~s}$, ainda há gradiente de composição de todos os elementos químicos, tanto na ferrita quanto na austenita, o que mostra que o aço em questão não atingiu o equilíbrio proposto pelo Thermo-Calc ${ }^{\circledR}$ Por isso, é de extrema importância que se realize a simulação computacional da cinética de transformação de fases no DICTRA ${ }^{\circledR}$, proposta nesta dissertação.

Figura 69 - Perfil de composição de Cr no patamar a $1090^{\circ} \mathrm{C}$ (trecho 4) em função da distância

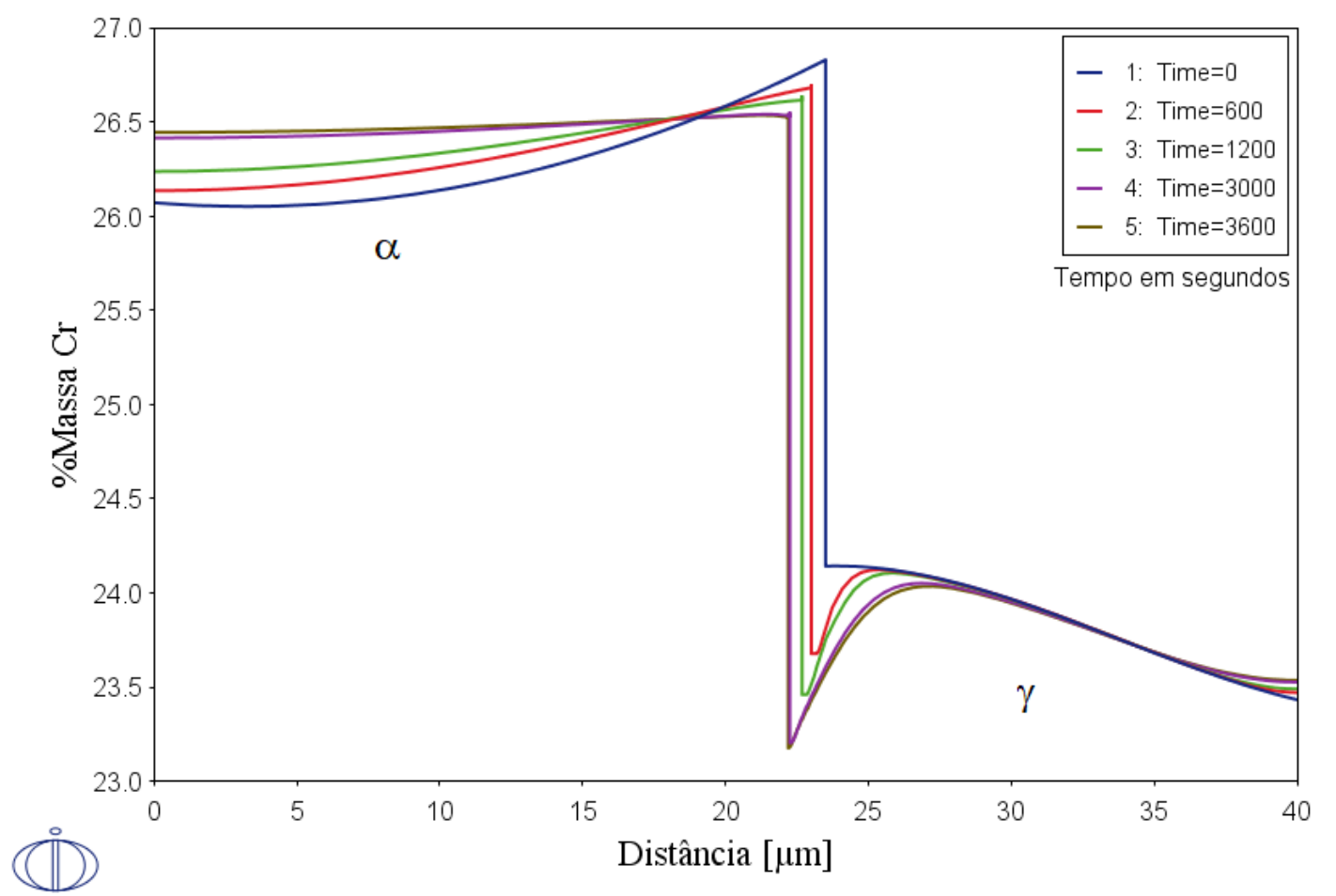

Fonte: Autora 
Figura 70 - Perfil de composição de Mo no patamar a $1090^{\circ} \mathrm{C}$ (trecho 4) em função da distância

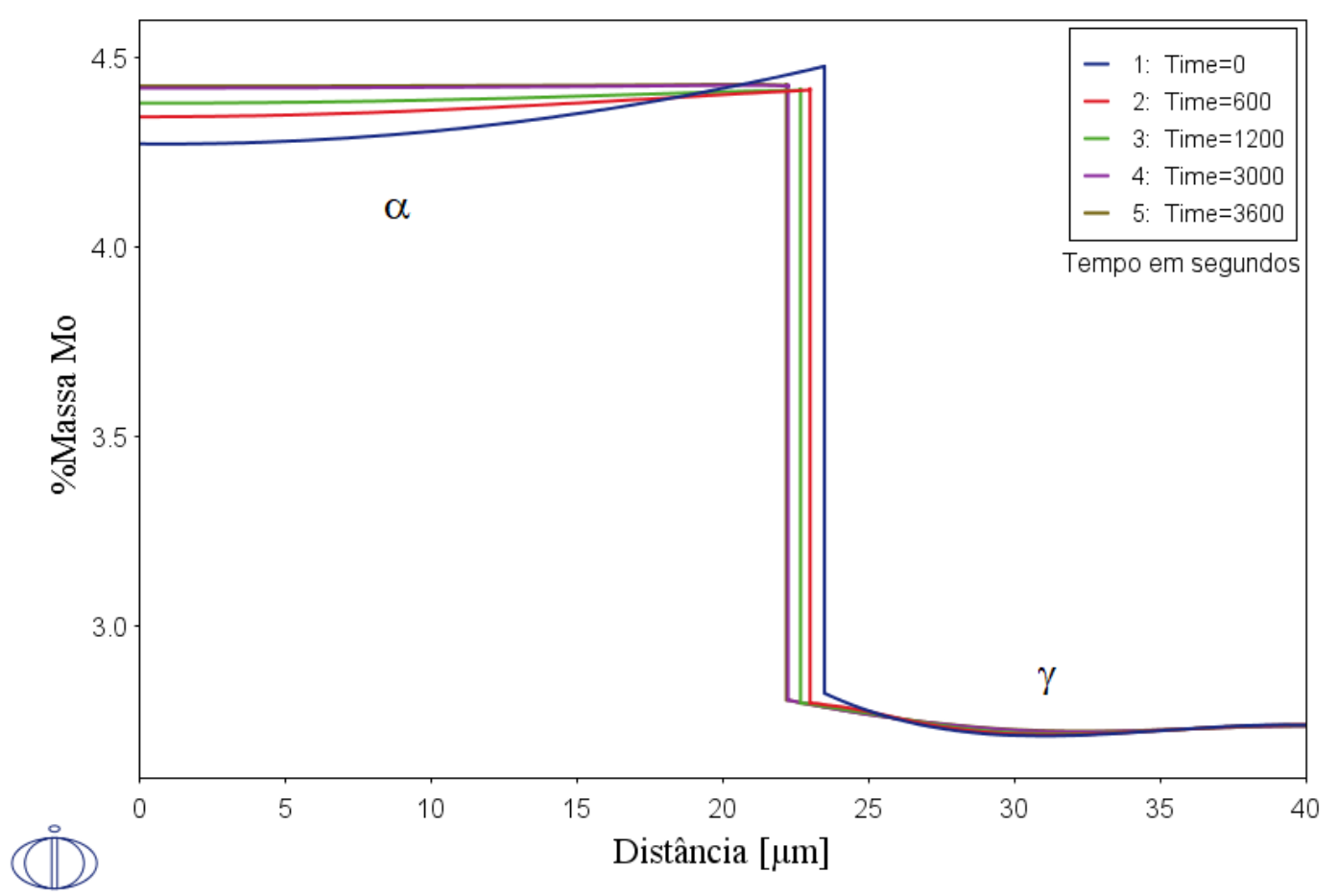

Fonte: Autora

Figura 71 - Perfil de composição de Ni no patamar a $1090^{\circ} \mathrm{C}$ (trecho 4) em função da distância

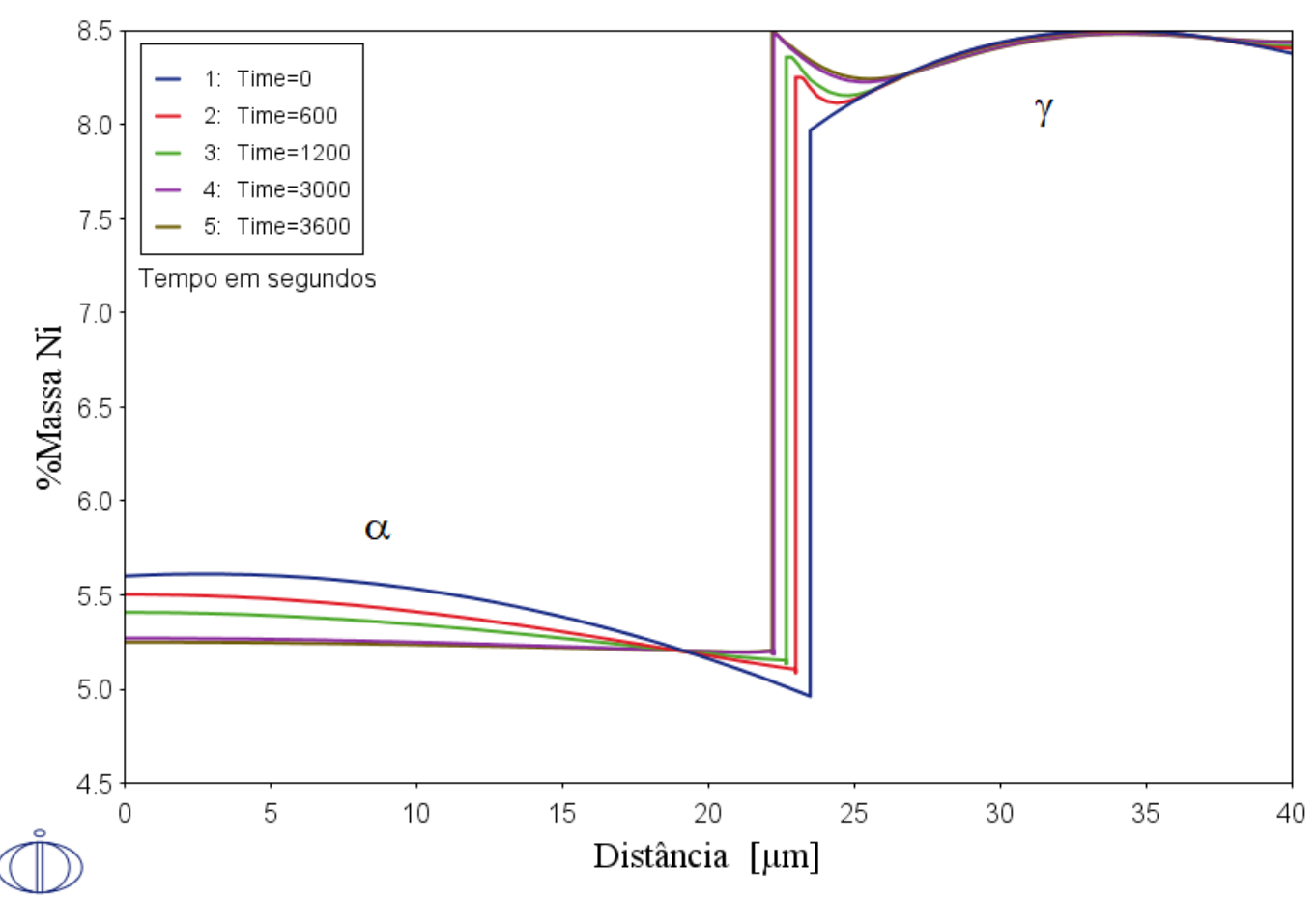

Fonte: Autora 
Figura 72 - Perfil de composição de N no patamar a $1090^{\circ} \mathrm{C}$ (trecho 4) em função da distância

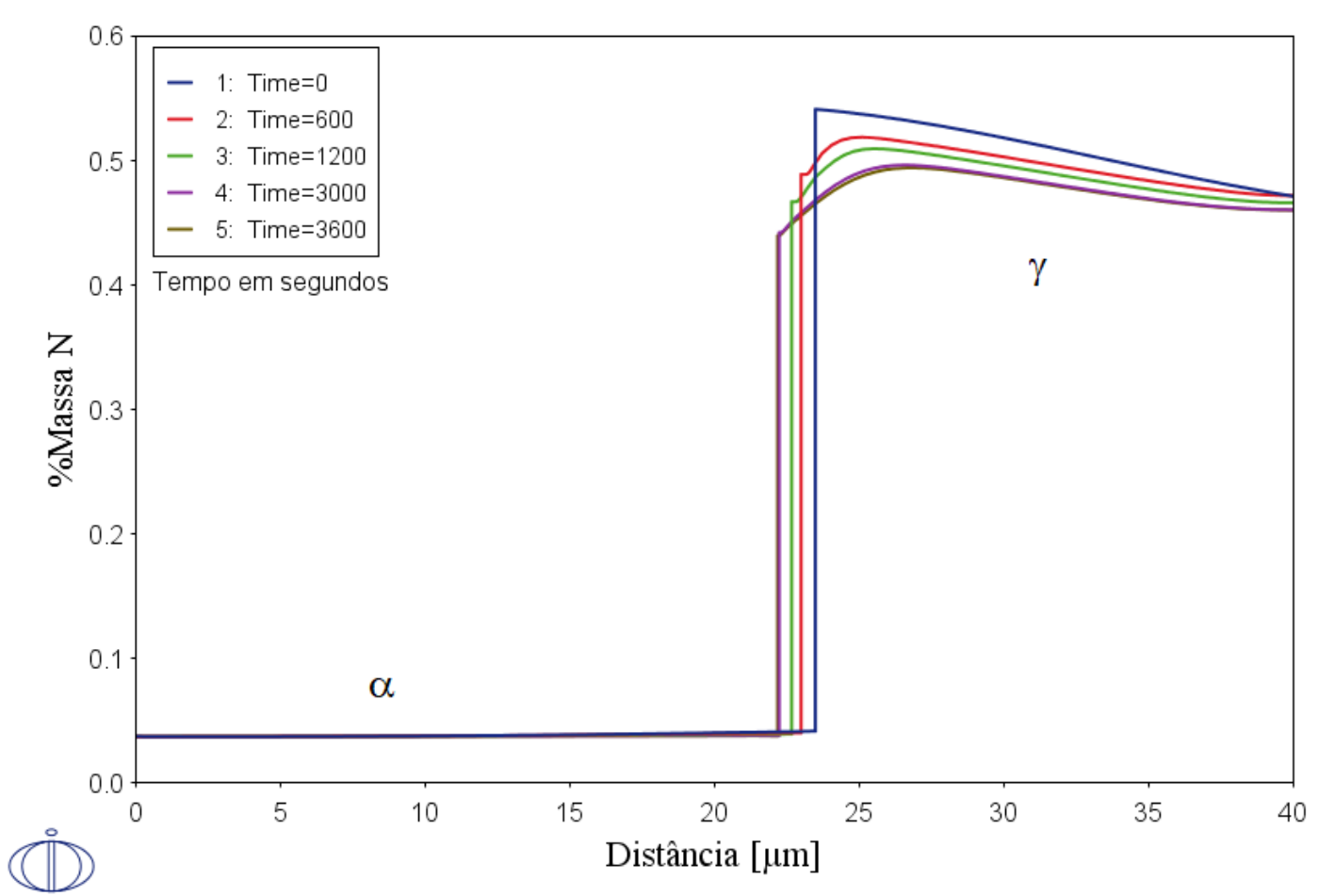

Fonte: Autora

\subsection{SIMULAÇÃO COMPUTACIONAL DO TRECHO 5}

A curva de tempo final de tratamento térmico de cada elemento químico do trecho 4 foi utilizada para obter-se as funções matemáticas que as descrevem em ambas as fases, necessárias para simular-se o trecho 5 (representado pela linha azul) da Figura 37, que corresponde ao resfriamento a partir do equilíbrio atingido previamente em $1090{ }^{\circ} \mathrm{C}$ até a temperatura de $790{ }^{\circ} \mathrm{C}$, em que não se deseja qualquer transformação de fase, mantendo-se a estrutura dúplex desejada.

Como sigma pode precipitar em temperaturas inferiores a $1050{ }^{\circ} \mathrm{C}$, vide diagrama de equilíbrio da Figura 38, a fase inativa foi inserida à direita da ferrita como dado de entrada da simulação. O trecho 5 foi simulado em dois tempos, $1000 \mathrm{~s}$ e $3000 \mathrm{~s}$, para comparar as taxas de resfriamento de $0,30{ }^{\circ} \mathrm{C} / \mathrm{s}$ (semelhante aos trechos anteriormente simulados) e $0,60{ }^{\circ} \mathrm{C} / \mathrm{s}$ (o dobro da anterior, que por ser mais alta, pode evitar ou reduzir a precipitação de sigma).

A fração volumétrica das fases na simulação do trecho 5, isto é, no resfriamento do equilíbrio a $1090{ }^{\circ} \mathrm{C}$ até $790{ }^{\circ} \mathrm{C}$ a uma taxa de $0,30{ }^{\circ} \mathrm{C} / \mathrm{s}$, podem ser vistos a seguir nas Figuras 73 a 75 . Observa-se que a fração de ferrita parte de 55,5\% e atinge 56,9\%, que a austenita parte 
de $44,5 \%$ e atinge fração de 40,6\% e ainda precipitam-se $2,5 \%$ de fase sigma. Neste caso, o aumento da fração de ferrita e redução de austenita, se deve ao reequilíbrio $\alpha / \gamma$ do gradiente de composição que ainda restava no trecho 4 , seguido da formação de fase sigma no sistema.

Figura 73 - Fração de ferrita no resfriamento do aço de $1090^{\circ} \mathrm{C}$ até $790^{\circ} \mathrm{C}$ (trecho 5) à taxa de $0,30^{\circ} \mathrm{C} / \mathrm{s}$

Taxa de resfriamento: $0,30^{\circ} \mathrm{C} / \mathrm{s}$

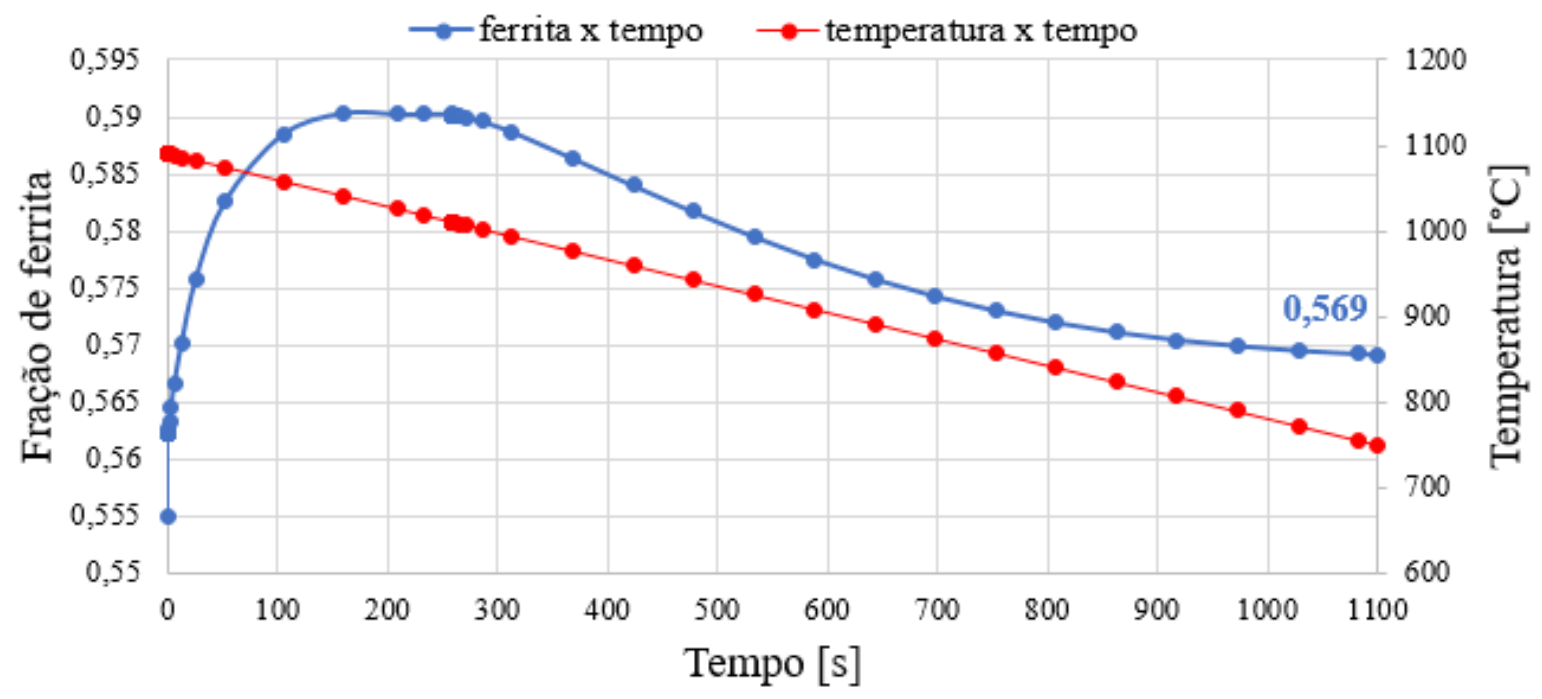

Fonte: Autora

Figura 74 - Fração de austenita no resfriamento do aço de $1090^{\circ} \mathrm{C}$ até $790^{\circ} \mathrm{C}$ (trecho 5) à taxa de $0,30^{\circ} \mathrm{C} / \mathrm{s}$

Taxa de resfriamento: $0,30^{\circ} \mathrm{C} / \mathrm{s}$

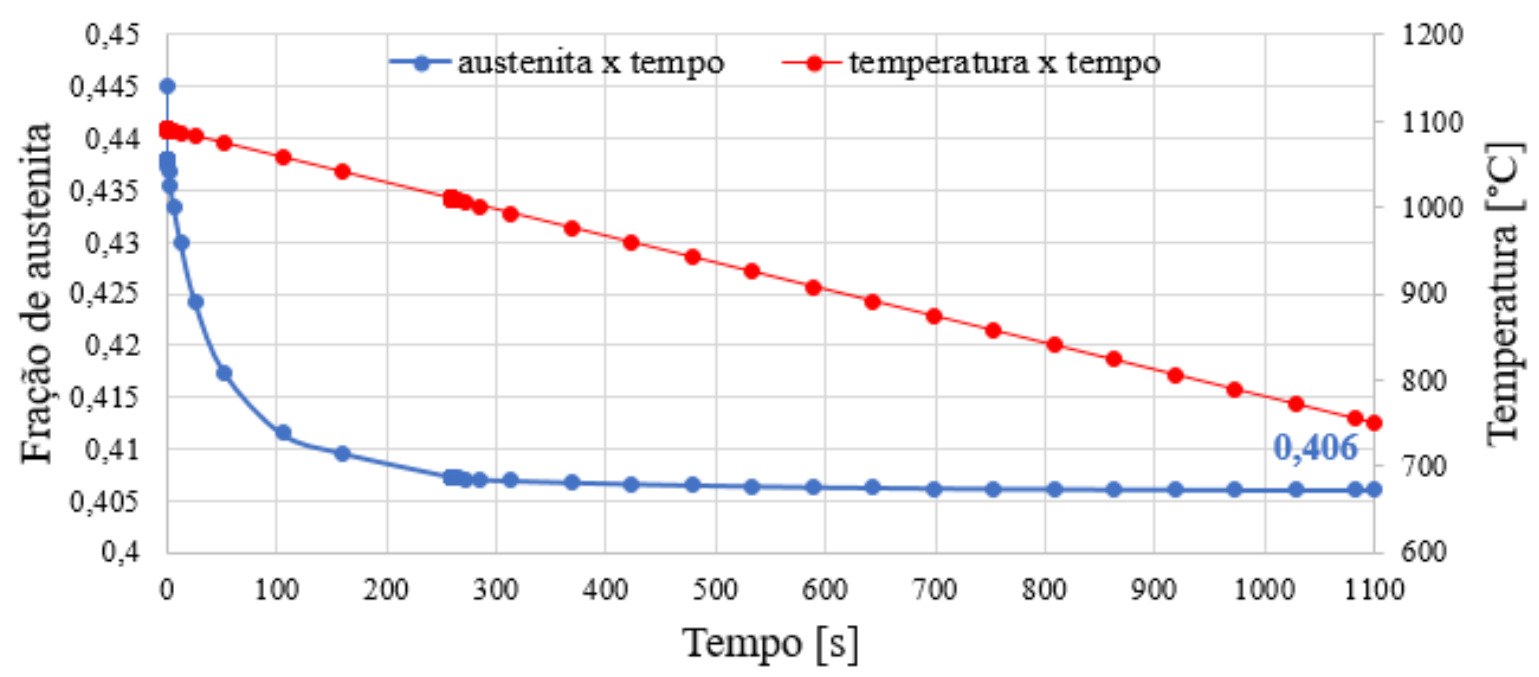

Fonte: Autora 
Figura 75 - Fração de sigma no resfriamento do aço de $1090^{\circ} \mathrm{C}$ até $790^{\circ} \mathrm{C}$ (trecho 5) à taxa de $0,30^{\circ} \mathrm{C} / \mathrm{s}$

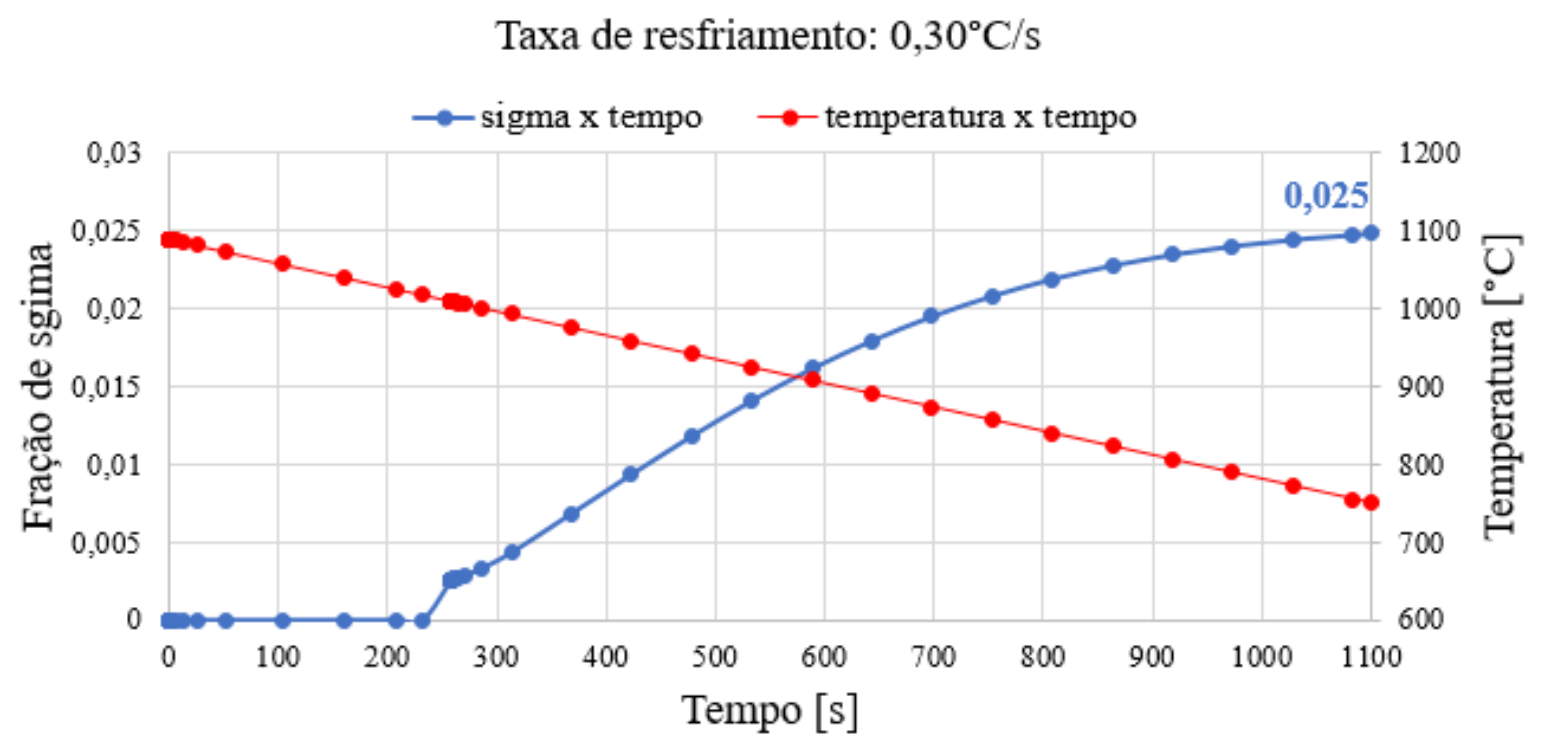

Fonte: Autora

Os perfis de composição química do trecho 5 no resfriamento à taxa de $0,30{ }^{\circ} \mathrm{C} / \mathrm{s}$ podem ser vistos a seguir, mostrando que há maior concentração de Cr e Mo na ferrita, Figura 76 e 77, e maior concentração de Ni na austenita, Figuras 78 e 79, como era de se esperar. É possível notar também que há mais gradiente de composição química na interface $\alpha / \gamma$ do que na difusão entre as fases através da interface. Isso se deve à formação heterogênea de fase sigma na interface entre as fases, promovendo enriquecimento de $\mathrm{Cr}$ e Mo na região. 
Figura 76 - Perfil de composição de Cr no resfriamento de $1090^{\circ} \mathrm{C} \mathrm{a} 790^{\circ} \mathrm{C}$ (trecho 5) em função da distância à taxa de $0,30^{\circ} \mathrm{C} / \mathrm{s}$

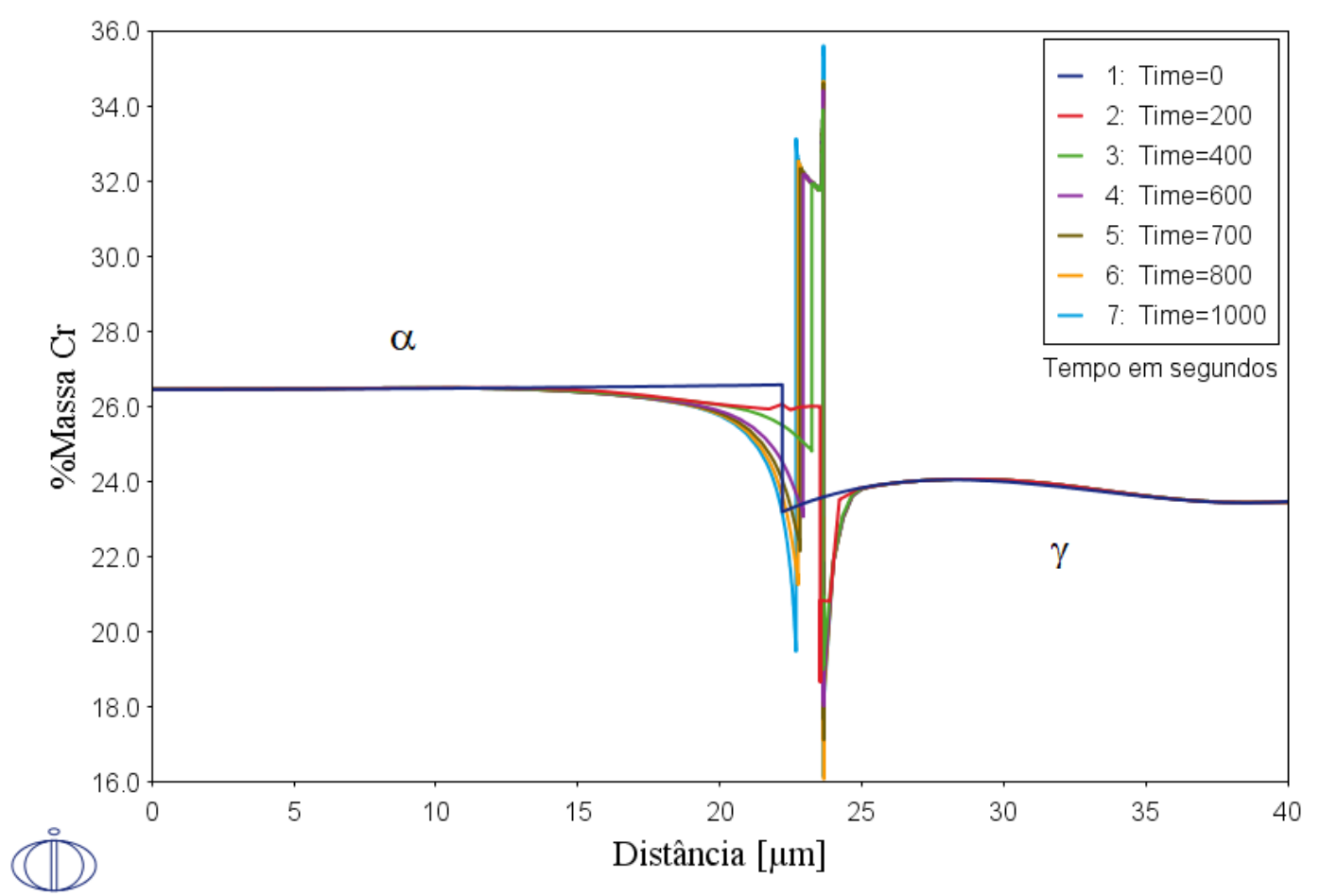

Fonte: Autora

Figura 77 - Perfil de composição de Mo no resfriamento de $1090^{\circ} \mathrm{C}$ a $790^{\circ} \mathrm{C}$ (trecho 5) em função da distância à taxa de $0,30^{\circ} \mathrm{C} / \mathrm{s}$

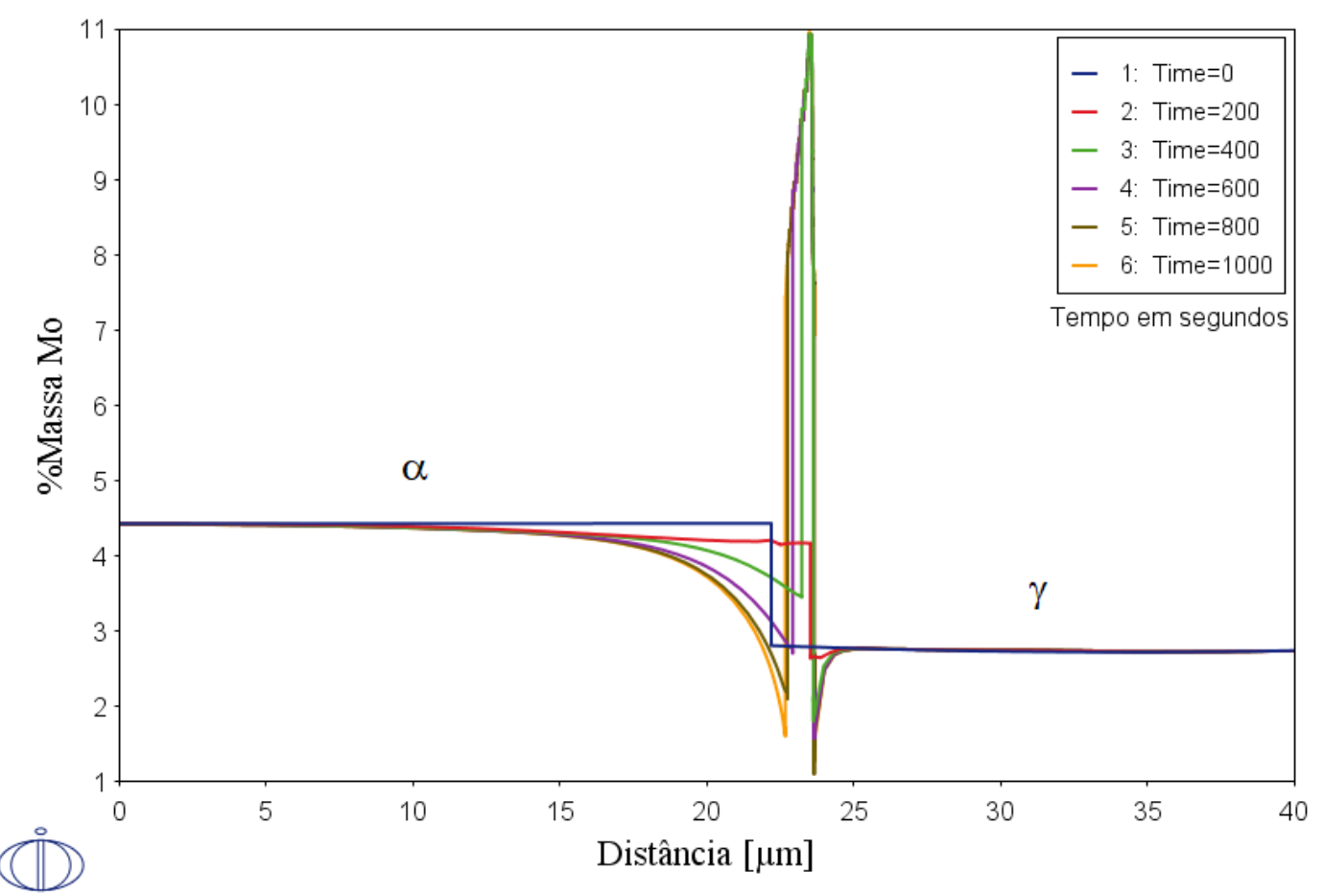

Fonte: Autora 
Figura 78 - Perfil de composição de Ni no resfriamento de $1090^{\circ} \mathrm{C}$ a $790^{\circ} \mathrm{C}$ (trecho 5) em função da distância à taxa de $0,30^{\circ} \mathrm{C} / \mathrm{s}$

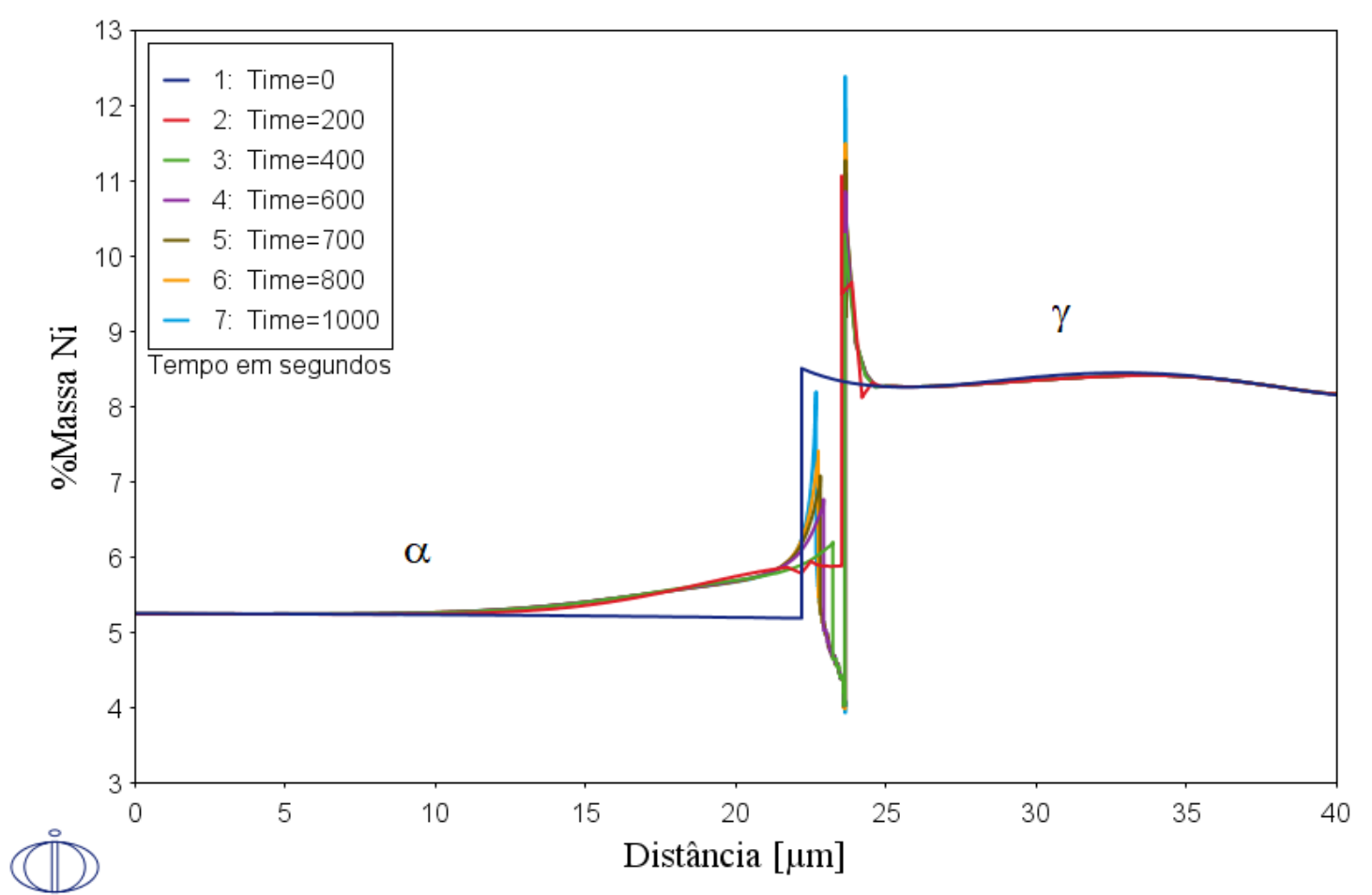

Fonte: Autora

A simulação do resfriamento de $1090{ }^{\circ} \mathrm{C}$ a $790{ }^{\circ} \mathrm{C}$ do trecho 5 também foi feita com taxa de $0,60{ }^{\circ} \mathrm{C} / \mathrm{s}$ para comparar à taxa de $0,30^{\circ} \mathrm{C} / \mathrm{s}$, na tentativa de reduzir a fração de sigma precipitada, obtendo-se fração volumétrica das fases vide Figura 79 a 81 . Nota-se que a fração de ferrita parte de $55,5 \%$ e atinge $56,4 \%$, a austenita parte de $44,5 \%$ e atinge fração de $41,7 \%$ e ainda é formado $1,8 \%$ de fase sigma. 
Figura 79 - Fração de ferrita no resfriamento do aço de $1090^{\circ} \mathrm{C}$ até $790^{\circ} \mathrm{C}$ (trecho 5) à taxa de $0,60^{\circ} \mathrm{C} / \mathrm{s}$

Taxa de resfriamento: $0,60^{\circ} \mathrm{C} / \mathrm{s}$

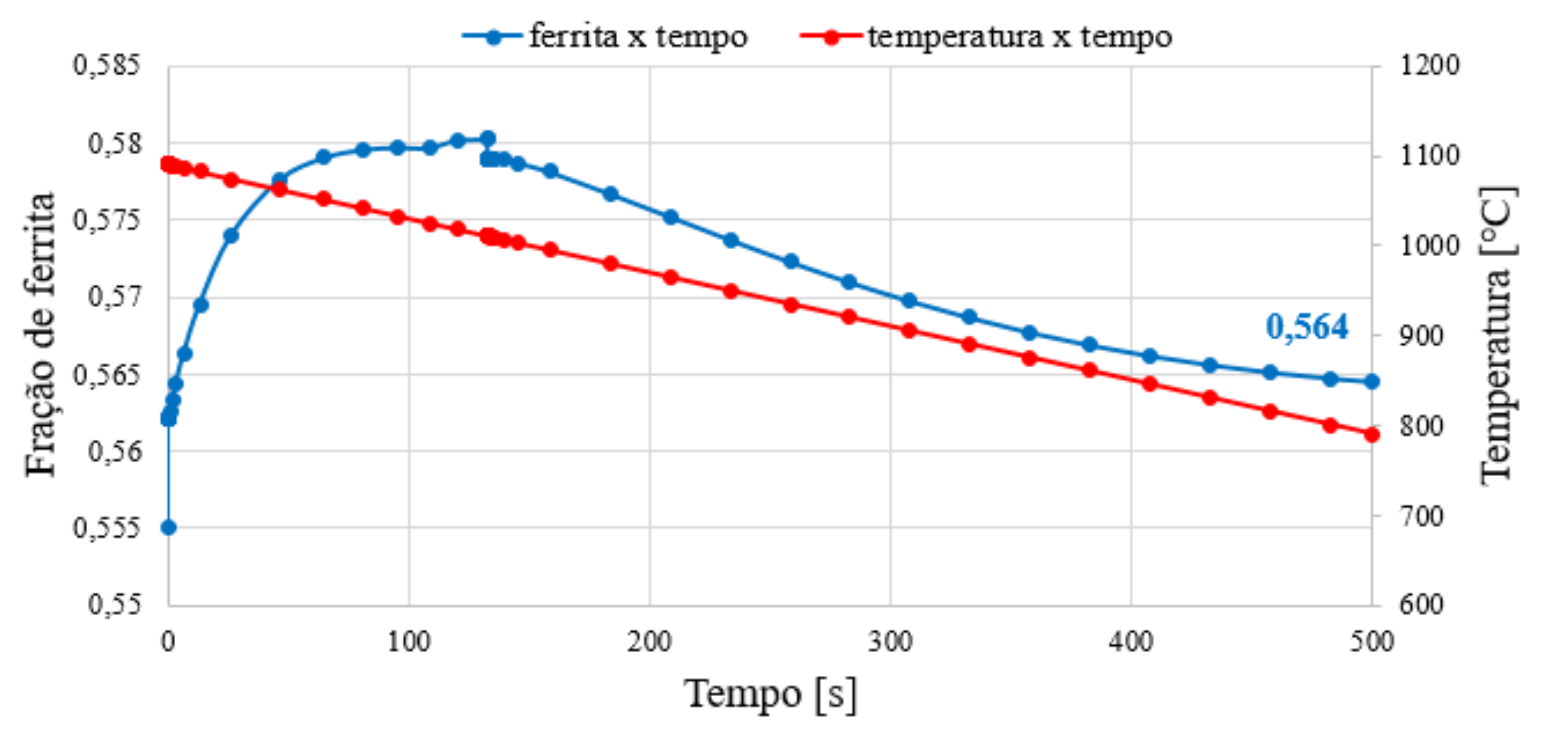

Fonte: Autora

Figura 80 - Fração de austenita no resfriamento do aço de $1090^{\circ} \mathrm{C}$ até $790^{\circ} \mathrm{C}$ (trecho 5) à taxa de $0,60^{\circ} \mathrm{C} / \mathrm{s}$

Taxa de resfriamento: $0,60^{\circ} \mathrm{C} / \mathrm{s}$

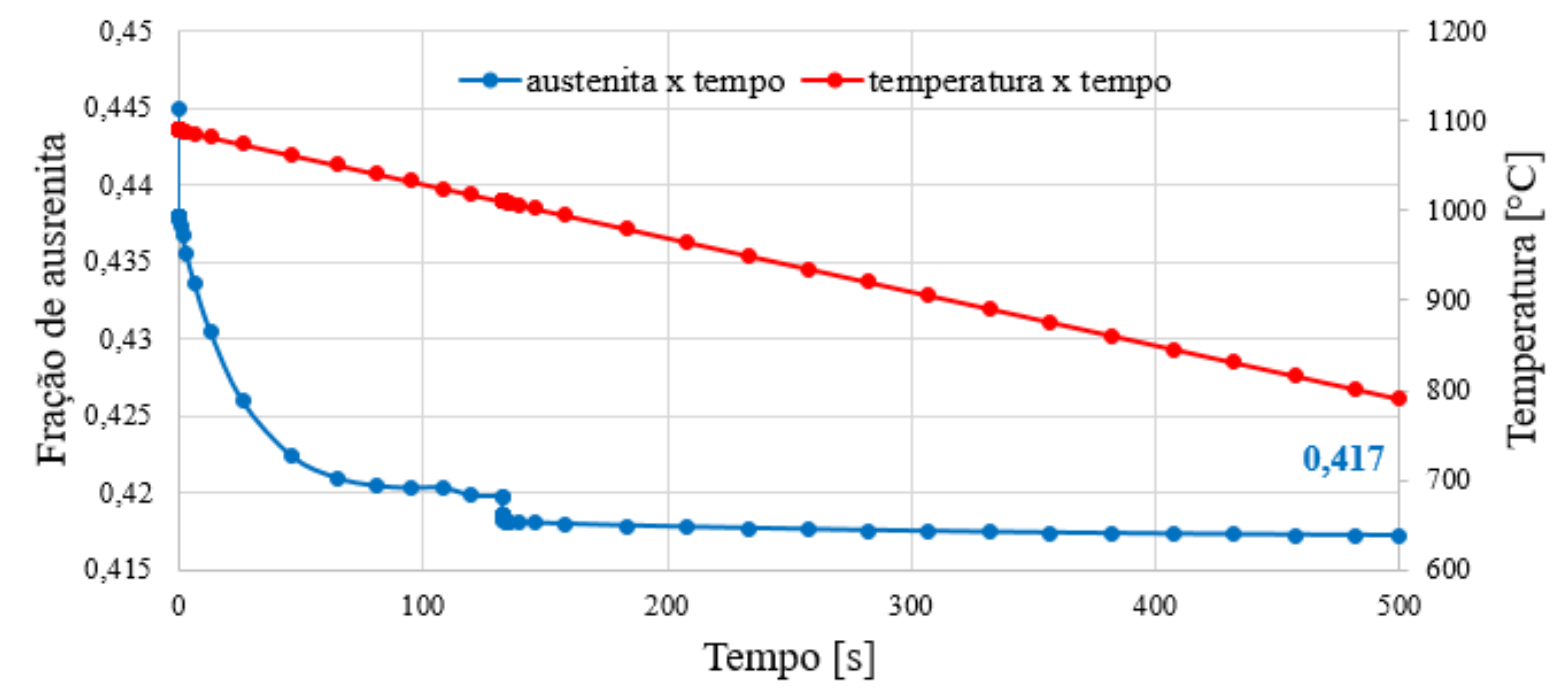

Fonte: Autora 
Figura 81 - Fração de sigma no resfriamento do aço de $1090^{\circ} \mathrm{C}$ até $790^{\circ} \mathrm{C}$ (trecho 5) à taxa de $0,60^{\circ} \mathrm{C} / \mathrm{s}$

\section{Taxa de resfriamento: $0,60^{\circ} \mathrm{C} / \mathrm{s}$}

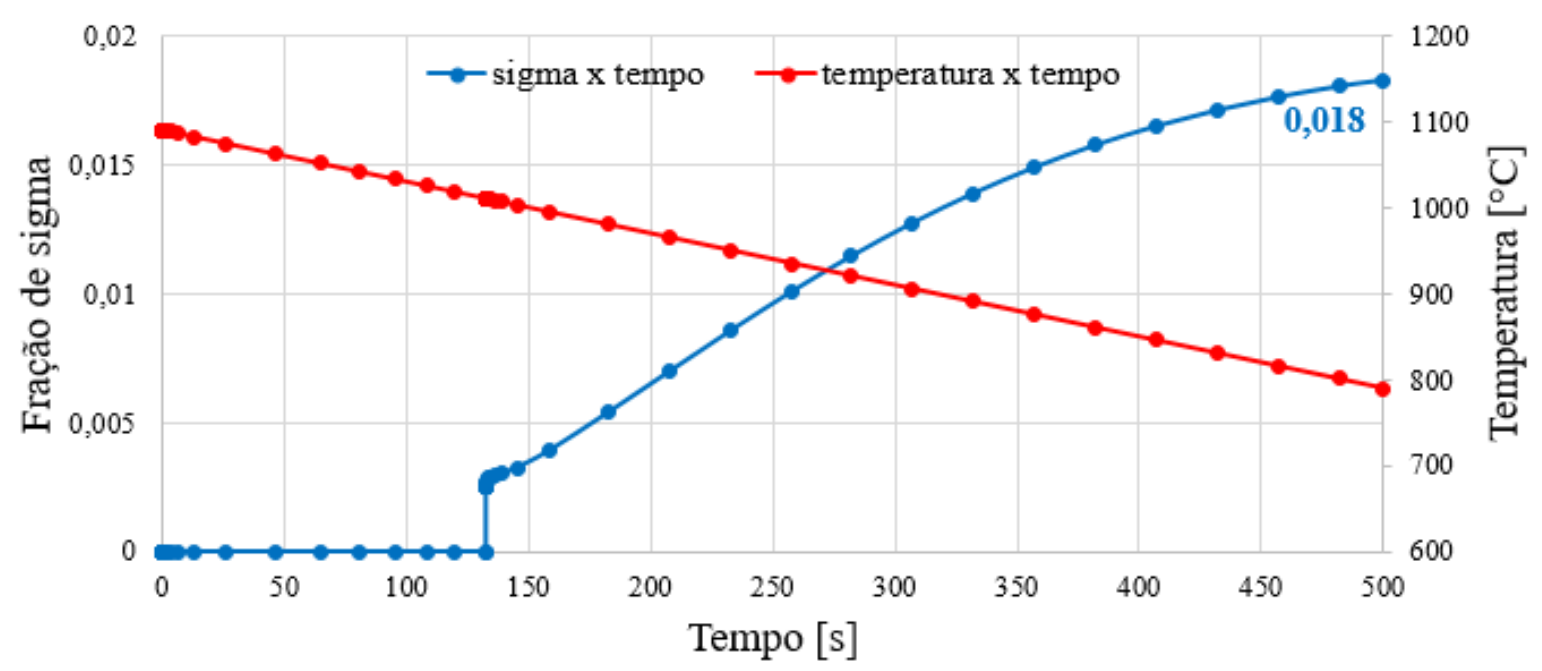

Fonte: Autora

Entretanto, ao contrário do que reportou Nilsson (1992) para o aço inoxidável superdúplex UNS S32750 e composição química $\mathrm{Fe}-22,9 \% \mathrm{Cr}-6,9 \% \mathrm{Ni}-3,8 \% \mathrm{Mo}$, as taxas de resfriamento simuladas nesta dissertação acima de $0,40{ }^{\circ} \mathrm{C} / \mathrm{s}$ também para o aço superdúplex UNS S32750, na composição química de $\mathrm{Fe}-25,7 \% \mathrm{Cr}-6,31 \% \mathrm{Ni}-3,88 \% \mathrm{Mo}$, formam mais que $1 \%$ de sigma e, portanto, se faz necessário definir a taxa crítica para o sistema em questão.

Por este motivo, simulou-se o trecho 5 às taxas de resfriamento de $0,9^{\circ} \mathrm{C} / \mathrm{s}, 1,2^{\circ} \mathrm{C} / \mathrm{s}$, $1,5^{\circ} \mathrm{C} / \mathrm{s}$ e $3{ }^{\circ} \mathrm{C} / \mathrm{s}$, além de $0,3{ }^{\circ} \mathrm{C} / \mathrm{s}$ e $0,6^{\circ} \mathrm{C}$ já apresentadas, até que se encontrasse a menor taxa capaz de formar menos de $1 \%$ de fase sigma. O gráfico da Figura 82 mostra a comparação entre as frações de sigma formadas ao longo do tempo em função das diferentes taxas de resfriamento.

As maiores taxas de resfriamento apresentam menor fração de sigma precipitada e, consequentemente, atingem o equilíbrio de fração máxima da fase em menor tempo. Conforme diminui-se a taxa de resfriamento, maior é a fração de sigma formada, uma vez que há mais tempo para a difusão dos elementos. A fração volumétrica de sigma varia desde $2,48 \%$ à taxa de $0,3{ }^{\circ} \mathrm{C} / \mathrm{s}$ até $0,97 \%$ à taxa de $3,0^{\circ} \mathrm{C} / \mathrm{s}$, sendo este último, o valor mínimo esperado pela literatura para taxas superiores a $0,4{ }^{\circ} \mathrm{C} / \mathrm{s}$, segundo Nilsson (1992). A comparação da fração máxima obtida em função da taxa de resfriamento do trecho 5 está exposta na Tabela 16. 
Figura 82 - Fração de sigma formada ao longo do tempo em função da taxa de resfriamento no trecho 5

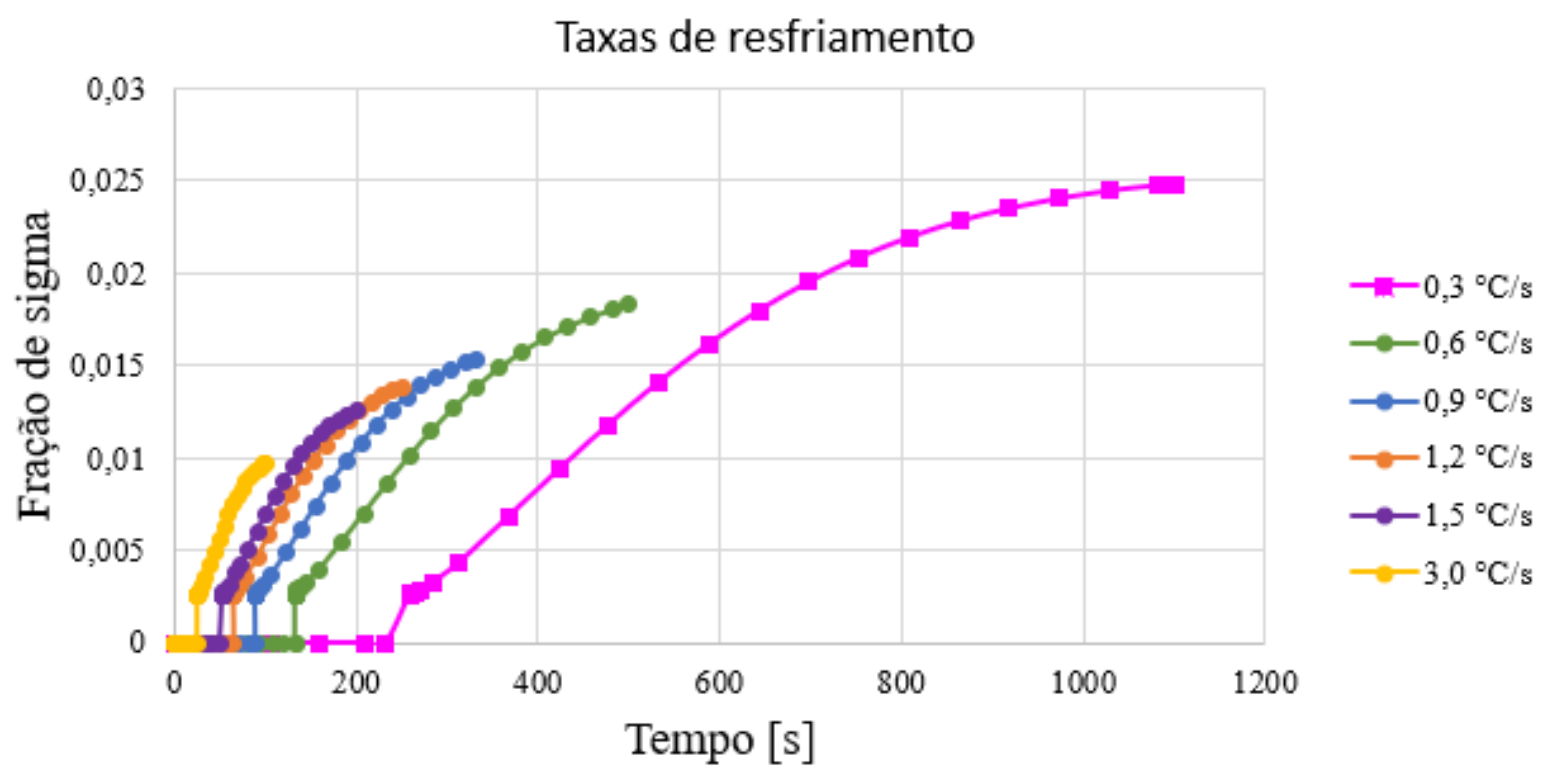

Fonte: Autora

Tabela 16 - Fração máxima de sigma formada em função da taxa de resfriamento no trecho 5

\begin{tabular}{ccc}
\hline & $\begin{array}{c}\text { Taxa de } \\
\text { resfriamento }\end{array}$ & $\begin{array}{c}\text { Fração máxima } \\
\text { de sigma }\end{array}$ \\
\cline { 2 - 3 } Trecho 5 & $0,3^{\circ} \mathrm{C} / \mathrm{s}$ & $2,48 \%$ \\
\cline { 2 - 3 } & $0,6^{\circ} \mathrm{C} / \mathrm{s}$ & $1,83 \%$ \\
\cline { 2 - 3 } $0,9^{\circ} \mathrm{C} / \mathrm{s}$ & $1,53 \%$ \\
\hline $1,2^{\circ} \mathrm{C} / \mathrm{s}$ & $1,38 \%$ \\
\hline $1,5^{\circ} \mathrm{C} / \mathrm{s}$ & $1,25 \%$ \\
\hline $3,0^{\circ} \mathrm{C} / \mathrm{s}$ & $0,97 \%$
\end{tabular}

Fonte: Autora

Considerando-se que somente com taxas de resfriamento superiores a $3,0^{\circ} \mathrm{C} / \mathrm{s}$ é que se tem frações de sigma abaixo de $1 \%$, tem-se então $3{ }^{\circ} \mathrm{C} / \mathrm{s}$ como a taxa crítica do resfriamento de $1090{ }^{\circ} \mathrm{C}$ a $790{ }^{\circ} \mathrm{C}$. As Figura 83 a 85 mostram as frações volumétricas das fases formadas à taxa de $3,0{ }^{\circ} \mathrm{C} / \mathrm{s}$, obtendo-se $55,9 \%$ de ferrita, $43,1 \%$ de austenita e $0,97 \%$ de sigma, atingindose a condição dúplex desejada, com o mínimo de sigma precipitada à menor taxa de resfriamento possível. 
Figura 83 - Fração de ferrita no resfriamento do aço de $1090^{\circ} \mathrm{C}$ até $790^{\circ} \mathrm{C}$ (trecho 5) à taxa de $3,0^{\circ} \mathrm{C} / \mathrm{s}$

Taxa de resfriamento: $3,0^{\circ} \mathrm{C} / \mathrm{s}$

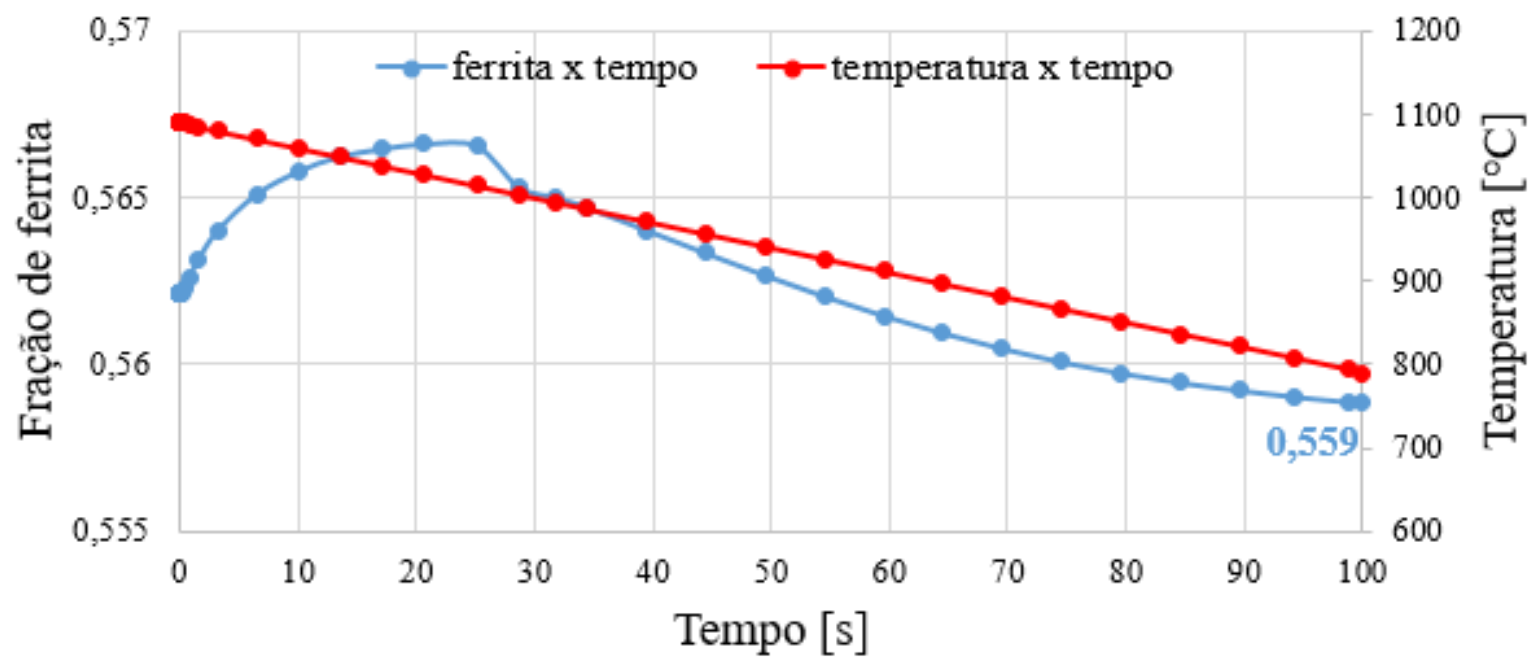

Fonte: Autora

Figura 84 - Fração de austenita no resfriamento do aço de $1090^{\circ} \mathrm{C}$ até $790^{\circ} \mathrm{C}$ (trecho 5) à taxa de $3,0^{\circ} \mathrm{C} / \mathrm{s}$

Taxa de resfriamento: $3,0^{\circ} \mathrm{C} / \mathrm{s}$

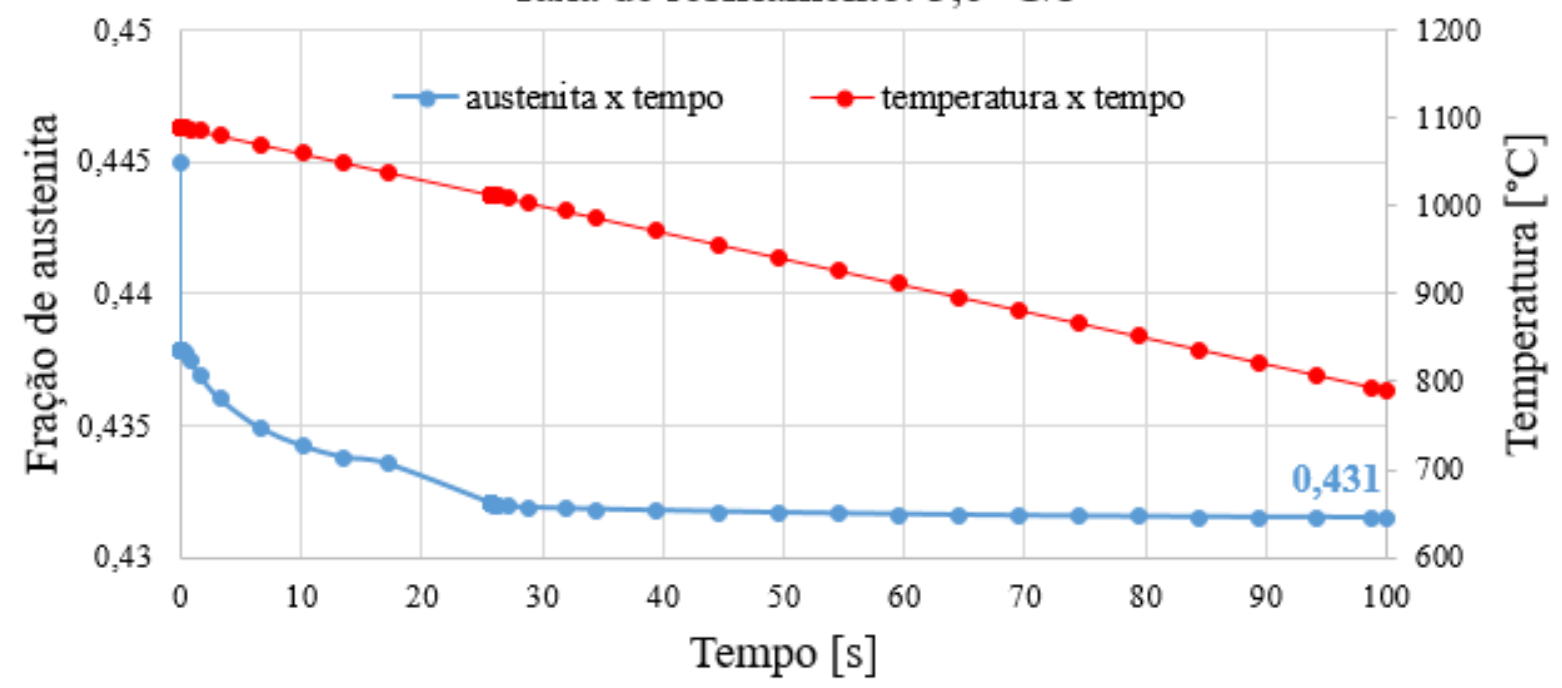

Fonte: Autora 
Figura 85 - Fração de sigma no resfriamento do aço de $1090^{\circ} \mathrm{C}$ até $790^{\circ} \mathrm{C}$ (trecho 5) à taxa de $3,0^{\circ} \mathrm{C} / \mathrm{s}$

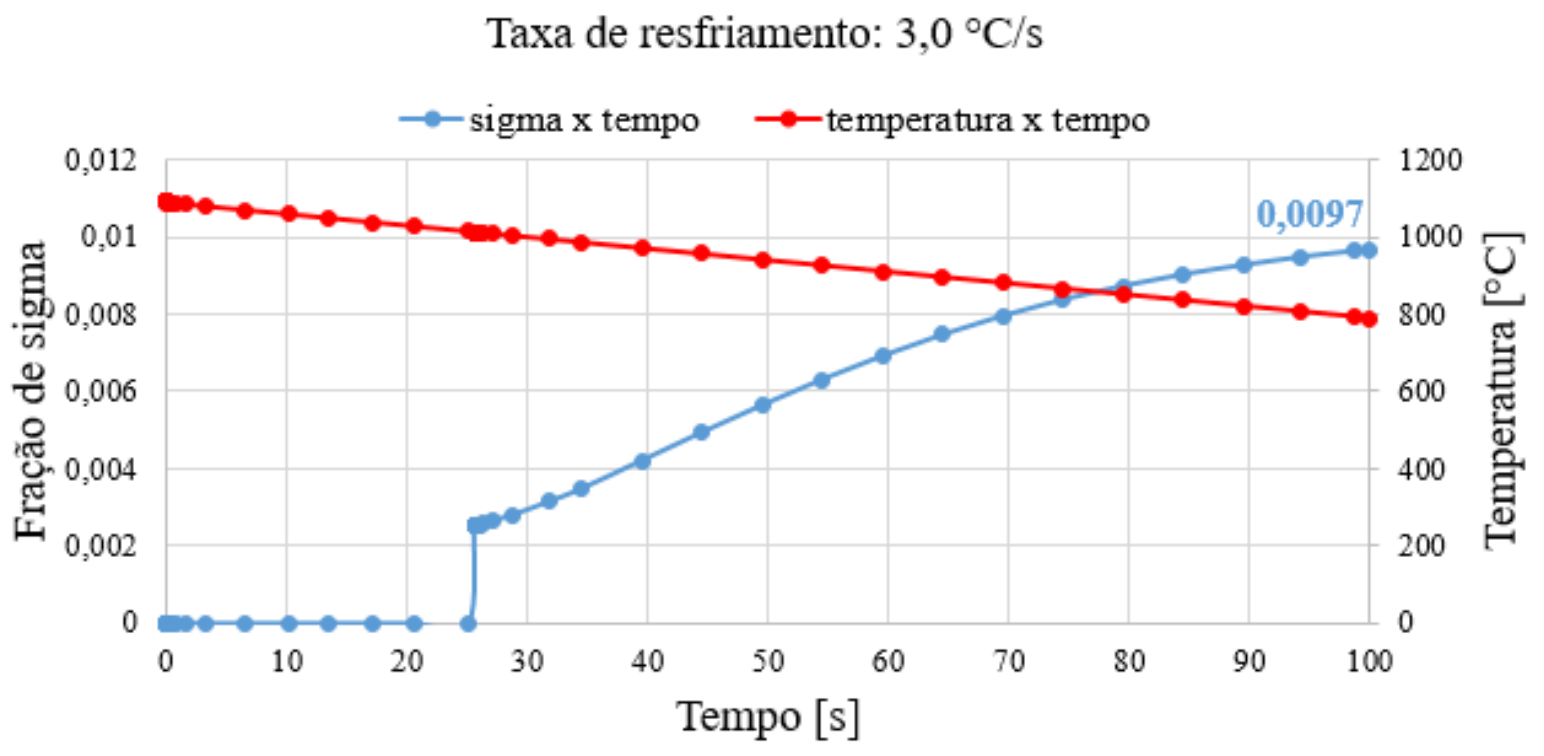

Fonte: Autora

Para a simulação do resfriamento do trecho 5, que tem por intuito verificar a possibilidade de precipitação de sigma que se dará na interface ferrita/austenita, removeu-se o $\mathrm{N}$ da composição química das fases, pois as bases de dados não definem $\mathrm{N}$ como elemento constituinte da fase sigma, conforme já discutido no item 3.2.5. Assim sendo, não há resultado de perfis de composição de $\mathrm{N}$ no resfriamento até $790{ }^{\circ} \mathrm{C}$ do trecho 5 .

Os perfis de composição química do trecho 5 no resfriamento à taxa de $3,0^{\circ} \mathrm{C} / \mathrm{s}$, isto é, no tempo de tratamento de $100 \mathrm{~s}$, podem ser vistos a seguir, Figuras 86 a 88, mostrando, uma vez mais, que há maior concentração de Cr e Mo na ferrita e maior concentração de Ni na austenita. Nota-se que também há mais gradiente de composição química na interface $\alpha / \gamma$ do que na difusão entre as fases através da interface, devido à formação heterogênea de fase sigma na interface entre as fases, promovendo enriquecimento de $\mathrm{Cr}$ e Mo na região. 
Figura 86 - Perfil de composição de Cr no resfriamento de $1090^{\circ} \mathrm{C}$ a $790^{\circ} \mathrm{C}$ (trecho 5) em função da distância à taxa de $3,0^{\circ} \mathrm{C} / \mathrm{s}$

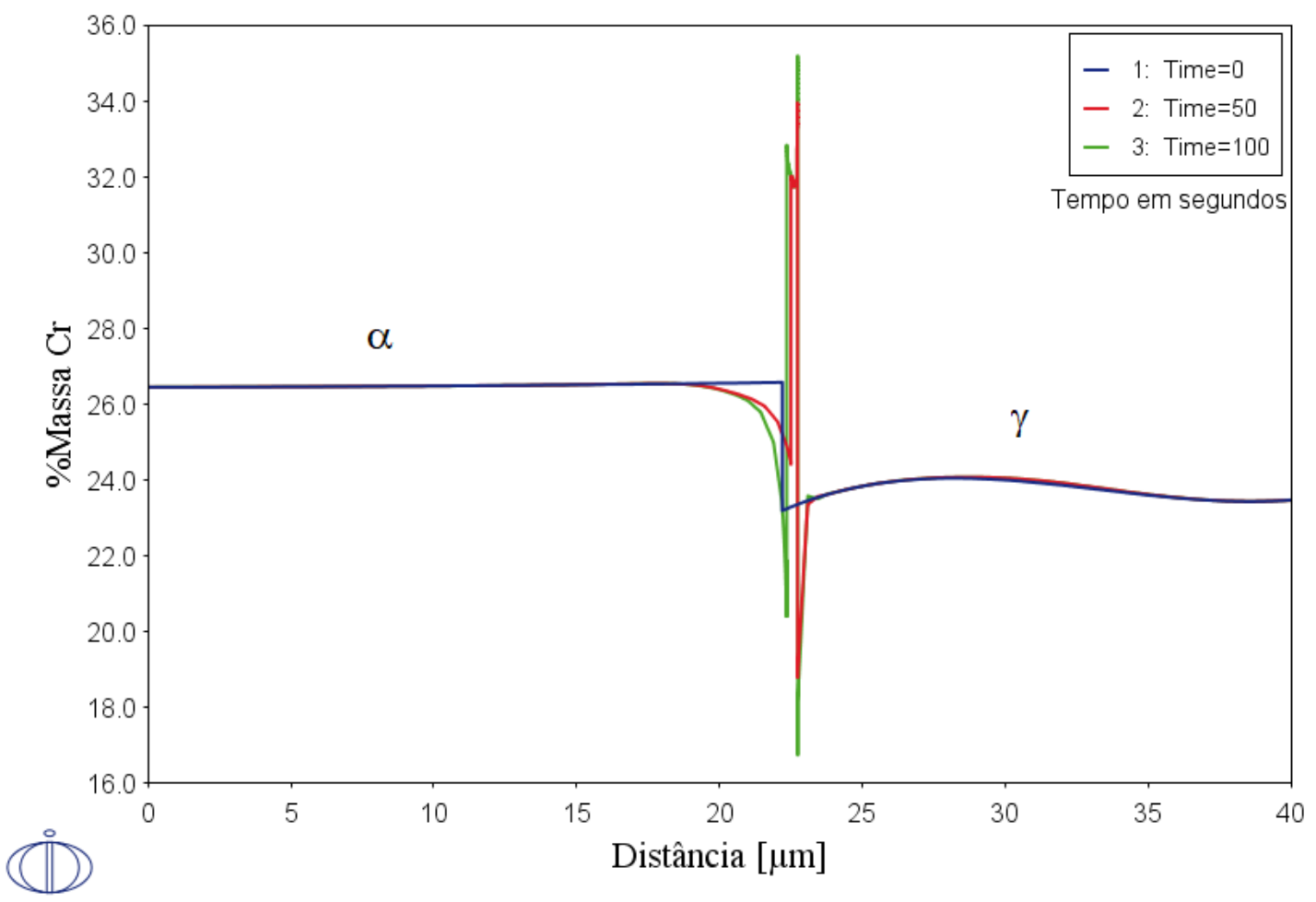

Fonte: Autora

Figura 87 - Perfil de composição de Mo no resfriamento de $1090^{\circ} \mathrm{C}$ a $790^{\circ} \mathrm{C}$ (trecho 5) em função da distância à taxa de $3,0^{\circ} \mathrm{C} / \mathrm{s}$

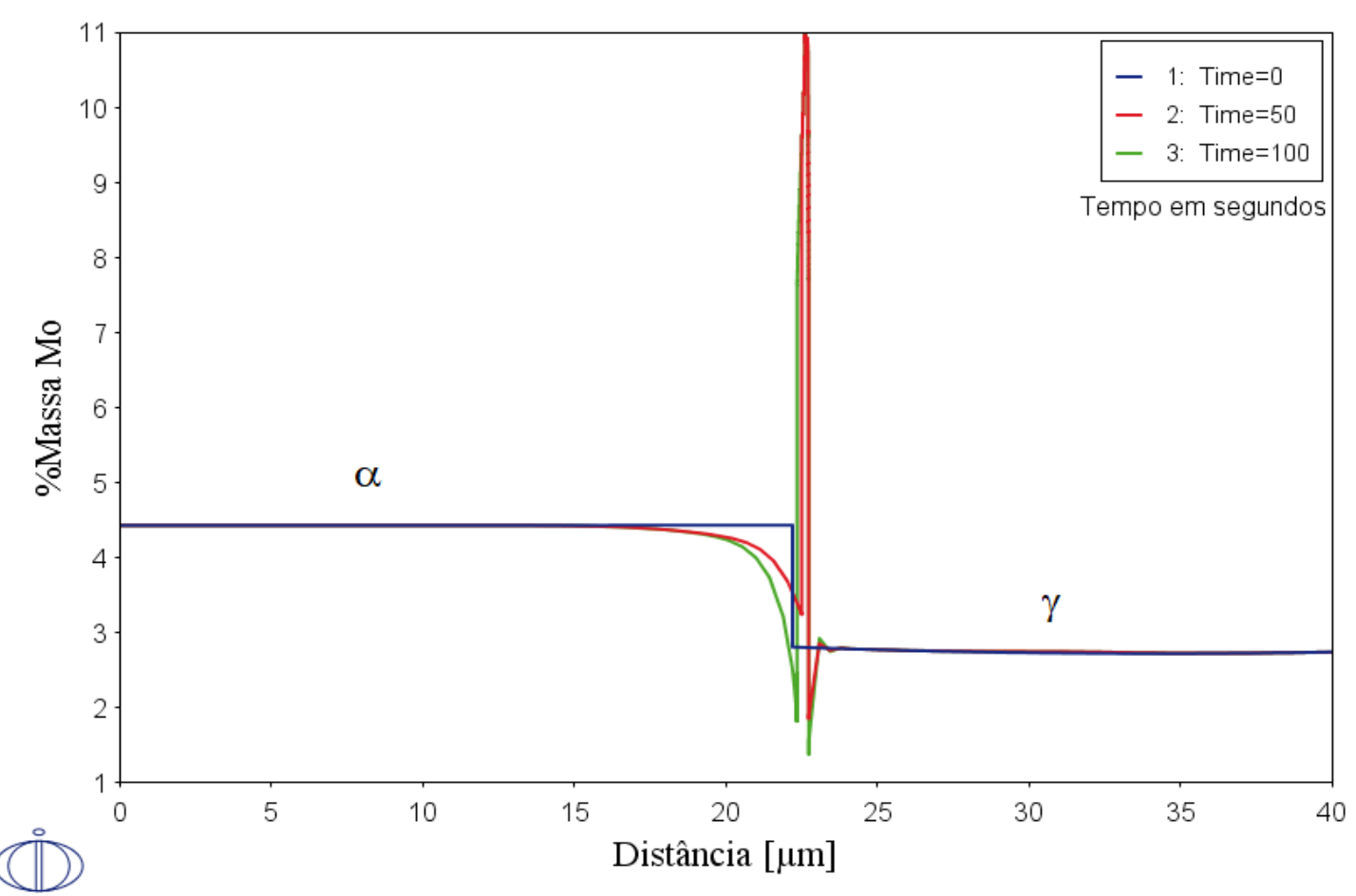

Fonte: Autora 
Figura 88 - Perfil de composição de Mo no resfriamento de $1090^{\circ} \mathrm{C}$ a $790^{\circ} \mathrm{C}$ (trecho 5) em função da distância à taxa de $3,0^{\circ} \mathrm{C} / \mathrm{s}$

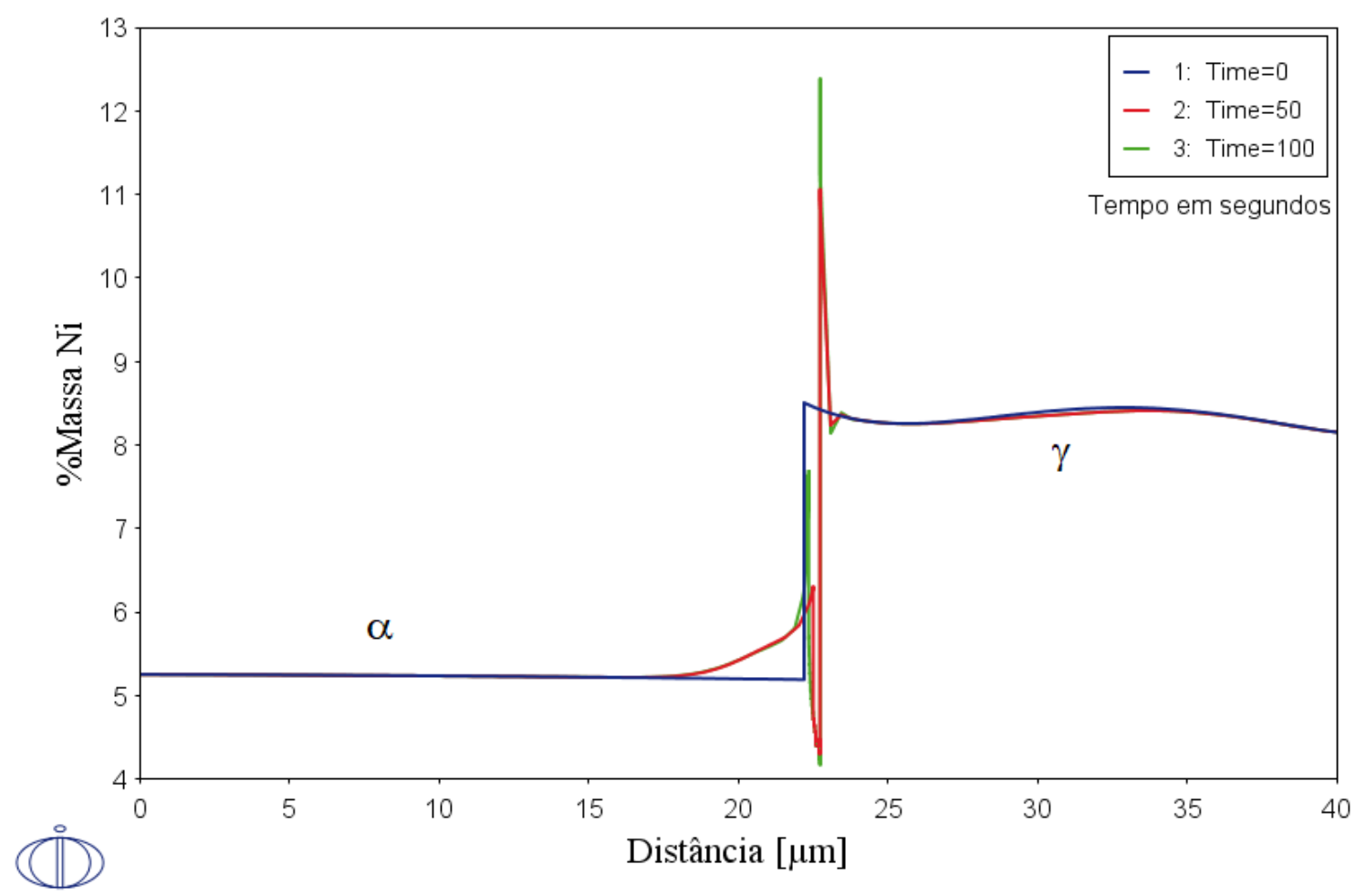

Fonte: Autora

\subsection{SIMULAÇÃO COMPUTACIONAL DO TRECHO 6}

Semelhante ao trecho 5, conforme já mencionado no item 3.2, também pode ser feito o resfriamento ao final do tratamento térmico do trecho 3, isto é, assim que se atinge a temperatura de solubilização, $1090^{\circ} \mathrm{C}$, sem levar em consideração o tempo de patamar, como mostra o trecho 6 (indicado pela seta roxa) da Figura 37, o que pode levar a formação de fases indesejáveis como a sigma. Considerando-se essa condição, realizou-se o resfriamento do trecho 6 à taxa de $0,30^{\circ} \mathrm{C} / \mathrm{s}$ e $3,0^{\circ} \mathrm{C} / \mathrm{s}$, baseado na menor e maior taxas simuladas no trecho 5 .

A simulação do trecho 6 no resfriamento de $1090{ }^{\circ} \mathrm{C}$ até $790{ }^{\circ} \mathrm{C}$ à taxa de $0,30{ }^{\circ} \mathrm{C} / \mathrm{s}$, resulta em uma fração volumétrica de ferrita que parte de 58,7\% (ao final do trecho 3) e atinge $60,9 \%$, Figura 89, uma fração de austenita que parte de 41,3\% e atinge 36,7\%, Figura 90, e ainda formam-se $2,4 \%$ de fase sigma, Figura 91. 
Figura 89 - Fração de ferrita no resfriamento do aço de $1090^{\circ} \mathrm{C}$ até $790^{\circ} \mathrm{C}$ (trecho 6) à taxa de $0,30^{\circ} \mathrm{C} / \mathrm{s}$

\section{Taxa de resfriamento: $0,30^{\circ} \mathrm{C} / \mathrm{s}$}

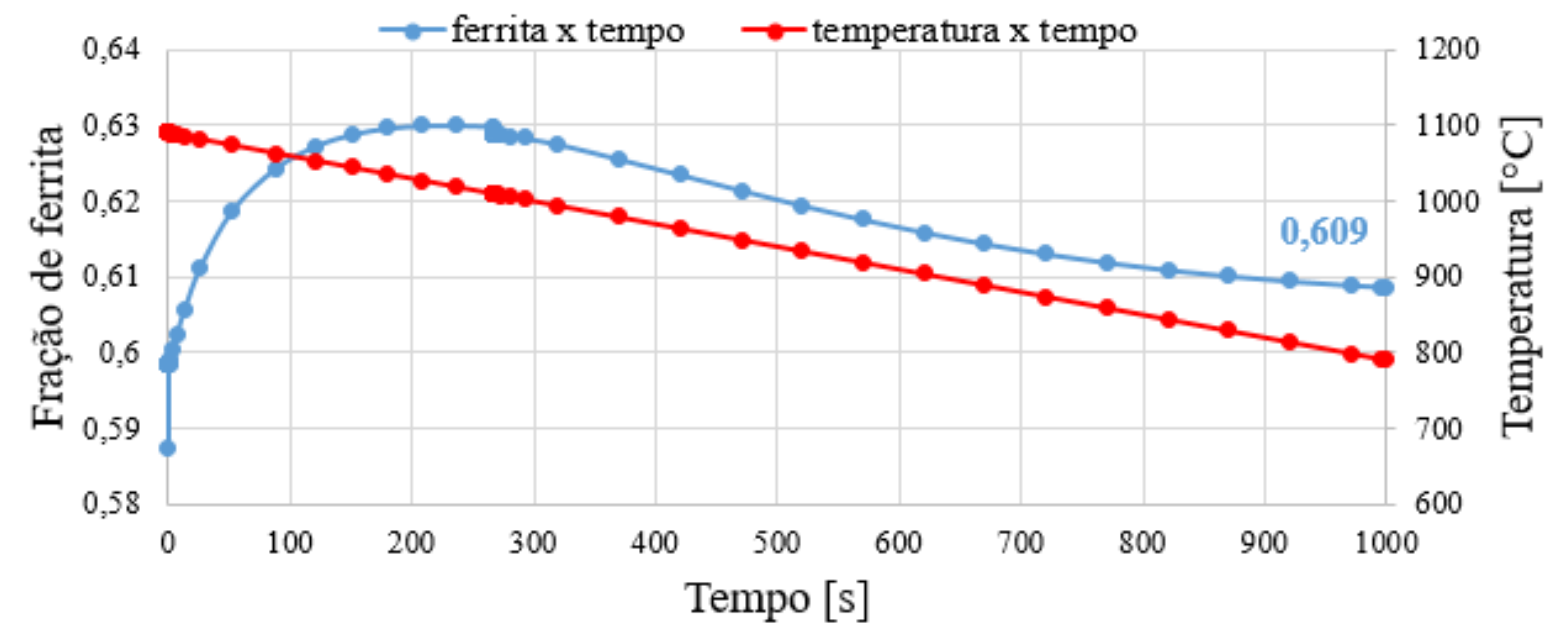

Fonte: Autora

Figura 90 - Fração de austenita no resfriamento do aço de $1090^{\circ} \mathrm{C}$ até $790^{\circ} \mathrm{C}$ (trecho 6) à taxa de $0,30^{\circ} \mathrm{C} / \mathrm{s}$

Taxa de resfriamento: $0,30^{\circ} \mathrm{C} / \mathrm{s}$

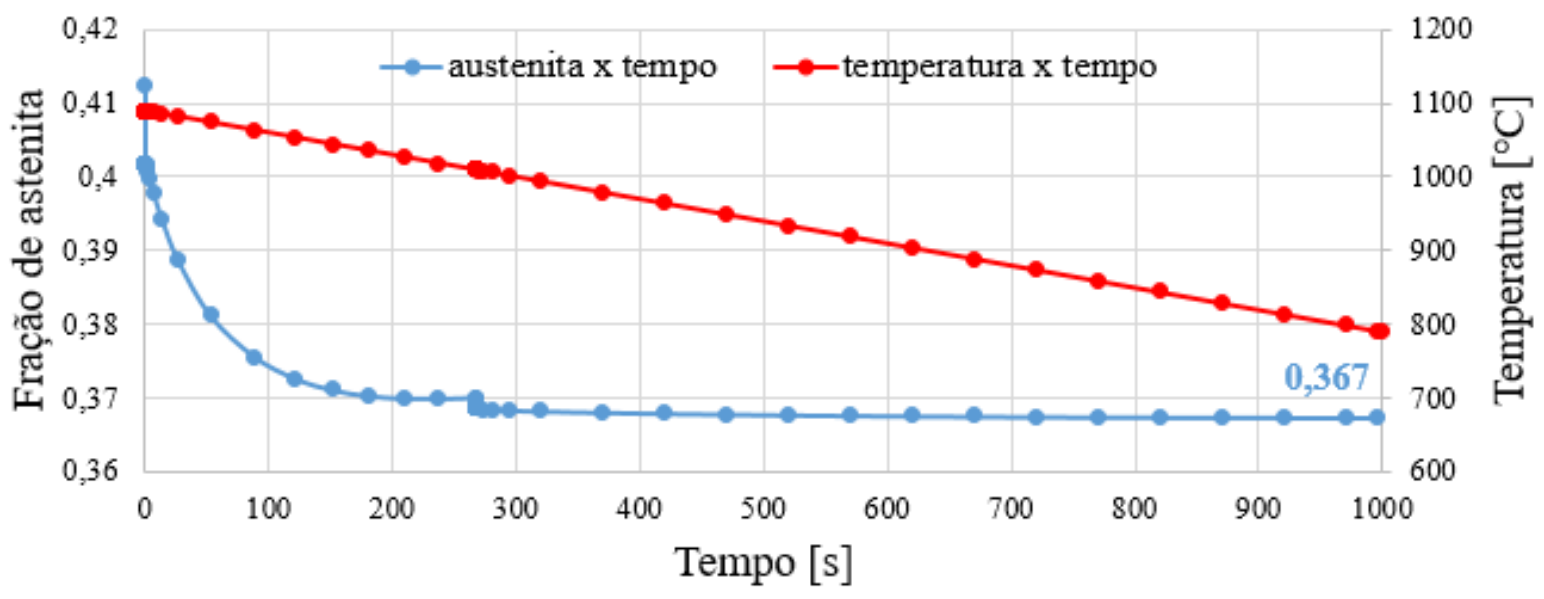

Fonte: Autora 
Figura 91 - Fração de sigma no resfriamento do aço de $1090^{\circ} \mathrm{C}$ até $790^{\circ} \mathrm{C}$ (trecho 6) à taxa de $0,30^{\circ} \mathrm{C} / \mathrm{s}$

Taxa de resfriamento: $0,30^{\circ} \mathrm{C} / \mathrm{s}$

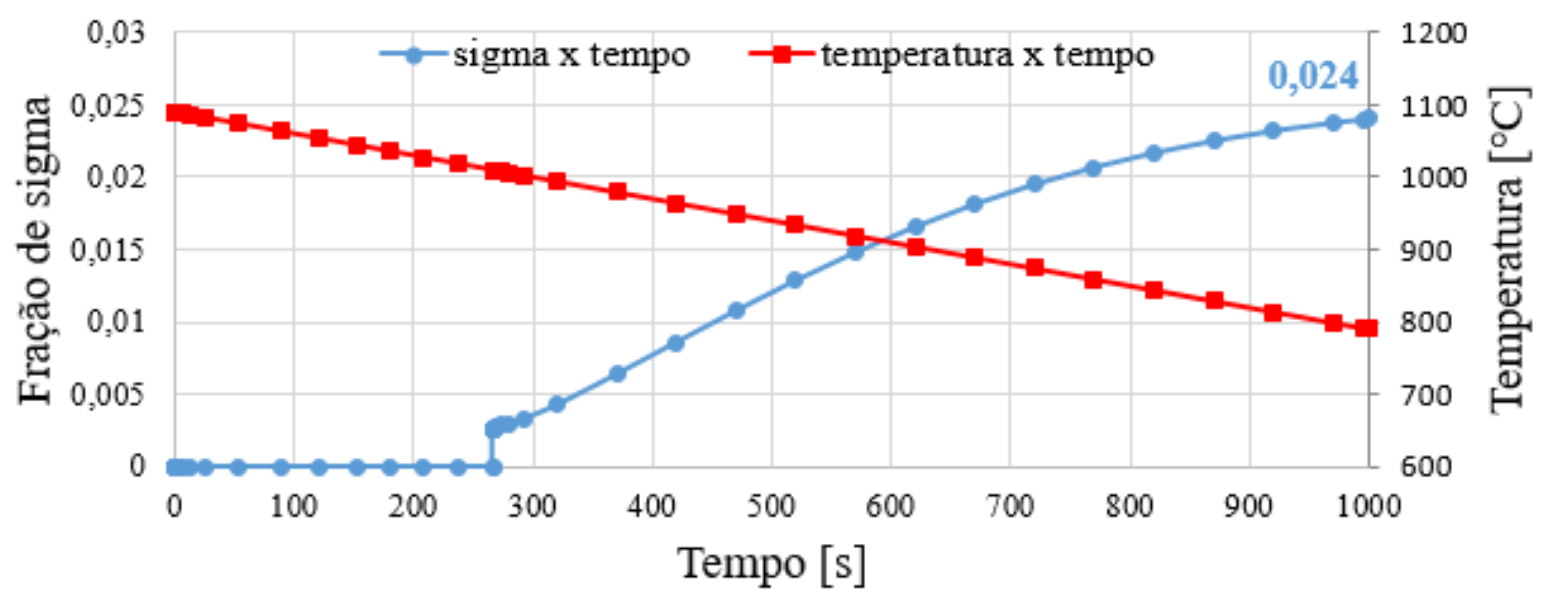

Fonte: Autora

Visando encontrar valores abaixo de $1 \%$ de sigma e baseado nas taxas simuladas no trecho 5, realizou-se o resfriamento do trecho 6 à taxa de $3,0^{\circ} \mathrm{C} / \mathrm{s}$, obtendo-se frações volumétricas de 59,6\% de ferrita partindo de 58,7\%, Figura 92, 39,5\% de austenita partindo de 41,3\%, Figura 93, e 0,90\% de sigma precipitada, Figura 94. Portanto, a taxa crítica de resfriamento do trecho 6 é de $3,0^{\circ} \mathrm{C} / \mathrm{s}$, ideal para resfriamento após solubilização.

Figura 92 - Fração de ferrita no resfriamento do aço de $1090^{\circ} \mathrm{C}$ até $790^{\circ} \mathrm{C}$ (trecho 6) à taxa de $3,0^{\circ} \mathrm{C} / \mathrm{s}$

Taxa de resfriamento: $3,0^{\circ} \mathrm{C} / \mathrm{s}$

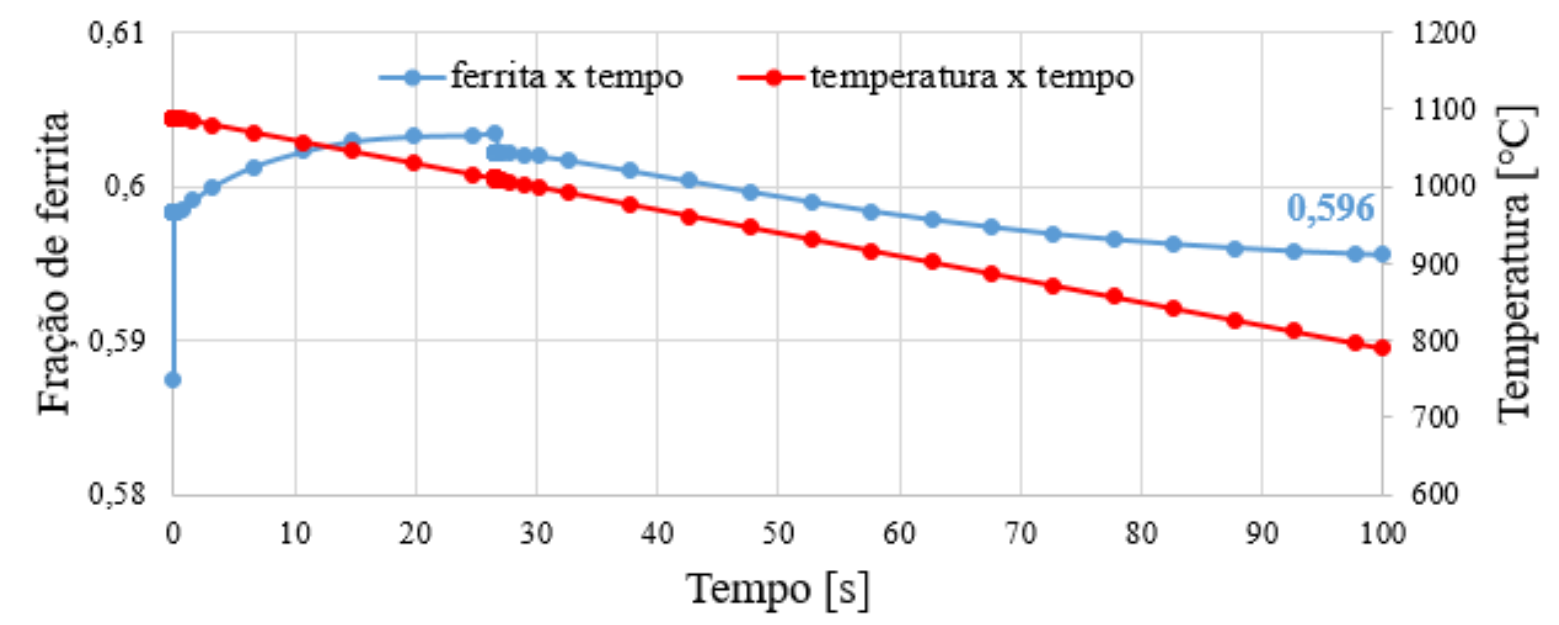

Fonte: Autora 
Figura 93 - Fração de austenita no resfriamento do aço de $1090^{\circ} \mathrm{C}$ até $790^{\circ} \mathrm{C}$ (trecho 6) à taxa de $3,0^{\circ} \mathrm{C} / \mathrm{s}$

Taxa de resfriamento: $3,0^{\circ} \mathrm{C} / \mathrm{s}$

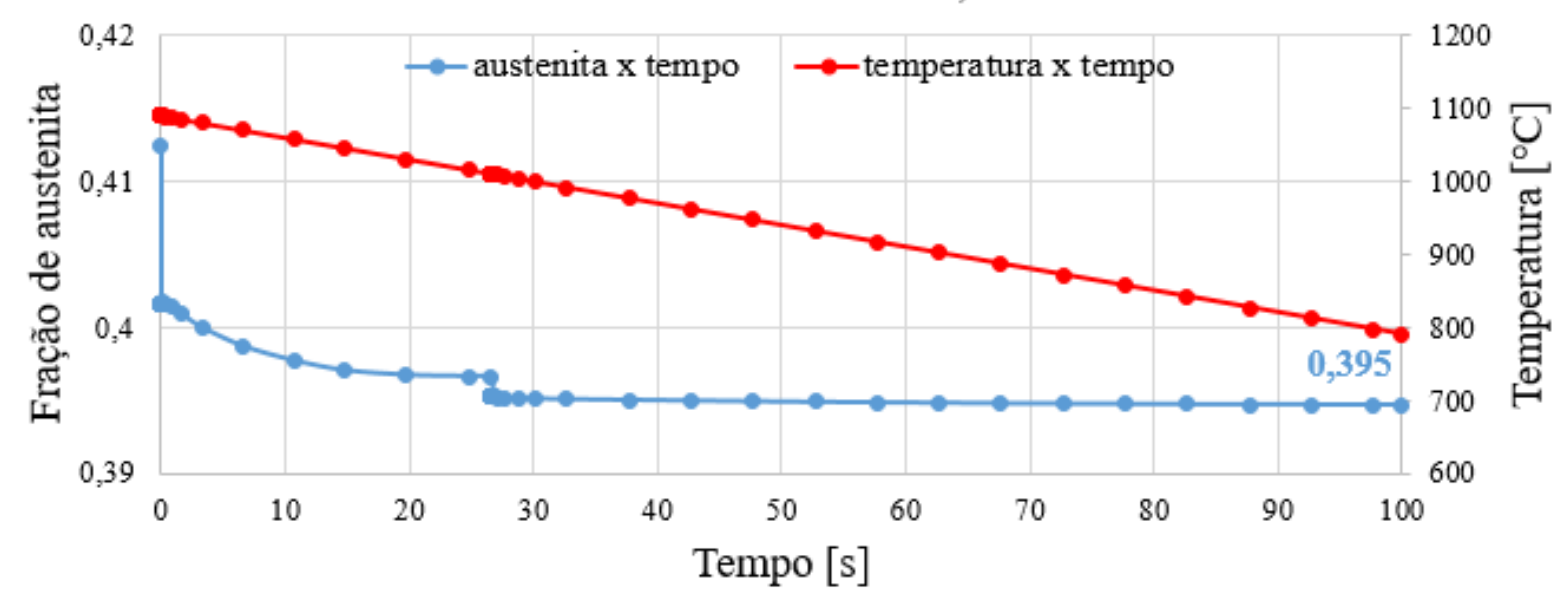

Fonte: Autora

Figura 94 - Fração de sigma no resfriamento do aço de $1090^{\circ} \mathrm{C}$ até $790^{\circ} \mathrm{C}$ (trecho 6) à taxa de $3,0^{\circ} \mathrm{C} / \mathrm{s}$

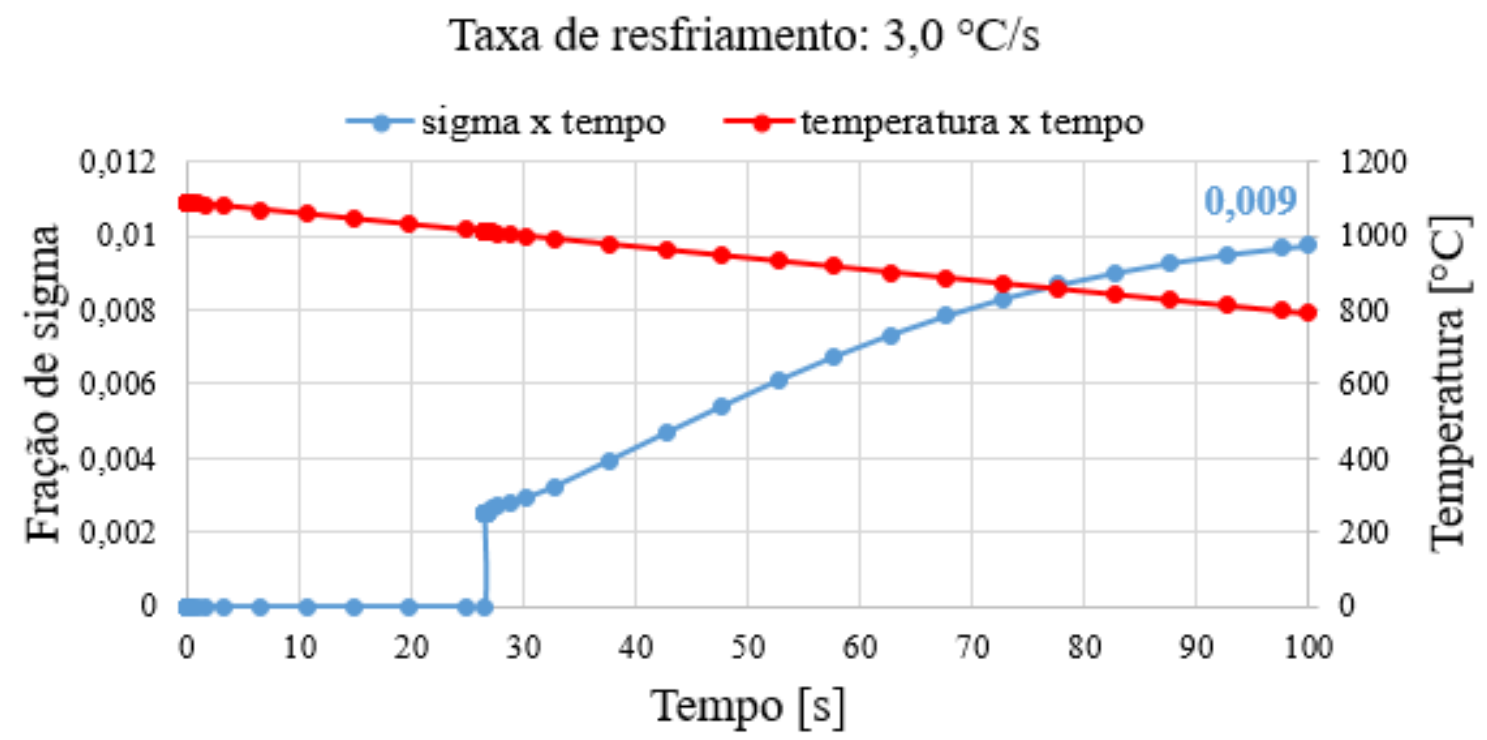

Fonte: Autora

Sendo a taxa de resfriamento de $3,0^{\circ} \mathrm{C} / \mathrm{s}$ a crítica para simulação do trecho 6 , obteve-se os perfis de composição química nesta condição, os quais podem ser vistos nas Figura 95 a 97 , no tempo máximo de $100 \mathrm{~s}$. Assim como foi feito para a simulação do resfriamento do trecho 5, também removeu-se $\mathrm{N}$ da composição química das fases, e assim não há resultado de perfís de composição de $\mathrm{N}$ no resfriamento até $790^{\circ} \mathrm{C}$ do trecho 6 . 
Nota-se nos resultados obtidos que também há mais gradiente de composição química na interface $\alpha / \gamma$ do que na difusão entre as fases através da interface, devido à formação heterogênea de fase sigma na interface entre as fases, promovendo enriquecimento de $\mathrm{Cr}$ e Mo na região. Além disso, se comparados aos perfis de composição química do resfriamento do trecho 6 com o trecho 5, é possível observar que os resultados são semelhantes entre si.

Figura 95 - Perfil de composição de Cr no resfriamento de $1090^{\circ} \mathrm{C}$ a $790^{\circ} \mathrm{C}$ (trecho 6) em função da distância à taxa de $3,0^{\circ} \mathrm{C} / \mathrm{s}$

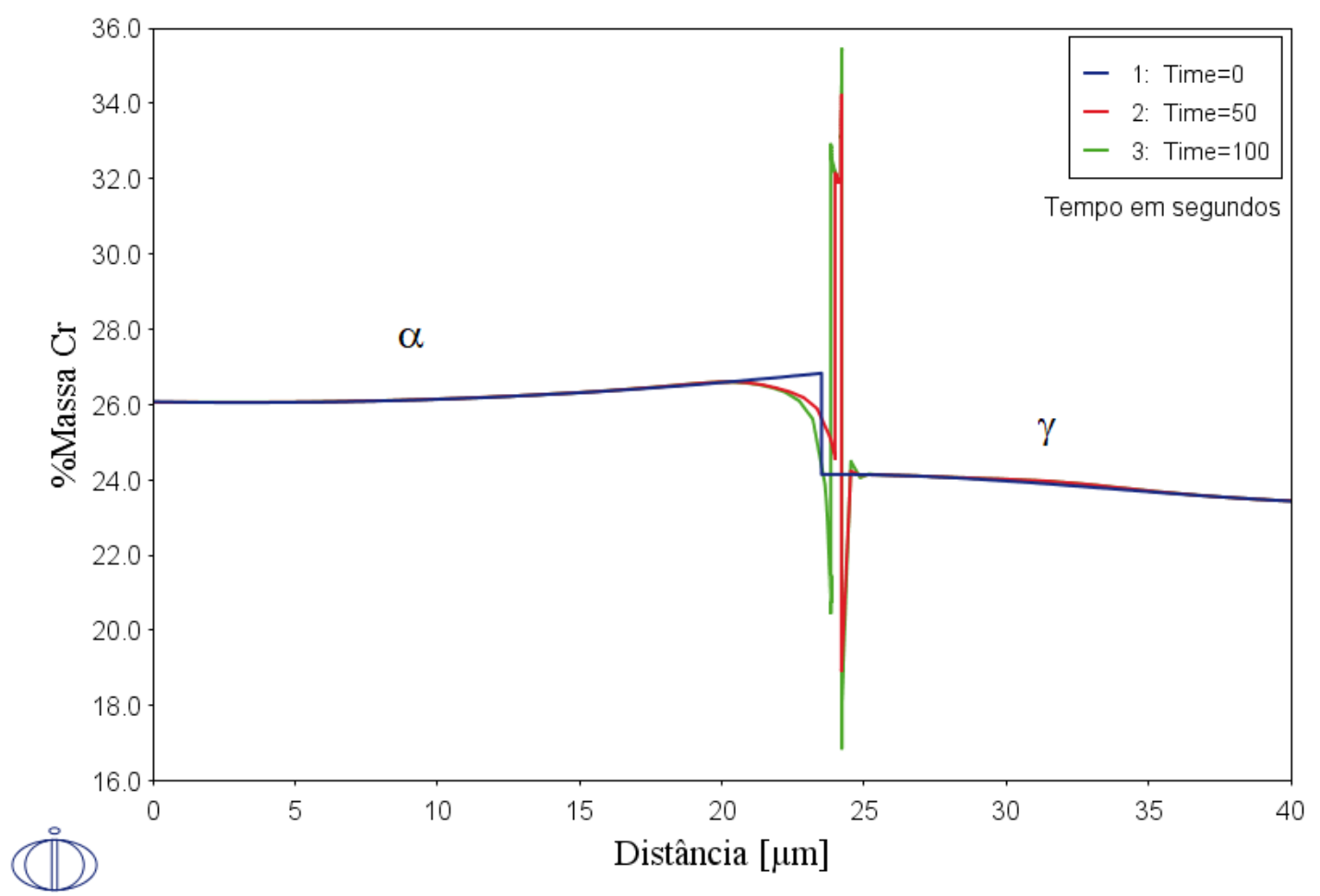

Fonte: Autora 
Figura 96 - Perfil de composição de Mo no resfriamento de $1090^{\circ} \mathrm{C}$ a $790^{\circ} \mathrm{C}$ (trecho 6) em função da distância à taxa de $3,0^{\circ} \mathrm{C} / \mathrm{s}$

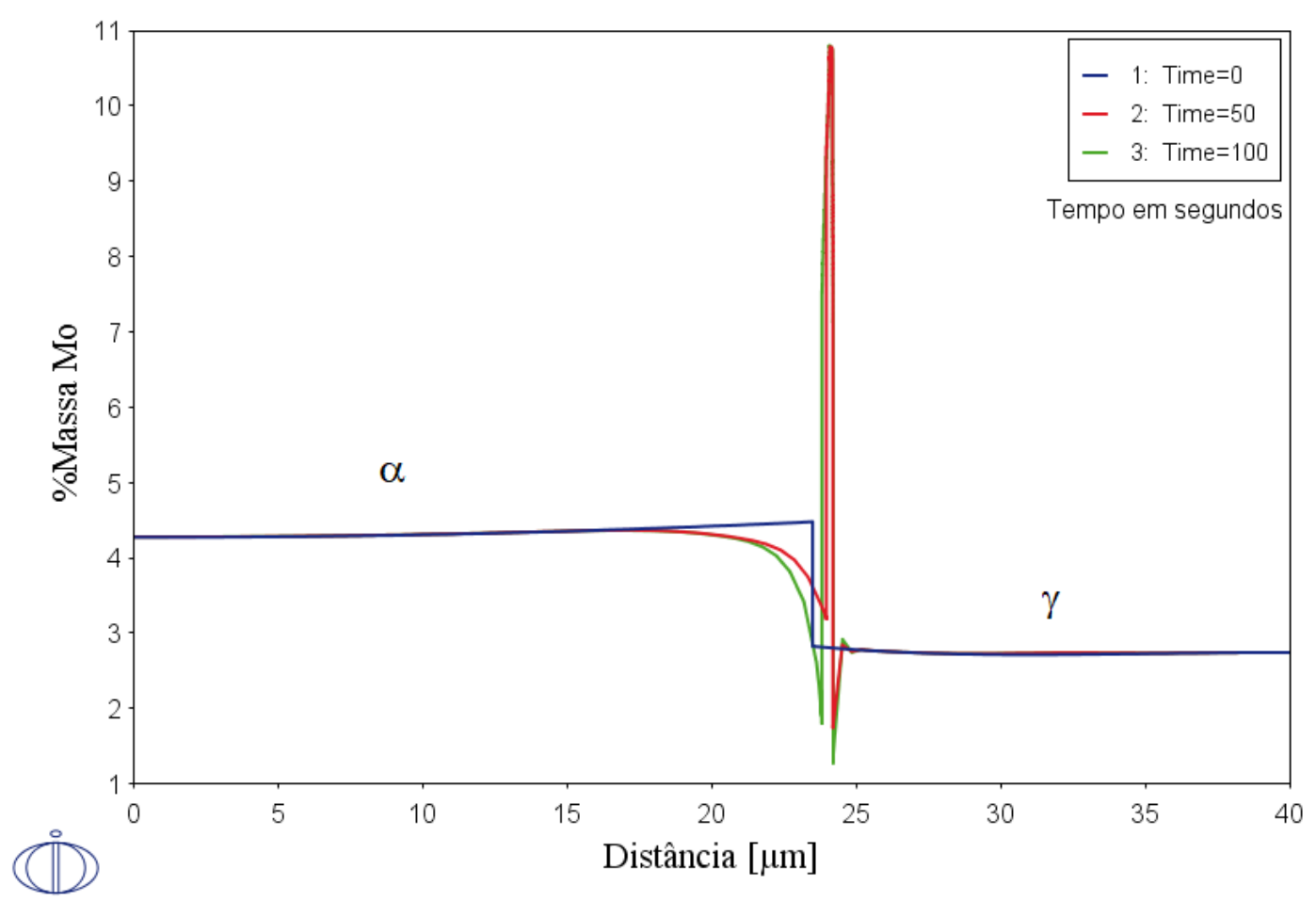

Fonte: Autora

Figura 97 - Perfil de composição de Ni no resfriamento de $1090^{\circ} \mathrm{C}$ a $790^{\circ} \mathrm{C}$ (trecho 6) em função da distância à taxa de $3,0^{\circ} \mathrm{C} / \mathrm{s}$

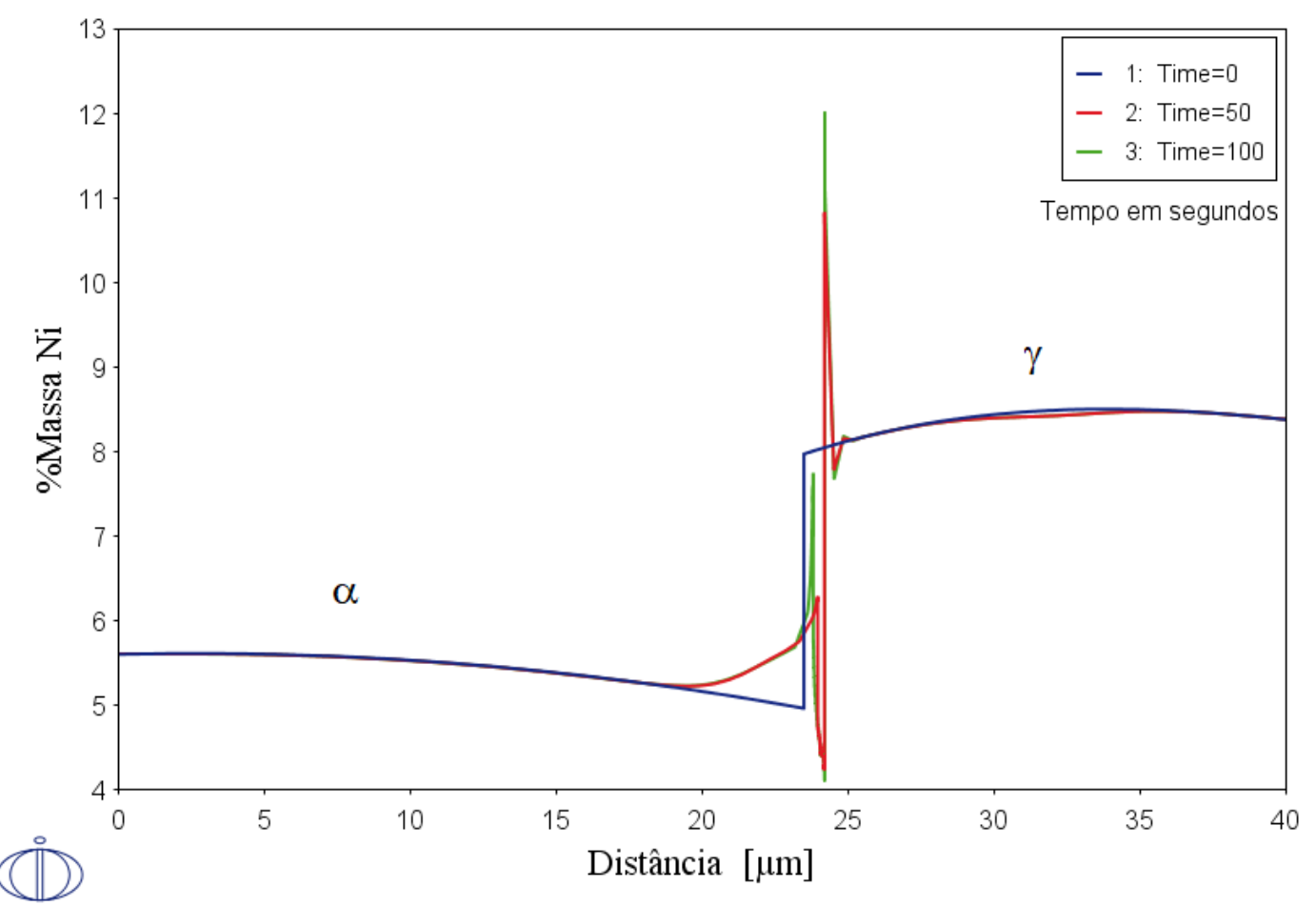

Fonte: Autora 
A Tabela 17 compara as frações volumétricas obtidas para as fases do aço superdúplex UNS S32750 no resfrimento do trecho 5 e trecho 6 à taxa de $3,0^{\circ} \mathrm{C} / \mathrm{s}$. Nota-se que o patamar à $1090{ }^{\circ} \mathrm{C}$ que antecede o trecho 5, permite que o aço atinja uma condição mais próxima e esperada para um aço dúplex, respresentando o ciclo ideal de tratamento térmico para o sistema em estudo nesta dissertação.

Tabela 17 - Fração volumétrica das fases obtidas no resfriamento dos trechos 5 e 6 à taxa de resfriamento de $3,0^{\circ} \mathrm{C} / \mathrm{s}$

\begin{tabular}{cccc}
\hline $\begin{array}{c}\text { Taxa de resfriamento: } \\
3,0{ }^{\circ} \mathrm{C} / \mathrm{s}\end{array}$ & \% ferrita & \% austenita & \% sigma \\
\hline Trecho 5 & 55,9 & 43,1 & 0,97 \\
\hline Trecho 6 & 59,6 & 39,5 & 0,90 \\
\hline
\end{tabular}

Fonte: Autora

É importante mencionar que por diversas tentativas, buscou-se simular os trechos 5 e 6 , adicionando-se $\mathrm{N}$ à composição química das fases, para avaliação da formação de nitreto de cromo no resfriamento do aço em questão, assim como foi feito para sigma. Entretanto, ainda não foram obtidos resultados robustos da precipitação de nitretos de cromo utilizando-se o DICTRA $^{\circledR}$, uma vez que ou o software mostrou-se incapaz de prever a supersaturação de $\mathrm{N}$ na austenita nos ciclos térmicos mencionados e condições estudadas, ou por não ter ocorrido a supersaturação como esperada, o que deixa tais resultados ainda não obtidos como sugestão para trabalhos futuros deste grupo de pesquisa.

\subsection{USO DOS RESULTADOS NA DETERMINAÇÃO DE CICLO TÉRMICO DE PROCESSAMENTO DO AÇO EM ESTUDO}

A partir dos resultados coletados pelas simulações computacionais em DICTRA ${ }^{\circledR}$ e discussões feitas, foi possível obter o ciclo de processamento térmico do aço inox superdúplex UNS S32750 de composição química $\mathrm{Fe}-25,17 \% \mathrm{Cr}-6,88 \% \mathrm{Ni}-3,61 \% \mathrm{Mo}-0,27 \% \mathrm{Ni}$, considerando-se as taxas críticas de aquecimento e resfriamento, os menores tempos de patamar, as menores frações de fase sigma precipitadas e a composição química exata para simular cada trecho, atingindo-se as condições dúplex desejadas, conforme mostra a Figura 98 e resume a Tabela 18, além de ser factível de reprodução pela indústria, principalmente pela relevância da otimização obtida. 
Figura 98 - Modelo esquemático final das transformações de fases simuladas para o aço UNS S32750

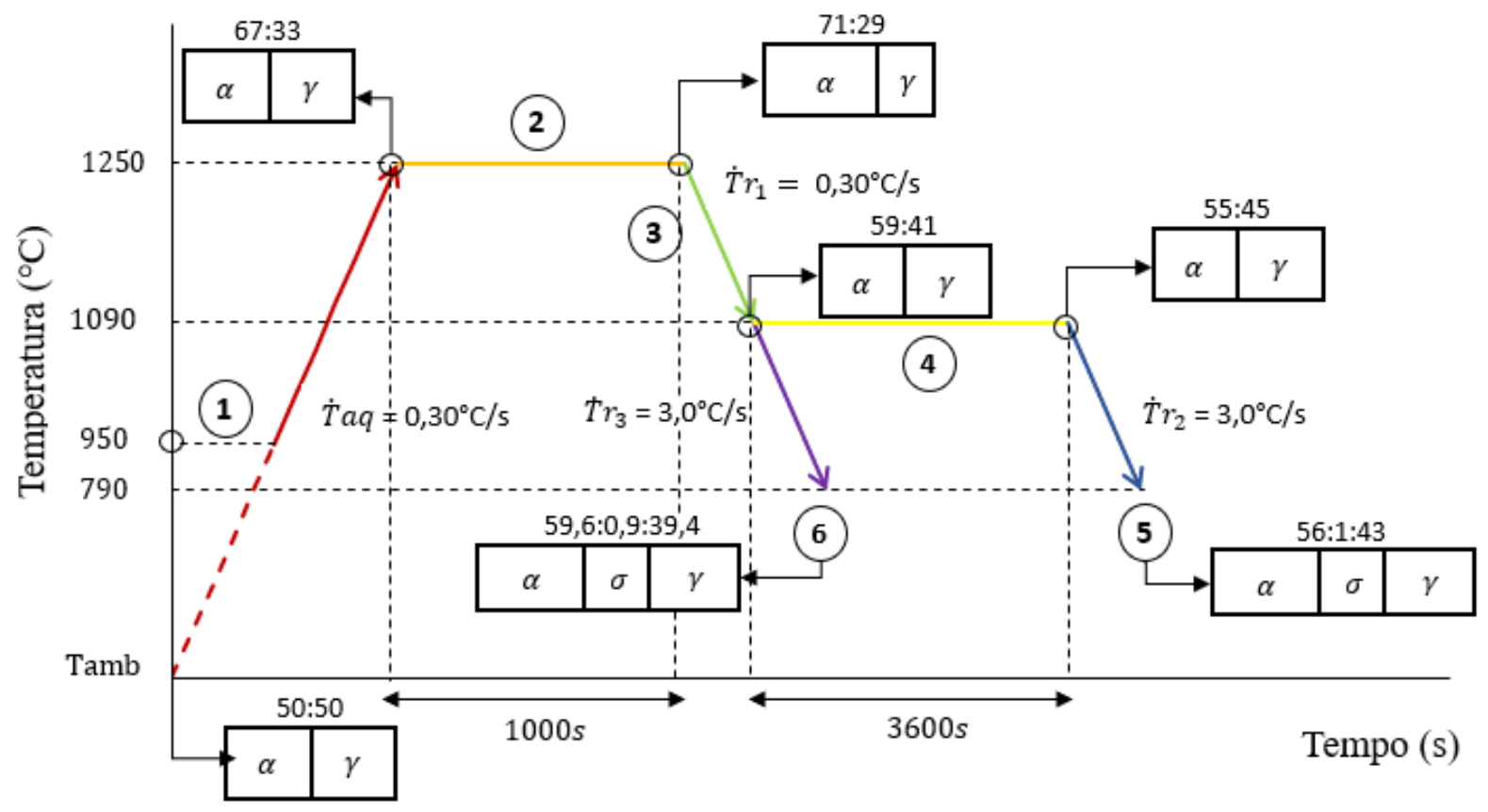

Fonte: Autora

Tabela 18 - Condição ideal de processamento do aço superdúplex UNS S32750

\begin{tabular}{ccc}
\hline Trecho & Taxa ou tempo utilizados & Fração volumétrica atingida \\
\hline 1 & $0,30{ }^{\circ} \mathrm{C} / \mathrm{s}$ & $66,6 \% \alpha: 33,4 \% \gamma$ \\
\hline 2 & $1000 \mathrm{~s}$ & $70,7 \% \alpha: 29,3 \% \gamma$ \\
\hline 3 & $0,30{ }^{\circ} \mathrm{C} / \mathrm{s}$ & $58,7 \% \alpha: 41,3 \% \gamma$ \\
\hline 4 & $3600 \mathrm{~s}$ & $55,5 \% \alpha: 44,5 \% \gamma$ \\
\hline 5 & $>3,0{ }^{\circ} \mathrm{C} / \mathrm{s}$ & $56 \% \alpha:<1 \% \sigma: 43 \% \gamma$ \\
\hline 6 & $>3,0{ }^{\circ} \mathrm{C} / \mathrm{s}$ & $\gamma$ \\
& &
\end{tabular}

Fonte: Autora

É importante ressaltar que nenhuma destas discussões seria possível sem os perfis de composição química simulados pelo DICTRA ${ }^{\circledR}$, visto que não há experimentos capazes de replicar em laboratório com tamanha precisão os gradientes de composição química criados nas fases a cada etapa do ciclo térmico para diferentes taxas de aquecimento e resfriamento, e como pode ser constatado, as transformações de fase são muito influenciadas pelo potencial químico de cada elemento, e pela possibilidade ou não de supersaturação de elementos nas interfaces. 


\section{CONCLUSÕES}

O diagrama de equilíbrio obtido pelo Thermo-Calc ${ }^{\circledR}$ para o aço superdúplex UNS S32750 mostra que a condição para haver apenas ferrita e austenita ocorre entre $1050{ }^{\circ} \mathrm{C}$ e $1300{ }^{\circ} \mathrm{C}$, atingindo-se o balanço de $50 \%$ de cada fase em $1090{ }^{\circ} \mathrm{C}$ e $30 \%$ de austenita e $70 \%$ de ferrita em $1250{ }^{\circ} \mathrm{C}$, temperatura escolhida para simular o trabalho à quente. Nota-se também que a formação de sigma se inicia a temperaturas inferiores a $1050{ }^{\circ} \mathrm{C}$.

A simulação da taxa de aquecimento do trecho 1 indica que quanto menor esta for, maior será a fração de ferrita formada, uma vez que dá-se tempo para a difusão dos elementos, sobretudo os alfagênicos, atingindo-se fração volumétrica de ferrita que varia desde 59,2\% à taxa de $2{ }^{\circ} \mathrm{C} / \mathrm{s}$ até $66,6 \%$ à taxa de $0,30^{\circ} \mathrm{C} / \mathrm{s}$, este último valor próximo ao esperado pela simulação de equilíbrio, isto é $70 \%$ de ferrita em $1250{ }^{\circ} \mathrm{C}$.

Notou-se que apesar do diagrama de equilíbrio obtido pelo Thermo-Calc ${ }^{\circledR}$ indicar a temperatura de solubilização $1090{ }^{\circ} \mathrm{C}$ para atingir $50 \%$ de cada fase, as simulações em DICTRA $^{\circledR}$ do patamar de tratamento térmico a esta temperatura por $3600 \mathrm{~s}$ resultou em $55,5 \% \alpha$ e 44,5\% $\gamma$, não se atingindo o equilíbrio termodinâmico esperado. Isto se deve ao fato de ainda haver gradiente de composição química de todos os elementos, tanto na ferrita quanto na austenita.

As simulações do resfriamento dos trechos 5 e 6 , da temperatura de solubilização de $1090^{\circ} \mathrm{C}$ até $790^{\circ} \mathrm{C}$, mostraram que a opção que mais se aproxima da condição dúplex desejada ao final do ciclo térmico de processamento, é a do trecho 5 à taxa crítica de $3,0{ }^{\circ} \mathrm{C} / \mathrm{s}$, em que se considera o tempo de patamar na temperatura de solubilização prévio ao

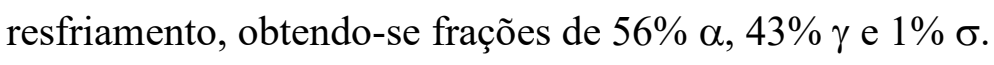

Contudo, o DICTRA ${ }^{\circledR}$ mostrou-se incapaz de simular a formação de nitretos de cromo no resfriamento dos trechos 5 e 6 , ou por não prever a supersaturação de $\mathrm{N}$ na austenita ou por não haver a supersaturação nos ciclos térmicos em questão e condições estudadas.

Por fim, o modelo computacional do DICTRA ${ }^{\circledR}$ foi capaz de descrever as transformações de fase durante um ciclo térmico de processamento do aço superdúplex UNS S32750 de maneira robusta e eficaz, determinando taxas de aquecimento e resfriamento críticas, tempo ideal de patamar, e composição química exata de cada trecho do ciclo, que são viáveis de se reproduzirem na indústria, principalmente pela relevância da otimização obtida. 


\section{REFERÊNCIAS}

ALVAREZ-ARMAS, I. Duplex stainless steels: brief history and some recent alloys. Recent Patents on Mechanical Engineering, v. 1, p. 51-57, 2008.

ANDERSSON, J-O.; HELANDER, T.; HOGLUND, L.; SHI, P.; SUNDMAN. Thermo-Calc \& Dictra, computational tools for materials science. Calphad. v. 26, n 2, p. $273-312,2002$.

APERAM, 2019. Disponível em: https://brasil.aperam.com/produtos/aco-inox/. Acesso em 11 nov. 2019

AVRAMI, M. Kinetics of phase change I. Journal of Chemical Physics, v.7, p.1103 a 1112, dez. 1939.

AVRAMI, M. Kinetics of phase change II: transformation-time relations for random distribution of nuclei. Journal of Chemical Physics, v. 8, p.212-224, fev. 1940.

BADJI, R.; BOUABDALLAH, M.; BACROIX, B.; KAHLOUN, C.; BELKESSA, B.; MAZA, H. Phase transformation and mechanical behavior in annealed 2205 duplex stainless steel welds. Materials Characterization. n.59, p.447-453, 2008.

BAIN, E; GRIFFITHS, W. An introduction to the Iron-Chromium Nickel Alloys. Trans.AIME, pág. 75,166-213, 1927.

BRANDI, S. D.; PADILHA, A. F. Precipitação de fase siga em aços inoxidáveis ferríticosausteníticos com microestrutura duplex. INOX'90 (seminário), p. 135- 52, 1990.

BORGENSTAM et al. DICTRA, a tool for simulation of diffusional transformations in alloys. Journal of Phase Equilibria. v. 21, n³, p. 269 - 280, 2000.

CALLIARI I., RAMOUS E., BASSANI P. Phase transformation in duplex stainless steels after isothermal treatments, continuous cooling and cold working. Material Science Forum Vols 638-642, p. 2986-2991, 2010.

CHRISTIAN, J.W. The theory of Transformations in Metals and Alloys. Part I, 2ed., Pergamon, Oxford, United Kingdom, p.529-552, 2002.

CHBANE, G; MAGNABOSCO, R. DICTRA simulations of sigma phase formation in duplex stainless steels In: 11th European Stainless Steel Conference Science \& Market and the 8th European Duplex Stainless Steel Conference \& exhibition, 2019, Viena. 11th ESSC and 8th DSS. Viena: ASMET, v.u. p.278 - 284, 2019.

CHEN, T; YANG, J. Effects of solution treatment and continuous cooling on s-fase precipitation in a 2205 duplex stainless steel. Materials Science and Engineering A, v. 311, p. $28-41,2001$.

ECKENROD, J.; PINNOW, K. Effects of chemical composition and thermal history on the properties of alloy 2205 duplex stainless steel. Conference Proceedings, New Developments in Stainless Steel Technology, Detroit, p. 77, 1984. 
ELMER, J. PALMER, T.A.; SPECHT, E.D. Direct Observations of Sigma Phase Formation in Duplex Stainless Steels Using In -Situ Synchrotron X-Ray Diffraction. Metallurgical and Materials Transactions A, v. 38A, p. 464-475, 2007.

FORGAS, A. Transformação de ferrita em austenita induzida por deformação plástica no aço inoxidável dúplex UNS 31803, 2016. Tese. Instituto de Tecnologia de Aeronáutica (ITA), São José dos Campos, 2016.

FRAZÃO, I. Desenvolvimento de Teste para a Avaliação Comparativa CPT para Ligas de Alta Resistência à Corrosão por Pite. Dissertação. Centro Universitário FEI, São Bernardo do Campo, São Paulo, 2019.

GIRALDO, C. Precipitação de fases intermetálicas na zona afetada pelo calor de temperatura baixa (ZACTB) na soldagem de aços inoxidáveis duplex. Dissertação. Escola Politécnica da Universidade de São Paulo, São Paulo, 2001.

GUNN, R. N. Duplex stainless steels microstructure, properties and applications. Ed Woodhead Publishing Ltd, v.u., 2003.

KNYAZEVA, M.; POHL, M. Duplex Steels - Part II: Carbides and Nitrides. Metallography Microstructure and Analysis v.2: p. 343-351, 2013.

LIU et al. Experimental study and kinetic calculation on migration of $y / a$ interface boundary during high temperature aging for 2205 duplex stainless steel. Journal of Iron and Steel Research, 17 (8), p. 45-59, 2010.

MAEHARA, Y. et al. Effects of alloying elements on $\sigma$ phase precipitation in $\delta-\gamma$ dúplex phase stainless steels. Metal Science, v. 17, p. 541-7, 1983

MAGNABOSCO, R. Modelling of sigma phase formation during isothermal aging of superduplex stainless steel. 8th European Stainless Steel Conference Science \& Market, Graz. 8th ESSC - conference proceedings, v. u. p. 400-409, 2015.

MAGNABOSCO, R. Kinetics of sigma phase formation in a duplex stainless steel. Materials Research, v. 12, No. 3, p. 321, 2009.

MAGNABOSCO, R. Influência da microestrutura no comportamento eletroquímico do aço inoxidável UNS S31803 (SAF 2205), 2001. Tese. (Doutorado em Engenharia) - Escola Politécnica de São Paulo, Universidade de São Paulo, São Paulo, 2001.

MAGNABOSCO, R., ALONSO-FALLEIROS, N. Efeito do rápido envelhecimento a $850^{\circ} \mathrm{C}$ na resistência à corrosão por pite do aço SAF 2205 (UNS S31803). Conferência Brasileira de Temas de Tratamento Térmico, 2003.

MAGNABOSCO, R; MORAIS, L; DOS SANTOS, D. Use of composition profiles near sigma phase for assessment of localized corrosion resistance in a duplex stainless steel. Calphad-Computer Coupling of Phase Diagrams and Thermochemistry, v. 64, p. 126130, 2019 
MAGNABOSCO, R., FIORANTE, M. Thermo-Calc and DICTRA simulations of solution heat treatment of superdúplex stainless steel. $11^{\text {th }}$ European Stainless Steel Conference Science \& Expo and the $8^{\text {th }}$ European Duplex Stainless Steel Conference \& Exhibition, Viena, 2019.

MELO, E. MAGNABOSCO, R. Influence of the Heterogeneous Nucleation Sites on the Kinetics of Intermetallic Phase Formation in Aged Duplex Stainless Steel. Metallurgical and Materials Transactions A, 2017.

MICHALSKA, j., SOZANSKA, M. Qualitative and quantitative analysis of $\sigma$ and $\chi$ phases in 2205 duplex stainless steel. Materials characterization. Department of materials science, Poland, p. 355-362, 2006.

MORAIS, L. C. Simulação da cinética de formação da fase sigma durante o envelhecimento isotérmico de aço inoxidável dúplex. Dissertação, Centro Universitário FEI, São Bernardo do Campo, 2017.

NILSSON, J. Super duplex stainless steels. Materials Science and Technology, v. 8, p. 685, 1992.

NILSSON, O., WILSON, A. Influence of isothermal phase transformations on toughness and pitting corrosion of super duplex stainless steel SAF 2507. Materials Science and Technology, v. 9, p. 545 - 554, 1993.

NOBLE, D. N. Welding, Brazing and Soldering. ASM Metals Handbook. v.6, p. 1206, 1993.

OUTOKUMPU, 2020. Disponível em: https://www.outokumpu.com/en/products/stainlesssteel-types. Acesso em: 11 nov. 2020.

PARDAL et al., Study of deleterious phase precipitation under continuous cooling of superduplex stainless steel UNS S32750. Materials Science and Technology, v. 28, p. 295 $302,2012$.

PETTERSSON, N.; PETTERSSON, R.; WESSMAN, S. Precipitation of Chromium Nitrides in the Superduplex Stainless Steel 2507. Metallurgical and materials transactions A, 2015.

PORTER, D.A; EASTERLING, K.E. Phase transformations in metals and alloys. 2 ed. New York: Taylor \& Francis, 514p, 1992.

POTGIETER, J; CORTIE, M. Determination of the microstructure and alloy element distribution in experimental duplex stainless steels. Materials Characterization 26, Randburg, South Africa, p. 155 -165, 1991.

RAYNOR, G. V.; RIVLIN, V.G. Phase equilibria in iron ternary alloys. A critical assessment of the experimental literature. London: The Institute of Metals, 1988.

RAMIREZ, A.J.; LIPPOLD, J.C; BRANDI, S.D. The relationship between Chromium Nitride and secondary austenite precipitation in dúplex stainless steels. Metallurgical and Materials Transactions A, v. 34A, p.1575-1597, 2003. 
SANDVIK, 2019. Disponível em:

https://www.materials.sandvik/contentassets/13070e50f22e4cc6bcf5b072e5f76746/datasheetsandvik-saf-2507.pdf. Acesso em: 11 nov. 2019

SANTOS, D. Estudo da formação de sigma e sua influência no potencial de pite em solução 0,6M cloreto de sódio do aço UNS $S 31803$ envelhecido a $850^{\circ} \mathrm{C}$ e $900^{\circ} \mathrm{C}$.

Dissertação, Centro Universitário FEI, São Bernardo do Campo, São Paulo, 2010.

SANTOS, D. Estudo das transformações de fase isotérmicas do aço UNS S31803 envelhecido entre $7_{00}^{\circ} \mathbf{C}$ e $9^{\circ} 0^{\circ} \mathrm{C}$. Tese (Doutorado em Engenharia Aeronáutica e Mecânica) - Instituto Tecnológico de Aeronáutica, São Paulo, 2013.

SANTOS, D., MACARRÃO, I., MAGNABOSCO, R. Relation between pitting potential and PREN value for ferrite and austenite in duplex stainless steels. $11^{\text {a }}$ European Stainless Steel Conference Science \& Expo and the 8th European Duplex Stainless Steel Conference \& Exhibition, Viena, 2019. 11th ESSC and 8th DSSC. Viena: ASMET, v.u. p.80 - 87, 2019.

SEDRIKS, J. Corrosion of stainless steels, John Wiley, New York, 2. ed., p. 47-53, 1996.

SHIN et al. Precipitation condition and effect of volume fraction on corrosion properties of secondary phase on casted super-duplex stainless steel UNS S32750. Anti-Corrosion Methods and Materials, Vol. 66 Issue: 1, pp.61-66, 2018.

SOLOMON, H. DEVINE T. Jr., Duplex stainless steels: a tale of two phases. Conference Proceedings, Duplex stainless steels, Metals Park, p. 693, 1982.

STRAFELLINI et al. Effect of Aging on the Fracture Behavior of Lean Duplex Stainless Steels. Metallurgical and Materials Transactions A, v. 40A, p. 2616-2621, 2009.

THERMO-CALC Software, 2017. Disponível em: <http:www.thermocalc.com>. Acesso em: 10 setembro 2017.

THORVALDSSON, T. ERIKSSON, H. KUTKA, J. SALWÉN, A. Influence of microstructure on mechanical properties of a duplex stainless steel. Stainless steels 84, Conference, 1984. Conf. Proceedings, The Institute of Metals, London, p. 101-105, 1985.

TAVARES, S; Silva, V; Pardal, J; Corte, J. Investigation of stress corrosion cracks in a UNS S32750 superduplex stainless steel. Eng. Fail. Anal 35, p. 88-94, 2013.

VILLARES METALS, 2019. Disponível em: http://www.villaresmetals.com.br/villares/pt/Produtos/Acos-Inoxidaveis. Acesso em: 11 nov. 2019

WANG et al. Diffusion of chromium in nanocrystalline iron produced by means of surface mechanical attrition treatment. Acta Materialia, v. 51, p. 4319 - 4329, 2003. 
116

APÊNDICE I - FUNÇÕES MATEMÁTICAS DOS PERFIS DE COMPOSIÇÃO 
A partir das simulações dos gradientes de composição química de cada elemento na ferrita e na austenita, foi possível obter a função matemática correspondente ao tempo final de tratamento térmico de cada trecho do ciclo térmico representado pela Figura 37, necessárias para simular o trecho seguinte. As funções matemáticas obtidas podem ser vistas nas Tabelas 19 a 22.

Tabela 19 - Perfis de composição química do trecho 1 para simular o trecho 2

\begin{tabular}{ccc}
\hline & Ferrita & Austenita \\
\hline$\% \mathrm{Cr}$ & $\mathrm{y}=-0,0009 \mathrm{x}^{2}-0,0169 \mathrm{x}+26,45$ & $\mathrm{y}=-1 \mathrm{E}-06 \mathrm{x}^{4}+3 \mathrm{E}-05 \mathrm{x}^{3}-0,0002 \mathrm{x}^{2}+$ \\
& $\mathrm{y}=-0,0002 \mathrm{x}^{2}-0,0029 \mathrm{x}+4,1065 \mathrm{x}+23,489$ \\
\hline$\% \mathrm{Mo}$ & $\mathrm{y}=-9 \mathrm{E}-05 \mathrm{x}^{4}+0,0027 \mathrm{x}^{3}-0,0278 \mathrm{x}^{2}$ \\
& & $+0,1128 \mathrm{x}+2,6576$ \\
\hline$\% \mathrm{Ni}$ & $\mathrm{y}=0,0006 \mathrm{x}^{2}+0,0112 \mathrm{x}+5,7518$ & $3 \mathrm{E}-05 \mathrm{x}^{4}-0,0008 \mathrm{x}^{3}+0,0082 \mathrm{x}^{2}-$ \\
& & $0,0318 \mathrm{x}+8,5626$ \\
\hline$\% \mathrm{~N}$ & $\mathrm{y}=-9 \mathrm{E}-06 \mathrm{x}^{2}-0,0002 \mathrm{x}+0,0962$ & $\mathrm{y}=-2 \mathrm{E}-07 \mathrm{x}^{4}+6 \mathrm{E}-06 \mathrm{x}^{3}-5 \mathrm{E}-05 \mathrm{x}^{2}+$ \\
& & $6 \mathrm{E}-05 \mathrm{x}+0,5675$
\end{tabular}

Fonte: Autora

Tabela 20 - Perfis de composição química do trecho 2 para simular o trecho 3

\begin{tabular}{ccc}
\hline & Ferrita & Austenita \\
\hline$\% \mathrm{Cr}$ & $\mathrm{y}=4 \mathrm{E}-06 \mathrm{x}^{3}-0,0002 \mathrm{x}^{2}+0,0009 \mathrm{x}+$ & $\mathrm{y}=0,0052 \mathrm{x}^{2}-0,1052 \mathrm{x}+24,028$ \\
& 25,809 & \\
\hline$\% \mathrm{Mo}$ & $7 \mathrm{E}-07 \mathrm{x}^{3}-2 \mathrm{E}-05 \mathrm{x}^{2}+0,0002 \mathrm{x}+$ & $\mathrm{y}=-0,0013 \mathrm{x}^{2}+0,0266 \mathrm{x}+2,6428$ \\
& 3,9853 & \\
\hline$\% \mathrm{Ni}$ & $\mathrm{y}=-5 \mathrm{E}-08 \mathrm{x}^{4}+1 \mathrm{E}-06 \mathrm{x}^{3}-4 \mathrm{E}-06 \mathrm{x}^{2}+$ & $\mathrm{y}=-8 \mathrm{E}-06 \mathrm{x}^{4}+0,0002 \mathrm{x}^{3}-0,0023 \mathrm{x}^{2}$ \\
& $3 \mathrm{E}-05 \mathrm{x}+6,0356$ & $+0,0089 \mathrm{x}+8,5607$ \\
\hline$\% \mathrm{~N}$ & $\mathrm{y}=-3 \mathrm{E}-07 \mathrm{x}^{2}-4 \mathrm{E}-06 \mathrm{x}+0.0975$ & $\mathrm{y}=0,0003 \mathrm{x}^{2}-0,0061 \mathrm{x}+0,6424$ \\
\hline
\end{tabular}

Fonte: Autora 
Tabela 21 - Perfis de composição química do trecho 3 para simular o trecho 4 a $0,3^{\circ} \mathrm{C} / \mathrm{s}$ e para simular o trecho 6

\begin{tabular}{ccc}
\hline & Ferrita & Austenita \\
\hline$\% \mathrm{Cr}$ & $\mathrm{Y}=0,0019 \mathrm{x}^{2}-0,0124 \mathrm{x}+26,071$ & $\mathrm{y}=0,0002 \mathrm{x}^{3}-0,0062 \mathrm{x}^{2}+0,0049 \mathrm{x}+$ \\
& $\mathrm{y}=0,0004 \mathrm{x}^{2}-0,0007 \mathrm{x}+4,2722$ & $\mathrm{y}=-1 \mathrm{E}-04 \mathrm{x}^{3}+0,0035 \mathrm{x}^{2}-0,0356 \mathrm{x}+$ \\
$\% \mathrm{Mo}$ & $\mathrm{y}=-0,0015 \mathrm{x}^{2}+0,0081 \mathrm{x}+5,5997$ & $\mathrm{y}=0,0001 \mathrm{x}^{3}-0,007 \mathrm{x}^{2}+0,113 \mathrm{x}+$ \\
& & 7,9686 \\
\hline$\% \mathrm{Ni}$ & $\mathrm{y}=1 \mathrm{E}-05 \mathrm{x}^{2}-5 \mathrm{E}-05 \mathrm{x}+0,037$ & $\mathrm{y}=1 \mathrm{E}-05 \mathrm{x}^{3}-0,0003 \mathrm{x}^{2}-0,002 \mathrm{x}+$ \\
& & 0,5408 \\
\hline \%N & &
\end{tabular}

Fonte: Autora

Tabela 22 - Perfis de composição química do trecho 4 para simular o trecho 5

\begin{tabular}{ccc}
\hline & Ferrita & Austenita \\
\hline$\% \mathrm{Cr}$ & $\mathrm{y}=0,0002 \mathrm{x}^{2}+0,0013 \mathrm{x}+26,441$ & $\mathrm{y}=0,0011 \mathrm{x}^{3}-0,0369 \mathrm{x}^{2}+0,3238 \mathrm{x}+$ \\
& $\mathrm{y}=1 \mathrm{E}-05 \mathrm{x}^{2}+2 \mathrm{E}-06 \mathrm{x}+4,4243$ & $\mathrm{y}=0,0006 \mathrm{x}^{2}-0,0145 \mathrm{x}+2,8057$ \\
\hline$\% \mathrm{Mo}$ & $\mathrm{y}=-9 \mathrm{E}-05 \mathrm{x}^{2}-0,0008 \mathrm{x}+5,2514$ & $\mathrm{y}=6 \mathrm{E}-05 \mathrm{x}^{4}-0,0027 \mathrm{x}^{3}+0,0376 \mathrm{x}^{2}-$ \\
$\% \mathrm{Ni}$ & $\mathrm{y}=8 \mathrm{E}-07 \mathrm{x}^{2}+7 \mathrm{E}-06 \mathrm{x}+0,0372$ & $\mathrm{y}=-172 \mathrm{x}+06 \mathrm{x}^{4}+0,0002 \mathrm{x}^{3}-0,0042 \mathrm{x}^{2}$ \\
& & $+0,0268 \mathrm{x}+0,4374$ \\
\hline$\% \mathrm{~N}$ & &
\end{tabular}


APÊNDICE II - PERFIS DE COMPOSIÇÃO DO TRECHO 3 À TAXA DE $0,1^{\circ} \mathrm{C} / \mathrm{s}$ 
Conforme citado no item 4.3, o resfriamento do trecho 3 , de $1250{ }^{\circ} \mathrm{C}$ até $1090{ }^{\circ} \mathrm{C}$, também foi simulado à taxa de $0,1{ }^{\circ} \mathrm{C} / \mathrm{s}$, para se comparar com a taxa de resfriamento de $0,3{ }^{\circ} \mathrm{C} / \mathrm{s}$, e os perfis de composição química obtidos podem ser vistos da Figura 99 a 101 . Notase que apresentam o mesmo comportamento do resfriamento a taxa de $0,30{ }^{\circ} \mathrm{C} / \mathrm{s}$, isto é, com a interface $\alpha / \gamma$ caminhando da austenita para a ferrita e com frações de composição química similares.

Figura 99 - Perfil de composição de $\mathrm{Cr}$ no resfriamento de $1250^{\circ} \mathrm{C}$ a $1090^{\circ} \mathrm{C}$ em função da distância à taxa de $0,10^{\circ} \mathrm{C} / \mathrm{s}$

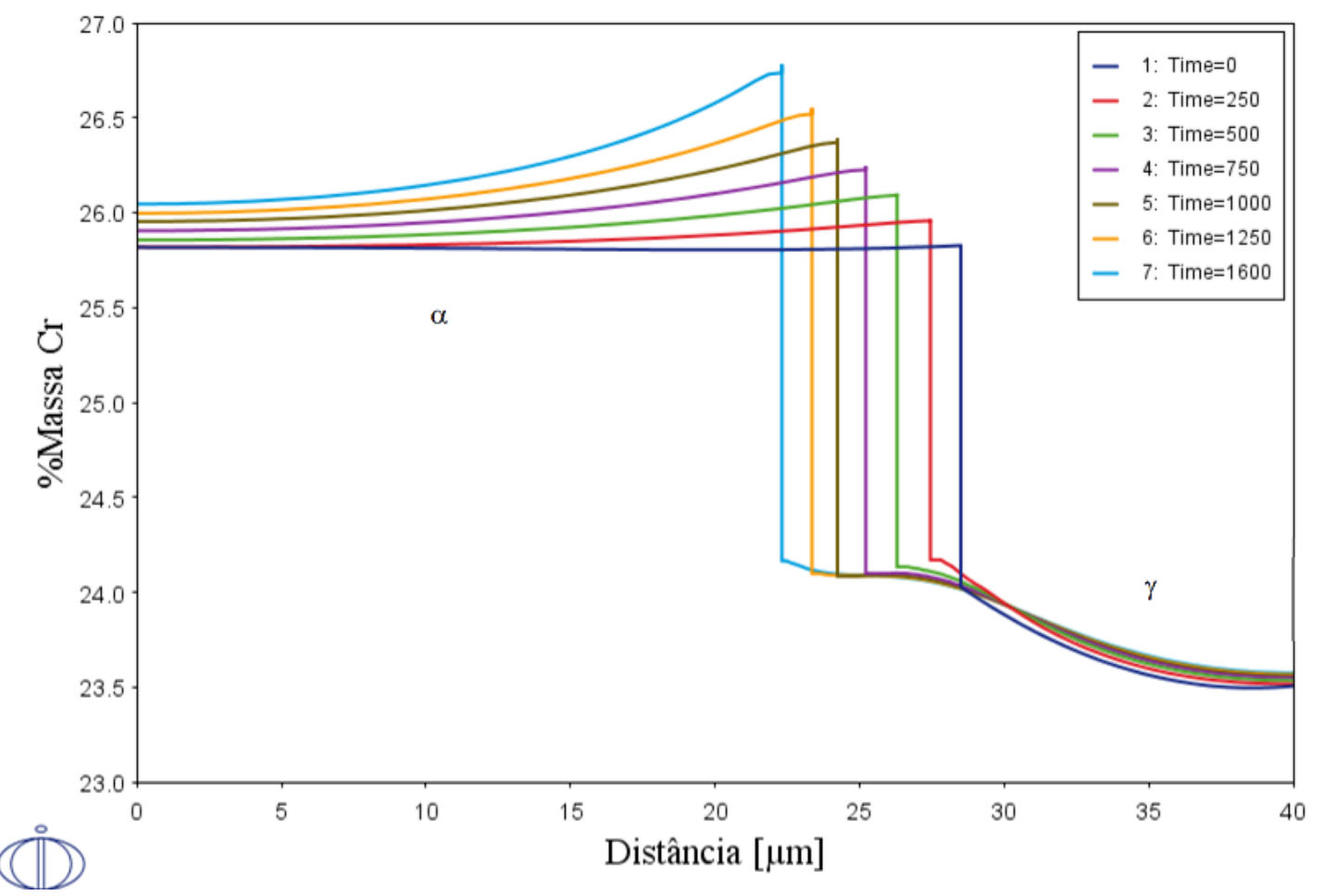

Fonte: Autora 
Figura 100 - Perfil de composição de Mo no resfriamento de $1250^{\circ} \mathrm{C}$ a $1090^{\circ} \mathrm{C}$ em função da distância à taxa de $0,10^{\circ} \mathrm{C} / \mathrm{s}$

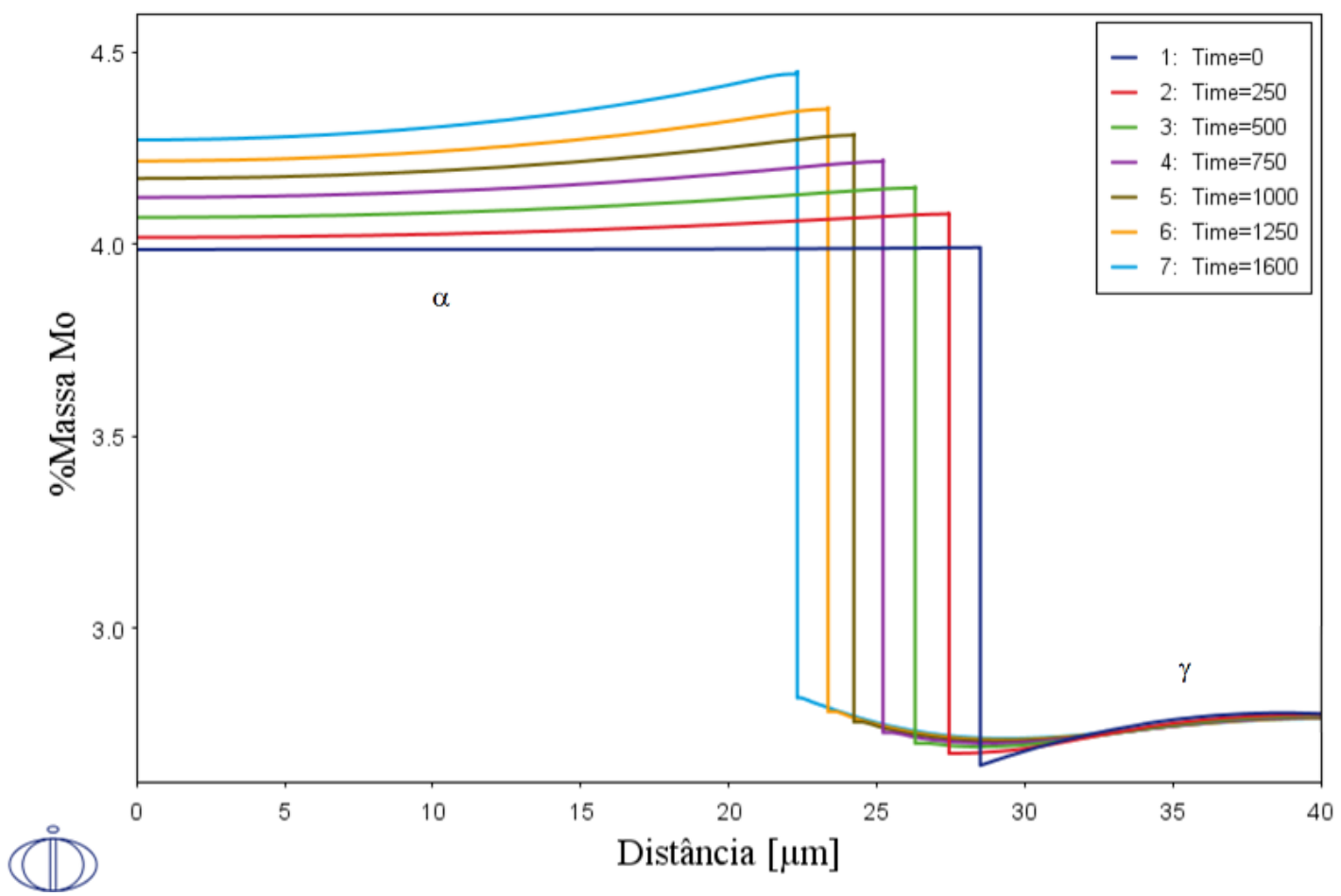

Fonte: Autora

Figura 101 - Perfil de composição de Ni no resfriamento de $1250^{\circ} \mathrm{C}$ a $1090^{\circ} \mathrm{C}$ em função da distância à taxa de $0,10^{\circ} \mathrm{C} / \mathrm{s}$

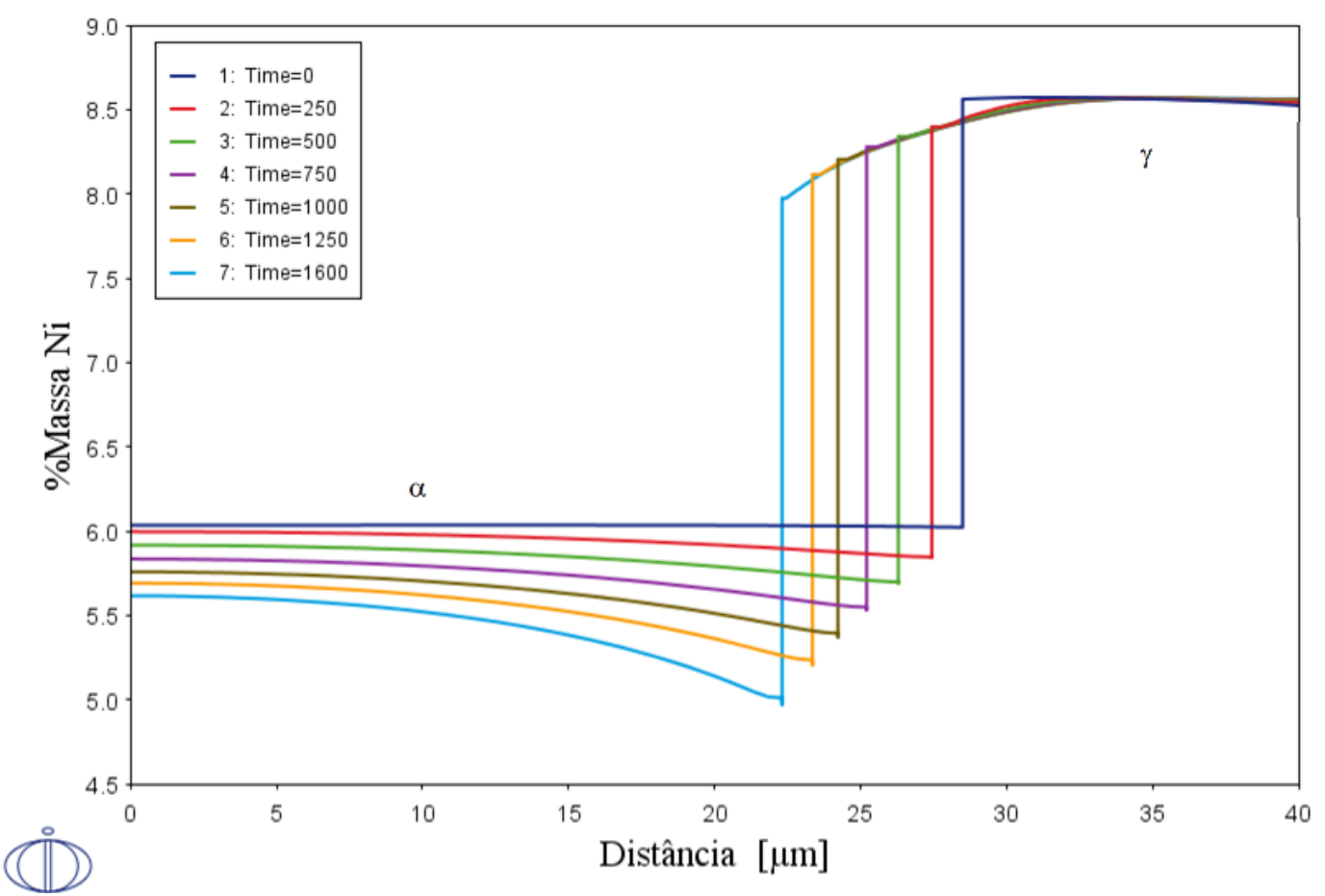

Fonte: Autora 
Figura 102 - Perfil de composição de $\mathrm{N}$ no resfriamento de $1250^{\circ} \mathrm{C}$ a $1090^{\circ} \mathrm{C}$ em função da distância à taxa de $0,10^{\circ} \mathrm{C} / \mathrm{s}$

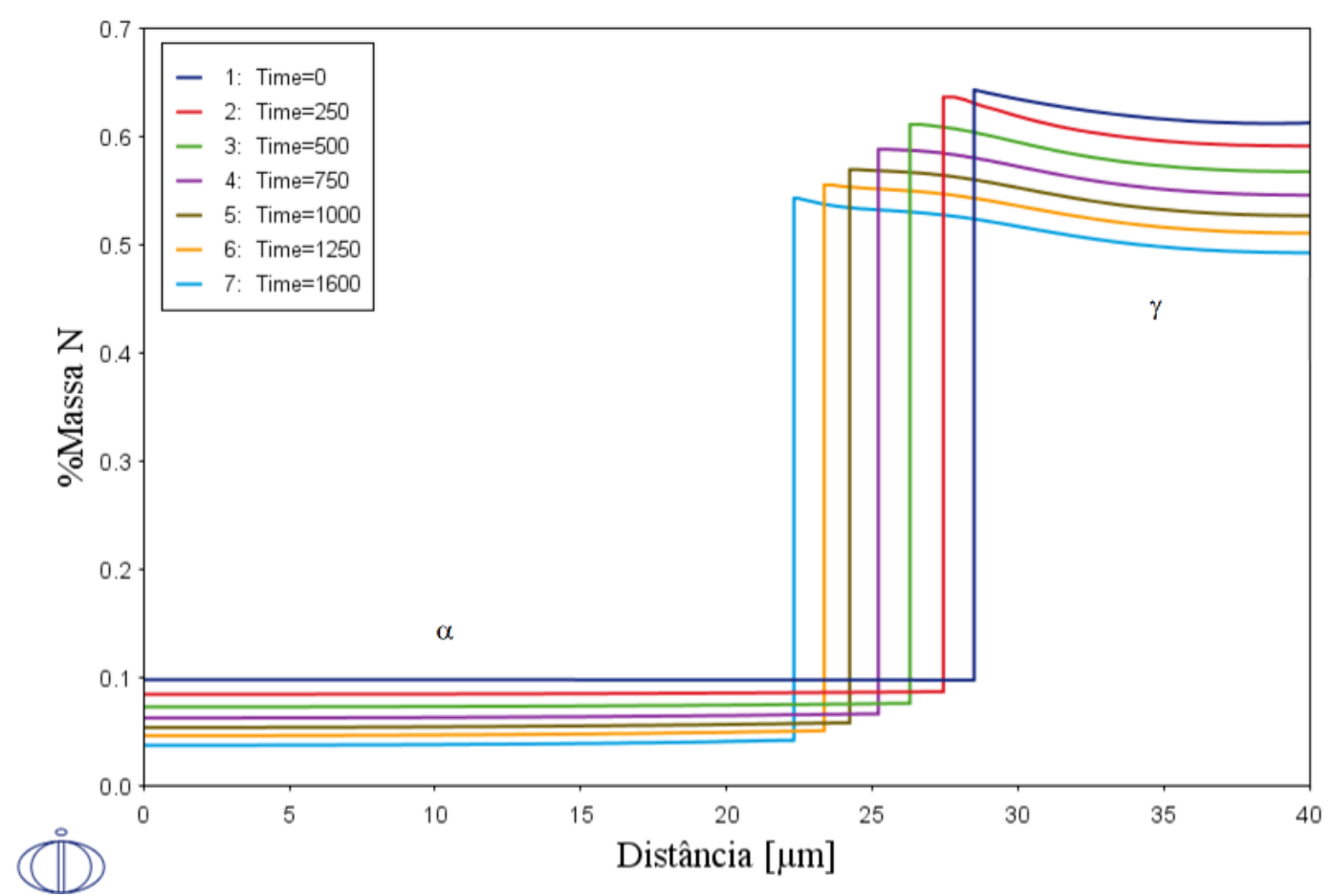

Fonte: Autora

Caso esta fosse a taxa de resfriamento ideal, os perfis de composição química que dariam sequência as simulações da trecho 3 são os expostos na Tabela 23.

Tabela 23 - Perfis de composição química do trecho 3 para simular o trecho 4 a $0,1{ }^{\circ} \mathrm{C} / \mathrm{s}$

\begin{tabular}{ccc}
\hline & Ferrita & Austenita \\
\hline$\% \mathrm{Cr}$ & $\mathrm{y}=0,0001 \mathrm{x}^{3}-0,0024 \mathrm{x}^{2}+0,0182 \mathrm{x}$ & $\mathrm{y}=0,0056 \mathrm{x}^{2}-0,1766 \mathrm{x}+24,911$ \\
\hline$\% \mathrm{Mo}$ & $\mathrm{y}=0,0009 \mathrm{x}^{2}-0,0054 \mathrm{x}+4,1348$ & $\mathrm{y}=-0,0002 \mathrm{x}^{3}+0,0058 \mathrm{x}^{2}-0,0549 \mathrm{x}$ \\
& & $+2,8766$ \\
\hline 8Ni & $\mathrm{y}=-0,0024 \mathrm{x}^{2}+0,0191 \mathrm{x}+5,852$ & $\mathrm{y}=0,0004 \mathrm{x}^{3}-0,017 \mathrm{x}^{2}+0,2381 \mathrm{x}+$ \\
& & 7,5195 \\
\hline$\% \mathrm{~N}$ & $\mathrm{y}=1 \mathrm{E}-06 \mathrm{x}^{3}-2 \mathrm{E}-05 \mathrm{x}^{2}+0,0001 \mathrm{x}+$ & $\mathrm{y}=0,0006 \mathrm{x}^{2}-0,0169 \mathrm{x}+0,6292$ \\
& 0,0375 &
\end{tabular}

